\title{
A CONCURRENT MIXED-METHODS STUDY OF A LEADERSHIP MODEL FOR PHYSICIAN ASSISTANTS: IMPLICATIONS FOR PRACTICE AND TRAINING
}

\author{
A Dissertation \\ presented to \\ the Faculty of the Graduate School \\ at the University of Missouri-Columbia \\ In Partial Fulfillment \\ of the Requirements for the Degree \\ Doctor of Education \\ by: \\ TRACY L. CLEVELAND \\ Dr. Cynthia MacGregor, Dissertation Supervisor \\ JULY, 2017
}


(C) Copyright by Tracy L. Cleveland 2017

All Rights Reserved 
The undersigned, appointed by the dean of the Graduate School, have examined the dissertation entitled:

\section{A CONCURRENT MIXED-METHODS STUDY OF A LEADERSHIP MODEL FOR PHYSICIAN ASSISTANTS: IMPLICATIONS FOR PRACTICE AND TRAINING}

presented by Tracy L. Cleveland

a candidate for the degree of Doctor of Education

and hereby certify that, in their opinion, it is worthy of acceptance.

Dr. Cynthia MacGregor

Dr. William Agnew

Dr. Jeffrey Cornelius-White

Dr. Beth Hurst 


\section{DEDICATION}

I dedicate my dissertation to my family and friends:

My Grandparents and Parents

You instilled in me the most important things in life, faith in God and family. You taught me the value of hard work and persistence. Thank you!

My husband, Joe

Thank you for your patience, love and support! You never give up on me! I love you!

My children,

$$
\text { Jenaya, Chandler, Cale and Tatum }
$$

You have taught me a whole new way to love and I am forever grateful that God chose me to be your mother. Love you forever!

My family \& friends,

Your words of encouragement and your prayers have meant the world to me! Thank you!

“I can do all things through Christ who strengthens me." Philippians 4:13 


\section{ACKNOWLEDGEMENTS}

This dissertation would not have been possible without the support from some very important individuals. I would like to thank the professors at Missouri State University and throughout the Missouri Statewide Cooperative. Your knowledge and perspective has been insightful and I feel honored to have been one of your students.

Specifically, I would like to thank Dr. Cynthia MacGregor, my dissertation chair for allowing me to take on a project that I really felt called to do. Thank you for the many conversations, your patience, believing that I could accomplish the research, and working with me and competing priorities. I am truly grateful to have had your insight and guidance. Thank you to Dr. Robert Watson, better known as Dr. Bob. Your kind and gentle heart always showed through and it was always apparent that you wanted nothing but success for each of us. It has been a privilege to have both Dr. MacGregor and Dr. Watson as professors.

I would also like to acknowledge the contributions of my dissertation committee, Dr. Jeffrey Cornelius-White, Dr. Beth Hurst, and Dr. William Agnew. Your time, expertise, and contributions to my dissertation provided new insight and greatly improved the finished product. Thank you for your open minds with my exploration of leadership within medicine.

Thank you to my colleagues for your support throughout the last 6 years and to all the PAs and PA educators out there who participated by taking my survey. Your willingness to take time out of your busy schedules to participate in this study regarding 
leadership in medicine exemplifies your devotion to our profession. Thank you for your commitment to patients and to PA students. We accomplish great things when we all work together.

A special thank you to cohort 8! I am a better educator and leader today because of the enlightening discussions we shared and the insight each of you provided. To my good friends, Karen Engler and Jeremy and Kate Schenk, who were a constant support, I am forever grateful.

Finally, thank you to my friends and family for the love, support and prayers over the last 6 years. Your love is never ending and your belief in me radiates within my soul. Many thanks! 
TABLE OF CONTENTS

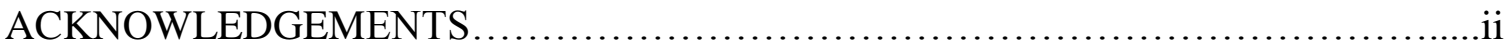

LIST OF FIGURES AND TABLES................................................ii

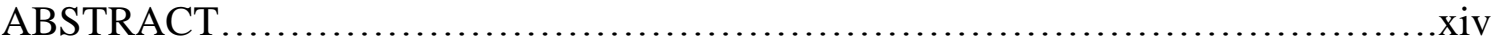

Chapter

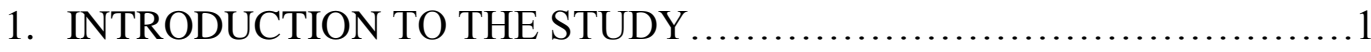

Problem Statement..........................................................

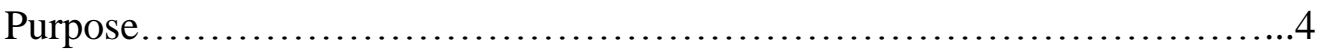

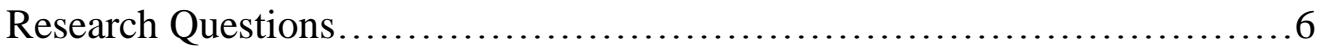

Conceptual Underpinnings Guiding Study..............................6

The Medical Leader..................................................

Learning Leader............................................ 8

Patient Advocate............................................. 9

Engaged Professional.......................................10

Builder of Future Professionals.............................. 10

Community Activist........................................11

Team Collaborator..............................................12

Design and Methods................................................. 13

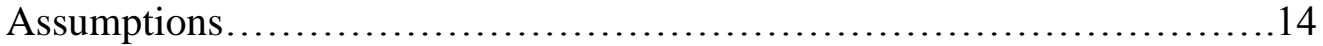

Significance of the Research for Leadership Practice......................15

Definition of Key Terms............................................. 16 


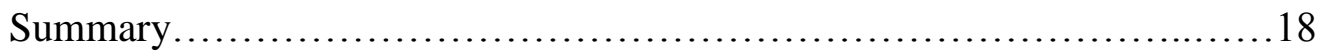

2. REVIEW OF RELATED LITERATURE ..............................20

History of Physician Assistants......................................21

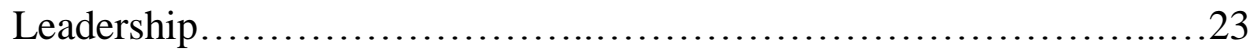

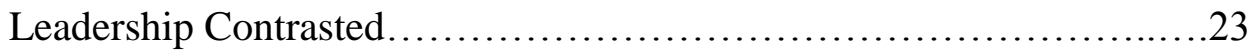

Trait Theory .................................................. 24

Situational Leadership.......................................24

Skills Approach..............................................24

Team Leadership..........................................25

Transformational Leadership...............................27

Authentic Leadership.....................................29

Servant Leadership........................................ 32

Ethical Leadership............................................33

Leadership in Medicine: Leadership or Management..............36

All Clinicians Included......................................... 38

Medical Leader...................................................... 40

Learning Leader............................................. 41

Patient Advocate..............................................47

Engaged Professional.........................................54

Builder of Future Professionals...............................61

Community Activist...........................................64 
Team Collaborator..............................................69

Leadership Training in Medical Curriculum..........................74

What Topics Should Be Taught?...................................................76

How is Leadership Content Delivered?.........................................79

What is the Right Length of Leadership Training?........................80

How Does One Get Leadership Training?.....................................81

What Are We Doing Now?...........................................................81

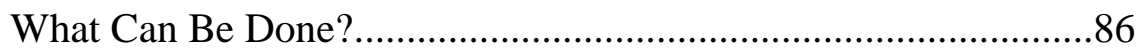

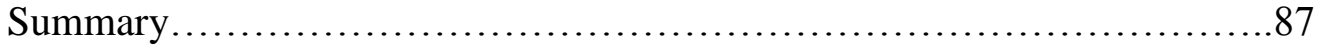

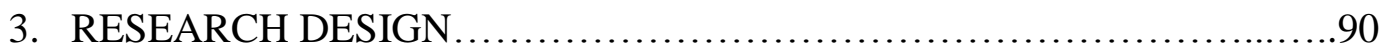

Purpose and Research Questions......................................91

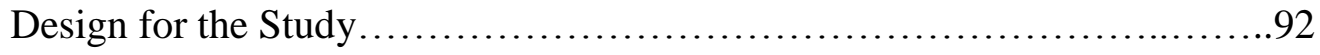

Action Research...................................................

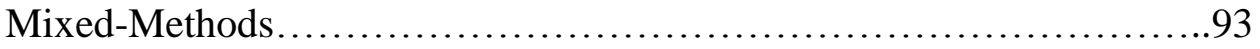

Timing ................................................... 94

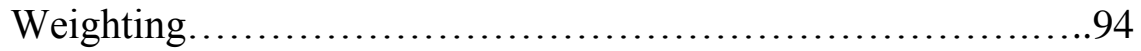

Mixing of Data...................................................... 95

Explicit Theoretical Perspective.................................95

Research Positionality and Bias..........................................

Participants......................................................... 96

Human Subjects' Protection and Other Ethical Considerations............98 
Data Collection and Instrumentation..................................... 99

Survey Instruments...........................................100

Reliability and Validity.......................................101

Methods of Data Collection.......................................103

Data Analysis Procedures for Surveys................................104

Study Limitations and Assumptions................................. 106

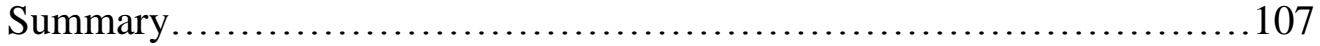

4. PRESENTATION OF FINDINGS......................................

Introduction...................................................... 119

Data Collection..................................................... 111

Demographics of Practicing PAs................................112

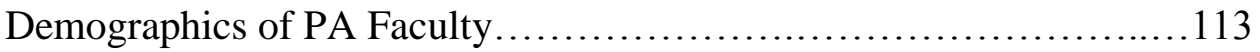

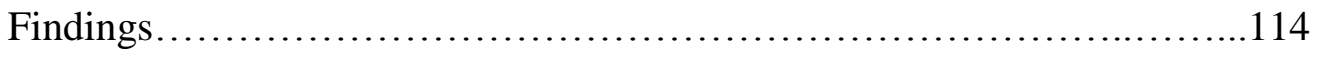

Research Question One......................................114

Learning Leader Quantitative Findings.....................114

Learning Leader Qualitative Findings.....................116

Patient Advocate Quantitative Findings.....................120

Patient Advocate Qualitative Findings.....................122

Engaged Professional Quantitative Findings.................131

Engaged Professional Qualitative Findings..................134

Builders of Future Professionals Quantitative Findings.........136 
Builders of Future Professionals Qualitative Findings..........137

Community Activist Quantitative Findings..................140

Community Activist Qualitative Findings....................142

Team Collaborator Quantitative Findings....................144

Team Collaborator Qualitative Findings.....................147

Summary of Research Question One........................150

Research Question Two.......................................154

Learning Leader Quantitative Findings.......................154

Learning Leader Qualitative Findings......................155

Patient Advocate Quantitative Findings.......................158

Patient Advocate Qualitative Findings.......................160

Engaged Professional Quantitative Findings..................164

Engaged Professional Qualitative Findings..................165

Builders of Future Professionals Quantitative Findings.........168

Builders of Future Professionals Qualitative Findings...........169

Community Activist Quantitative Findings..................171

Community Activist Qualitative Findings....................174

Team Collaborator Quantitative Findings...................178

Team Collaborator Qualitative Findings....................179

Summary of Research Question Two.......................181

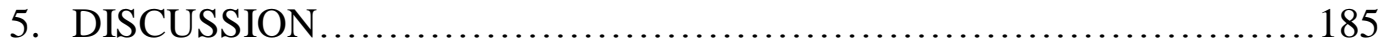




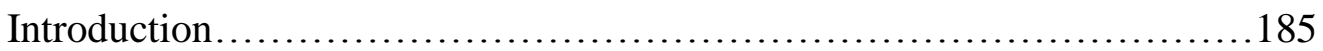

Description of Study............................................... 186

Summary of Findings............................................... 189

Learning Leader................................................... 189

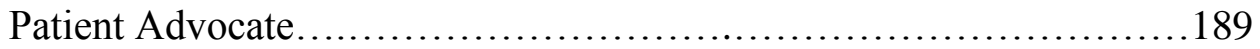

Engaged Professional.............................................. 190

Builders of Future Professionals......................................190

Community Activist....................................................190

Team Collaborator.................................................. 191

Prevalence of Practice of PA Leadership...............................191

Prevalence of Learning Leadership..........................192

Learning Leader in Practice...................................192

Prevalence of Patient Advocacy.................................193

Patient Advocacy in Practice.................................193

Preparation to be Patient Advocate............................... 194

Prevalence of Professional Engagement.........................195

Engaged Professional in Practice..............................196

Prevalence of Building Future Professionals.....................196

Builders of Future Professionals in Practice..................... 197

Prevalence of Community Activist.............................197

Community Activist in Practice.................................197 
Prevalence of Team Collaboration..........................198

Team Collaborator in Practice................................198

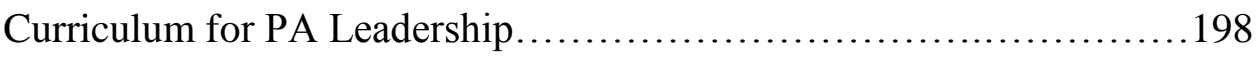

Learning Leader Program Preparation...................... 199

Patient Advocate Program Preparation.......................199

Engaged Professional Program Preparation.................200

Builders of Future Professionals Program Preparation..........200

Community Activist Program Preparation.....................201

Team Collaborator Program Preparation....................201

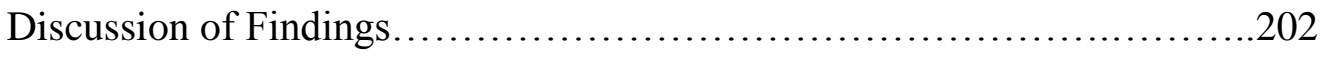

Learning Leader..............................................202

Patient Advocate...............................................206

Engaged Professional........................................212

Builder of Future Professionals..................................2214

Community Activist.........................................217

Team Collaborator..........................................220

Necessary Changes in PA Curriculum...........................223

Learning Leader.......................................225

Patient Advocate.........................................226

Engaged Professional..................................227

Builders of Future Professionals............................228 
Community Activist.................................228

Team Collaborator......................................229

Summary of Research Question Three....................230

Implications for Practice Beyond Changes to Curriculum...............230

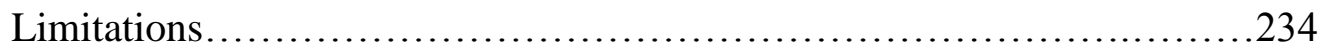

Future Research................................................237

REFERENCES........................................................239

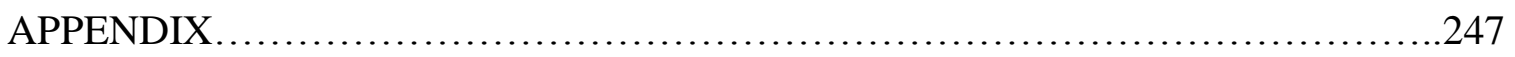

Appendix A: Transmittal Letter......................................247

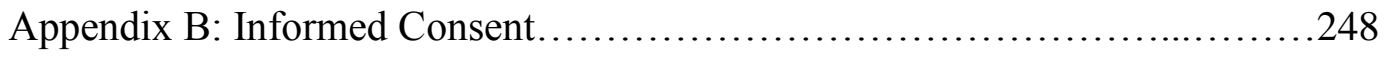

Appendix C: Medical Leadership Survey: For Practicing Physician Assistants.250

Appendix D: Medical Leadership Survey: For Physician Assistant Faculty ....270

Appendix E: The Medical Leader: Synthesis of Findings....................284

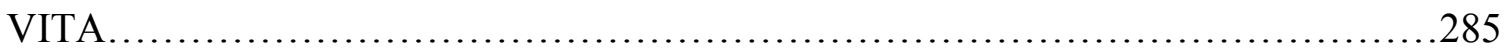




\section{LIST OF FIGURES AND TABLES}

Figure

1 Components of the Medical Leader........................................ 8

Table

1 Practicing PAs Who Participate in Learning Opportunities.....................115

2 Learning Opportunities Among Practicing PAs in Order of Prevalence.........116

3 Prevalence of Agreement of Practicing PAs- Patient Advocate- High Levels

of Agreement.........................................................121

4 Prevalence of Agreement of Practicing PAs-Patient Advocate-Lower Levels

of Agreement..................................................... 122

5 Prevalence of Practicing PAs Actively Engaged Within Their Profession........132

6 Prevalence of Level of Participant Involvement in Organizations...............133

7 Prevalence of Agreement of Practicing PAs Who Serve to

Build Future Professionals.................................................. 137

8 Prevalence of Agreement of Practicing PAs Who Are Community Activists-

High Levels of Agreement.......................................... 141

9 Prevalence of Agreement of Practicing PAs Who Are Community Activists-

Low Levels of Agreement.......................................... 142

10 Prevalence of Agreement of Practicing PAs- Patient Care Requirements.........145

11 Frequency With Which Practicing PAs Communicate With Others to

Care for Patients...................................................... 146 
12 Supported Quantitative Constructs and Emerging Qualitative Themes for the Medical Leader Conceptual Underpinnings- Practicing PA..................154

13 Prevalence of Agreement of PA Faculty Who Believe Students Are Being Prepared to be Learning Leaders.

14 Prevalence of PA Faculty Whose Program Prepares Students to be Patient Advocates

15 Prevalence of PA Faculty Whose Program Prepares Students to be Engaged Professionals.

16 Prevalence of PA Faculty Whose Program Prepares Students to be Builders of Future Professionals.

17 Prevalence of Faculty Who Believes Their Students are Being Prepared to be Community Activists- High Levels of Agreement.

18 Prevalence of Faculty Who Believe Their Students are Being Prepared to be Community Activists- Low Levels of Agreement. .174

19 Prevalence of PA Faculty Who Believe Students Are Being Prepared to Collaborate 179

20 Supported Quantitative Constructs and Emerging Qualitative Themes for the Medical Leader Conceptual Underpinnings- PA Faculty

21 Supported Constructs for the Medical Leader Conceptual Underpinnings- Comparison of Quantitative and Qualitative Findings.

22 Summary of Recommendations for Practicing PAs and PA Program Faculty.....234 
A CONCURRENT MIXED-METHODS STUDY OF A LEADERSHIP MODEL FOR PHYSICIAN ASSISTANTS: IMPLICATIONS FOR PRACTICE AND TRAINING

\author{
Tracy L. Cleveland
}

Dr. Cynthia MacGregor, Dissertation Supervisor

\begin{abstract}
A physician shortage currently exists in the United States and is projected to continue for at least a decade. Physician assistants (PA) are expected to help fill this healthcare gap, often requiring not just medical competence, but leadership skills. Leadership training is not often a component of PA medical training, and literature on PA leadership is limited. This study investigated a leadership model for PAs rooted in ethical leadership. The PA, as a medical leader, further defined as a learning leader, patient advocate, engaged professional, builder of future professionals, community activist and team collaborator was explored through a concurrent mixed-methods approach that evaluated survey data collected from practicing PAs and PA faculty. Of the 681 practicing PAs invited, 107 (16\%) participated, and of the 71 PA faculty members recruited, 43 (61\%) participated. Results showed alignment in responses between the two surveys. The greatest level of alignment was noted for the patient advocate, the team collaborator, and the learning leader, followed by the builder of future professionals and the engaged professional. The greatest amount of contrast between survey findings was with the community activist. Although all areas were supported, more research is needed to further support this model.
\end{abstract}




\section{CHAPTER ONE}

\section{INTRODUCTION TO THE STUDY}

According to the Health Resources and Services Administration Bureau of Health Professionals National Center for Health Workforce Analysis in November of 2013, the estimated physician shortage by 2020 is 20,400 . This is especially true for rural and other medically underserved geographic locations, as well as, underserved populations such as those of low socioeconomic status and the growing number of elderly (Doescher et al., 2009; Health Resources \& Services Administration Health Workforce, 2013; Scott, 2011; Snyderman, Eibling, \& Johnson, 2011). This was supported and even expanded upon in 2016 by the Association of American Medical Colleges who reported even more significant shortages ranging between $61,000-95,000$ physicians and extending to as far as 2025 (Association of American Medical Colleges, 2016). The Association of American Medical Colleges (2016) reported shortages not only in primary care, but also across all medical and surgical specialties.

Ensuring all Americans receive quality healthcare is an ethical challenge. Physician assistants (PA) are identified as medical providers to help bridge this physician shortage in the United States (Snyderman et al., 2011). However, it is not just the medical skills possessed by these healthcare providers that will be necessary to successfully bridge the healthcare gap, but leadership skills too (Abbas, Quince, Wood, \& Benson, 2011; Nordquist \& Grigsby, 2011). 
Leadership qualities are highly acknowledged in today's society. Leaders are no longer solely identified by the size of a corporation they run, but can be found and recognized among all professions and societal classes. Medicine is no different. Physicians are often called upon to be leaders in all realms of life because they are thought to be educated, reliable, and trustworthy individuals. Although many physicians would agree that leadership is a vital commodity, it is one that many physicians do not feel prepared with during their medical training (Abbas et al., 2011; Baird, Soldanska, Anderson, \& Miller, 2012; Collins-Nakai, 2006).

Physicians are not alone when it comes to leadership in healthcare. In fact, Blumenthal, Bernard, Bohen, and Bohmer (2012) argued that all healthcare providers must possess leadership skills. Physicians (Collins-Nakai, 2006) and advanced practice providers, such as PAs (Huckabee \& Wheeler, 2008), are often tasked with a variety of leadership roles with respect to community, state, and national healthcare problems, patient advocacy, staff, professional organizations, politics, and training the next generation. Much like physicians, preparedness for the leadership responsibilities physician assistants encounter is an essential component of professional competency (Collins-Nakai, 2006; Huckabee \& Wheeler, 2008).

Recent research has addressed the issue of current practice in leadership training for physicians and other clinicians. Lee, King, and MacDonnell (2011) stated, "Expecting clinicians to lead without adequate training is indeed naïve and probably setting them up for a fall” (p. 996). Although identified as helpful (Baird et al., 2012; Deane \& Ringdahl, 2012; Knowles, O’Dowd, Hewett, Schafer, \& Wilkinson, 2012), formal leadership training is not a part of the vast majority of medical training programs 
(Baird et al., 2012; Knowles et al., 2012; Lee et al., 2011; O’Connell \& Pascoe, 2004). It is not because leadership training is unimportant, but rather is less of a priority, with the focus spent on acquisition of medical knowledge, skill, critical thinking, and problem solving ability (Souba, 1998).

Like medical school, PA education does not typically consist of formal leadership training (M. Statler, personal communication, February, 2013). How can PA programs ensure that the PAs trained will graduate equipped with the skills necessary to rise to the challenges that lay ahead? Questions like this are particularly relevant since the expectation is that PAs will fill the healthcare gap in locations where there are fewer physicians. Identifying the answer to this question is an important step to educating healthcare professionals with both the medical and leadership skills necessary to sustain and grow the PA profession and bridge the healthcare gap; ensuring healthcare for all.

\section{Problem Statement}

The current medical leadership problem is multifaceted. First, numerous articles and studies over the last several years have expressed a need for medical leadership and leadership training (Collins-Nakai, 2006; Snyderman et al., 2011). Second, there is not one leadership theory that is specific to medical leaders (Knowles et al., 2012). Third, with the current emphasis on healthcare teams (Collins-Nakai, 2006; Snyderman et al., 2011), it is imperative that all members of the teams exhibit leadership qualities (Blumenthal et al., 2012; Hays, 2008; Scott, 2011). Fourth, although PAs work under physician supervision, a degree of autonomy requiring critical thinking, problem solving, and leadership is common and required (Huckabee \& Wheeler, 2008). Finally, with the exception of some residency programs incorporating leadership training for some 
physicians, there is a lack of formal leadership training during medical training (Awad, Hayley, Fagan, Berger, \& Brunicardi, 2004; Baird et al., 2012).

Although leadership theories abound in the medical literature, particularly as a basis for leadership curriculum in residency programs, many of the governing national organizations have identified professional competencies as the practice and leadership standards (Competencies, 2012; National Center for Healthcare Leadership, 2010). Competencies, which guide the practice, skills, behaviors, professionalism, and interactions of medical professionals, are no doubt necessary components of a successful healthcare professional (Competencies, 2012; National Center for Healthcare Leadership, 2010). However, despite their necessity they lack clarity in the true understanding of the medical leader. Some researchers (Collins-Nakai, 2006; Huckabee \& Wheeler, 2008;

O'Connell \& Pascoe, 2004) have explored leadership theory and applied varying leadership models to medical practice. Although many of these theories can be identified and explained within medical practice, they are not all inclusive or comprehensive. The medical leader may need to draw upon a variety of leadership styles in their daily life to be successful. Ethical, servant, and transformational leadership serve as a solid base for the medical leader, but there does not seem to be one style or theory that addresses all facets of the medical provider and the roles and responsibilities they bear (Huckabee \& Wheeler, 2008).

\section{Purpose}

The purpose of this concurrent, triangulation mixed methods study was to explore the leadership opportunities and demands within the PA profession and identify gaps in training to best prepare current physician assistant students for the leadership 
opportunities ahead. Survey data quantified which areas of leadership were most prominent among practicing physician assistants and what, if any, leadership training they received in their PA training. In addition, qualitative data collected helped delineate out specific roles held by practicing PAs.

Concurrently, another survey consisting of both quantitative and qualitative questions sent to PA faculty determined in what ways they are preparing PA students for leadership opportunities. Data from the two surveys was analyzed independently and then compared, contrasted, and triangulated with one another. The results informed necessary changes to PA curricula in order to better prepare students for future leadership roles (Creswell, 2009).

This study intended to fill the research gap in three ways. First, the specific leadership roles most often held by PAs within practice were identified and quantified. Identification of leadership roles and the frequency with which they are performed provides invaluable insight when preparing a specific and concise, yet comprehensive, leadership curriculum that highlights the knowledge and skills necessary to approach various situations. Second, much of the research that exists on leadership training in medical school occurred during residency. This study aimed to inform a leadership curriculum for both didactic and clinical education for physician assistant students. Finally, this study offered a model of the medical leader based on roles rather than just competencies. More specifically, it identified the many leadership roles of the medical professional as an individual and as a member of a healthcare system and community at a variety of levels (Northouse, 2010). 


\section{Research Questions}

Within the context of this study, the following research questions were addressed:

1) What is the prevalence and practice of the leadership roles of physician assistants (PAs) as...
a. learning leaders?
b. patient advocates?
c. engaged professionals?
d. builders of future professionals?
e. community activists?
f. team collaborators?

2) In what ways does current curricula prepare physician assistant (PA) students for future leadership roles?

3) What changes are needed in physician assistant (PA) curriculum to better prepare students for future leadership roles?

\section{Conceptual Underpinnings Guiding Study}

As previously stated, although leadership theories are readily noted in the medical literature, particularly as a basis for leadership curriculum in residency programs, many of the national medical organizations have identified professional competencies as the practice and leadership standards (Competencies, 2012; National Center for Healthcare Leadership, 2010). Competencies, which guide the practice, skills, behaviors, professionalism, and interactions of medical professionals, are no doubt necessary components of a successful medical leader, but despite their necessity, they lack clarity in the true understanding of the medical leader. 
Some researchers have explored leadership theory and applied varying leadership models to medical practice. Huckabee and Wheeler (2008) recognized the following leadership models as being evident within the practice of physician assistants: (a) situational or contingency model, (b) transactional, (c) charismatic, (d) transformational, and (e) servant. Others have identified teamwork through multidisciplinary teams as the cornerstone of quality patient care and effective healthcare (Blumenthal, et al., 2012; Collins-Nakai, 2006; Knowles et al., 2012; O'Connell \& Pascoe, 2004; Snyderman et al., 2011). Stoller, Rose, Lee, Dolgan, and Hoogwerf (2004) recognized Kouzes’ and Posner's (2011) work in transformational leadership as effective for the medical leader. Other researchers have looked to the field of business and management for answers to leadership (O’Connell \& Pascoe, 2004; Snyderman et al., 2011). Finally, ethical leadership, with its people centered platform provided an important groundwork for the medical provider and leader with its focus on five principles: (a) "building community," (b) "respect for others," (c) "serving others," (d) "manifesting honesty," and (e) "showing justice" (Northouse, 2010 p. 387). Although each of these theories can be identified and explained within medical practice, they are not all inclusive or comprehensive.

\section{The Medical Leader}

As evidenced above, the medical leader may need to draw upon a variety of leadership styles in their daily life. Although some leader's styles may align more closely with certain leadership theories, there does not seem to be one style that addresses all facets of the medical provider and the roles and responsibilities they bear. The broader concepts introduced above will now be narrowed to the more specific conceptual underpinnings (Heppner \& Heppner, 2004) of the medical leader (Figure 1). 


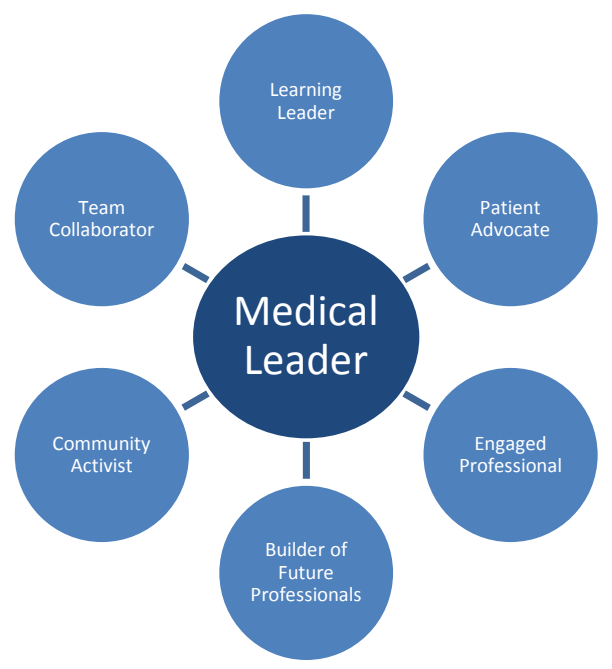

Figure 1. Components of the medical leader.

Learning leader. A learning leader is a PA who participates in learning opportunities to improve themselves both personally and professionally. The words "learning" and "leader" go hand in hand. Professionalism or the display of professional attitude through one's actions, words and deeds is an important component of the learning leader. Professionalism encompasses both personal and professional development and occurs through critical self-reflection (Northouse, 2010) and selfdiscipline (Competencies, 2012). As identified in the competencies for the physician assistant profession, it is essential for PAs to continue to develop throughout their careers both personally and professionally through continual learning opportunities (Competencies, 2012).

Physician assistants who are learning leaders are self-directed learners. Successful leaders are individuals who continually look for ways to improve themselves and their leadership ability (Souba, 1998). The learning leader is also a learning professional. Professional development refers to the continuation of educational opportunities within a particular field. One form of professional development is through 
continuing medical education in the form of lectures, workshops, and journal reading, among others. Another way to enhance learning is through experiences. Performance improvement (PI) projects and self-assessment projects are two examples of experiential learning that have recently been incorporated into the recertification process by the NCCPA (American Academy of Physician Assistants, 2015b; National Commission on Certification of Physician Assistants, 2015). First implemented in 2005 by the American Medical Association, PI-CME is designed to improve the practice of individual PAs and teams (American Academy of Physician Assistants, 2015b).

A learning leader is a PA who participates in learning opportunities to improve themselves both personally and professionally. Personal improvement comes with being a self-directed learner and improving our self-awareness and self-discipline. Whereas, professional improvement is the result of continuing to gain medical knowledge and be able to apply that knowledge in practice to both maintain and improve competence.

Patient advocate. Altruistic behaviors, place a focus on putting the needs of others ahead of themselves (Northouse, 2010; Stone, 2012). Both ethical and servant leadership place an emphasis on people that is deeply entrenched to service and respect. Servant leadership is especially focused on the construct that all people should be valued (Northouse, 2010). In addition, Schumann (2001) discussed the care principle, which "maintains that we express care for others with whom we have special relationships by nurturing their development in a way that allows them to make their own choices and live their own lives" (p. 104). The PA competencies emphasize effective communication and ethical interpersonal relationships. 
The patient advocate is about caring for patients through the development of trusting and respectful relationships based on compassion, listening, and making the patient feel as if they matter. It is also about service or leading patients through the complexities of medical disease and health-system complexities. The patient advocate shows justice and provides unconditional acceptance. They treat all patients fairly and equally despite their race, ethnicity, socioeconomic status, or anything else that may differentiate one patient from another. Finally, being a patient advocate is about going above and beyond. It is about doing what is right and just for your patients all the time; putting their best interests at the forefront of every decision.

Engaged professional. Ethical and transformational leadership is associated with finding and fighting for common goals (Northouse, 2010). Servant leadership has stressed organizational stewardship (Northouse, 2010). Engaged professionals are involved within local, state, and national professional organizations, politically and within their clinical setting. Involvement within professional organizations on all levels helps to promote big picture thinking in an effort to move the organization and profession forward. Organizations thrive when there is an alignment of collaborative member action with a shared organizational vision. Strength in numbers and an attitude of collaboration and organizational service or stewardship is a vital component of organizational strength (Northouse, 2010).

Builder of future professionals. The building of future professionals can be viewed from ethical, servant and transformational leadership. In giving back to the profession, PA professionals demonstrate an altruistic behavior (Northouse, 2010; Stone, 2012). In addition, they are modeling a sense of service as they mentor new PA 
professionals through their didactic and clinical training. Through these actions, they have an opportunity to empower future PAs and instill among these new professionals medical expertise and skills related to teamwork and collaborative practice (Northouse, 2010). Builders of future professionals display a professional commitment of training the next generation, prescribing to something bigger than oneself as they help to lay the foundation for future medical professionals. Educational involvement and support may be portrayed through faculty appointments, guest lecturing, and precepting students, among others.

Community activist. A strong sense of community is demonstrated in ethical, servant, and transformational leadership. In all cases, leaders are concerned with building and sustaining community through active listening, empowering member contributions, developing trust and relationships, and respecting others (Northouse, 2010). As promoters of healthcare, PAs have had an opportunity to provide significant contributions in the communities where they practice. These contributions may be seen through community health education or the development of community partnerships. Communities benefit from clinician involvement through newspaper healthcare columns, wellness initiatives, health fair participation, and healthcare education (Huckabee \& Wheeler, 2008). Health promotion can be a challenge if done within a silo. However, collaborative efforts between healthcare providers and community organizations offers an opportunity for a greater number of people to be served. An example of this type of collaboration is evidenced through health systems partnering with medical schools to provide healthcare to the uninsured. 
Team collaborator. Team leadership and collaboration is playing an everexpanding role within medicine today due to a multidisciplinary approach to healthcare; requiring excellent communication and collaboration skills among a variety of healthcare professionals (Blumenthal et al., 2012; Collins-Nakai, 2006; Knowles et al., 2012; O’Connell \& Pascoe, 2004; Snyderman et al., 2011). As a result, healthcare today is considered a team sport. This is nothing new to PA practice, which has utilized physician and physician assistant teams since its conception.

Effective teamwork requires developing relationships that rely on trust, respect, listening skills, support, and cooperation among members of the team to deliver the best patient care possible (Northouse, 2010). In order for effective team collaboration, leadership may need to rest in many hands, depending on what may be best for the situation (Huckabee \& Wheeler, 2008). Open communication built on listening and understanding the viewpoints of others can allow for team member engagement and all voices being heard. PAs frequently communicate and collaborate with physicians, nurses, social workers, therapists, and others to ensure quality care for patients.

Teams succeed when all members are working together for the same goal. Performance improvement projects allow clinicians to work together on a common goal to improve a process or way of caring for patients that benefit not only the patients they serve, but also the clinical practice and ultimately the system or community. Not only is teamwork present on the level of patient care, but also from a broader systems perspective, which may require committee or policy work (Huckabee \& Wheeler, 2008). 


\section{Design and Methods}

The methodology utilized for this research study was a concurrent, triangulation mixed - methods approach. This approach explored the prevalence and practices of leadership roles among physician assistants to determine if current curricula supports the development of leadership skills. The first part of the research study collected quantitative and qualitative data in the form of two different surveys.

The first survey titled Medical Leadership Survey: For Practicing Physician Assistants was created and distributed via Qualtrics. This survey was distributed to 681 members of the American Academy of Physician Assistant Huddle networking site and the Missouri PA organization. This survey identified the prevalence and practices of leadership roles among physician assistants. The data collected aimed to answer the first research question, "What is the prevalence and practice of the leadership roles of physician assistants as: (a) learning leaders, (b) patient advocates, (c) engaged professionals, (d) builders of future professionals, (e) community activists, and (f) team collaborators?"

The second survey titled Medical Leadership Survey: For Physician Assistant Faculty was created and distributed via Qualtrics to 71 PA faculty across the United States. This survey aimed to answer research question number two, "In what ways does current curricula prepare physician assistant students for future leadership roles?" Frequency results of the quantitative data collected was independently analyzed. Qualitative findings were analyzed then triangulated.

In order to address research question number three, "What changes are needed in physician assistant curriculum to better prepare students for future leadership roles?" the 
findings of paired questions from each survey were compared against one another. The data was then triangulated to reveal a richer, understanding of the findings.

Trustworthiness of the qualitative data was ensured with: (a) confirmability (Trochim, 2006), (b) critical reflection on biases (Creswell, 2009), and (c) descriptive validity (Gay, Mills, \& Airasian 2012).

\section{Assumptions}

A pragmatic worldview "arises out of actions, situations, and consequences" (Creswell, 2009, p. 10) and places more concern on understanding problems. For pragmatists, research is contextual depending on what has occurred historically, politically, or socially (Creswell, 2009). The researcher viewed this study from the pragmatic perspective.

Every attempt was made to minimize bias. However, potential bias within this research may result due to researcher affiliations with the PA profession, educational realm of medicine, professional organizations, and the researcher's passion for leadership. The researcher has been a PA for 14 years, and a member of the AAPA for 16 years, which includes two years of student membership. In addition, the researcher has been a PA educator and member of the PAEA for 10 years. The researcher has a passion for people including her students and patients, and the medical profession, specifically the PA role. Finally, she has sought a doctoral degree in educational leadership reflecting her interest and internal belief of importance within this field. In order to keep in check these personal biases, the researcher had the results vetted through her dissertation supervisor and committee.

Assumptions identified while considering these potential biases included a set of beliefs. The first assumption was that PAs hold a belief that they are leaders and have 
leadership roles within medicine. Second, the researcher assumed that physician assistant participants would be honest and forthcoming with information regarding their leadership practice. Finally, was an assumption that there is value in formal and intentional leadership training.

\section{Significance of the Research for Leadership Practice}

The significance of this study extends beyond filling a gap in the literature regarding leadership in medicine, but also provides an informed foundation for practicing PAs and PA educators within the leadership arena. In the July 2013 AAPA research agenda it listed leadership under the section, role expansion for PA practice (American Academy of Physician Assistants, 2013). Therefore, the information gathered from this study is valuable to the AAPA organization, specifically, the body of knowledge collected on the prevalence of leadership positions and roles of practicing PAs.

This study has provided a leadership model for PAs, based on clearly defined roles rather than nonspecific competencies. More significantly, it has provided a leadership model that is attainable by all PAs who are engaged within their profession from a more holistic perspective. Ultimately, the benefit of utilizing this model could extend beyond the individual practicing PA to the PA profession as a whole, if all PAs would commit to meeting all the components of the medical leader. Although designed for the PA, the model could be applied to other healthcare professions, widening its scope.

PA programs and students are also benefactors of data gathered through this study. The research findings have provided educators with the evidence necessary to make informed decisions when deciding to incorporate leadership into their PA 
curriculum. This information has afforded PA programs the opportunity to be intentional in preparing students for the leadership positions held by practicing PAs and fill existing gaps in the curriculum.

\section{Definition of Key Terms}

Below are a list of key terms used in this study. Each term includes a definition, which is essential to understanding the context and meaning for which the term is intended.

Leadership. "Leadership is a process whereby an individual influences a group of individuals to achieve a common goal" (Northouse, 2010, p. 3).

Leadership roles. One of the ways Northouse (2010) conceptualizes leadership is through leadership acts or behaviors. This is further defined to, "the things leaders do to bring about change in a group" (Northouse, 2010, p. 2). Leadership roles may also be described as the responsibilities or duties of a leader.

Physician assistant. "A physician assistant (PA) is a nationally certified and state-licensed medical professional. PAs practice medicine on healthcare teams with physicians and other providers” (American Academy of Physician Assistants, 2015f, lines 1-4).

Preceptor/Precepting. An experienced healthcare provider who agrees to guide students through a learning process where medical knowledge is put into practice within a healthcare setting.

\section{Medical Leader}

For this research study, the term "medical leader" serves as the overarching theme to the proposed conceptual framework. According to this study the medical leader is 
defined as a: (a) builder of future professionals, (b) community activist, (c) engaged professional, (d) learning leader, (e) patient advocate, and (f) team collaborator. A definition of each of the medical leader conceptual underpinnings is below.

Learning leader. A learning leader is a PA who participates in learning opportunities to improve themselves both personally and professionally.

Patient advocate. The patient advocate is a PA who demonstrates altruistic behavior, by putting the needs of others ahead of themselves (Northouse, 2010; Stone, 2012). This may be demonstrated through developing an ethical relationship with a patient built on trust and respect, open and honest communication, placing service above reward, and justice. The guiding principles are nonmaleficence, "First, do no harm" and beneficence “do good” (Bickley \& Szilagyi, 2013 p. 92).

Engaged professional. An engaged professional is a PA who demonstrates organizational stewardship through involvement within local, state, and national organizations in order to form a coalition that is working toward a common goal. Engaged professionals are actively involved in politics and health policy, as well as, their local and broader health care system.

Builder of future professionals. A builder of future professionals is a PA who demonstrates professional commitment through serving as an educator to new PA professionals during their didactic and clinical training; modeling both clinical and professional skills. Through their commitment and modeling, they empower future PA professionals to learn. 
Community activist. The community activist is a PA who demonstrates a strong sense of community and concern for others by promoting healthcare through community health education and the formation of community partnerships to serve the greater good.

Team collaborator. A team collaborator is a PA who works effectively within a healthcare team to deliver the best patient care possible through alignment of goals and trusting relationships based on open and honest communication. This may include direct patient care or initiatives and policy, which affect the systems based healthcare delivery.

\section{Summary}

The current medical leadership problem is multifaceted and complex. Although a plethora of literature exists that advocates for medical leadership, there is a lack of consensus as to what theories should be taught, how they should be taught, and at what level of medical training leadership instruction should be implemented. This study aimed to answer each of those questions through a concurrent, triangulation, mixed - methods approach focusing on examining the conceptual underpinnings of the medical leader. The conceptual underpinnings of the medical leader included the: (a) learning leader, (b) patient advocate, (c) engaged professional, (d) builder of future professionals, (e) community activist, and (f) team collaborator. Through quantitative and qualitative survey data collected from practicing physician assistants, the study identified prevalence of each leadership role for the medical leader and how those roles materialize in practice. Additionally, quantitative and qualitative survey data collected from PA faculty identified current curricular preparation for those leadership roles.

Every attempt was made to recognize and minimize bias within the study. Identification of potential bias and having the results vetted through the researcher's 
dissertation supervisor and committee aided this process. Assumptions included that physician assistants: (a) believe they are leaders in medicine, (b) were honest and forthcoming with information regarding leadership practice, and (c) believe there is value in formal and intentional leadership training.

The information gleaned from this study has provided valuable insight into leadership in medicine, specifically PA leadership. The medical leader framework, offers PAs an obtainable leadership model with clearly defined roles. This study has provided the foundational information on PA leadership needed to successfully identify gaps in PA curricula and implement the necessary changes. 


\section{CHAPTER TWO \\ REVIEW OF RELATED LITERATURE}

Medicine has undergone numerous changes over the last several hundred years. Great medical leaders from long ago are still remembered today for the impact they made on medicine and the medical community. From the father of medicine, Hippocrates, to Roentgen's discovery of x-rays in 1895 (History of Medical Discoveries, 2012), to Fleming's invention of penicillin in 1928 (History of Medical Discoveries, 2012), medicine has undergone numerous transformations. In the age of the internet, managed care, global travel, and healthcare shortages, medicine is continuing to evolve to fit the times. Not only are these changes evident in the delivery of healthcare, but also in the expectations of those serving on the front lines (Blumenthal et al., 2012). The complexity and sophistication of the medical world today calls for effective communication and collaboration among medical teams to deliver the most effective patient care. The ability to carry out these skills requires medical professionals to possess expertise in a wide variety of leadership abilities.

Although traditional medicine has relied heavily on physician autonomy for delivery of healthcare, a transition to a more integrated health-system that incorporates a multidisciplinary healthcare team has ensued (Knowles et al., 2012). The healthcare team consists of physicians, advanced practice providers, such as PAs and advanced practice nurses, nurses, and allied health professionals working in unison to care effectively for patients. Although physicians often serve as the team leader, leadership skills are needed among all levels of care to ensure the patient's needs are met 
(Blumenthal et al., 2012). This is especially true for advanced practice providers, such as physician assistants.

\section{History of Physician Assistants}

On June 10, 1961, Dr. Charles Hudson, who at the time was the president of the American Medical Association, published an article in the Journal of the American Medical Association (JAMA). In the article he called for a the development of a "class of assistants with special training, intermediate between that of the technician and that of the doctor, who could not only handle many technical procedures ... but could also take some degree of medical responsibility (p. 96)". The physician assistant profession began in the 1960's by Dr. Eugene Stead, Jr. and his counterparts, Richard Smith, MD, Hu Myers, MD, and Henry Silver, MD (Cawley, 2007).

The first class of PAs were a group of highly qualified corpsman from World War II. These men were found to be well trained, but without certification or an opportunity to utilize their skills. The model of PA education stemmed from the idea of taking individuals with healthcare experience such as nurses and corpsman, and training them to be medical providers under an educationally efficient model based on competency. To gain this competency, physician assistant programs have traditionally run for approximately two years or slightly more. The first class of PAs graduated from Duke University in 1967 (Cawley, 2007).

The challenges that faced medicine in the 1960s during the time of Dr. Hudson's reign as president of the American Medical Association have parallels to the challenges in healthcare today. In 1966, Medicare went into effect. This left doctors and healthcare workers with many uncertainties as to what Medicare would do to their profession. The 
uncertainties identified in an article by Dr. Charles Hudson, titled, "Meeting the Challenge" (Hudson, 1966) are not unlike many of the uncertainties physicians, advanced practice providers, nurses, and other healthcare workers face today with Healthcare Reform. Much like today, the increasing need for healthcare providers included a restructuring of a traditional model of medicine. The first class of PAs, who graduated from Duke University in 1967 served as a solution to this problem (Cawley, 2007) and although these early graduates had to be persistent pioneers to gain acceptance into the medical community they were able to establish their place within the big picture of medicine.

Since the first graduating PA class in 1967 (Cawley, 2007), PA education has become even more formalized with all programs adhering to a certain set of accreditation standards. Strict adherence to these standards provides programs a guide in educating future PAs and generalizability to the education received by all graduates. In addition, acceptance into PA schools has continued to become increasingly competitive corroborating the popularity of the profession. In fact, the PA profession was recently rated as one of the top 10 best jobs for 2015 as defined by U.S. News and World Report Money (U.S. News and World Report Money, 2015) and as the top job in 2015 as defined by Forbes (Adams, 2015).

The gaining popularity of the PA profession may be coming just in time. As previously mentioned, the healthcare industry has faced numerous challenges. One of the challenges healthcare is facing today is the estimated physician shortage. Data published in 2016 from the American Medical Colleges showed physician shortages of 61,00095,000 that are projected to continue for nearly a decade. These shortages are not just 
true for the rural and underserved populations, where healthcare disparities are often evident, but across all medical and surgical specialties. As a country, we face with uncertainty the best remedy for this problem. One possible solution is to train more advanced practice providers, such as PAs who work collaboratively with physicians in a healthcare team. Another solution may be to ensure that well trained PAs are operating at the top of their license within a healthcare team. In order to be successful in this mission, leadership skills are required at every level of healthcare in order to ensure care for all patients (Knowles et al., 2012).

\section{Leadership}

Literature on leadership is extensive and diverse. Throughout history, several theories regarding leadership have been introduced. The question, "What makes a great leader?" has entertained serious debate. Many authors define leadership in different ways. Some believe leadership is an innate trait that cannot be learned. While others, believe it can be learned and developed. Northouse (2010) described leadership as "a process whereby an individual influences a group of individuals to achieve a common goal" (p. 3).

Leadership is often associated with power and influence within a group (Northouse, 2010). Northouse (2010) conceptualized leadership through acts or behaviors, further defined to, "the things leaders do to bring about change in a group" (p.

2). Leadership roles may also be described as the responsibilities or duties of a leader.

Leadership contrasted. As previously described, leadership theory is vast. Scholars have researched a variety of individual leaders within many different fields of work. A literature search on leadership leaves the researcher with a collection of 
theories, many of which have extensive supportive works. Below is only a snapshot of the vast array of literature that exists on this topic.

Trait theory. Trait theory is one of the oldest attempts at studying leadership. It is based on the premise that individuals possess certain characteristics, which make them great leaders. Many theorists have explored which traits are necessary for leaders. Although commonalities exist, no clear consensus has arisen from the literature as to the magic traits leaders hold (Northouse, 2010).

Situational leadership. Situational leadership, first developed by Hersey and Blanchard focused on leaders who adapt their style of leadership to fit employee needs in different situations. This leadership theory depends on the leader to act as a delegator, supporter, coach, or director to fit the level of competency of the subordinate. Within this theory, leadership allows leader flexibility, is well practiced, intuitive, and prescriptive, telling the leader what to do or not to do depending on the situation (Northouse, 2010).

Skills approach. In contrast to trait theory and situational leadership, skills, which can be learned and perfected, have also been studied. This model takes certain personal attributes or traits and adds training of specific skills or competencies, which ultimately result in the desired outcomes (Northouse, 2010). The theory works by providing a guide of the skills required to achieve leadership. Katz's Skills Theory described leaders as needing technical (knowledge to perform tasks), human (ability to work with people), and conceptual (ability to make ideas reality) skills. The need for these skills was different depending on the leadership or administrative duties one possessed. In his model top level administrators needed human and conceptual skills 
while mid-level administrators must develop human, technical, and conceptual skills equally (Ledlow \& Coppolla, 2014; Northouse, 2010).

This theory is advantageous in that it works from a goal and focuses on the training and skills to achieve that outcome. Additionally, it is available to everyone who gains the competence in skills. However, this theory is not without its drawbacks. It is not specific to leadership and can be applied to a variety of situations. In addition, it is highly dependent on the personal attributes of individuals and their ability to achieve skill competence (Northouse, 2010). Similar to skill-based leadership is competency-based leadership, first described by Bennis. In this form of leadership, leaders learn skills through education, training, and experience (Ledlow \& Coppolla, 2014).

Team leadership. Northouse (2010) described teams as, “organizational groups composed of members who are interdependent, who share common goals, and who must coordinate their activities to accomplish these goals" (p. 241). Lencioni (2002) described five components that lead to dysfunctional teams. He noted these components to be: (a) “absence of trust," (b) "fear of conflict," (c) "lack of commitment," (d) "avoidance of accountability," and (e) "inattention to results" (p.188). Lencioni (2002) described that the presence of any one of these dysfunctions causes trouble within teams and work suffers. Notably, the converse to these dysfunctions, trust, facing and discussing areas of conflict, commitment to team goals and proposed action, accountability to one another, and achievement of results, can foster good working relationships and team success (Lencioni, 2002).

Many parallels can be drawn between Lencioni (2002) and the work done by Larson and Lafasto (2002). Larson and Lafasto (2002) described five characteristics 
associated with successful teams. These components included: (a) positive, actionoriented, experienced team members, (b) relationships among team members built on trust and open, honest communication, (c) the ability to problem-solve in an open, positive climate, (d) a competent leader who keeps the group focused on the goal by encouraging a collaborative environment where the team members are supported, but managed appropriately for goal attainment, and finally (e) an organizational environment which helps to pave the way to success and rewards the members of the group for a job well done. Like Lencioni (2002), Larson and Lafasto (2002) identified trusting relationships among team members and open, honest communication. Additionally, a positive climate to problem-solve mentioned in Larson and Lafasto's (2002) work was similar to Lencioni's facing and discussing areas of conflict and keeping one another accountable. Finally, Lencioni (2002) noted the importance of team members being attentive to results, whereas, Larson and Lafasto (2002) not only made that a job of the team, but ultimately the responsibility of the team leader.

This theory is advantageous in that it provides a guide for leaders to design effective teams. It does not focus on a position, instead it is malleable within teams; allowing them to focus on what teams must do to achieve. This results in allowing leadership to be open to a variety of team members. Additionally, by knowing what makes teams successful one can determine the best leadership positions based on their ability to establish a supportive environment of trusting relationships, competence, open communication, accountability, and problem-solving skills who is not afraid to take action when needed (Northouse, 2010). Conversely, team collaboration and leadership is a complex process with many variables, so despite all the support for teamwork, there is 
no doubt that there are often a variety of internal and external variables that can complicate each step. These variables do not often come with quick or easy solutions and can make leadership challenging (Northouse, 2010).

Transformational leadership. Transformational leadership is one of the most popular and researched theories of leadership today. Northouse (2010) described transformational leadership as a "process that changes and transforms people" (p. 171). This form of leadership focuses on both the leader and the follower, allowing both to be a part of the change process. Much of its recognition stems from its emphasis on the ability for growth in the follower through internal desire. Leaders evaluate the goals and emotions of followers and inspire followers to accomplish more than what they may have imagined. Concern is placed on moral and ethical standards along with evaluating the human as a whole (Northouse, 2010).

Although Downton was the first to recognize the idea of transformational leadership, it was made popular by work of James MacGregor Burns who identified two types of leadership, "transactional" and "transformational" (Northouse, 2010, p. 172). Transactional leadership is described as a process of exchange where the leader compensates services or tasks performed by the follower. In contrast, transformational leadership results when the leader and follower establish a relationship that raises awareness and morality in both of them (Northouse, 2010).

Bernard Bass expanded on Burns original ideas of transactional and transformational leadership and reported that although different, these two types of leadership are often used in combination by successful leaders. He noted the major difference between the two as the motivation and commitment exhibited by the follower. 
Transformational leadership increases follower motivation for task completion due to the trust, respect and devotion they feel for their leader. In transformational leadership, the leader takes time to inform followers about the importance of their role in the task and outcomes which results in greater commitment to the organization and personal growth (Yukl, 2013). In contrast, transactional leadership will produce results at the request of the leader, but the followers are less likely to feel committed to the task or outcome (Yukl, 2013).

Kouzes and Posner (2010) discussed five strategies that allow leaders to be successful. The five strategies include: (a) "model the way," (b) "inspire a shared vision," (c) "challenge the process," (d) "enable others to act" and, (e) "encourage the heart" (p. 13). The first practice, model the way, prescribed that leaders need to know what they believe in and share it with others through their actions. This includes keeping their promises and acting in a way that represents their core beliefs. Second, leaders must inspire a shared vision; creating a picture for the future. Leaders need to genuinely believe that they can make a difference. They listen to their subordinates and help give their aspirations life; making them a reality. Third, leaders challenge the process or organizational standards and are willing to take small risks in order to improve. They view failures from risks as learning opportunities and ways to grow. Next, leaders enable others to act through establishing trusting relationships and developing environments of collaborative and team based work. These leaders demonstrate respect for their subordinates by actively listening to and supporting their opinions, and equipping them with the tools necessary to thrive. Finally, they encourage the heart by celebrating accomplishments of subordinates. Effective leaders realize hard work and determination 
are fostered in individuals when they are rewarded for a job well done (Kouzes \& Posner, 2011; Northouse, 2010).

Many strengths can be associated with Transformational Leadership. Due to its appeal of leaders being transformational artists for the good, it has been the subject of research in a variety of fields, which has helped to substantiate its place within leadership theory. Further, it has a strong underlying moral component, which emphasizes that leadership is not just about the leader, but benefits the followers and the greater community as a whole. Additionally, it looks at leadership as a process of exchanges, which include the leader being concerned for the needs of the followers. Finally, there is an instrument, which has successfully correlated leadership with positive follower feedback and organizational results (Northouse, 2010).

Despite the many strengths, Transformational Leadership is not without its weaknesses. Northouse (2010) described that the theory is composed of very broad concepts, which brings into question where each begins and ends. Additionally, there is question to the validity of the Multifactor Leadership Questionnaire (MLQ), the instrument used to measure transformational leadership. Finally, transformational leadership has been criticized for espousing that great leaders are above others, similar to superheroes who move in and make everyone around them better as they move to greater levels of morality while instilling upon them their values and visions.

Authentic leadership. Is leadership genuine? This is the question addressed with studying authentic leadership. Although no clear definition of authentic leadership has emerged from research, scholars have focused on authentic leadership from three different viewpoints: (a) intrapersonal or information regarding the self, (b) 
developmental or information that can be engineered and cultivated, and (c) interpersonal or created between the interaction of a leader and a follower (Northouse, 2010). Avolio and Gardner (2005) said the following about authentic leadership:

Authentic leaders are anchored by their own deep sense of self; they know where they stand on important issues, values and beliefs. With that base they stay their course and convey to others, oftentimes through actions, not just words, what they represent in terms of principles, values and ethics. (pp. 329-330)

Although several authors have depicted and reported the characteristics of authentic leadership, Bill George has authored several books focusing on this specific leadership theory (Northouse, 2010). In his book, True North: Discover Your Authentic Leadership, he noted that there are five dimensions of effective leadership. These dimensions included: (a) “purpose," (b) “heart," (c) “values," (d) "relationships,” and (e) “self-discipline" (George, 2007, p. xxxii).

George (2007) described that leaders must identify their purpose for leadership and then pursue it with passion. Second, George (2007) described that authentic leaders not only lead with their head, but also with their heart; showing compassion to one another. He was careful to make sure that this was not misunderstood to think that authentic leaders were "soft" (p. xxxiii), but rather were able to be empathetic with those around them. Next, although George (2007) noted that leaders must examine their values regularly through a process of self-reflection, experience, and discussion with others to further define their true belief system, he stated that integrity was necessary for all authentic leaders. Specifically, he noted that, "if you do not have integrity, no one will trust you, nor should they" (George, 2007, p. xxxii). Fourth, George (2007) 
identified the importance of relationships. He noted that subordinates want to feel like they know and trust their leaders. An open relationship between leaders and followers deepens commitment, loyalty, and lays the groundwork for a sense of connectedness with one another and the organization. Finally, George (2007) noted that in order to get results leaders set the mark high for themselves and their subordinates. Achieving these lofty goals requires self-discipline. A component of self-discipline, then, requires that leaders be accountable and hold others accountable for outcomes, regardless if they are good or bad. He noted that self-discipline should be reflected in all realms of one's life in order to be authentic (George, 2007).

Further research on authentic leadership by Walumbwa, Avolio, Gardner, Wernsing, and Peterson (2008) found four components of the authentic leader, which included: (a) "self-awareness," (b) "relational transparency," (c) "balanced processing," and (d) "internalized moral perspective" (p. 95). These components were derived in part from previous work by Kernis in 2003. Self-awareness is about knowing oneself at your core, strengths, weaknesses, and beliefs. Self-aware leaders can trust their actions because they are based out of strong internal conviction (Kernis, 2003). Relational transparency is described as being open with others or showing them your true self. Balanced processing is an ability to evaluate all data in an unbiased manner before making a decision. Finally, internalized moral perspective is demonstrated by a leader's ability to let their outward actions reflect their internal beliefs rather than the external environment (Kernis, 2003; Northouse, 2010). Walumbwa et al., (2008), studied these four components with an instrument called the Authentic Leadership Questionnaire (ALQ). This questionnaire is a validated instrument designed specifically to measure 
these four components of Authentic Leadership (Northouse, 2010; Walumbwa et al., 2008).

The strengths of authentic leadership are rooted in the ideal of having trustworthy individuals who are guided by a moral compass focused on what is right for society. More importantly, it suggested that the skills required to lead authentically could be developed and refined over time. Finally, there is an established, well-studied instrument to measure authentic leadership. One weakness of authentic leadership, specifically for the characteristics established by Bill George and others proposing a practical approach, was that there was no tool to validate their approaches. Additionally, given that authentic leadership is somewhat of a newer idea many questions still exist as to the involved moral component and further definition and explanation as to how authentic leadership can help organizations (Northouse, 2010).

Servant leadership. Service to others and altruistic behavior are at the heart of servant leadership. Robert Greenleaf was the first to describe this type of leadership and his influence is evidenced throughout the literature. This service described can be realized through a variety of ways such as supporting followers through "listening, empathy, and unconditional acceptance of others" (Northouse, 2010 p. 385). These ideas were supported by Spears (2005) who listed listening, empathy and commitment to the growth of people in his top 10 characteristics of servant leadership. Similarly, Souba (2011) recognized the importance of listening and stated, "Leadership in a very real sense, is born out of listening" (p. 7). Servant leadership is specifically focused on the relationship between the leader and the follower, particularly how the leader responds to the needs of the follower (Northouse, 2010). Spears (2005) who described stewardship 
as a characteristic of servant leadership supported this idea. His definition of stewardship noted a "commitment to serving the needs of others" (p. 4) through a sense of openness.

Servant leaders respond to their followers by meeting their needs and empowering them to do what is good, just, and right. As a result, these leaders watch for signs of injustice or inequality, ensuring acceptance of all. Consequently, the integrity of these leaders and concern they demonstrate for others leads to favorable relationships with their followers built on loyalty, trust and commitment (Yukl, 2013). Although servant leadership has gained popularity and researchers have attempted to develop instruments to measure servant leadership, no specific tool has been established as the gold standard for measurement (Northouse, 2010).

Ethical leadership. Northouse (2010) described ethics as "the kinds of values and morals an individual or society finds desirable or appropriate" (p. 378). Further defined, ethics are the standards or rules by which one lives and decisions are made. In the broadest sense, this reflects doing the right thing for the right reason, which has a number of implications.

Northouse (2010) reported that ethical leadership could be examined by looking at the behavior and the character of a leader. Behavior of a leader is concerned with what a leader does, and can be broken into teleological theory or deontological theory. Teleological theories focus on the result or consequence of a decision and consist of: (a) ethical egoism, (b) utilitarianism, and (c) altruism. Ethical egoism is concerned with making decisions that will benefit oneself (Northouse, 2010). An example of ethical egoism can be found in transactional leadership where the leader's self-interest are of ultimate concern. Utilitarianism is concerned with making decisions to benefit the 
greatest number of people. Finally, altruism, described as putting the needs of others in front of one's own desires (Northouse, 2010; Stone, 2012) is identified as the common thread among transformational, authentic, and servant leadership; interconnecting their common ethical undertones (Northouse, 2010; Yukl, 2013). Deontological theory focuses on leaders making decisions based on doing an action that is morally right. It is these actions that serve as a basis for the principles in ethical leadership (Northouse, 2010).

In contrast to teleological and deontological theories, the character of a leader can be viewed through virtue-based theories. Virtue-based theories focus on who the leader is within their heart. It is believed that this type of moral living can be taught and practiced, making it attainable by all individuals. This is similar to transformational leadership where leaders help followers move to a higher moral standard, but different from trait theory which is innate (Northouse, 2010; Yukl, 2013).

Ethical leadership is comprised by five guiding principles. These guiding principles have described that an ethical leader: (a) "builds community", (b) "respects others", (c) "serves others", (d) "manifests honesty", and (e) "shows justice" (Northouse, 2010, p. 387). As previously noted, evidence of these ethical principles can also be identified throughout transformational, servant, and authentic leadership theories.

Ethical leaders build community by developing relationships with their followers while working toward a common goal. Community building is not just limited to the leader and the followers, but has implications in a broader context for the common good (Northouse, 2010; Stone, 2012). Similarly, in transformational leadership, Kouzes and Posner (2011) described, "enable others to act" (p. 5) which is based on empowering 
others to collaboratively pursue shared goals. Community building can also be seen in authentic leadership (George, Sims, McLean, \& Mayer, 2007/2011; Northouse, 2010). This may be demonstrated through the importance of establishing relationships with followers that are mutual, open, and built on trust; resulting in a committed community (Northouse, 2010; George et al., 2007/2011).

The second principle, "respect others" (Northouse, 2010, p. 386) was described as leaders who listen to and acknowledge their follower's ideas and opposing views, and ultimately "treat others as worthy human beings" (Northouse, 2010, p. 388). This is similar to transformational leadership, which is associated with showing respect for others through listening to follower ideas, collaboration, and supporting other's decisions (Kouzes \& Posner, 2011). Likewise, servant leadership is linked to the care, concern, and respect for all, especially those who may not always have a voice (Northouse, 2010; Yukl, 2013).

The third principle of ethical leadership is "serve others" (Northouse, 2010, p. 388). Service to others can be described on a personal level or from a broader organizational perspective. The main idea of this principle is altruistic behavior (Northouse, 2010; Stone, 2012). Servant behavior can be seen in healthcare when decisions are made to benefit the patient. In servant leadership, serving others aligns similarly with showing respect, as particular attention is spent serving the have-nots in society (Northouse, 2010; Yukl, 2013). Senge (1990) described how leaders could be stewards by supporting the organizational vision and aligning their own goals with those of the organization, prescribing to something bigger. 
The fourth principle of ethical leadership is "manifests honesty" (Northouse, 2010, p. 387). Ethical leaders tell the truth and are not deceitful. Honesty is at the core of trusting relationships. Leaders being open and honest about their beliefs best describes building trust in transformational leadership (Northouse, 2010; Yukl, 2006). Kouzes and Posner (2011) reported that leaders should "model the way" (p. 2) which meant being upfront about their beliefs and position, and delivering on their promises.

Finally, ethical leadership is just. An ethical leader "shows justice" (Northouse, 2010, p. 387) by being fair and attempting to treat others equally. This principle is at the forefront of decision-making and any wavering from equal treatment of others requires a higher moral reason. Similarly, authentic leadership (Northouse, 2010), servant leadership, and transformational leadership utilized higher moral reasoning in leaders and followers to emphasize justice and equality (Northouse, 2010; Yukl, 2013).

Leadership in medicine: leadership or management. It is not uncommon for educated persons to be called upon as leaders. This rings true for physicians and other medical professionals. Physicians and other healthcare professionals are often perceived as honest and trustworthy, not only because they are educated but also for their prominence within the communities that they serve (Collins-Nakai, 2006). However, when the idea of leadership enters the conversation within medicine it is traditionally associated with an administrative position and responsibility. When physicians make the choice to become leaders in this model it takes time away from their work as clinicians and puts emphasis on administration, resulting in comments and thoughts of "Oh, you are moving into leadership" as if this move to administration made them a leader. Middleton 
(2013) who reported that in conversations with nursing students the terms leadership and management were often interchanged supports this.

The question then becomes how is leadership viewed in medicine? Is it a merely a position within administration or is it something more? Souba (1998) stated, "Leadership means responsibility, not privilege... it is not a position; it is a collection of practices and behaviors, a set of skills" (p.1).

Leadership can be viewed from varying perspectives. Unlike the way traditional medicine views leadership as a managerial or administrative position, Kotter (1990/2011) explored the difference between leadership and management. Kotter (1990/2011) delineated leadership from management stating that they are two separate entities that complement one another. Kotter's description of management to create structure and develop incentives is similar to the description of transactional leadership where an exchange takes place between leader and follower. Similarly, Kotter's (1990/2011) definition of a leader to create vision, communicate goals, seek commitment, encourage collaboration and teamwork, inspire and satisfy unmet needs are consistent with theory set forth by Kouzes and Posner of transformational leadership where leaders inspire a shared vision by communicating and modeling their beliefs, establish relationships with their followers, incorporate teamwork and allow for realization of followers dreams resulting in long-time commitment (Kouzes \& Posner, 2011; Northouse, 2010).

Physician leadership or medical leadership in general is more than just management or an administrative role that a physician or healthcare worker chooses to or is selected to do. As stated by Snell, Briscoe, and Dickson (2011), "physician leadership is the ability to assume responsibility to set direction for positive change in health and 
wellness in the health system, to exercise that responsibility in a caring and compassionate fashion and to influence others to work together to achieve those changes" (p. 2). There is no doubt that positions of power are a vital component to bring about change. Therefore, it is not surprising that physician leaders are often those within administrative positions of power, but leadership is not reserved for only those within administrative positions, nor is it limited to only physicians. In fact, Thoms and Duffield (2012) as paraphrased by Middleton (2013) described, "Leadership is not positional, that is, it is not associated with holding a position of power, but is able to be achieved by all" (p. 84). Leadership is available to and a responsibility of all healthcare providers, physician assistants and nurses included. Medical leadership may be slightly different depending on one's specific specialty or position, but all are equally important in the accomplishment of quality patient care and medical systems.

All clinicians included. Traditionally, the physician has been identified as the leader when considering medical decision-making. However, recently there has been a shift in medicine to more a team-based collaborative approach to patient care. With this approach, the physician is identified as the team leader (Snyderman et al., 2011). Although the physician is the team leader, leadership skills are paramount for all clinicians (Blumenthal et al., 2012) and throughout the healthcare system (Hays, 2008). The responsibilities afforded PAs and advanced practice providers do not include just implementing the wishes of the physician, but include a "high degree of autonomous, daily strategizing and decision-making" (Huckabee \& Wheeler, 2008, p. 24). These responsibilities have proven to be successful and effective for this group of clinicians both economically and within in the realm of patient care. In fact, Snyderman et al. 
(2011) stated that physician assistants and other advanced practice providers deliver "comparable care for many routine health problems... at reduced cost without substantive changes in quality" (p. 1348).

Not only are these leadership responsibilities evident in patient care, but also within communities, health systems, education, and politically. In an article by Cawley (2007) he identified jobs of physician assistants over the history of the profession. He described the early leaders of the profession as pioneers as they were often required to participate in a variety of roles. In fact, he stated:

The job could be summarized as one in which an educator needed to be both an internal and an external ambassador for the PA concept, in addition to being a teacher in the classroom and clinic, an administrator, a counselor and advisor, a curriculum designer and educational researcher, and community service provider. (p. 8)

In addition, these early leaders defended and supported the profession to political and medical naysayers (Cawley, 2007).

The evolution of leadership in medicine has led us to today. Leadership in medicine is not just a position of administration, but rather necessary among all levels to fully embrace and accomplish the interprofessional and collaborative teamwork that is required for effective quality patient care. Leadership in medicine is not just a position of administration, rather a journey of individual self-directed learning and advocating not only for oneself, but also for the entire profession on a variety of levels within health systems, locally, statewide, and nationally. Leadership in medicine is not just a position, 
rather an educator of future healthcare leaders and the community as a whole.

Leadership in medicine is not just a position.

\section{Medical Leader}

One question that has continually appeared in the medical literature is, "What part of leadership theory is most important for the medical leader?" Through exploration of leadership theory, one may find that specific theories relate better to certain people or professions. Although medical providers may see a correlation between their profession and certain leadership theories, there does not seem to be a theory that has provided a perfect fit with that of a medical leader. A variety of researchers have attempted to take leadership theories already in place and caress the responsibilities of the physician, advanced practice provider, or other allied health professional to make them fit, but there is often something missing that requires the exploration of other leadership theories. The medical leader operates under a variety of different lenses dependent upon their role, and must utilize a combination of leadership skills to address each facet of their profession.

Skills or competencies have been at the heart of quality PA practice. Current competencies identified by the four national PA organizations (American Academy of Physician Assistants, Physician Assistant Education Association, Accreditation Review Commission on Education for the Physician Assistant and the National Commission on Certification of the Physician Assistant) (Competencies, 2012) are focused on overall practice and although suggest some components of leadership, are not specific to leadership. Ethics is at the heart of medical practice and ethical undertones support commonalities in transformational, authentic and servant leadership theory. It is through these lenses that the conceptual underpinnings of the medical leader framework exist. 
The medical leader is not only a clinician, but also someone who demonstrates a pursuit of quality improvement in him or herself, their patients, community, profession, medical education, and healthcare system. He or she is an active member of the medical knowledge community demonstrated by their active participation and engagement with: (a) the communities where they practice, (b) their profession, (c) their healthcare system, and (d) the next generation of medical professionals. Much like Kouzes' and Posner's (Northouse, 2010) model in transformational leadership medical leaders are pioneers in medicine who lead through example and provide opportunities for teamwork and collaboration. Likewise, they show evidence of Bill George's leadership approach on authentic leadership, identified through both compassion and passion (Northouse, 2010). Compassion for others, specifically patients, and service to those patients and the broader community, as in servant leadership, is a quality that successful clinicians are able to exhibit. Passion for medicine is evidenced through a strong commitment to the medical profession as a whole (Northouse, 2010).

For this research study, the term "medical leader" served as the overarching theme to the proposed conceptual framework. The medical leader is defined here as a: (a) learning leader, (b) patient advocate, (c) engaged professional, (d) builder of future professionals, (e) community activist, and (f) team collaborator (see figure 1). Below is a more holistic description of each of the medical leader conceptual underpinnings.

Learning Leader. A learning leader is a physician assistant who participates in learning opportunities to improve himself or herself both personally and professionally. The words "learning" and "leader" go hand in hand. In fact, some would argue that you simply could not have effective leadership without learning. Heifetz and Laurie 
(1997/2011) proposed that leaders who learn have the ability to "get on the balcony" (p. 60) or see things from a broader perspective to determine what is working, while still being in the game and part of the action. Both Marquardt (2011) and Morgan (2006) noted the importance of learning in their work. Marquardt (2011) identified learning as a key ingredient in learning organizations. While Morgan (2006) noted models of change, exemplified by double loop learning where learning is part of continuous change and growth. Learning is not just a component of success that is limited to organizations and their executives, but rather occurs on a variety of levels and includes everyone.

Successful leaders are individuals who continually look for ways to improve themselves and their leadership ability (Souba, 1998). George (2007) identified "selfdiscipline" and "values" as two of his five dimensions of authentic leadership. He stated that leaders must examine their values through self-reflection, experience and discussion. Additionally, he reported that to get results leaders set the mark high for themselves and others, which requires self-discipline and accountability. Kernis (2003) discussed selfawareness as knowing strengths, weakness and beliefs.

Professionalism or the display of professional attitude through one's actions, words and deeds is an important component of the learning leader. As stated in the Annals of Internal Medicine, "Professionalism is the basis of medicine's contract with society. It demands placing the interests of patients above those of the physician, setting and maintaining standards of competence and integrity, and providing expert advice to society on matters of health" (Sox, 2002, p. 244). Professionalism encompasses both personal and professional development and occurs through critical self-reflection (Northouse, 2010) and self-discipline (Competencies, 2012). As identified in the 
competencies for the physician assistant profession, it is essential for PAs to continue to develop throughout their careers both personally and professionally through continual learning opportunities (Competencies, 2012).

Learning. Learning occurs through a variety of venues. Marquardt (2011) described different types of learning that can occur on different levels. First, he described that learning occurs within individuals, groups, and finally within organizations. Second, he described, adaptive learning which includes reflection on experiences, and then modification of future actions. Finally, he described action learning, which allows individuals to actively learn while concurrently applying a solution to a problem, reflecting on the results and then making necessary adjustments. The application of these concepts to the broader context of PA continuing education and experiences serves as a firm foundation.

Numerous researchers have documented the need for continued individual learning within the context of the larger organization. Physician assistants accept the responsibility to be self-directed learners. This includes not only being effective at their current position, but also continuing to gain the knowledge and skills required for continued quality medical practice. Not only does this include gaining medical knowledge, but also building skills, which enhance professionalism within the medical community. Therefore, for the purposes of the medical leader, learning will be described from two main perspectives: a) self-directed learner and b) self as a learning professional.

Self-directed Learner. Personal growth is an essential component of learning to become a successful leader (Souba, 1998; Wisniewski, 2003). In an address to the PA classes of 2012, Bushardt, PharmD, PA-C wrote, “To be successful, you must be 
responsible for your own learning. You will never possess all the knowledge you need to serve your patients, so learn to harness knowledge and recognize your limitations" (p. 13). Traditionally, we think of learning as an external process by which we take information from an outside source and then apply it to our own lives or profession. Although learning through this method is certainly one way, it is not the only way. In fact, Souba (2011) described that in order to restore ethics as the basis for medical practice, leaders must focus on, "being a leader as the basis for what leaders know, have, and do... rather than focusing on adding more degrees, titles, and awards to our leadership lapel" (p. 2).

In a paper by Topper (2009) she stated that, "if we are to be effective leaders of others, we must first be effective leaders of ourselves" (p. 561). She noted leaders, "help others tap into things they care about and help them to move forward in achieving their goals" (p. 561). In a review article by Collins-Nakai (2006), she identified an "inward journey of self-discovery and self-development" (p. 70) as important to physician leadership. An important component of personal growth and development occurs through critical self-reflection and self-discipline, both which are related to the professionalism competency that governs the PA profession. The ability to self-reflect allows an individual to investigate concerns and beliefs from a variety of perspectives ultimately allowing for clarity and a more informed decision (Davis, 2004; Wisniewski, 2003). Self-discipline, as described by George (2007) provides the motivation necessary for the commitment to and achievement of excellence.

Self as a Learning Professional. Professional development refers to the continuation of educational opportunities within a particular professional field, which 
nurture growth and expertise. This definition is very broad, encompassing many realms within the professional lives of physicians, advanced practice providers, nurses, and other allied health professionals.

Medical knowledge. Professional development within medicine is associated with credits awarded for each hour a professional spends in an approved educational event. These credits are termed continuing medical education/experiences (CME), most often used for physicians and PAs or continuing education units (CEU), most often used for advanced practice nurses, nursed, and other allied health professionals. The number of hours spent in professional development is different depending on one's medical profession. Physician assistants are required to spend 100 hours in professional development every two years to maintain National Commission on Certification of Physician Assistants (NCCPA) certification. CME credits can be earned in variety of ways. One of the most common ways to obtain CME credits is through medical lectures provided during a conference. However, PAs may also choose to do any of the following: (a) journal reading, (b) precept students, (c) lecture, (d) video or audio recordings of lectures, (e) complete certification courses, and (f) special committee work, among others. Additionally, PAs retake the Physician Assistant National Recertification Examination (PANRE) every 10 years to maintain certification.

Continuing medical experiences are a vital component of professional growth and development of clinical expertise in medical providers. However, they are not the only way for PAs to develop. Lucey and Souba (2010) stated, "Physicians should understand the need for continuous education in professionalism as a core component of continuing medical education and maintenance of certification" (p. 1022). They further explained 
that despite there being issues with professionalism in medicine daily, less effort is spent on developing solutions to these problems and they are often approached with simple solutions that do not provide a remedy. Lucey and Souba (2010) recommended teaching physicians to handle stressful situations and competing responsibilities which can often be the source of conflict and at the core of unprofessional actions rather than just adding more rules and policies on professionalism.

Self as experiential learner. The Competencies for the Physician Assistant Profession discussed "Practice-based Learning \& Improvement" (Competencies for the Physician Assistant Profession, 2012, p. 3-4) as one of the six main competencies of the PA profession. The competencies delineated that PAs are to "analyze practice experience and perform practice-based improvement activities using a systematic methodology in concert with other members of the health care delivery team" (p. 4). The National Committee on Certification of Physician Assistants (NCCPA) has since integrated performance improvement projects and self-assessment projects within the certification maintenance process to not only incorporate this competency within practice, but to improve accountability and a higher quality of healthcare (National Commission on Certification of Physician Assistants, 2015).

First implemented in 2005 by the American Medical Association, PI-CME is designed to improve the practice of individual PAs and teams (American Academy of Physician Assistants, 2015). A study done by Shershneva, Mullikin, Loose, and Olson (2008), observed a clinical practice where Performance Improvement (PI) CME was done to improve blood pressure in a group of patients. Because of this study, the researchers 
determined that PI CME is a way for clinicians to not only gain knowledge, but also improve their practice.

A learning leader is a PA who participates in learning opportunities to improve themselves both personally and professionally. Personal improvement comes with being a self-directed learner and improving our self-awareness and self-discipline. Whereas, professional improvement is the result of continuing to gain medical knowledge and be able to apply that knowledge in practice to both maintain and improve competence.

Patient advocate. The patient advocate is a PA who demonstrates altruistic behavior, by putting the needs of others ahead of themselves (Northouse, 2010; Stone, 2012). This may be demonstrated through developing an ethical relationship with a patient that includes trust, just treatment, open and honest communication, respect for their autonomy and confidentiality, service, and an altruistic behavior that reflects going above and beyond the call of duty. The guiding principles are nonmaleficence, "First, do no harm” and beneficence "do good” (Bickley \& Szilagyi, 2013 p. 92).

Altruistic behaviors place a focus on putting the needs of others ahead of oneself (Northouse, 2010; Stone, 2012). In a study by Curry, Smith, and Robinson (2009) it was found that altruism most likely falls along a continuum with varying degrees of behavior. Their research showed that true altruism is not likely attainable due to there always being some degree of secondary gain associated with altruistic acts, even if that meant just feeling good about helping. They also found altruism associated with the concepts of social justice and empathy. In the area of social justice, it was noted that altruism might be evident when there was need to help people who are marginalized or may not be able to help themselves. Additionally, altruism has been associated with empathy and 
explained by one helping another when they are suffering. Given these explanations and how altruism may materialize on a daily basis, it is easy to see why those in the helping professions may display altruistic behaviors.

Many of the helping professions, such as those in healthcare, are composed of people who care about and want to help others and that is why they chose the profession, to help others (Curry et al., 2009). For healthcare providers, such as physician assistants, helping others is at the basis of why they chose the PA profession. To celebrate PA week, Barton Associates asked PAs about why they wanted to be a PA. Part one of their tallied responses were about helping others and patient care. PA comments included answers to the statement I am a PA because "the honor of working as patient advocates", "I love helping others", and "my Love of people" (Seng, 2015) just to mention a few.

Both ethical and servant leadership emphasize justice, service, and respect for people. Servant leadership is especially focused on the construct that all people should be valued (Northouse, 2010). Schumann (2001) discussed the care principle, which "maintains that we express care for others with whom we have special relationships by nurturing their development in a way that allows them to make their own choices and live their own lives" (p. 104). This is similar to ethical leadership where leaders focus on the followers and make them more knowledgeable and self-sufficient so they may later help others (Northouse, 2010).

Given the uniqueness of their job and patient relationships that develop over time, clinicians are often called upon to be an advocate for their patients. Patient advocacy has many faces, but is based on the constructs of justice, service, and developing relationships built on trust and respect. Patient advocacy is at the heart of being a 
medical professional. In fact, in the Annals of Internal Medicine it is stated, "Professionalism is the basis of medicine's contract with society. It demands placing the interests of patients above those of the physician, setting and maintaining standards of competence and integrity, and providing expert advice to society on matters of health" (Sox, 2002, p. 244). These constructs are the cornerstone of good patient care, and are certainly important components of the patient advocate.

Trusting and respectful relationships. Patient advocacy is a complex construct built on the foundation of developing trust and respect with patients. Bill George and his work in authentic leadership noted the importance of relationship building among leaders and followers. Much like this relationship, patients want to have access to their healthcare provider where they have the opportunity to develop a connection and trusting relationship. Likewise, George explained compassion, which concentrates on a leader being sensitive to his followers needs; much like a healthcare worker is sensitive to the needs of their patients (George, 2007; Northouse, 2010). These needs are not just the superficial needs that may be seen in the conversational exchange occurring between a physician and patient during an office visit, but come with a greater understanding of the patient's life story, which provides a deeper understanding of who they are (Northouse, 2010).

Servant leadership places a focus on listening (Northouse, 2010). The art of listening has been identified in medicine as a key ingredient to treating patients. "Listening to a patient makes much of the expense associated with medicine unnecessary... the art of medicine and the listening ear have no parallel structure...good doctors listen...That is why alternative medical practitioners and nontraditional 
practitioners are so popular. People just want to be heard and understood" (Troncale, 2010). In a recent survey one PA reported, "I am PA because listening and helping other is my passion" (Seng, 2015). Much like servant leadership, ethical leaders are respectful. They not only listen, but also understand (Northouse, 2010).

A study done on nearly 200 patients seen at the Mayo Clinic helped to identify the top characteristic of the ideal doctor. Of the seven characteristics identified, six were directly related to how the doctor made the patient feel. On the list included: (a) empathetic- described as a feeling that the doctor was trying to understand how the patient was feeling, (b) humane- described as caring, compassionate and kind, (c) personal- described as the doctor was interested in me outside of the illness, (d) respectful- described by taking the patient's input seriously, (e) forthright- described as being told what was needed in a forthright manner, and (f) confidence- described by the displaying of confidence which made the patient also feel confident (Hitti, 2006). The PA competencies recognize the importance of the patient - provider relationship and emphasize effective communication and ethical interpersonal relationships as vital components of PA practice (Competencies, 2012).

Service to others. Service and the act of serving others is the foundation in servant leadership and a component of ethical leadership. Servant leadership focuses on caring for others by taking a special interest in their needs (Northouse, 2010). This is a natural fit for the patient-provider relationship. In this relationship, patients seek out providers for their healthcare needs and healthcare providers serve patients by helping them achieve good health. This transaction may seem very simple and in some instances, it may be. However, a provider who values service goes beyond the simple transaction. 
Diagnosing a patient with chronic disease in one example, which demonstrates the true complexities of this process.

When a patient advocate diagnoses a patient with a chronic disease, he takes the patient by the hand and leads them through the many intricacies of the disease process to health. This process is often very long and challenging as it requires numerous steps including, but not limited to: (a) evaluating the whole patient, not just the disease, (b) gaining a full and complete understanding of the patients daily life and the challenges they will face, (c) educating the patient on the disease and treatments, (d) discussing risks, benefits, and complications of both the disease and its treatments, and (e) answering all the patients questions. Only then will the patient have the opportunity to make an informed decision about their healthcare. This process may be repeated numerous times over the course of the disease process.

The example described above is only one example of service in the patientprovider relationship. Patient advocacy may also include, but is not limited to: (a) determining a practical medication regimen, (b) writing letters to insurance companies for services, (c) providing education on treatment options, (d) determining a plan of care that is feasible for both patient and clinician, (e) being cognizant of patient's financial situation when prescribing treatment, and (f) identifying factors that may negatively impact the well-being of patients. Huckabee and Wheeler (2008) stated that individual patient needs are important when determining a treatment plan and that PAs are an integral component in leading patients to well-being.

Service is not just about the patient and provider encounter, but also related to helping patients navigate the health system. The PA profession certainly recognizes the 
importance of patient advocacy under the heading of "systems-based practice" within the competencies of the profession (Competencies, 2012, p. 4). Under this heading is stated, "advocate for quality patient care and assist patients in dealing with system complexities" (p. 4).

The amount of time and effort that can be required to be a patient advocate can be overwhelming, especially when there is a push to see more patients with less time (Souba, 2011). However, The Annals of Internal Medicine described patient welfare, respect for patients informed decisions, and working for the good of all patients as the fundamental principles of medicine. It further described that patient well-being should be above all external pressure or gain and that all patients deserve equal and fair treatment (Sox, 2002). Similarly, Souba (2011) stated, "When one is being a leader in medicine who takes a stand for the inviolability of the doctor-patient relationship, one naturally places service above reward" (p. 8).

Justice. Something that is just is also moral, honest, ethical, good, fair, unbiased, impartial, right, or justified, among others. Unconditional acceptance especially for marginalized populations is a concept associated with servant leadership. Likewise, ethical leadership places an emphasis on being fair and treating others equally (Northouse, 2010). Disparities within healthcare are evident especially with respect to race, ethnicity, and socioeconomic status just to name a few (National Healthcare Quality \& Disparities Reports, 2015). The patient advocate fights for the marginalized patient placing equal treatment for patients at the forefront of decision-making. In a recent survey, one PA reported his desire to help those less fortunate, "I became a PA to help 
less fortunate and because God led me to this profession. I retired last year after 41 years as a PA and it has rewarded me beyond measure" (Seng, 2015).

Above and beyond. There is little doubt that patient advocacy has its roots in the constructs of honest, trusting, and respectful relationships, serving others, and fair, equal treatment. Some may report that all of these concepts are obvious components of being a healthcare provider. However, if you asked a healthcare provider about these concepts, they could probably name someone specifically; whom they believe goes above and beyond the call of duty. Someone, who like Mother Theresa, demonstrates an altruistic, empathic, and servant like behavior beyond measure.

Being a leader in patient advocacy is not about just doing your job of taking care of your patient's needs, but it is about going above and beyond at all times. It is about doing what is right and just for your patients all the time. It is about having the ethical foundation of medicine guide every decision that is made.

In an article by Souba (2011) he stated that "the ethical foundation of the medical profession, which values service above reward and holds the doctor-patient relationship as inviolable, continues to be challenged by the commercialization of health care" (p. 1). In order to combat this he recommends a transformation of the one's mindset in what it means to be a leader in healthcare that is focused on the ethical foundation of "acting in the best interest of the patient, safeguarding patient choice, and ensuring justice" (Souba, 2011, p. 2). He stated this could be done by using a leadership framework built on the constructs of awareness, commitment, integrity and authenticity. Souba stated:

The transformation of health care begins with a shift in our understanding of what it means to be a leader. When a physician creates for himself a future for 
healthcare to which he is committed that is bigger than his own agenda, that future "uses" him in that it provides a context from which his correlated actions are altruistic, service-oriented, and attentive to social justice. When a hospital executive distinguishes his already-always-listening that says "we want to avoid uninsured patients", it creates the possibility for taking a stand for patient autonomy and justice. When a health care provider gives his word to the Charter on Professionalism, he makes a promise (that uses him) to maintain patient confidentiality, improve quality of and access to care, and to practice medicine so as to ensure the just distribution of finite resources. (Souba, 2011, p. 9)

Taking all of these points into account, being a patient advocate may mean doing the right thing at all times, even when it is more challenging, time consuming, or even going against the social norm or system pressures of the bottom dollar. It may mean never having to question what the right thing is because one's being is so entrenched within those ethical roots of honesty, justice, service, and respect for patients that one cannot imagine doing anything different from the most altruistic action. Finally, patient advocacy may mean that the guiding principle of "do good" (p. 92) reigns supreme (Bickley \& Szilagyi, 2013).

Engaged professional. An engaged professional is a physician assistant who demonstrates organizational stewardship through involvement within local, state, and national organizations in order to form a coalition that is working toward a common goal. Bolman and Deal (2008) recognized the idea of soul or a sense of spirituality in organizations that they related to ethics. They described it as an interconnectedness that gave the organization a vision or purpose of who they were and what they stood for. 
Organizations with a culture that reflect a bigger purpose have been linked to longstanding success, rather than unethical or illegal action.

Bolman and Deal (2008) identified four frames through which to view organizations that included: (a) structural, (b) human resources, (c) symbolic, and (d) political. Organizational ethics can be closely related to ethical leadership through these frames. All five ethical principles identified for leadership focused on how leaders should treat followers. This reflects a deep connection to the significance of people and moral principle within organizations (Northouse, 2010).

The human resource frame, described as being people-centered, allows for exploration and support of members personal goals (Bolman \& Deal, 2008; Shafritz, Ott, \& Jang, 2011). In return, members feel more ownership and responsibility for their work and are more connected and committed to their organization (Bolman \& Deal, 2008; Marquardt, 2011). This concept along with a collaborative work environment are characteristic of learning organizations (Marquardt, 2011). Within this frame leaders should show love and establish an organizational culture of caring.

The organizational ethic identified in the political frame, was justice. Northouse (2010) found justice to be one principle of ethical leadership. Bolman and Deal (2008) and McGregor (1957/2011) reported that leaders give away power by decentralization which results in empowerment of members resulting in a feeling of justice. Decentralization of power has other benefits with concern to organizational ethics. In the structural frame, it allows for authorship, deepening employee commitment to the organization through feeling their work has a greater purpose (Bolman \& Deal, 2008; McGregor, 1957/2011). Finally, the symbolic frame is characterized by leadership, 
which views the work of the organization as significant, by providing purpose and meaning to goals and reinforcing the vision. Additionally, the organization is based on a deep faith of the values shared among the community of people and strengthened by the ethical success of the company (Bolman \& Deal, 2008; Schein, 2004/2011).

Many PAs and other healthcare providers participate in local, state, and national organizations, which enhance their professional development (Huckabee \& Wheeler, 2008). Local, state, and national organizations allow for collaboration among medical providers and an opportunity for service and growth within the profession, in turn deepening their commitment to the organization. This growth may take place from serving on committees to holding a local, state, or national office. In fact, Ledlow and Coppola (2014) wrote, "joining professional organizations is critical to establish a leader's credibility and relevancy... the greatest benefit offered by any professional organization is the opportunity to network and collaborate with peers" (p. 342).

Organizational commitment. Being an engaged professional is not limited to personal gain, but is also beneficial for the organizations. Ethical and transformational leadership is associated with finding and fighting for common goals (Northouse, 2010). Servant leadership has stressed organizational stewardship (Northouse, 2010). Engaged professionals are involved within local, state, and national organizations. Involvement within professional organizations on all levels helps to promote big picture thinking in an effort to move the organization and profession forward.

At local, state, and national levels, collaboration provides an opportunity to align members from varying medical specialties to work together in a supportive, nonthreatening environment to achieve a goal. The American Academy of Physician 
Assistants is the voice of practicing physician assistants on the national level. This organization has been around since 1968 as an advocate for and educator of the PA profession. The AAPA website lists leadership and service as one of their four values. On the site it states, "We inspire a shared vision to lead the profession, emphasize service to our members and enhance the ability of PAs to serve patients and their communities (American Academy of Physician Assistants, 2015a). Additionally, the site recognizes (a) foster PA excellence, (b) optimize PA practice, and (c) grow the PA profession as its strategic commitments to the PA profession in partnership with the constituent organizations (American Academy of Physician Assistants, 2015a).

Not only does membership and involvement at the national level help to provide resources for advocacy and alignment of goals for practicing PAs, but this trickles down to the state level too. State PA organizations, which work under even a stricter set of laws and standards, must work to advocate and educate the public about the profession at both the state and on a local level. PAs advocate on a state level through meetings with legislators and those who make laws or on a local level with hospital and clinic administrators. Education to build on their individual professional acumen is available to PAs. Local educational dinners and business meetings or continuing educational experiences are two examples.

Organizations thrive when there is an alignment of collaborative member action with a shared organizational vision. Strength in numbers and an attitude of collaboration and organizational service or stewardship is a vital component of organizational strength (Northouse, 2010). An engaged professional is one who realizes that advocating for themselves and others within the profession is their fight and is willing to take action. In 
their zest to be members of the profession, students demonstrate excitement for the profession at large. Organizational engagement started early with student involvement at the local, state, and national level while in school, strengthens their tie to the profession. Students can help with membership drives, educational events, and community service events to promote the profession.

Not only do PAs have the support of the AAPA, but also PAs within academia have the support of the Physician Assistant Education Association (PAEA). PAEA is a national organization that represents physician assistant educational programs. The organization distributes information about its member programs and provides those programs with educational services to be successful. According to its website, the vision of PAEA is, "To improve the quality of health care for all people by fostering excellence in physician assistant education" (Physician Assistant Education Association, 2015, Vision statement section, para. 1). PAEA offerings are broad and include information and resources on assessment, didactic education, clinical education, conferences, ethics, curriculum, faculty development, cultural competence, diversity, leadership and others. PAEA offers a platform for faculty to become involved within the goal of quality education for students; making a difference at both local and national levels of PA education.

Politics and health policy. Political activism has a variety of faces with regard to medicine. Healthcare professionals may be involved in creating and evaluating health policy at both the state and national levels. In addition, advanced practice providers may be heavily involved in obtaining and maintaining favorable practicing laws that allow healthcare to be delivered in the most time efficient and effective manner. Without 
effective practicing laws, delays in healthcare treatment are inevitable and may cause a shift in the way patients are cared for from preventative care to acute care treatment (Snyderman et al., 2011). Practicing laws for advanced practice providers are different in states across the country affecting medical practice. Without PA involvement politically, PAs may not be able to meet the healthcare shortage and other patient needs. This has been a big push of the Missouri Academy of Physician Assistant's President, Paul Winter. Winter stated:

I have always advocated that it is imperative for every PA to be aware and involved in both the activities of their state organization as well as the national organization. The degree of involvement is of course an individual decision, but the minimum I have always encouraged PAs has been, 1) Active membership in both MOAPA and AAPA 2) Know who your state rep and senator is and possibly reach out to them and just at least introduce yourself 3) Keep aware of the latest activity of the organization by reading and acting upon emails as requested 4) Donate $\$ 100.00 /$ year to the MOAPA PAC fund. I have explained that none of these items listed above are time consuming, and the PAC donation is just a little more than $\$ 10.00$ per month. If every PA at least held themselves to accomplishing these items, we would have increased profession awareness, the organization would have significantly more financial resources to invest directly back into the profession and the promotion of it throughout the state and possibly offer even more resources to the needs of PAs in Missouri. I have also lectured to students, as well as practicing PAs, and left them with this thought, we are still too small of a profession not have everyone doing their fair share. This does not 
mean everyone is called to be in a board position, however, the items listed above have again, been drafted with everyone's time constraints in mind, but we need every PA representing our profession and supporting the causes that are being done directly on its behalf. (P. Winter, personal communication, May 18, 2015)

Clinical involvement. Although the focus of the engaged professional has been concentrated on professional organizational membership and politically up to this point, there is another component that must be explored; clinical involvement. Clinical involvement much like the others includes collaborative work with shared goals. Evidenced by the business side of medicine, this includes committee involvement on projects within the clinic or hospital setting that focus on the improvement of patient care, the facility, operations, or personnel.

Physician assistants who have the opportunity to be involved with committees within their workplace have a voice within their work environment and an opportunity to affect change. One such example is the transition to electronic medical record (EMR) which has been occurring recently over the last several years across the US. The implementation of EMR has required leadership on all levels for the successful transition of medical records from paper to a live, electronic form. For example, the designation of specific individuals within nursing, providers, allied health workers, etc. who can be available as the "go to" person within each of those fields when problems arise during implementation. These individuals or in some cases these "superusers" help ensure those being trained adapt to the new system with understanding and proficiency within their daily work of the hospital and clinical settings. One PA who served as a superuser for a local hospital that recently transitioned to EMR stated, "PA involvement as a superuser 
with the EMR implementation at Mercy was important as it allowed another view and insight to the pieces of the EMR needed for providers to effectively optimize patient care. (J. DelVecchio, personal communication, October 26, 2015)

The engaged professional is active on a variety of levels. These levels of engagement include: (a) professional organizations, (b) politics and health policy, and (c) clinically. Each of these areas of engagement allow the leader to be at the forefront on decision-making and professional advancement, which can have implications for the future.

Builder of future professionals. A builder of future professionals is a physician assistant who gives back to the profession by serving as an educator to new PA professionals during their didactic and clinical training; modeling both clinical and professional skills. Ethical, servant, and transformational leadership serve as the basis for the builder of future professionals. In giving back to the profession, PA professionals demonstrate an altruistic behavior (Northouse, 2010; Stone, 2012). In addition, they are modeling a sense of service as they mentor new PA professionals through their didactic and clinical training. Through these actions, they have an opportunity to empower future PAs and instill among these new professionals medical expertise and skills related to teamwork and collaborative practice (Northouse, 2010).

Involvement in the educational training of the next generation is another way healthcare professionals portray leadership. Educational involvement and support may be portrayed through faculty appointments, guest lecturing, or precepting students among others. Faculty must stay abreast not only of medical advancements, but also advancements in education. Faculty appointments are often associated with a component 
of research and service, which include involvement professionally in national educational organizations. Guest lecturing and precepting of students allow full-time practicing clinicians to be involved as leaders in mentoring and training the next generation. In a recent commentary Pagel (2012) wrote, "One of the most effective ways to advance professionalism and leadership among practicing PAs is through precepting students" (p. 14).

Modeling. Kouzes and Posner (2011) with their work in transformational leadership described five components of leadership. One of these components was "modeling the way" (p. 2). Modeling allows one to lead by example through their behaviors and interaction with others. "Modeling is regarded as the best and most practical methods of transferring professional values and attitudes" (p. 8) zero tolerance for unprofessional behavior (Danielson \& Cawley, 2007). A study by Baird et al. (2012) found that $97 \%$ of dermatology residents agreed that their leadership skills were acquired through observation of others and $91 \%$ by modeled behavior. Therefore, as models of the PA profession, if we want PA students to be good clinicians and representatives of our profession then we should be willing and ready to teach them to do so.

Empowerment. Kouzes and Posner (2011) with their work in Transformational leadership reported, "enabling others to act" (p. 4) which includes collaborating with, encouraging, and supporting others. Medical school provides a learning environment where students can be empowered to learn under the direct supervision of their preceptor and other experts within the medical community. Preceptors empower students to learn through practical experiences. This empowerment results in a sense of belonging to the profession and PA community. Josanne Pagel stated, "I like giving back to my 
profession." "I feel like I have something to give, and it fills me with an enormous sense of gratitude." "We can build a stronger profession by mentoring our future colleagues" (Pagel, 2012).

Professional commitment. Ethical and Servant Leadership have their foundation in altruism or acts that are rooted in the serving the best interests of others (Northouse, 2010). There is no doubt that lecturing takes time away from the busy clinician's day. So why, then do clinicians agree to partake in these activities. Some may enjoy this activity, but it is fair to say that most clinicians do it for the benefit of future clinicians and their patients. One preceptor and guest lecturer stated, "I enjoy lecturing and teaching the skills class, and I believe it is a way to give back to the program that has provided me the knowledge to succeed. It is rewarding to see the students engaged and eager to learn. As a preceptor, I believe I have a responsibility to assure they are prepared for their future. The PA students will someday be my colleagues, and I think it is important to assist and mentor them anyway I can" (T. N. St. Clair, personal communication, December 7, 2014).

This is consistent with one of the responsibilities noted in an article published in the Annals of Internal Medicine regarding physician professionalism. Not only did it state that each individual should have a personal commitment to life-long learning, but that we have a responsibility to hold all members of our profession accountable to being competent individuals. This is not just about being altruistic, but also about commitment (Sox, 2002). Souba (2011) stated:

Commitment is a standing for something that is bigger than oneself such that our commitment becomes who are.... Leaders must be committed to a future that is 
larger than themselves. Such a commitment is most powerful when it defines

oneself and one's purpose in life while simultaneously caring for others. (pp. 4-5)

This commitment is not limited to training future professionals and holding them accountable for their knowledge, but also modeling behaviors that are beneficial to the bigger picture such as: quality healthcare (improve patient safety, decrease medical error, participate in developing better measures), improved healthcare access, and wise utilization of resources (Sox, 2002).

Community activist. The community activist is a physician assistant who demonstrates a strong sense of community and concern for the greater good by promoting healthcare, in traditional and nontraditional ways such as a newspaper healthcare column, health fair, or through other health education programs. Ethical, servant, and transformational leadership demonstrate a strong sense of community. In all cases, leaders are concerned with building and sustaining community through active listening, empowering member contributions, developing trust and relationships, and respecting others (Northouse, 2010). As promoters of healthcare, PAs have an opportunity to provide significant contributions in the communities where they practice. Communities benefit from clinician involvement through newspaper healthcare columns, public health, wellness initiatives, health fair participation, healthcare education, and leadership of organizations (Huckabee \& Wheeler, 2008). An opportunity for community involvement is evidenced in rural and underserved areas where healthcare providers are scarce and health educational opportunities are limited.

Community activism is about building health communities. It may be described by altruistic behavior and collaborative efforts that empower communities. Altruism, is a 
common thread among transformational, authentic, and servant leadership; interconnecting their common ethical undertones (Northouse, 2010; Yukl, 2006). Persons who display altruistic behavior are about helping others in need. This helping behavior can aid in building a sense of community; one of the tenets of ethical leadership.

Ethical leaders build community by building relationships with followers while working toward a common goal. Community building is not just limited to the leader and the followers, but has implications in a broader context for the common good (Northouse, 2010; Stone, 2012). Similarly, in transformational leadership, Kouzes and Posner (2011) described, "enable others to act" (p. 5) which is based on empowering others to collaboratively pursue shared goals. Community building can also be seen in authentic leadership (George et al., 2007/2011; Northouse, 2010). George et al. (2007/2011) identified the importance of establishing relationships with others that are mutual, supportive, open, and built on trust. These relationships often result in a committed community (Northouse, 2010). Physician assistants build stronger communities through their participation in programs, which engage their community both through education and by building partnerships to serve others.

Community health education. As stated earlier, community health education can occur through a variety of avenues over the course of a PAs career. Lectures, support groups, health screenings, newspaper articles, community newsletters, and local educational programs for both children and adults are just a few ways in which this may transpire. Community outreach projects and education are also important components of PA training. These educational opportunities and projects may be done as part of 
coursework or through a student PA organization. With respect to participating in a community outreach project, one student stated:

Being able to share what we have been learning in the classroom is incredibly gratifying. Giving back to the community makes all of the long hours of lectures and studying worth it. There's nothing quite like seeing a child/person understand a concept and be able to implement it into their day-to-day life in order to improve their health. (L. Irby, personal communication, October 11, 2015) The Oregon Health and Science University PA program requires students to design, develop, and implement a community outreach program based on a public health concern from Healthy People 2020 and then present their results and recommendations to faculty and students (Oregon Health and Science University School of Medicine Physician Assistant Program, 2015). Members of the Missouri State University PA student organization made efforts to educate children on oral health, which has recently been an area of special interest for the AAPA (American Academy of Physician Assistants, 2015c). The PA class of 2016 at Missouri State University chose to promote the components of good oral health to preschool children ages 2-6 at a local daycare. Through this experience, more than fifty children were provided with the necessary supplies and education on brushing their teeth and flossing, while their parents were given educational information regarding the potential systemic adverse effects that can result from poor dental hygiene and what to do to prevent it. One student said:

The most valuable contribution (PA/medical) students as aspiring providers can offer is health education through community outreach; whether it is something as simple as proper teeth brushing technique to something as invaluable as 
supporting a runner's first 5k. It takes no tools, no labs, no stethoscope and is the single most empowering gift to their future patients. (P. Yang, personal communication, October 11, 2015)

Another student said:

The impact we made on those young kids during a short oral health demonstration and card making activity is very fulfilling. I feel like all the hard work and effort that I am putting in will be worth it just to be able to even help a few people and know that I can put a smile on someone's face. I am also learning through community outreach programs that even though I don't have all the answers people look to me and count on me to guide them. (Reno, M, personal communication, October 11, 2015)

Community health education and programming can provide an avenue to the development of strong communities. Health education offers an opportunity for building relationships and empowering others. Harnessed with this knowledge, community members are equipped to make better choices; influencing their health.

Community partnerships. Health promotion is a challenge if performed within a silo. Collaboration between healthcare providers and community organizations to accomplish health goals within a community is an essential component of community activism. A productive collaborative effort relies on effective communication, trust, and clear goals (Cleary \& Hunt, 2010; Northouse, 2010).

The Association of Family Practice Physician Assistant website noted efforts to collaborate with clinics or organizations within the city of their annual conference to garner support for the medically underserved through activities such as blood drives or 
runs/walks (Association of Family Practice Physician Assistants, 2015). Another example may be the Physician Assistant Foundation, which is the philanthropic branch of the AAPA. This group gives a Caring for Communities Award annually to deserving PAs or PA students who are collaborating with charities to make the social or medical aspects of other's lives better. Over the last five years, the charities awarded have helped (a) health workers in Liberia have proper protective equipment, (b) homeless people in Boston, MA receive health care, (c) uninsured and low-income people receive free food, clothing and medical care in Washington, DC, (d) hungry people in Toronto, Ontario, and (e) homeless and abused women and children in Las Vegas, NV receive free healthcare (Physician Assistant Foundation, 2015).

The work of building communities of collaboration begins early in the career of PAs. An example includes the Central Michigan University PA class of 2009, which was given special recognition for its work with: (a) the local county health department to assist with influenza vaccinations, (b) the local library to initiate a health literacy program for children, and (c) for organizing a 5K for Hospice of Central Michigan (Central Michigan University College of Health Professions, 2008). Additionally, the PA students at the University of Utah School of Medicine know a little about missional community service as they participate in a student-run free clinic twice a month (University of Utah School of Medicine, 2015). Similarly, around the country PAs and PA students have had the opportunity to serve in similar types of free clinics where they assist those in need. However, this work is not limited to the United States. One PA said, "I love serving my patients stateside and being able to use my career to serve missions globally" (Seng, 2015)! Another PA, who has participated in medical missions abroad stated: 
Serving abroad in medical missions is an integral part of giving people of the world a hand up versus a handout to create a sustainable society. These patients will touch you in ways you didn't know were possible. You will cry from your heart before your eyes can catch up with you. These are experiences that change your life, that change your practice, that serve the very least of these. (C. Dancey, personal communication, October 25, 2015)

The purpose of community activism is the improvement of health by educating and providing for the needs of patients through collaborative efforts to establish a community of people working for people. Health education and collaborative efforts of community partners provide patients and consumers with the information and tools needed. Harnessed with this information and the support of a helping hand patients are empowered and enabled to make the necessary health changes.

Team collaborator. A team collaborator is a PA who works effectively within a healthcare team to deliver the best patient care possible. This may include direct patient care or initiatives and policy, which affect the systems based healthcare delivery. Team leadership and collaboration is playing an ever-expanding role within medicine today due to a multidisciplinary approach to healthcare; requiring excellent communication and collaboration skills among a variety of healthcare professionals (Blumenthal et al., 2012; Collins-Nakai, 2006; Knowles et al., 2012; O'Connell \& Pascoe, 2004; Snyderman et al., 2011). This is nothing new to PA practice, which has utilized physician and physician assistant teams since its conception. Effective teamwork relies on trust, respect, listening skills, support, and cooperation among members of the team to deliver the best patient care possible (Northouse, 2010). 
The team collaborator exemplifies many of the best parts of an ethical leader. As previously stated, ethical leaders are about building communities, serving people, respecting people, and being honest (Northouse, 2010). These components of the ethical leader tie into the key underpinnings of the team player. They are also at the heart of quality healthcare. In a study by Baggs et al. (1992) nurses reported statistically significant better patient outcomes when there was good collaboration with residents with transferring patients from the ICU to a regular medical floor opposed to poor collaboration.

Team sport. Kouzes and Posner (2010) described leadership as, "a team sport" (p. 62). The idea of team leadership and collaboration has had an ever-expanding role in medicine over the last several years, and is occurring on a variety of levels. Quality patient care requires not only the work of physicians, but also the work of patients, nurses, mid-level providers, and other allied health professionals working in unison to achieve optimal care and wellness (Scruggs Garber, Madigan, Click, \& Fitzpatrick, 2009; Stoller et al., 2004; Baggs et al., 1992). In order for effective team collaboration, leadership may need to rest in many hands, depending on what may be best for the situation (Huckabee \& Wheeler, 2008). PAs frequently communicate and collaborate with physicians, nurses, social workers, therapists, and others to ensure quality care for patients. This type of collaboration requires a respect for other team members and their ability to fulfill their responsibilities.

Relationships. Relationships seem to be at the heart of good teamwork. Kouzes and Posner (2010) noted that success is built on the ability to form good relationships and work with one another. Lencioni (2002) cited trust as the basis for all good relationships 
and that vulnerability and honesty are two big components to making this successful. He noted that in the absence of trust, team members might not be completely honest with one another or forthcoming with information, which could be vital to ultimate goal achievement. This can lead to grudges between team members and time wasted. George (2007) stated that open relationships help to deepen loyalty and commitment to organizations. Finally, Blanchard (2013) stated that trust develops when leaders are dependable, competent, believable, and build relationships. In a study by Snell et al. (2011) physicians were interviewed regarding their engagement in leadership. When asked about teamwork, physician participants stated that their level of engagement was heightened through relationships developed by working in teams, trusting others to contribute, and support received which aided personal growth. Trust among team members on all levels of healthcare is vital as health systems of all sizes operate in an ever-changing external environment. Teams who have established trust are readily equipped with the ability to adapt their previously successful tactics to new situations in order to achieve their goals and improve patient care and the healthcare organization (Felix, 1997).

Open communication. Not only do relationships require honesty and trust, but they also need open communication. Kouzes and Posner (2010) explained that leaders, who are good communicators, listen and understand the viewpoints of their subordinates. They further discussed this as empathy or listening coupled with understanding. Lencioni (2002) described the importance of open communication. In his second of five dysfunctions of teams he described, "fear of conflict" (p. 202). He noted that functional teams are able to engage within open discussions and debates with one another which 
results in all voices being heard. This is an example of showing respect for others a component of ethical leadership where opposing views and ideas are heard (Northouse, 2010).

Scruggs Garber et al. (2009) examined attitudes of servant leadership and collaboration among nurses, physicians, and residents. The study found that registered nurses scored higher in their attitudes for collaboration and servant leadership than did physicians and residents. Despite this result, all three, nurses, physicians and residents perceived themselves as examples for collaboration. With respect to servant leadership, although they all perceived themselves as servant leaders, they did not believe that their organization practiced servant leadership. The findings of this study were consistent with previous studies, which identified nurses as having positive attitudes to collaboration. A foundation for successful collaboration includes relationships and communication. The authors concluded that collaboration was a key component to quality patient care and an effective work environment, which was corroborated with a variety of other sources in their study.

Alignment of goals. Goal alignment is a key in teamwork and collaboration. Kouzes and Posner (2010) described inspiring a shared vision, which encouraged leaders to unite their followers under a common goal. Lencioni (2002) described that successful teams were those, which displayed commitment. He explained that committed teams demonstrated alignment toward one goal and could clearly define what needed to be done in order to achieve that goal. A component of ethical leadership is building communities. Here leaders and followers align together to work toward common goals that have a broader purpose for the good of all (Northouse, 2010). 
One characteristic of successful healthcare teams is alignment of goals. Although not new to medicine, PI CME is new to PA continuing medical education. Performance Improvement (PI) is one way in which collaboration can occur with the intention of making a process or way of caring for patients better. In a sense, to work on a common goal with the intention of making a greater impact not only on oneself, but patients, practice, and ultimately the system or community. In a study by Shershneva et al. (2008) researchers observed a clinical practice where PI CME was done to improve blood pressure care and evaluation in a group of patients. The researches commented, "As participant observers, we learned about the importance of shared goals, agreement on the process, and clearly-defined roles when conducting the PI CME activity, all of which are consistent with the recommended features of successful collaboration" (p. 7).

Collaboration took place both formally and informally through avenues such as meetings and educational events. Through these communications, physicians, PAs, and nurses were able to voice concerns regarding the process and implementation of the PI CME project (Shershneva et al., 2008).

Kouzes and Posner (2010) described working for something bigger than oneself. They described that great leaders create situations and opportunities for their subordinates to work for something that will better the world around them, something that is meaningful. Similarly, Northouse (2010) described clarifying and nurturing a shared vision greater than oneself as a component of an ethical leader.

The most evident component of collaboration in the life of a PA is through their work with a physician in direct patient care. However, collaboration is not limited to this one example. Physician Assistant service to others is notable not just in the sector of 
provider- patient care, but also within the organizational realm of healthcare. Huckabee and Wheeler (2008) noted that physician assistants "often serves on or chairs committees at local health care institutions, leadership in quality control, pharmaceutical requirements, infection control, ethics and medical staff policies" (p. 24-25). In addition, they may hold supervisory positions in the hospital and clinic settings evaluating the work of other PAs and other allied health professionals. While others may manage their

own clinical practice (Huckabee \& Wheeler, 2008). Additionally they may work in teams from a broader systems perspective which may require committee or policy work (Huckabee \& Wheeler, 2008).

As previously stated, the concept of teamwork is not new to PAs. In fact, the profession is built on the concept of teamwork and collaboration with a physician, and is the reality of a PAs daily work life. Healthcare is a team sport, which relies on the work of many. It requires relationships, open communication, and alignment of goals. Teamwork is not limited to direct patient care, but also spans the broader context that includes committee and policy work within clinics, hospitals and communities.

\section{Leadership Training in Medical Curriculum}

The literature has evidenced an expectation that physicians and advanced practice clinicians fill leadership roles within a variety of different facets of the medical profession. Despite this expectation, physicians have reported inadequate preparation for the leadership responsibilities that lay ahead (Collins-Nakai, 2006; Lee et al., 2011). Although surgical and other highly technical skills will continue to be important, some researchers have noted that physician skills will continue to evolve requiring more management and executive skills along with an ability to look from a balcony perspective 
(Heifetz \& Laurie, 1997/2011) at the whole, while strategizing about the future of healthcare (Snyderman et al., 2011).

It is not that there are no leadership programs available for training. In fact, there are several system-wide leadership and external leadership programs where physicians can learn the skills necessary for this important role. However, physicians are often placed into elected or appointed leadership positions before they receive the appropriate leadership training. Additionally, these training programs are aimed at physician executives or physicians in administrative positions (Ackerly et al., 2011; Scott, Tangalos, Blomberg, \& Bender, 1997). Traditional medical school training has not typically included training in leadership. Therefore, unless a physician is in administration there is a low likelihood that he or she has received leadership training.

The need for formal leadership training within medical education has been identified as a priority (Scott et al., 1997). This is being partially addressed with residency training programs incorporating leadership training (Baird et al., 2012). However, there is continued concern that training should occur earlier, such as within the didactic training of medical school. PA education also lacks leadership training. To date, few programs have documented formal leadership training within didactic or clinical education.

Unfortunately, this issue is not as easy as simply adding a leadership curriculum to medical education. In fact, numerous barriers exist which often prevent medical schools from adopting leadership curriculum. First, the most researched explanation to the lack of leadership training in curriculum is evidenced by a lack of time within the didactic portion of medical school (Baird et al., 2012; Souba, 1998). The limited time is 
consumed with the accumulation of medical knowledge so clinicians are prepared to be physicians and advanced practice providers. Medical curricula is packed with learning the essentials of medicine and educators are challenged with finding space to formally teach about leadership. Second, there is no established standard for teaching leadership within medical curricula with relation to content, delivery, or length of training. Therefore, although many leadership-training programs demonstrate similarities, there are also numerous differences. Finally, leadership training even within residencies is not always available to everyone, despite the call by some researchers to the importance of leadership training for everyone (Blumenthal et al., 2012). The paragraphs ahead will describe some of the variations within leadership curricula content, content delivery, and length of leadership curricula.

What topics should be taught? After reviewing several articles on what topics should be taught as part of a leadership curriculum it is easy to see that although there are some similarities there is no clear consensus among researchers. Some studies focused on developing personal leadership skills and aligning values with behavior. Wisniewski (2003) stated that effective leadership educational programs must include a mixture of the following:

enhance the development of leadership skills, provide feedback to enable participants to distinguish patterns of effective as well as ineffective behavior and inconsistencies between their behaviors and espoused values; further participants' conceptual knowledge regarding information and insights they can put into immediate practice; and, focus on personal growth, assisting individuals in 
identifying their core values and beliefs, and in developing a personal philosophy of leadership. (p. 32)

In a response to an article by Leslie et al. regarding leadership training for young pediatricians Boulanger, Buencamino, and Dovichi (2005) commented on their own exploration of leadership through a series of interviews they had done with individuals in medicine, law and administration. Similar to Wisniewski (2003) their results aligned with personal goals and feats. Some common leadership threads they identified included: (a) having a vision, (b) improving ability to take advantage of career opportunities, and (c) knowing one's own goals, priorities and motivation.

Other researchers focused more on the leader's interaction with the external environment. Baird, Soldanska, Anderson, and Miller (2012) surveyed all US dermatology residency programs and found that the topics most recently taught within leadership curricula included communication and interpersonal skills, cultural sensitivity, teaching/education, health policy, and managed care. Other topics included leadership theory, teambuilding, management skills and conflict resolution.

In other studies, the emphasis of leadership training focused on the management of the healthcare system as a whole. In a study by Scott, Tangalos, Blomberg, and Bender (1997), a survey was sent out to CEOs of 122 institutions with 26 responding regarding training and tracking of physician leadership. Of the 26 institutions that responded, 15 of them tracked leadership training done outside of the health system. The topics most likely discussed in the training programs included: "quality management, issues in health care, leadership principles, strategic planning, management principles, 
economics of health care, finance and accounting, and government and policy issues" ( $\mathrm{p}$. $660)$.

In contrast to Baird et al. (2012) Scott et al. (1997) found "courses that dealt with communication and interpersonal skills were of less importance" (p. 660). Similarly, the AAPA recently began what they call the Leadership and Advocacy Summit. The topics of the sessions focused on teaching political advocacy and leadership skills. They described leadership skills as: (a) promotion of the PA profession, (b) federal laws and regulations impacting PAs, (c) strategy, (d) meeting facilitation, (e) administrative and financial management, (f) cyber security, among others (American Academy of Physician Assistants, 2015d).

Finally, some researchers noted a broader and more balanced approach to leadership training focusing on both personal and professional development and external systems leadership. Eubank, Geffken, Orzano, and Ricci (2012) described teaching adaptive leadership to family medicine residents. They used a method of coaching through experiential learning that focused on: personal mastery (awareness of assumptions, emotional awareness, realistic reflection), communication (listening, positive influence styles, testing mental models), collaboration (giving/seeking feedback, other awareness, accountability, resolve conflict), systems thinking (work with diverse worldviews, differentiate events from fundamental issues, inter-relationships), and change management (understand the emotional journey of change, increase motivation, negotiation, and reframing).

Middelton (2012) described leadership theory, values, culture, team building, leadership in practice (encompassing leadership attributes and behaviors, coaching, 
facilitation, change and conflict management), personal preparation for practice (personal care, stress, self-awareness, emotional intelligence and reflection), and preparation for professional practice. Finally, Snell et al. (2009) recommended medical schools take a more holistic role in order to engage physicians as leaders in medicine. They proposed that "medical training curricula could encompass leadership development, system/community approaches, the meaning of being a team player, and the utilization of a multidisciplinary lens" (p. 14).

How is leadership content delivered? Scott et al. (1997) stated that no standardized approach has been identified to teach leadership skills. Marquardt (2011) described action learning as an effective tool in the building of learning organizations. Middleton (2013) who incorporated active learning into leadership training for nurses supported this. Active learning creates an environment of constant learning and reflection. It is real people working on real problems that ultimately result in real solutions through a process of reflective questioning and improved actions (Marquardt, 2011). Souba (1998) reported that those studying leadership should understand the basics of leadership theory. Additionally, Baird et al. (2012) found observation and modeling to be the most common way participants reported learning leadership skills. Therefore, they noted modeling and mentoring to be an essential component of leadership development. Effective behavior modeling is evident within military leadership where individuals strive to be the best that they can be and modeling behavior that improves themselves and transforms others to do the same. (Ledlow and Coppola, 2014).

Baird et al. (2012) found that lectures, seminars or workshops, videos, projects, case studies, journal clubs, and readings were utilized to teach leadership. Role-playing, 
case studies, group projects, simulations and other problem-solving exercises can help students actively learn skills by doing or practicing those skills (Marquardt, 2011; Meyers \& Jones, 1993). A case study by Fisher and Briel (2012) found that students would benefit from lectures on the organizational structure of health services along with observational opportunities of committee work, planning teams, and quality improvement and performance. Eubank et al. (2012) described seminars, workshops, Masters of Public Health curriculum, and improvement projects as components of their curriculum for teaching adaptive leadership.

To better equip their students with leadership skills the Vanderbilt Medical Scientist Training Program developed a leadership curriculum that utilized three workshops where lecturing was complemented with relevant case studies where the lecture material could be applied and evaluated by the students. Faculty utilized a challenge cycle to teach the information (Ciampa et al., 2011). Similarly, the AAPAs recent and newly formed Leadership and Advocacy Summit focused on teaching political advocacy and leadership skills through educational sessions and meetings with members of Congress to put their learning into action (American Academy of Physician Assistants, 2015d).

What is the right length of leadership training? There does not appear to be a set training program or length of training for the development of leadership skills, but rather a variety of lengths, which are dependent on the sponsor and method of training. Baird et al. (2012) reported that $79 \%$ of US dermatologic residency programs that responded to their survey agreed that formal leadership training should occur throughout residency. A variety of ways exists in which to teach leadership. Training can be done 
as short educational sessions that occur over the course of several months or years, in workshops, or as part of a course. Eubank et al. (2012) described their adaptive leadership program as a component of their family medicine residency taking 4 years and 6 months to 5 years to complete. Whereas, some training programs occur over the course of a couple of days. This is true of the AAPAs Leadership and Advocacy Summit which takes place over the course of two and a half days (American Academy of Physician Assistants, 2015d).

How does one get leadership training? In a study by Scott et al. (1997) a survey was sent out to CEOs of 122 institutions with 26 responding regarding training and tracking of physician leadership. Of the 26 institutions that responded, 15 of them tracked leadership training done outside of the health system. Eight of the institutions, offered in-house training programs targeted for physician executives, but more than $60 \%$ also targeted attending physicians and administrators. Leadership programs look to be expanding their programs to not only those already in leadership positions, but to other physicians who may be interested in leadership. In many instances, residency programs are now more formally teaching leadership skills (Baird et al., 2012). The AAPAs Leadership and Advocacy Summit is available to all PAs for a small fee (American Academy of Physician Assistants, 2015d).

What are we doing now? Recent research has addressed the issue of current practice in leadership training for physicians and other clinicians. A recent article stated, "Expecting clinicians to lead without adequate training is indeed naïve and probably setting them up for a fall” (Lee et al., 2011). Although formal training has been identified as helpful (Deane \& Ringdahl, 2012), leadership training is not a part of the 
vast majority of medical schools for physicians and physician assistants. Leadership training is important, but is less of a priority in comparison to the acquisition of medical knowledge, skill, critical thinking, and problem solving ability (Souba, 1998). Kochar, Robertson and Mone (2003) who stated, "the administrative and organizational skills necessary for physician leaders are not typically developed in medical schools or during graduate medical education" (p. 24), supported this.

If one agreed with the findings of Baird et al., (2012) that observation and modeling were the most common ways to learn leadership skills, then it would seem only logical to start with the faculty of PA programs. Kochar et al. (2003) who reported a need for leadership development in faculty recognized this. As a result, a collaborative effort between two universities in Wisconsin resulted in a program that offered leadership training to 30 busy full-time faculty members. The training addressed the following areas: (a) managing people, (b) health care finance and accounting, (c) leadership, (d) marketing, (e) health care informatics and information technology, (f) health care quality, (g) health care economics, and (h) time management (Kochar et al., 2003). Training faculty in leadership seems as a logical place to start if the eventual goal would be to develop and incorporate leadership in a curriculum.

Intentional leadership training. Some residency programs have started to incorporate some aspect of leadership training, but no standard currently exists as to what should be involved in the training to best prepare clinicians for the challenges that lay ahead (Scott et al., 1997). Baird et al. (2012) found that $91 \%$ of respondents to their survey agreed that leadership skills could be taught and learned through observation and 
training. This provides further evidence to support leadership training incorporated within both didactic and clinical phases of PA education.

The literature has suggested many residency programs are moving toward some component of collaborative leadership training. Collins-Nakai (2006) identified collaborative leadership as the cornerstone of physician training as they work within healthcare teams. A study by Awad et al. (2004) identified significant improvement in resident scores of alignment, communication, and integrity following the integration of a six-month leadership curriculum designed to improve the management of teams. Currently, very few physician assistant schools include a formal leadership curriculum as a component of their education.

Consistent with her ideas of improving personal leadership skills and aligning values with behavior, Wisniewski (2003) identified seven competencies for an effective leadership education program. The seven competencies included: (a) "A core set of values and vision, (b) effective communication- listening, speaking, and writing, (c) reflection and analysis, (d) establishing a positive climate, (e) facilitation and collaboration, (f) problem solving and risk taking, (g) perseverance" (Wisniewski, 2003, p. 33). Wisniewski's competencies combine ways to incorporate personal growth and integrate ideas of collaboration, which is consistent with Collins-Nakai (2006) and Awad et al. (2004).

More evidence for teamwork and collaboration can be found from a study done by Stoller et al. (2004) who incorporated a teambuilding activity, which required students to first read a scenario then answer a series of questions on their own, then in formal teams, which allowed them to discuss other points of view. The team scores were 
compared to the individual scores. Six out of seven teams arrived at the correct solution to the problem. In these teams, teamwork was demonstrated by the teams' ability to clearly define their objective, allow leadership to change within the group as needed, and inclusion of all members by allowing leaders to facilitate discussion. In the instance of the team that was not successful, one individual's personal experience swayed the team away from the correct answer.

The focus of the intervention was to cultivate teamwork and leadership skills. Participant evaluations showed that they enjoyed situations where they were able to engage in teamwork and were able to identify leadership skills within these activities. Additionally, participants saw that the teams performed better over individuals. Stoller et al. (2004) reported that their efforts in teaching leadership and teamwork are consistent with goals of several official groups such as the American Council on Graduate Medical Education (ACGME), American Academy of Pediatrics, Agency for Health Care Research and Quality and American Board of Internal Medicine, which have all identified teamwork and collaboration as an important component of quality medical practice (Stoller et al., 2004)

Unintentional leadership training. Arguably, leadership training has been taking place in medical education unintentionally for years. This is evidenced through observation of faculty interactions with other staff and students or other PAs within the community. Communication skills are learned in courses where students are taught how to interact with patients and their families. This may be further enhanced in their clinical years where students not only interact with patients and families, but also may learn how to work with experienced PAs or physician colleagues (R. Canales, personal 
communication, October 26, 2015). Other coursework may lead to development of leadership skills. For example, case studies provide insight into medical decision-making (Huckabee \& Wheeler, 2008) and small group activities foster teamwork among PA students.

Student leadership skills may be further developed while in school with activities not always associated with traditional schooling. For example, community engagement may be encouraged through extracurricular activities done through student organizations or coursework. Students may also gain a sense of caring for the greater good when a topic within coursework or through an extracurricular activity makes them more aware of a public health issue and stimulates their interest to do something about it. This is not limited to the community, but can also be seen as students become more engaged within their profession and associated state or national organizations. It is possible that by encouraging students to be members of their national and state organizations and helping them to foster a commitment to these organizations through conference attendance or participation in other ways entrenches within them organizational values and a yearning to stay involved. Finally, through observations students may learn about what it takes to give back to your profession when they see practicing PAs giving their time to precept students or guest lecture for PA programs (R. Canales, personal communication, October 26, 2015).

Given the arguments above, there are already numerous ways through which leadership skills are developed and modeled within PA curricula. Further, it may be assumed that students will acquire these leadership skills on their own. However, this does not seem to be the case since numerous studies (Lee et al., 2011; Collins-Nakai, 
2006) previously documented within this literature review show that physicians feel unprepared to lead based on their medical training. This raises the questions, "Are the opportunities through which leadership skills are taught made intentional by the faculty teaching or leading them?" and "Are the right leadership skills being taught?" Without a curriculum that intentionally identifies and teaches the leadership roles needed there is likely, something lost.

What can be done? Although some believe that leadership is innate, others believe that leadership is comprised of a group of skills that can be developed. Still, others believe leadership is innate but that it can be further developed through intentional training. Stoller, Taylor, and Farver (2013) looked at emotional intelligence, one component often associated with leadership skill, and proposed that it develops over a physician's career as they transition throughout their career from medical training through clinical practice. The spiral model demonstrated by Stoller et al. (2013) described the relationship of self-reflection that takes place as an individual transitions through each phase of their career. Although designed to describe emotional intelligence and its relationship to leadership, it seems plausible that this developmental approach to leadership education is appropriate for those who believe that leadership can be taught. Furthermore, because it is a model that is based on development, it takes into account the stages of personal and professional growth, experience, and responsibility that a medical professional would have at varying stages of their career. This is not different from medical education, which often takes a layered approach with its curriculum, recognizing that it begins with the basis of acquiring medical knowledge through didactic education and then providing hands on clinical experiences with clinical rotations where students 
have the ability to apply the evidence based knowledge they have acquired. Finally, it is anticipated that through continued life-long learning and experience these clinicians will continue to develop, broadening their medical knowledge with time. If this model were applied to the proposed conceptual framework described as the medical leader consisting of: (a) learning leader, (b) patient advocate, (c) engaged professional, (d) builder of future professionals, (e) community activist, and (f) team collaborator then it would seem reasonable to begin by initiating education, training, and conversation regarding these conceptual underpinnings during the didactic year of training and then revisit it again during the clinical year, and over the career through life-long learning.

\section{Summary}

Medicine has undergone numerous changes over the last several years. These changes are evident not only in the way we deliver healthcare, but also in the expectations of those serving on the front lines (Blumenthal et al., 2012). The

complexity and sophistication of the medical world requires effective communication and collaboration among medical teams to deliver quality care to patients. The ability to carry out these skills requires that medical professionals at all levels demonstrate leadership (Blumenthal et al., 2012; Scott, 2011). This is particularly true for PAs and other advanced practice providers who are being summoned to help fill the physician shortage gap (Healthcare Resources \& Services Administration Health Workforce, 2013).

Leadership literature is diverse and extensive. Although some authors describe leadership as innate, others believe that leadership skills can be learned and developed (Northouse, 2010). While there are many credible leadership theories, this study is 
anchored within ethical leadership and its strong roots to transformational, servant, and authentic leadership.

The medical leader, which is the overarching theme for this study is defined within this chapter by its conceptual underpinnings, which include: (a) learning leader, (b) patient advocate, (c) engaged professional, (d) builder of future professionals, (e) community activist, and (f) team collaborator. The learning leader is a PA who participates in learning opportunities to improve themselves both personally and professionally. The patient advocate concentrates on developing an ethical relationship between the provider and patient that is built on trust, just treatment, open and honest communication, respect, service, and an altruistic behavior that reflects going above and beyond the call of duty. The engaged professional is a physician assistant who demonstrates organizational stewardship through involvement within local, state, and national organizations, as well, as health policy. The builder of future professionals is a PA who gives back to the profession by serving as an educator to new PA professionals during their didactic or clinical training. The community activist is a PA who demonstrates a strong sense of community and concern for the greater good by participating in nontraditional activities such as community health education and collaborative community partnerships. Finally, the team collaborator is a PA who works effectively within a healthcare team. Healthcare is a team sport that requires trusting relationships, open communication, and the alignment of goals.

Finally, the literature has shown an expectation that physicians and advanced practice clinicians hold leadership roles within a variety of areas in medicine. Despite this expectation, physicians have reported inadequate preparation for the leadership 
responsibilities that lay ahead (Collins-Nakai, 2006; Lee et al., 2011). Although several leadership programs are available, training is often not available until physicians are already within organizational leadership positions rendering a need for the development of these skills earlier in one's career. Recently, more residency programs have started to offer leadership training; however, this training is often selective. Additionally, there is no known established leadership curricula among programs with respect to content, delivery, or length of training. Assuming that leadership skills can be developed, it seems plausible that by recognizing the prevalence and extent of leadership roles held by practicing PAs and by evaluating leadership taught in current PA curricula, identification of potential gaps could inform future curricular changes. 


\section{CHAPTER THREE}

\section{RESEARCH DESIGN}

Although leadership theories abound in the medical literature, particularly as a basis for leadership curriculum in residency programs, many of the national organizations have identified professional competencies as the leadership standards (Competencies, 2012; National Center for Healthcare Leadership, 2010). Competencies, which guide the practice, skills, behaviors, professionalism, and interactions of medical professionals, are no doubt necessary components of a successful healthcare professional (Competencies, 2012; National Center for Healthcare Leadership, 2010). However, despite their necessity they lack clarity in the true understanding of the medical leader.

Some researchers (Collins-Nakai, 2006; Huckabee \& Wheeler, 2008; O'Connell \& Pascoe, 2004) have explored leadership theory and applied varying leadership models to medical practice. Although many of these theories can be identified and explained within medical practice, they are not all inclusive or comprehensive. The medical leader may need to draw upon a variety of leadership styles in their daily life to be successful. Ethical, servant, and transformational leadership serve as a solid base for the medical leader, but there does not seem to be one style or theory that addresses all facets of the medical provider and the roles and responsibilities they bear (Huckabee \& Wheeler, 2008).

In the following paragraphs, the roadmap in exploration of this problem of practice will be further explained. The methodology utilized for this research study was a concurrent, triangulation, mixed-methods approach (Creswell, 2009); integrating both 
quantitative and qualitative data. First, the purpose of the study and research questions will be reviewed. Second, the design of the study including the specific approach, methodology, researcher positionality, and bias are explored. Next, the participants included in the study and the recruitment of those participants is identified, followed by an explanation of the institutional review board (IRB) process and efforts to maintain confidentiality.

Following information on the participants in the study, the methodology will be explored. Survey instrumentation for both practicing PAs and PA faculty is discussed including how validity and reliability of the instrument was achieved. Next, the methods of data collection and data analysis are examined. Then the data collection and analysis, including an exploration of trustworthiness is discussed. Finally, limitations and assumptions of the study are explored. This study was intended to: (a) identify what leadership roles are most prominent among physician assistants (PAs), (b) explore what is currently being done within PA curriculum to enhance leadership skills, and (c) discover where there are gaps, if any, in current leadership preparation to best support the specific leadership roles current PAs hold.

\section{Purpose and Research Questions}

The purpose of this study was to explore the leadership opportunities and responsibilities within the PA profession and identify gaps in training to best prepare current physician assistant students for the leadership opportunities ahead. A survey was utilized to identify, quantify, and understand the specific leadership roles most prevalent among practicing physician assistants. A second survey identified ways that current PA curricula prepares students for these roles. This data was then analyzed and triangulated 
to inform what current gaps are present in PA curricula in the preparation of PAs as leaders in medicine. Within the context of this study, the following research questions were addressed:

1) What is the prevalence and practice of the leadership roles of physician assistants (PAs) as...
a. learning leaders?
b. patient advocates?
c. engaged professionals?
d. builders of future professionals?
e. community activists?
f. team collaborators?

2) In what ways does current curricula prepare physician assistant (PA) students for future leadership roles?

3) What changes are needed in physician assistant (PA) curriculum to better prepare students for future leadership roles?

\section{Design for the Study}

The aim of the proposed study was to provide solutions to a current problem of practice (Fraenkel \& Wallen, 2009). It has been identified that physicians graduating from medical school feel unprepared for the leadership roles that lay before them (Abbas et al., 2011; Baird et al., 2012; Collins-Nakai, 2006), but little has been done to provide a solution. In addition, given the healthcare responsibility afforded to physician assistants as healthcare providers, leadership skills are required (Blumenthal, Bernard, Bohen, \& Bohmer, 2012; Hays, 2008; Huckabee \& Wheeler, 2008). 


\section{Action Research}

Fraenkel and Wallen (2009) defined action research as research, "conducted by one or more individuals or groups for the purpose of solving a problem or obtaining information in order to inform local practice" (p. 589). Action research may be further delineated into practical action research and participatory action research. Practical action research focuses on a specific problem and concludes with an action plan that will be later incorporated. It is this type of research that will be applied in this study (Fraenkel \& Wallen, 2009). Through practical action research, this study will identify: (a) current leadership opportunities and responsibilities among practicing PAs, (b) current practices in leadership training, and (c) curriculum designed to meet the leadership needs of practicing PAs. These components will be identified through utilization of a Concurrent, Triangulation, Mixed-Methods study approach and viewed through a pragmatic worldview (Creswell, 2009).

\section{Mixed-Methods}

A mixed-methods approach to research incorporates both qualitative and quantitative research methodologies. According to Fraenkel and Wallen (2009), "mixedmethods research can help to clarify and explain relationships" and "allows us to explore relationships between variables in depth" (p. 558). In this specific study the researcher aimed to identify (a) the frequency of specific leadership roles, (b) how those leadership roles were perceived for practicing PAs, (c) faculty perception of leadership preparation, and (d) gaps in curriculum as perceived between the results of practicing PAs and PA faculty. A mixed methods approach fully evaluated these variables. This approach allowed to not only further clarify the leadership roles held by PAs through quantitative 
analysis, but also allowed for further exploration of other leadership roles not already identified qualitatively. Additionally, it permitted evaluation of the perception of both practicing PAs and PA faculty regarding preparation for leadership roles. This evaluation allowed analysis at a deeper level to identify gaps in curriculum (Fraenkel \& Wallen, 2009).

When considering a mixed-methods research design the researcher must determine: (a) the timing of data collection, (b) weighting or priority given to qualitative and quantitative components, (c) when the data will be mixed, and (d) whether there will be an implicit or explicit theoretical perspective used (Creswell, 2009). In a mixedmethods study, data collection can occur concurrently or sequentially (Creswell, 2009; Fraenkel \& Wallen, 2009).

Timing. This study utilized a concurrent data collection model (Creswell, 2009; Fraenkel \& Wallen, 2009). A survey consisting of both quantitative and open-ended survey questions was administered to both participant groups simultaneously. Simultaneous collection of data allowed for different perspectives (PA faculty and practicing PA) on similar questions. The concurrent data collection (Creswell, 2009) also allowed for analysis of the data from both groups to occur independently, but then also together. This process allowed for triangulation (Fraenkel \& Wallen, 2009) of the data, which helped to provide a richer explanation of the findings to inform gaps within the PA curriculum.

Weighting. Quantitative and qualitative data were afforded equal priority as both were utilized in data collection (Creswell, 2009, Fraenkel \& Wallen, 2009). As previously stated, the collection of survey data occurred concurrently and mixed 
quantitative and qualitative information analyzed independently. Additionally, the results combined through triangulation (Fraenkel \& Wallen, 2009; Hatch, 2002) provided a richer and thicker analysis of the data. This integration and mixing of the data results helped to inform and answer the third research question, "What changes are needed in PA education to better prepare PA students for future leadership roles" (Creswell, 2009; Fraenkel \& Wallen, 2009)?

Mixing of data. Mixing of data, as described above, occurred at two points. First, both surveys collected both quantitative and qualitative data. This information reported the level of frequency, and added to the richness and depth of the data collected. Second, another level of mixing of the data occurred after the initial analysis of the survey data. This second mixing allowed for triangulation of the data and increased validation of the findings (Blessing \& Forister, 2013; Fraenkel \& Wallen, 2009; Hatch, 2002).

Explicit theoretical perspective. This research study utilized an explicit theoretical perspective (Creswell, 2009). Leadership theory, explored within the literature review, provided the basis for the entire research design, which investigated leadership within the physician assistant profession. The participants in the study, the questions utilized within the survey and the implications made from the analysis of the results were all based on viewing through the lens of physician assistants and the leadership roles they possess (Creswell, 2009).

\section{Researcher Positionality and Bias}

Creswell (2009) described a worldview as, "a general orientation about the world and the nature of research that a researcher holds" (p. 6). A pragmatic worldview is one 
that "arises out of actions, situations, and consequences" (Creswell, 2009, p. 10) and places more concern on understanding problems. Pragmatists utilize all methods necessary to accomplish their goal of understanding problems; therefore, a mixedmethods approach to research is favored. Concern is placed on what and how to do research, pulling liberally from both qualitative and quantitative methods. For pragmatists research is contextual and focused on what has occurred historically, politically or socially (Creswell, 2009). This study was viewed from the pragmatic perspective.

Every attempt was made to minimize bias. However, potential bias within this research may have occurred because of researcher affiliations with the PA profession, educational realm of medicine, and professional organizations. The researcher has been a PA for 14 years and a member of the American Academy of Physician Assistants (AAPA) for 16 years, which includes two years of student membership. In addition, the researcher has been a PA educator and member of the Physician Assistant Education Association (PAEA) for 10 years. The researcher has a passion for people including her students and patients, and the medical profession, specifically the PA role. In order to keep in check these personal biases, the researcher identified outside researchers to evaluate themes that emerged from qualitative data. These outside researchers include: (a) doctoral dissertation supervisor and (b) dissertation committee.

\section{Participants}

The first participants in the study included nine individuals who agreed to pilot the surveys. A convenience sample (Fraenkel \& Wallen, 2009) of six physician assistants currently practicing in the state of Missouri were selected to pilot test the 
survey for practicing PAs. Additionally, a convenience sample (Fraenkel \& Wallen, 2009) of three PA faculty in the state of Missouri agreed to pilot test the survey for PA faculty. Access to these individuals was achieved through a process of personal communication with the researcher and volunteerism.

A total of 681 practicing PAs were recruited to participate in the study by taking the practicing PA survey. Participants were randomly sampled (Fink, 2009) from over 53,500 AAPA members on an AAPA networking site, called Huddle (AAPA, 2015e). The random selection occurred through a method of selecting participants based on their last name, listed alphabetically on the huddle website. A survey was sent via email through the Huddle site to the first name of every 100 names that appeared on the web page (AAPA, 2015e). In cases where it was evident that an AAPA member was not a practicing PA, the next name on the list was used. Additionally, purposive sampling occurred through posting the survey on the Huddle site. This was done to increase participation from PAs who may not have been randomly selected, but that used the Huddle site regularly as a means of networking. It also served as a reminder to those who used the site and had received an invitation to participate in the survey. In addition, a purposive convenience sample (Fraenkel \& Wallen, 2009) was done of PAs practicing in Missouri who were identified through the Missouri Academy of Physician Assistant website. Surveys were emailed to all PAs who listed an email address on the organizational website.

Faculty participants consisted of 71 current PA program faculty, which were selected via a purposive sample (Fraenkel \& Wallen, 2009) of PA program faculty from across the United States. The first group included 57 faculty currently serving on either 
the PAEA Rotation Exam Review Committee (RERC) or the PAEA Assessment Council. This group of individuals was selected for two reasons. First, this particular group represented individuals from PA programs across the country. Second, it was assumed that the members represented respectable PA educators because committee membership requires an application and interview process. Additionally, a second group of 14 faculty were invited to participate. This group of faculty members consisted of a purposive, convenience sample (Fraenkel \& Wallen, 2009) of PA educators in Missouri. This group was invited because the researcher is a PA educator in Missouri and had a special interest in the perspectives of other PA educators within the state.

\section{Human Subjects' Protection and Other Ethical Considerations}

Prior to the collection of any data, a proposal was submitted to the Institutional Review Board (IRB) and human subject approval was obtained. A transmittal letter (Appendix A) and an informed consent (Appendix B) were administered to all participants (Fink, 2009). This occurred via the Qualtrics surveys (Appendices C and D) for participants. Informed consent was obtained from all subjects prior to study participation. This occurred by having participants click an "I agree" button before beginning the Qualtrics survey.

An attempt to maintain confidentiality was a focus of the researcher throughout the study. The Qualtrics system collected no personal identifiable information for survey participants; however, email addresses were present within the system. All paper copies containing data are stored in a locked cabinet and will be destroyed after seven years (Fink, 2009). 


\section{Data Collection and Instrumentation}

The study utilized two surveys consisting of both quantitative and qualitative questions to answer the first and second research questions:

1) What is the prevalence and practice of the leadership roles of physician assistants (PAs) as...
a. learning leaders?
b. patient advocates?
c. engaged professionals?
d. builders of future professionals?
e. community activists?
f. team collaborators?

2) In what ways does current curricula prepare physician assistant (PA) students for future leadership roles?

A copy of the first survey, Medical Leadership Survey: For Practicing Physician Assistants is located in Appendix C. The quantitative survey questions were designed to identify the prevalence and practice of the leadership roles of physician assistants as: (a) learning leaders, (b) patient advocates, (c) engaged professionals, (d) builders of future professionals, (e) community activists, and (f) team collaborators. The qualitative questions were designed to add to the richness of the data by explaining how the prevalence of the leadership roles identified appear within the lives of physician assistants.

The second survey Medical Leadership Survey: For Physician Assistant Faculty is located in Appendix D. The quantitative survey questions within this instrument were 
designed to identify if educators felt the curriculum they used prepared physician assistants for roles as: (a) learning leaders, (b) patient advocates, (c) engaged professionals, (d) builders of future professionals, (e) community activists, and (f) team collaborators. The qualitative questions were designed to add to depth and richness of the data by explaining how PA programs prepare students to be: (a) learning leaders, (b) patient advocates, (c) engaged professionals, (d) builders of future professionals, (e) community activists, and (f) team collaborators. The paragraphs ahead further explain the survey instruments utilized in the study, how they were created, what measures were taken to ensure validity and reliability of the instruments, and the methodology used to collect the data.

\section{Survey Instruments}

Two survey instruments collected both quantitative and qualitative data through closed and open-ended questions. The data collected identified: (a) prevalence of leadership practices among practicing PAs, (b) leadership training, and (c) PA demographic data. As supported by Fink (2009) the survey placed questions related to the purpose of the survey near the beginning and easier to answer questions, at the end of the survey. An example of this includes more complex and purposeful questions regarding previous leadership training and specific leadership positions among practicing PAs placed first, followed by demographic information at the end. The questions regarding the specific PA leadership positions were directly related to the six components of the medical leader conceptual framework previously discussed.

Survey questions aimed to be: (a) meaningful, (b) clearly written, (c) concrete, (d) without bias, and (e) consist of only one thought (Fink, 2009). Multiple-choice questions 
were utilized to determine agreement with the six components of the medical leader conceptual framework. As suggested by Fink (2009) multiple choice questioning was used to enhance the reliability of the survey by providing consistent responses. The multiple choice survey questions utilized even numbered options forcing the respondent to choose a side of agreement or disagreement (Fink, 2009; MacGregor personal communication, 2012). Additionally, checklists were utilized to specifically differentiate the actions or duties performed by the PA under each of the content areas of the medical leader framework. Each checklist included an "other" category with an associated request for the participant to specify qualitatively what action had occurred. Checklists are recommended when there is a possibility of multiple answers to a question. Fink (2009) reported, "checklists help remind respondents of some things they might have forgotten" (p. 27). In addition, the questions collected a combination of categorical, differential, and ordinal data (Fink, 2009). Ordinal data was used in the form of questions, which allowed for ranking of answers on a continuum of most likely to least likely.

\section{Reliability and Validity}

The survey administered was created by the researcher, therefore, was pilot tested for both reliability and validity. Survey results are reliable when they produce consistent responses despite fluctuations in variables (Fink, 2009). A valid survey produces an accurate measure of what you are sampling (Fink, 2009).

As described by Fink (2009) reliability can be accomplished in three ways: (a) test-retest reliability, (b) alternative forms equivalent, and (c) internal consistency. If the survey was given to the same group of individuals at two different times and their results 
were consistent in the two surveys the survey would be considered reliable. In addition, one may construct two forms of the survey and have the group take both surveys to make sure the answers were consistent in both surveys by correlating the mean and standard deviation scores for both surveys. Lastly, internal consistency can be measured by calculating the coefficient alpha which will determine how well different questions about the same characteristic measure against one another.

A valid survey is one that produces an accurate measurement of those whom you are surveying. When assessing validity one can consider: (a) predictive validity, (b) content validity, (c) concurrent validity, and (d) construct validity. A survey with predictive validity would accurately predict an expected outcome based on the survey results. A survey demonstrating content validity correctly measures the content it is intended to measure. Concurrent validity is demonstrated by survey results accurately compared to a standard or expert opinion. Lastly, a survey with construct validity is able to correctly measure a construct, previously established experimentally (Fink, 2009). "A well-designed, easy-to-use survey always contributes to reliability and validity" (Fink, 2009, p. 8).

For this specific study, a pilot group comprised of six physician assistants currently practicing in the state of Missouri was selected from a convenience sample (Fraenkel \& Wallen, 2009) to test the survey instrument for practicing PAs. Additionally, a second pilot group of three PA faculty were selected from a convenience sample (Fraenkel \& Wallen, 2009) to test the survey instrument for PA faculty. According to Fink (2009), pilot groups should be similar to the targeted participant group and researchers should enlist as many into the pilot group as logistically possible. From 
the pilot testing, questions that were unanswered, included comments on clarity, or had numerous answers were re-evaluated to improve reliability (Fink, 2009). An extensive literature review for content related to the medical leader aided in the support of validity, ensuring all pertinent topics were explored and surveyed (Fink, 2009). Additionally, data was collected by quantitative and qualitative means concurrently, which helped to provide concurrent validity by a means of triangulation of both quantitative and qualitative data (Creswell, 2009).

\section{Methods of Data Collection}

A survey, titled Medical Leadership Survey: For Practicing Physician Assistants, which contained both closed and open-ended questions was created using an on-line commercial survey developer, Qualtrics. The survey was distributed via Qualtrics to practicing PAs who were all members of the AAPA and to PAs from Missouri (Fraenkel \& Wallen, 2009). Participants received an email with a brief explanation of the study along with a link to access the survey. A reminder email to complete the survey was sent between two and three weeks after the initial email request. At the beginning of the survey, further information on the study's purpose along with consent to participate in the study was identified. Agreement of participation was evidenced by having participants click a box that stated they agreed to participate. In addition, completion of the survey served as consent. Questions 11-12, 14-17, 19-23, 25-26, 28-30, and 32-35 of the survey were used to answer research question number one, "What is the prevalence and practice of the leadership roles of physician assistants as: (a) learning leaders, (b) patient advocates, (c) engaged professionals, (d) builders of future professionals, (e) community activists, and (f) team collaborators?" Questions 13, 18, 24, 27, 31, and 36 of the survey 
were used to answer research question number two, "In what ways does current curricula prepare physician assistant students for future leadership roles?"

The second survey titled Medical Leadership Survey: For Physician Assistant Faculty, which contained both closed and open-ended questions was created using an online commercial survey developer, Qualtrics. This survey was distributed via Qualtrics to 71 PA faculty participants, which were selected via a purposive sample (Fraenkel \& Wallen, 2009) of PA program faculty from across the United States. The first group consisted of 57 faculty serving on either a PAEA Rotation Exam Review Committee (RERC) or the PAEA Assessment Council. A second group of 14 faculty from Missouri were selected to participate. This group of faculty members consisted of a purposive, convenience sample (Fraenkel \& Wallen, 2009) of PA educators in Missouri. Participants received an email with a brief explanation of the study along with a link to access the survey. A reminder email to complete the survey was sent between two and three weeks after the initial email request. Further information on the study's purpose along with consent to participate in the study was identified at the beginning of the survey. Participants clicked a box that stated they agreed to participate in the study. In addition, completion of the survey served as consent. Questions 11-26 on the survey were used to answer research question number two, "In what ways does current curricula prepare physician assistant students for future leadership roles?"

\section{Data Analysis Procedures for Surveys}

The data collected from the surveys was downloaded and analyzed for frequencies among the previously defined medical leadership framework categories. Frequencies allowed the categorical data to be summarized and highlighted. Percentages 
for each of the six medical leadership framework categories, and the more specific descriptive categories they contained, were calculated and placed in tables to illustrate the findings (Fraenkel \& Wallen, 2009).

The qualitative survey data was sorted through a process of deductive analysis using the six medical leadership framework categories (Fraenkel \& Wallen, 2009; Hatch, 2002). This data added to the richness of the results, by providing additional descriptive meaning to the quantitative findings (Fraenkel \& Wallen, 2009). This served as a way to triangulate the quantitative and qualitative survey results with the literature, which added to the validity of the findings (Fraenkel \& Wallen, 2009; Hatch, 2002). In addition to triangulation, validity was strengthened through confirmability, which was achieved through the practice of reflexivity, where the researcher deliberately and critically reviewed her assumptions and biases prior to reviewing the data (Fraenkel \& Wallen, 2009; Hatch, 2002).

Once the initial survey data was collected and analyzed another layer of data triangulation occurred to answer research question number 3: What changes are needed in physician assistant curriculum to better prepare students for future leadership roles? This research question was addressed through a process of evaluation and comparison of the two data sets, one completed by practicing PAs and the other completed by PA faculty. The ability to triangulate and integrate the data from the two surveys added to the richness and validation of the data collected by allowing for a comparison between the perceptions of the two groups surveyed and identification of gaps in PA curricula (Creswell, 2009; Fraenkel \& Wallen, 2009; Hatch, 2002). 


\section{Study Limitations and Assumptions}

One limitation of this study are the surveys. Although they had been piloted and construction was embedded in the literature they had not been used in prior research or subject to reliability and validity studies. A second limitation is that the medical leader conceptual framework, although supported through literature, was designed by the researcher, therefore, had not yet been validated through previous research. The survey and conceptual framework are linked as the questions on the survey reflected each component of the medical leader conceptual framework.

A third limitation is in the robustness of the statistics. Although additional analyses could have been completed, the quantitative focus of the study was in determining the prevalence of the six medical leader conceptual underpinnings, which was accomplished. Finally, generalizability must be discussed. The population size recruited and comprehensive sampling of the convenience sample of physician assistant participants supports “population generalizability” (Fraenkel \& Wallen, 2009, p. 102). Therefore, it is likely that the results of the quantitative portion of the study may be generalizable to PAs across the United States as the surveyed population is representative of the larger population of PAs and similar results could likely be replicated. However, although the framework for the medical leader may apply to other healthcare professionals, this study focused on PAs specifically. Therefore, generalizability to other healthcare professionals cannot be supported. In addition, Fraenkel and Wallen (2009) contended that, "a limitation of qualitative research is that there is seldom methodological justification for generalizing the findings of a particular study" (p. 432). They stressed the importance of replicating studies to provide the proof of generalizability. 
Furthermore, they discussed transferability, which contends that the researcher must fully disclose content and context of the study, positionality, and any bias, to allow those reading the research to draw their own conclusions regarding generalizability (Fraenkel \& Wallen, 2009).

Three assumptions were also identified. First, this researcher assumed that physician assistants hold a belief that they are leaders and have leadership roles within medicine. Second, the researcher assumed that physician assistant participants would be honest and forthcoming with information regarding their leadership practice. Finally, the researcher assumed that there is value in formal and intentional leadership training for PAs.

\section{Summary}

In summary, a concurrent, triangulation, mixed-methods approach (Creswell, 2009) was used to explore the prevalence and practices of leadership roles among physician assistants and determine if current curricula supports the development of leadership skills. The first part of the research study collected quantitative and qualitative data in the form of two different surveys, created, pilot-tested, and distributed to two different groups respectively. The data collected from the survey sent to 681 practicing PAs, aimed at answering research questions number one and two. The data collected from the survey sent to 71 PA faculty, aimed at answering research question number two. Frequency results of the data collected along with information obtained from qualitative survey questions was independently analyzed and triangulated. The results of both surveys were then compared against one another and the data triangulated again to answer research question number three. Research question three focused on contrasts in 
the collected data and necessary changes in PA curricula to prepare PA students for future leadership roles.

This study was viewed through a pragmatic perspective. Every attempt was made to recognize and minimize bias within the study. This was primarily accomplished with identification of potential bias and having the results vetted through the researcher's dissertation supervisor and committee. Limitations of this study included both the survey and the conceptual framework which although were embedded in the literature were designed by the researcher and had not been previously studied. Additionally, there was a lack in the robustness of the statistics done for this study. Finally, generalizability for PA practice is likely; however, generalizability to other medical professions cannot be supported. Assumptions were based on physician assistant beliefs that they: (a) are leaders in medicine, (b) would be honest and forthcoming with information regarding leadership practice, and (c) believe there is value in formal and intentional leadership training. 


\section{CHAPTER FOUR}

\section{PRESENTATION OF FINDINGS}

\section{Introduction}

The Health Resources and Services Administration Health Workforce report in 2013 projected a shortage of 20,400 physicians in America by the year 2020. The Association of American Medical Colleges who reported an even greater physician shortage, up to 95,000 and extending to as late as 2025 , further supported this physician shortage in 2016. Physician assistants (PA) have been identified as medical providers to help fill this need within the United States (Snyderman et al., 2011). However, PAs will require not just quality medical training, but leadership training too (Abbas, Quince, Wood, \& Benson, 2011; Nordquist \& Grigsby, 2011).

Leadership qualities are highly acknowledged in today's society. Physicians are often called upon to be leaders in all realms of life because they are perceived as educated, reliable, and trustworthy individuals. Although many physicians would agree that leadership is a vital commodity, it is one that many physicians do not feel prepared with during their medical training (Abbas, et al., 2011; Baird, Soldanska, Anderson, \& Miller, 2012; Collins-Nakai, 2006).

Physicians are not alone when it comes to leadership in healthcare. Blumenthal, Bernard, Bohen, and Bohmer (2012) argued that all healthcare providers must possess leadership skills. Physicians (Collins-Nakai, 2006) and advanced practice providers, such as PAs (Huckabee \& Wheeler, 2008), are often tasked with a variety of leadership roles with respect to community, state, and national healthcare problems, patient advocacy, staff, professional organizations, politics, and training the next generation. 
Much like physicians, preparedness for the leadership responsibilities physician assistants encounter is an essential component of professional competency (Collins-Nakai, 2006; Huckabee \& Wheeler, 2008).

Ethics are the standards or rules by which one lives and decisions made. In the broadest sense, this reflects, doing the right thing for the right reason, which has a number of implications. Ethics and ethical practices are at the root of medical practice. It is only right then, that ethical leadership also have strong ties to medicine. Ethical leadership is comprised by five guiding principles. These guiding principles have described that an ethical leader: (a) "builds community", (b) "respects others", (c) "serves others", (d) "manifests honesty", and (e) "shows justice" (Northouse, 2010, p. 387). Ethical leadership and its guiding principles, along with its strong ties to transformational leadership, servant leadership, and authentic leadership is at the foundation of leadership for the medical leader.

This study explored the leadership opportunities and demands currently within the PA profession and identified if PA educational training prepares students for the necessary leadership responsibilities they will encounter. This researcher conducted a concurrent, mixed-methods study, which explored PA leadership through the lens of currently practicing PAs and current PA faculty. Through survey questionnaires quantitative and qualitative data was collected on the researchers six conceptual underpinnings for the Medical leader which were based on ethical leadership as described above and included the PA as a: (a) learning leader, (b) patient advocate, (c) engaged professional, (d) builder of future professionals, (e) community activist, and (f) team collaborator. 
Presented within this chapter are the quantitative and qualitative survey findings obtained through this research study. The following research questions guided this investigation of PA leadership:

1) What is the prevalence and practice of the leadership roles of physician assistants (PAs) as...
a. learning leaders?
b. patient advocates?
c. engaged professionals?
d. builders of future professionals?
e. community activists?
f. team collaborators?

2) In what ways does current curricula prepare physician assistant (PA) students for future leadership roles?

3) What changes are needed in physician assistant (PA) curriculum to better prepare students for future leadership roles?

\section{Data Collection}

A survey was created and distributed through an on-line commercial survey developer, Qualtrics. The survey collected both quantitative and qualitative data. Survey participants included PA faculty and practicing PAs across the United States. Presented in the sections below is a more thorough description of the demographics of the participants as well as the survey findings. 


\section{Demographics of Practicing PAs}

Practicing PA participants consisted of a random sampling (Fink, 2009) from over 53,500 AAPA members on an AAPA networking site, called Huddle (AAPA, 2015e) as well as a purposive sampling through posting the survey on the Huddle site. Additionally, a purposive convenience sample (Fraenkel \& Wallen, 2009) was done of PAs practicing in Missouri. Correspondence with the PAs practicing in Missouri was accomplished via email access through the state organization. Ultimately, the survey was administered to 681 practicing PAs with 107 PAs responding for a $15.7 \%$ return. PA respondents were $59.7 \%$ female and $40.3 \%$ male. The respondents were between 25 and 65 years old, with the majority (67.2\%) falling between the ages of 31 and 50. The PAs represented 18 different states with the most respondents (63.1\%) coming from Missouri.

Of the respondents, the largest percentage had been working as a PA for 11-15 years $(31.3 \%)$, followed closely by those working 6-10 years $(23.9 \%)$, less than 5 years (19.4\%), and 16-20 years $(9.0 \%)$. The remainder of the respondents $(16.4 \%)$ were divided among 4 age categories that represented anywhere from 21 to 40 years of work experience. A vast majority, 71.2\%, reported working in a metropolitan area, while $21.2 \%$ reported working in a non-metropolitan setting; and $7.6 \%$ reported working in an other category, which was defined by the respondents as either rural, suburban, or military.

Clinical practice, greater than 32 hours/week, was noted as the primary employment status for $73.1 \%$ of the respondents. This was followed by a category named other, which captured $10.5 \%$ of respondents. This category was further defined by the participants as those who did locum tenems work, worked overseas, or had some 
combination of clinical and administrative duties. Clinical practice, less than 32 hours/week, was noted of $7.5 \%$ of respondents. Respondents working primarily in hospital or clinic administration $(6.0 \%)$, academia $(1.5 \%)$ and research $(1.5 \%)$ followed these categories. Of the respondents, most (43.9\%) reported working in a clinic-based setting or primarily within the hospital $(40.9 \%)$. Other areas $(7.6 \%)$ included a combination of hospital and clinic practice, non-healthcare and rural health clinic. The remaining areas in which participants worked included an ambulatory care setting (4.6\%) and the university setting (3.0\%).

Surgery $(28.4 \%)$, internal medicine $(17.9 \%)$ and an other category $(17.9 \%)$ were among the highest noted as the primary work setting. The surgery category was further specified to include PAs working in plastics, orthopedics, cardiothoracic, neurosurgery, general, and dermatology. The internal medicine category included PAs working in cardiology, gastroenterology, endocrinology, nephrology, and critical care. The other category included PAs working in research, chronic pain, radiation oncology, and urology.

\section{Demographics of PA Faculty}

Faculty participants consisted of current PA program faculty from across the United States currently serving on PAEA Rotation Exam Review Committees (RERC), the Assessment Council, and PA educators within Missouri. The survey was sent to 71 faculty participants with 43 faculty responding for a $60.6 \%$ return. Of the faculty respondents, only 30 completed the demographic information regarding gender at the end of the survey. Of those 30 participants, $70.0 \%$ identified as female, $26.7 \%$ male, and $3.3 \%$ as other for gender. The vast majority of respondents were between 36 and 65 
years old, with only $6.9 \%$ respondents being 35 years old or younger. The faculty respondents represented 17 different states with the most respondents $(26.7 \%)$ coming from Missouri. All respondents reported working in PA education within the last 5 years, with $90 \%$ currently working primarily in academia, $6.7 \%$ primarily doing clinical work, and $3.3 \%$ reporting a combination of academia and clinical work.

\section{Findings}

In the following sections, the research findings will be explored. Each research question will be addressed individually for each survey. Both quantitative and qualitative data will be reported for each of the research questions.

\section{Research Question One}

What is the prevalence and practice of the leadership roles of physician assistants (PAs) as learning leaders, patient advocates, engaged professionals, builders of future professionals, community activists, and team collaborators?

Research question one included six parts, both containing quantitative and qualitative data. This practicing PA survey addressed this first research question. The survey items investigated the prevalence and practice of the leadership roles of physician assistants (PAs) as learning leaders, patient advocates, engaged professionals, builders of future professionals, community activists, and team collaborators. The findings for each of these underpinnings were explored individually. For each of the conceptual underpinnings the quantitative data was explored, followed by the qualitative data.

Learning leader: quantitative findings. All practicing PAs reported some degree of agreement with the following statement, "I consider myself to be a PA who participates in learning opportunities for professional growth," with $42.7 \%$ strongly 
agreeing, $45.6 \%$ agreeing and $11.8 \%$ somewhat agreeing. Nearly the same numbers were reflected in a similar question regarding participation in learning opportunities for personal growth (Table 1).

Table 1

Practicing PAs Who Participate in Learning Opportunities

\begin{tabular}{lcccccc}
\hline Item & $\begin{array}{l}\text { Strongly } \\
\text { Disagree }\end{array}$ & Disagree & $\begin{array}{l}\text { Somewhat } \\
\text { Disagree }\end{array}$ & $\begin{array}{l}\text { Somewhat } \\
\text { Agree }\end{array}$ & Agree & $\begin{array}{l}\text { Strongly } \\
\text { Agree }\end{array}$ \\
\hline $\begin{array}{l}\text { For Professional } \\
\text { Growth }\end{array}$ & $0.0 \%$ & $0.0 \%$ & $0.0 \%$ & $11.8 \%$ & $45.6 \%$ & $42.7 \%$ \\
$\begin{array}{l}\text { For Personal } \\
\text { Growth }\end{array}$ & $1.5 \%$ & $1.5 \%$ & $0.0 \%$ & $11.8 \%$ & $45.6 \%$ & $39.7 \%$ \\
\hline
\end{tabular}

To delineate which learning opportunities seemed most prevalent among practicing PAs, respondents selected all learning opportunities for which they participate (Table 2). Continuing medical education and medical conference attendance were the most prevalent with $95.7 \%$ and $89.9 \%$ reporting participation in these activities respectively. Workshops related to medical skill development, practice based performance improvement, and weekly journal reading were next in line. Fewer respondents reported weekly critical self-reflection and formal education after PA school. Finally, hospital based training programs and the other category rounded out the results. The other category was defined by respondents as writing research articles, taking selfdirected Spanish language courses, participating in self-assessment continuing medical education, discussing medical information with colleagues, and obtaining advanced clinical certifications. 
Table 2

Learning Opportunities among Practicing PAs in Order of Prevalence

\begin{tabular}{lcl}
\hline Item & Percent & Count \\
\hline Continuing medical education & 95.7 & 66 \\
Medical conference attendance & 89.9 & 62 \\
$\begin{array}{l}\text { Workshops related to medical skill } \\
\text { development }\end{array}$ & 59.4 & 41 \\
$\begin{array}{l}\text { Practice based performance } \\
\text { improvement }\end{array}$ & 58.0 & 40 \\
$\begin{array}{l}\text { Weekly journal reading } \\
\text { Weekly critical self-reflection }\end{array}$ & 58.0 & 40 \\
$\begin{array}{l}\text { Formal education since graduating } \\
\text { from PA school (doctoral or other } \\
\text { degree) }\end{array}$ & 36.2 & 25 \\
$\begin{array}{l}\text { Hospital based training program } \\
\text { for administrators }\end{array}$ & 21.7 & 15 \\
\begin{tabular}{l} 
Other \\
\hline
\end{tabular} & 10.1 & 7 \\
\hline
\end{tabular}

Learning leader: qualitative findings. Participants describe how their PA training prepared them to be a learning leader. Of the participants, 32 offered descriptive responses. The answers reflected an overall importance of lifelong learning. This overall importance was further defined through three themes, which included: a) Curricular preparation (14) b) Professional expectations (9), and c) Self teaching (8).

Many respondents reported that lifelong learning was emphasized in their PA education. One respondent noted, "It was emphasized that to remain an excellent 
healthcare provider, you need to strive to be a lifelong learner" (PAS, Q37, R32).

Another participant stated, "I'm always reading and learning. I recall training to instill in me that there is always something to learn and if you become stagnant you will not be a quality medical provider" (PAS, Q37, R24). Again, another participant who supported this claim stated:

You must be a life-long learner. PA school taught me that you can never know everything, and learning is always a work in progress. Accepting this, and understanding this helps you buy into the commitment to learning for personal and professional betterment (PAS, Q37, R30).

Others noted, "PA instructors strongly emphasized need for lifetime learning, and personal drive towards personal/professional development" (PAS, Q37, R5) Another PA said, “They said, learn what you don't know" (PAS, Q37, R4) One PA took it a step further noting how lifelong learning was essential in the medical profession and for patients. He noted:

The medical profession, including the PA profession is always progressing. We have to progress alongside with our profession. So, staying current with medicine, such as advances in diagnostics and treatment are very important to provide my patients what they deserve. These concepts were engrained during my PA training. I believe every PA should participate in learning opportunities to improve themselves both personally and professionally. It is essential to provide the best patient care possible (PAS, Q37, R9).

Curricular preparation. Some respondents felt the demands of the program curriculum and expectations was what taught them the importance of learning. One 
respondent said, "PA training is an intense learning experience that prepares you to continue your education" (PAS, Q37, R15). Another respondent said:

We took introduction to Clinical Medicine, a 3 or 4 hour class every morning for 4 months with the second year medical students and then we were divided up in groups with them in the afternoons in the hospital. We felt we had to be on our best game so no one could tell we were the PA in the group. The expectation was there that we needed to know the same information the MD students knew (PAS, Q37, R6).

Others felt that PA school taught them skills and gave tips that they have been able to apply within their work as a PA. One respondent stated, "We were taught about EBM (evidenced based medicine) and how to analyze articles and look for bias" (PAS, Q37, R10). Another stated, "It was stressed that we should subscribe to a general journal and perhaps another specialty journal if we worked outside of primary care" (PAS, Q37, R29).

Professional expectation. Some respondents (9) reported that being a learner is just part of working within the medical field. One respondent said, "Continued learning is part of what it means to be a healthcare provider today. Learning never stops" (PAS, Q37, R31). Others shared this sentiment. One respondent noted, "Feel it is built into the profession. My training allowed me to see top professionals in their fields always learning” (PAS, Q37, R7). Another said, "I think medicine in general necessitates a willingness to continue to learn. I do not feel this is necessarily anything specific to PAs" (PAS, Q37, R19). Another respondent noted, "It teaches you the importance of staying current in your field" (PAS, Q37, R20). One respondent noted, "Our profession requires 
it" (PAS, Q37, R21). While another PA noted, "Learning has grown out of the necessity to make myself a better clinical PA and a better leader" (PAS, Q37, R12).

Self-teaching. Some respondents (8) reported that they, themselves were more responsible for their willingness to be a learner. One individual noted:

Before a PA can participate in opportunities, a real learning leader is a PA who is self-aware and willing to admit he/she doesn't know everything and is willing to admit that fact. Only then, can real learning occur. In that moment of selfawareness, he/she has grown personally and can achieve almost anything (PAS, Q37, R2).

Another PA stated, "Again, this had nothing to do with my training. It is an expectation for me to continue to learn on my own and to better myself" (PAS, Q37, R1). This was shared by another PA who noted, "Again, I feel this is a personal goal or decision and was not necessarily taught during school" (PAS, Q37, R16). Some PAs shared what they do on their own to continue their learning. One PA noted, "I listen to new medical lectures on a daily basis and far exceed the required CME hours each year" (PAS, Q37, R14). Another PA said, "I'm always reading and learning" (PAS, Q37, R24).

Five PAs were adamant that they had not been prepared for learning opportunities by their PA training. One simply stated, "Did not prepare me" (PAS, Q37, R26). Another PA reported, “It didn't, I already had these skills” (PAS, Q37, R23). Finally, one simply said, "none" (PAS, Q37, R8). Two other respondents answered, "not applicable" (PAS, Q37, R18, 27).

Although several PA respondents noted that their PA training provided them with the tools to be learners of their profession, two respondents reported no training on how 
to improve themselves personally. One PA stated, "My PA training prepared me to be a subject matter expert, and in medicine there is no way to be that without continual clinical education. My PA training did not address personal development at all” (PAS, Q37, R17). Another stated, "My program routinely discussed the importance of continual learning as related to a professional PA. This was primarily focused on the expansion of medical knowledge from the professional standpoint more so than personal growth” (PAS, Q37, R22).

Patient advocate: quantitative findings. Participants indicated their level of agreement with 21 statements that addressed how they advocate for patients. Respondents graded their level of agreement on a 6 point Likert scale of agreement. Table 3 shows those areas where practicing PAs showed high levels of agreement. Specifically, greater than $70 \%$ of practicing PAs strongly agree that they (a) establish ethical relationships with patients, (b) are honest with patients, (c) communicate openly with patients, (d) respect patient confidentiality, (e) do not harm patients, (f) treat patients justly, (g) educate patients, and (h) act in the best interest of patients. When both columns of agree and strongly agree were added together, greater than $70 \%$ of practicing PAs agree that they (a) demonstrate altruistic behavior, (b) respect patient autonomy, (c) serve their patient's needs, (d) go beyond the call of duty for their patients, (e) put patient's needs above their own, (f) advocate for marginalized patient populations, (g) listen to patients, (h) assist patients with navigating the health system, (i) communicates with other healthcare providers on patient's behalf, and (j) develops treatment plans with the patient. Although it did not make the cutoff for greater than $70 \%$ agreement when the 
strongly agree and agree categories were combined, the category of calls patients with test results showed $82.4 \%$ agreement when all three categories of agreement were pooled.

Table 3

Prevalence of Agreement of Practicing PAs-Patient Advocate- High Levels of Agreement

\begin{tabular}{|c|c|c|c|c|c|c|}
\hline Item & $\begin{array}{l}\text { Strongly } \\
\text { Disagree }\end{array}$ & Disagree & $\begin{array}{c}\text { Somewhat } \\
\text { Disagree }\end{array}$ & $\begin{array}{c}\text { Somewhat } \\
\text { Agree }\end{array}$ & Agree & $\begin{array}{c}\text { Strongly } \\
\text { Agree }\end{array}$ \\
\hline Is honest with patients & $0.0 \%$ & $0.0 \%$ & $0.0 \%$ & $0.0 \%$ & $17.3 \%$ & $82.7 \%$ \\
\hline Does not harm patients & $0.0 \%$ & $0.0 \%$ & $0.0 \%$ & $2.7 \%$ & $20.0 \%$ & $77.3 \%$ \\
\hline Treats patients justly & $0.0 \%$ & $0.0 \%$ & $0.0 \%$ & $1.4 \%$ & $21.6 \%$ & $77.0 \%$ \\
\hline $\begin{array}{l}\text { Respects patient } \\
\text { confidentiality }\end{array}$ & $0.0 \%$ & $0.0 \%$ & $0.0 \%$ & $0.0 \%$ & $24.3 \%$ & $75.7 \%$ \\
\hline $\begin{array}{l}\text { Communicates openly with } \\
\text { patients }\end{array}$ & $0.0 \%$ & $0.0 \%$ & $0.0 \%$ & $1.4 \%$ & $24.3 \%$ & $74.3 \%$ \\
\hline $\begin{array}{l}\text { Establishes ethical patient } \\
\text { relationships }\end{array}$ & $0.0 \%$ & $0.0 \%$ & $0.0 \%$ & $0.0 \%$ & $27.0 \%$ & $73.0 \%$ \\
\hline Educates my patients & $0.0 \%$ & $0.0 \%$ & $0.0 \%$ & $2.7 \%$ & $26.0 \%$ & $71.2 \%$ \\
\hline $\begin{array}{l}\text { Acts in the best interest of } \\
\text { patients }\end{array}$ & $0.0 \%$ & $0.0 \%$ & $0.0 \%$ & $0.0 \%$ & $29.3 \%$ & $70.7 \%$ \\
\hline Listens to patients & $0.0 \%$ & $0.0 \%$ & $1.3 \%$ & $0.0 \%$ & $33.3 \%$ & $65.3 \%$ \\
\hline Respects patient autonomy & $0.0 \%$ & $0.0 \%$ & $0.0 \%$ & $4.0 \%$ & $36.0 \%$ & $60.0 \%$ \\
\hline Serves my patients needs & $0.0 \%$ & $0.0 \%$ & $0.0 \%$ & $1.3 \%$ & $41.3 \%$ & $57.3 \%$ \\
\hline $\begin{array}{l}\text { Develops treatment plans } \\
\text { with the patient }\end{array}$ & $0.0 \%$ & $0.0 \%$ & $0.0 \%$ & $4.0 \%$ & $38.7 \%$ & $57.3 \%$ \\
\hline $\begin{array}{l}\text { Goes above and beyond the } \\
\text { call of duty for my patients }\end{array}$ & $0.0 \%$ & $0.0 \%$ & $0.0 \%$ & $10.7 \%$ & $44.0 \%$ & $45.3 \%$ \\
\hline $\begin{array}{l}\text { Puts needs of patient above } \\
\text { my own }\end{array}$ & $1.4 \%$ & $1.4 \%$ & $1.4 \%$ & $21.6 \%$ & $35.1 \%$ & $39.2 \%$ \\
\hline $\begin{array}{l}\text { Advocates for marginalized } \\
\text { patient populations }\end{array}$ & $0.0 \%$ & $0.0 \%$ & $5.4 \%$ & $14.9 \%$ & $43.2 \%$ & $36.5 \%$ \\
\hline $\begin{array}{l}\text { Demonstrates altruistic } \\
\text { behavior }\end{array}$ & $0.0 \%$ & $0.0 \%$ & $0.0 \%$ & $12.3 \%$ & $53.4 \%$ & $34.3 \%$ \\
\hline $\begin{array}{l}\text { Calls patients with test } \\
\text { results }\end{array}$ & $4.1 \%$ & $4.1 \%$ & $9.5 \%$ & $14.9 \%$ & $35.1 \%$ & $32.4 \%$ \\
\hline $\begin{array}{l}\text { Assists patients with } \\
\text { navigating the health system }\end{array}$ & $0.0 \%$ & $0.0 \%$ & $1.3 \%$ & $21.3 \%$ & $48.0 \%$ & $29.3 \%$ \\
\hline
\end{tabular}


Practicing PAs showed less agreement with calling insurance companies on behalf of patients, and making house calls as evidenced in Table 4. Calling insurance companies on behalf of patients resulted in $66.2 \%$ agreement when all three categories of agreement were combined. However, making house calls showed its greatest level of prevalence in the strongly disagree category and when combined with the disagree column revealed a $78.0 \%$ level of disagreement.

Table 4

Prevalence of Agreement of Practicing PAs- Patient Advocate- Lower Levels of Agreement

\begin{tabular}{lcccccc}
\hline Item & $\begin{array}{c}\text { Strongly } \\
\text { Disagree }\end{array}$ & Disagree & $\begin{array}{c}\text { Somewhat } \\
\text { Disagree }\end{array}$ & $\begin{array}{c}\text { Somewhat } \\
\text { Agree }\end{array}$ & $\begin{array}{c}\text { Agree } \\
\text { Strongly } \\
\text { Agree }\end{array}$ \\
\hline $\begin{array}{l}\text { Calls insurance } \\
\text { companies on } \\
\text { behalf of patients }\end{array}$ & $6.8 \%$ & $12.2 \%$ & $14.9 \%$ & $25.7 \%$ & $24.3 \%$ & $16.2 \%$ \\
$\begin{array}{l}\text { Makes house } \\
\text { calls }\end{array}$ & $49.3 \%$ & $28.8 \%$ & $4.1 \%$ & $12.3 \%$ & $2.7 \%$ & $2.7 \%$ \\
\hline
\end{tabular}

Patient advocate: qualitative findings. Practicing PAs addressed two statements with regard to being a patient advocate. The first asked them to provide any additional ways in which they advocate for patients or go "above and beyond" over the course of a typical month. While the second asked them to describe ways, in which their PA training prepared them to be a patient advocate.

Themes that emerged from 38 PA responses with respect to additional ways in which they advocate for patients or "go above and beyond" over the course of a typical month included: (a) giving of time (28) (b) giving of financial resources (7), (c) patient convenience/comfort/safety (7), and (d) taking care of challenging patients (3). Of the 38 
responses, eight included multiple ways of going "above and beyond" which spanned more than one of the above themes.

Giving of time. Expressed in numerous ways, was the giving of time. Some of the most prevalent responses included writing letters, making phone calls to patients, other providers, and insurance or other companies on patient's behalf, spending additional time with patients to discuss barriers to healthcare or in education of their disease or treatment, helping patients gain access to resources, and working longer hours. One PA stated, "I write letters to judges, landlords, and employers on behalf of the patient” (PAS, Q14, R3). Another reported, “Calling medical supply company or submitting extra paperwork to get supplies covered" (PAS, Q14, R6).

Many PA respondents noted that they call their patients to check on them or to follow-up with them after the initiation of treatment or after treatment has changed. One PA said, "Call patients after a change in treatment plan to see how they are progressing" (PAS, Q14, R29). While another PA responded with, "Calling to check on them.

Getting them in when there is an issue. Calling their family members to explain medical issues and answer questions" (PAS, Q14, R30). With respect to following up with patients, one PA stated that he goes above and beyond by, "not letting the time of day determine if I will complete my work or make post clinic phone calls" (PAS, Q14, R18). Another participant noted, "I will take calls from patients on days when I am not on call. A lot call me at home if issues come up" (PAS, Q14, R21). With respect to barriers, one PA stated that they go above and beyond, "by identifying barriers to compliance and helping the patient in finding appropriate remedies to those barriers" (PAS, Q14, R11). Another PA noted: 
My practice is very strong with patient education and joint decision making.

Therefore we spend much over the norm in terms of time in the room with each patient explaining findings, outlining treatment options and making a joint decision with the patient (PAS, Q14, R20).

Gaining access to patient resources is another area that requires PA time and energy. One PA stated, "When necessary and appropriate, helping patients find and access community resources, that may assist with access to food, housing, personal safety" (PAS, Q14, R36). Another PA corroborated this statement by adding that he helps by, "providing community resources/education" (PAS, Q14, R37).

Finally, some PAs reported that in giving more time, they simply work longer, spending more time with patients, researching for patients, or in advocacy on a bigger level. One PA stated, "In my career I have spent many hours at the bedside with patients after my 'shift' ended in order to make sure they got the care they needed" (PAS, Q14, R33). Another said, "I have become involved in increasing the access to patients to healthcare through the state and national organizations." Finally, another PA noted, "I am constantly researching and learning as much as I can about the treatment of obesity, so I can provide my patients with the best care possible" (PAS, Q14, R8).

Giving of resources. The giving of financial resources was evident in PAs conscientiousness of prescribing certain medications that were less expensive, providing supplies to patients, or providing other financial assistance. One PA said, "I have a certain amount of supplies and material that I supply out of pocket for my patients on site" (PAS, Q14, R3). While another PA said that he, "change(s) medications to relieve financial burden (and) take(s) donated supplies to needy clinic" (PAS, Q14, R6). 
Similarly, one PA noted, "I try to find the best financial ways to afford medication, often having conversations with pharmacists in an ever changing arena of formularies" (PAS, Q14, R15). Going above and beyond for one PA has included paying patient bills. One PA stated, "I have been known to split the bill with the dentist for poor patients unable to afford dental work" (PAS, Q14, R3).

Patient convenience/comfort/safety. The third theme that emerged reflected PA practices that provided a convenience to patients. This ranged anywhere from house calls to rendering services when the clinic was not open to changing the providers schedule to accommodate a patient. One PA stated, "I visit elderly patients in their homes, if necessary (and) I open my clinic on Sunday mornings after Saturday night rodeos if the patient calls me at home" (PAS, Q14, R3). One PA said, "The physician and myself dropped a patient off at his home to make sure he climbed the steps to his home" (PAS, Q14, R31). Another PA said:

We do a lot of procedures in our clinic, and have lots of patients in outlying rural communities (2-3 hours away). I have made arrangements for patients to come in on days I don't typically see patients just because that day is more convenient for them (PAS, Q14, R13).

Caring for challenging patients. The final theme that emerged was caring for difficult patients. This related to patients who were waiting on referrals for psychiatric problems, had troubles with addiction or those who had been dropped from other healthcare providers. One PA said that they care for challenging patients, "By tending to the needs of patients that are difficult. Addiction, or those that feel that the ball was dropped. Explaining the situation, helping them to get to the next step" (PAS, Q14, R23). 
Another PA reported that she "see(s) patients for second touch and distress screenings to see if they need any referrals to financial counseling, onchopsychology, etc." (PAS, Q14, R9). Finally, one PA noted:

I will see the patients with severe mental health problems as a stop gap until I can get them in to the psychiatric care and treatment that is needed. I will agree to see the patients that others have dismissed from their practices and will at least give them the benefit of the doubt (to a limited degree) (PAS, Q14, R26).

The second statement asked respondents to report on whether or not their PA training helped prepare them to be a patient advocate. Thirty respondents said that their PA training did provide some instruction on how to be a patient advocate. Recurring themes centered on a) PA skill development (20), b) modeling (10), and c) serving the underserved (3).

PA skill development. With respect to the curriculum, respondents reported that patient advocacy was stressed in skills that they were taught and in the knowledge they acquired. One respondent stated:

My program emphasized good listening skills, a strong diagnostic background, respect for the costs of testing and an emphasis on using labs and tests only when necessary (not a replacement for thinking). Listening to your patients is by far the most important part of being "unselfish" and then treating them all as you would like your parents treated at their provider's office (PAS, Q17, R6).

Another PA noted:

My PA training provided me with the education and confidence to be able to effectively diagnose and treat patients. We are taught to be patient advocates, it is 
what our profession is all about. We develop relationships by having the medical knowledge, and our patients having the confidence in us as providers to give them the best care possible (PAS, Q17, R11).

Some PAs noted that altruism and patient advocacy were commonly discussed in coursework throughout the length of the program. One PA said:

This was routinely stressed in my PA education. Ethical and altruistic behavior was a thread in almost every class and was demonstrated by my faculty. In addition, we had open discussion and were presented with ethical dilemmas some of which forced the issue of providing unselfish or altruistic behavior (PAS, Q17, R37).

Others reported a bigger emphasis on attitudinal behaviors taken away from their PA training. One PA said, "there was a big focus on the patient always comes first and do no harm" (PAS, Q17, R16). Another PA said, "It taught me compassion and the importance of going above the standard of care to improve patient care" (PAS, Q17, R28). Finally, a third PA noted:

Being an advocate for the patient was highly emphasized within my program. This was highlighted by stories being relayed about cases where stepping in and speaking out for the patient really changed an outcome. We were consistently reminded that we have a responsibility to care for the patient beyond rote medical needs. We were encouraged to think beyond the "diagnosis" sitting in front of us, instead recognizing and addressing the "whole person." This exuded through many lectures, group discussion and case presentations (PAS, Q17, R31). 
Some PAs expressed that their education left them with a very deeply rooted responsibility to the care and needs of their patients even in the midst of a complicated health system or provider conflict. One PA noted:

My training and education instilled in me that, by definition, patient are people in need- they are seeking care. Often they are at a disadvantage when dealing with the healthcare system, they don't know how to navigate it, they don't have the money necessary, and they aren't savvy enough to realize when they are getting poor care from specialists of others. If the situation calls for it, I will act as a liaison between my patients and specialists (PAS, Q17, R4).

Another PA commented on the PA-physician relationship and said, "PA training instilled the importance of always doing what is ultimately best for the patient even if it may cause conflict between the PA and the physician"(PAS, Q17, R43).

Modeling. Preceptor modeling during the clinical year and a team approach to medicine were other ways that PAs felt their training prepared them to be a patient advocate. One PA stated, "I think the best way this is developed is by observance of providers who do these things and decide to model your practice around their styles" (PAS, Q17, R20). Another PA who stated, "Observing my professors and other PAs in the profession taught me how to be a patient advocate, corroborated this. Understanding the role of a PA is vital to becoming an advocate for your patients" (PAS, Q17, R31). Finally, one PA recalled a specific example of patient advocacy that she has never forgot. She stated:

I watched Dr. ... call an insurance company, chewed out whomever was on the other end of the phone, demanded to speak to the physician who was in charge of 
reviewing claims, waited 30 minutes on the phone for said physician, just to ensure insurance payment for a patient and her unborn child. It was inspiring (PAS, Q17, R36).

Regarding a team approach to healthcare, two PAs noted that advocating for your patients included recognizing them as a member of the healthcare team. One PA said he was, "taught to consider the encounter with a patient to be a team-approach along with the patient" (PAS, Q17, R44). Another PA who stated, "team model of healthcare teaches you that the patient is part of the team as well" (PAS, Q17, R40), supported this.

Serving the underserved. A few PAs believed that it was their experiences in caring for the underserved and minority populations as well as those with alternative lifestyles during their PA training that led them to advocate for patients. One PA stated:

Training took place in a large city that served underprivileged and populations with lifestyles that were discriminated against. This helped me see the struggles and limitations these populations have and helped me to develop compassion. I also learned from my training, by exposing me to different lifestyles and cultures to treat people equally and how to approach difficult or embarrassing conversations (PAS, Q17, R8).

Similarly, another PA said:

The Stanford PA program students work in an underserved area. Patients were usually not English speaking. A majority of patients were homeless and not legal citizens that had neglected their medical care. It was a humbling experience with an opportunity to change a person's life (PAS, Q17, R32). 
The exposure to different cultures was also beneficial for another PA who noted, "By working with a variety of patient cultures and socioeconomic backgrounds during training, it has allowed me to be more open and comfortable with a variety of patients in practice" (PAS, Q17, R12).

Eight individuals said that their PA training did not provide them with how to be a patient advocate. Four of these individuals voiced that their ability to be a patient advocate relates to their own personality and compassion for others. One PA stated, "My training did nothing. My compassion as a human and love for my job makes me a patient advocate" (PAS, Q17, R1). Similarly, another PA noted, "This is very related to personality and many who enter the medical field already have this" (PAS, Q17, R3) and yet another said, "I am not sure my PA training made me treat patients differently. I honestly believe caring and leadership shine through based on natural personality" (PAS, Q17, R17). Finally, one PA felt her drive to advocate for others came from her spirituality, "I don't necessarily feel that PA school gave me much real training in this regard. This comes out of my world view, and my desire to be an example of Christ's love to those in my world" (PAS, Q17, R42). Two respondents were passionate in their disagreement and cautioned that too much altruism can lead to burnout and selfdestruction. One of these individuals stated:

Altruism may be self-destructive... I have definitely been "too available" to help patients, and while my patients were better off, I just got burned out. It took years to find the balance of what I could do for my patients and still maintain my own physical and mental health. I've witnessed too many of my colleagues... become very hardened to their patients' needs and long ago turned to what I call 'survival 
mode'- no longer being the temporary heroes willing to stay late yet one more day or some such crazy habitual behavior that either threatened to, or actually did, destroy their marriages and/or personal life (PAS, Q17, R2).

Similarly, the second respondent stated:

I also disagree strongly with an ethic that requires health care providers to put the needs of others ahead of themselves as a global thing. We MUST care for our own health and well-being first, or eventually we will be no good to our patients. Glorifying placing one's own self-care last result(s) in burnout and in less effective providers also it means we are modeling a behavior we are telling our patients is unhealthy... self-care is not selfish, but a necessary component of true altruism (PAS, Q17, R21).

Engaged professional: quantitative findings. Participants rated their level of agreement with eight statements that explored how active he or she was within their professional organizations, PA politics, or health policy (Table 5). The greatest level of combined agreement with active engagement was with participant's state PA organization (66.3\%) and the national PA organization (62.6\%). Next in line was the combined agreement of active engagement in the local PA organization (55.4\%) and clinic board/committee $(52.1 \%)$. The remainder of the categories showed less than $50 \%$ of active engagement reported by respondents. 
Table 5

Prevalence of Practicing PAs Actively Engaged Within Their Profession

\begin{tabular}{|c|c|c|c|c|c|c|}
\hline Item & $\begin{array}{l}\text { Strongly } \\
\text { Disagree }\end{array}$ & Disagree & $\begin{array}{c}\text { Somewhat } \\
\text { Disagree }\end{array}$ & $\begin{array}{c}\text { Somewhat } \\
\text { Agree }\end{array}$ & Agree & $\begin{array}{c}\text { Strongly } \\
\text { Agree }\end{array}$ \\
\hline $\begin{array}{l}\text { Local PA } \\
\text { organization }\end{array}$ & $4.0 \%$ & $29.7 \%$ & $10.8 \%$ & $23.0 \%$ & $10.8 \%$ & $21.6 \%$ \\
\hline $\begin{array}{l}\text { Clinic } \\
\text { board/committee }\end{array}$ & $16.9 \%$ & $23.9 \%$ & $7.0 \%$ & $12.7 \%$ & $18.3 \%$ & $21.1 \%$ \\
\hline $\begin{array}{l}\text { State PA } \\
\text { organization }\end{array}$ & $4.0 \%$ & $20.3 \%$ & $9.5 \%$ & $31.1 \%$ & $14.9 \%$ & $20.3 \%$ \\
\hline $\begin{array}{l}\text { Hospital board/ } \\
\text { committee }\end{array}$ & $20.6 \%$ & $21.9 \%$ & $9.6 \%$ & $17.8 \%$ & $12.3 \%$ & $17.8 \%$ \\
\hline $\begin{array}{l}\text { National PA } \\
\text { organization }\end{array}$ & $9.3 \%$ & $18.7 \%$ & $9.3 \%$ & $28.0 \%$ & $17.3 \%$ & $17.3 \%$ \\
\hline $\begin{array}{l}\text { Specialty PA } \\
\text { organization }\end{array}$ & $19.2 \%$ & $26.0 \%$ & $6.9 \%$ & $26.0 \%$ & $5.5 \%$ & $16.4 \%$ \\
\hline $\begin{array}{l}\text { Political activism } \\
\text { for the PA } \\
\text { profession }\end{array}$ & $15.1 \%$ & $24.7 \%$ & $12.3 \%$ & $27.4 \%$ & $9.6 \%$ & $11.0 \%$ \\
\hline $\begin{array}{l}\text { Political } \\
\text { involvement in } \\
\text { health policy }\end{array}$ & $16.2 \%$ & $27.0 \%$ & $21.6 \%$ & $14.9 \%$ & $9.5 \%$ & $10.8 \%$ \\
\hline
\end{tabular}

Further exploration pursued the level of engagement of organizational members (Table 6). This determined if participants sought positions requiring more responsibility within the organizations. In all categories, membership alone was the most prevalent. However, 19 individuals reported serving in an officer role and 34 reported serving on a committee. Of those who served as officers, the largest number (7) served on a state 
APA chapter. Of those who served on committees, the state APA organization had the most volunteers (11) followed by the AAPA with eight.

Table 6

Prevalence of Level of Participant Involvement in Organizations

\begin{tabular}{lccc}
\hline Item & Member & Officer & $\begin{array}{c}\text { Committee } \\
\text { Member }\end{array}$ \\
\hline $\begin{array}{l}\text { American Academy of } \\
\text { Physician Assistants }\end{array}$ & 57 & 0 & 8 \\
State PA organization & 49 & 1 & 11 \\
Local PA organization & 44 & 5 & 4 \\
$\begin{array}{l}\text { National AAPA } \\
\text { Specialty Organization }\end{array}$ & 21 & & 4 \\
$\begin{array}{l}\text { Other organizations; } \\
\text { please specify below }\end{array}$ & 9 & 5 & 6 \\
$\begin{array}{l}\text { State AAPA Specialty } \\
\text { Organization }\end{array}$ & 8 & 1 & 0 \\
$\begin{array}{l}\text { Physician Assistant } \\
\text { Education Association }\end{array}$ & 6 & 0 & \\
\hline
\end{tabular}

Further exploration reported the depth of involvement PAs have had within their clinical and hospital settings within the last five years. Forty-four PAs reported being involved on some sort of committee in the past five years. Of the 44 PAs, 17 reported being members of a patient improvement committee, 10 on compliance committee and 9 PAs on the safety committee. The clinical executive committee followed with seven members. Infection control, conference planning committee and medical executive committee yielded six members and the risk management and ethics committees with five members each. The other category when further specified revealed three members of a 
pharmacy and therapeutics committee, credentialing, and electronic health record committee. Two participants reported being on a surgical executive committee and leadership committee.

Engaged professional: qualitative findings. PA participants addressed two statements with regard to being an engaged professional. The first asked them to describe any leadership roles they held because of their participation on clinic or hospital based committees. While the second asked them to describe ways, in which their PA training prepared them to be an engaged professional.

There were 24 responses to the question addressing leadership roles held because of participation on clinic or hospital based committees. Of the 24 respondents, seven stated that they had not had leadership roles on clinic or hospital based committees. One PA stated, "None. Here, only physicians can lead the committees" (PAS, Q49, R8). Of the remainder of the responses, only one theme emerged. Four respondents reported leadership as APP (advanced practice provider). This was described as lead APP (2), assistant director of advance practice (1), and advanced practice clinician task force (1). The remainder of the answers were scattered and showed no particular alignment.

The second question asked PA respondents to describe ways in which their PA training prepared them to be an engaged professional. There were 28 total responses to this question. Of the 28 responses, 14 reported that their training prepared them to be engaged professionals, whereas, 10 respondents did not feel they had been prepared to be an engaged professional through their PA training. Of those who reported their training had prepared them, ten felt this was due to involvement in and exposure to state and national organizations while they were a student. One respondent said, "My PA program 
encouraged involvement in MOAPA \& AAPA as student members. We were invited to the monthly regional MOAPA meetings, and were active participants. I also served as our program MOAPA student representative" (PAS, Q22, R5). Another PA stated, "My program exposed the students to regional and state PA organizations. While brief, they did discuss the importance of these organizations and how different levels of involvement are still very beneficial" (PAS, Q22, R17). One PA reported both a willingness to be involved and modeling by professors stimulated his interest. He noted:

I entered PA school planning on being involved. The school gave me the opportunity to get involved with the AAPA through the AOR/HOD, and I enjoyed it. Several of our professors were also active in the state chapter and encouraged my interest in it (PAS, Q22, R19).

Ten respondents did not feel their PA training prepared them to be an engaged professional. While some simply stated that they were not prepared, others provided a little deeper insight. One PA said:

I do not feel my training stressed the need for professional support and I served the first 4 years of my career outside a hospital (private practice) so I don't feel "political" or committee involvement is as realistic for PAs practicing outside of a hospital (PAS, Q22, R15).

Another PA simply felt that his involvement was due more to his own ambition rather than PA training preparation. He noted:

I think I developed this after graduating and practicing. I became someone who decided I could/should no longer just sit on the sideline and comment or complain 
about things and I should get involved if I thought change was needed. But not sure I developed that while in my PA training (PAS, Q22, R25).

Builders of future professionals: quantitative findings. Participants rated their level of agreement with how actively involved they were in building future PA professionals during their didactic and clinical years (Table 7). With all categories of agreement added together $62.8 \%$ of participants stated that they serve to build future professionals while in their didactic year, while $77.1 \%$ of participants stated that they serve to build future professionals while in their clinical year. Further delineation of how practicing PAs are involved in PA education revealed that 44 PAs reported serving as preceptors for clinical rotations and 19 served as guest lecturers. Other ways in which PAs reported being involved in PA education included adjunct faculty (6), small group facilitator (5), advisory board member (5), allow students to shadow (5), and lab instructor (4).

In order to establish a better sense of the level of commitment practicing PAs demonstrate in the building of future professionals, PAs estimated how many hours of time they spend educating students over the course of their didactic year. The greatest percentage of PAs (46.3\%) reported that they spent less than five hours and 24.4\% PAs reported giving between 6-15 hours of time to educate future professionals. This was followed by $17.1 \%$ of individuals who reported spending more than 45 hours a year educating future PAs and 7.3\% who reported giving between 26-35 hours of time. Only one respondent (2.44\%) reported giving between 16-25 hours of time and 36-45 hours of time. 
A similar question asked PAs how many weeks of time they spend precepting students over the course of their clinical year. Of the 60 respondents, $71.7 \%$ reported 10 weeks or less. An additional $21.7 \%$ reported giving 11-20 weeks of time. The remaining 6.7\% was divided between 21-30 weeks (1.7\%), 31-40 weeks (1.7\%) and 41-50 weeks $(3.3 \%)$.

Table 7

Prevalence of Agreement of Practicing PAs Who Serve to Build Future Professionals

\begin{tabular}{|c|c|c|c|c|c|c|}
\hline Item & $\begin{array}{l}\text { Strongly } \\
\text { Disagree }\end{array}$ & Disagree & $\begin{array}{c}\text { Somewhat } \\
\text { Disagree }\end{array}$ & $\begin{array}{c}\text { Somewhat } \\
\text { Agree }\end{array}$ & Agree & $\begin{array}{c}\text { Strongly } \\
\text { Agree }\end{array}$ \\
\hline Clinical Training & $4.3 \%$ & $18.6 \%$ & $0.0 \%$ & $27.1 \%$ & $25.7 \%$ & $24.3 \%$ \\
\hline Didactic Training & $14.3 \%$ & $18.6 \%$ & $4.3 \%$ & $17.1 \%$ & $25.7 \%$ & $20.0 \%$ \\
\hline
\end{tabular}

Builders of future professionals: qualitative findings. Participants described how their PA training prepared them to be builders of future professionals. Of the 35 qualitative responses, two main themes emerged. The two themes included: (a) giving back (26) and (b) no preparation (7).

Giving back. The vast majority of responses noted evidence of giving back. Some PAs reported that the concept of giving back was stressed within their PA programs and modeled by their preceptors. One PA said:

It was stressed in my PA education that we are standing on the shoulders of educators, both principle faculty and guest lecturers that were once students and that we should consider giving back to the profession in this way after we graduated (PAS, Q29, R31). 
Similarly, another PA stated, "My PA training instilled the importance of being a mentor and giving back to the profession" (PAS, Q29, R32). This was corroborated by another PA who said, "By receiving my training at the hands of those who volunteered to train me, I learned how important it is to 'return the favor' to those following me" (PAS, Q29, R34). This was further supported by another PA who noted, "having PAs precept me throughout my schooling instilled a need to give back" (PAS, Q29, R33).

One PA described how her experience as a student inspired her to not just give back, but to provide an excellent experience, "I was frustrated by poor instruction and inspired by excellent instruction, and I decided that, once I was able to teach, I would take the opportunity to try to be in the 'excellent' category" (PAS, Q29, R13). Another PA took his support a step further and commented on the type of help he provides for others. He stated, "recognizing where I needed help as a student and whether I did, or did not get it, and then trying to offer that help to PA students and future PA students" (PAS Q29, R30).

With respect to those who trained them, one PA said:

I had many exceptional didactic instructors and clinical preceptors who inspired me by their knowledge, empathy, and enthusiasm of providing care to patients. I believe that future PAs deserve the same, and I am committed to providing the same service (PAS, Q29, R9).

Another PA who supported this comment, noted:

Having solid, engaged PA professionals educate me during my training helped me to understand the importance of the educator role. More than anything I learned to appreciate the necessity of professionals as educators. In this type of work so 
much learning happens on the job, so it is invaluable to have people willing to slow their practice to accommodate educating new providers (PAS, Q29, R26).

Giving back not only helps the profession, but can also provide benefit to the PA. One PA noted, "I appreciated the preceptors that gave their time for me, I enjoy sharing what I know with others" (PAS, Q29, R23). Another PA who stated, "It allows you to set an example for future PAs" (PAS, Q29, R19), supported this. Another PA commented on how being a preceptor helps healthcare providers stay current in the medical literature, and wrote:

Routinely, the preceptors talked about the benefits of their role. These were outlined to include, personal/professional satisfaction, as well as forcing the preceptor to maintain at a higher level of competency for the students, thus providing a higher level of care to the patients (PAS, Q29, R21).

No preparation. Although there was a lot of evidence of PA training supporting the building of future professionals, five respondents stated that they had not been prepared by their PA training. One said:

It is my nature to teach and help others learn to properly use their knowledge in the treatment of patients. It is my love for medicine that spurs me to teach others what knowledge I have gained through my specialty. My training had nothing to do with it (PAS, Q29, R1).

Another PA said, "Nothing specific in my training was designed to prepare me for this" (PAS, Q29, R3). Additionally, two respondents reported that they were self-taught. One PA said: 
My training only prepared me to be a subject matter expert. I had health care teaching and mentoring experience prior to PA school, and I had fabulous mentors in in my clinical preceptors who helped me see how to be an effective preceptor myself. I have also taught didactically to PA students and to my peers, although not for many years- again, that was self-taught and a skill I had developed prior to PA training (PAS, Q29, R16).

Community activist: quantitative findings. Participants were asked to rate their level of involvement with fourteen items that represented activities a healthcare provider may participate in as an activist of health within their communities. Some of the items were attitudinal in nature while others were representative of activities one may perform. When adding all three columns of agreement together, greater than $85 \%$ of participants reported that they considered themselves to be PAs who demonstrate a strong sense of community, promote healthcare in the community, and believe in serving the greater good (Table 8). 
Table 8

Prevalence of Agreement of Practicing PAs Who Are Community Activists- High Levels of Agreement

\begin{tabular}{lcccccc}
\hline Item & $\begin{array}{c}\text { Strongly } \\
\text { Disagree }\end{array}$ & Disagree & $\begin{array}{c}\text { Somewhat } \\
\text { Disagree }\end{array}$ & $\begin{array}{c}\text { Somewhat } \\
\text { Agree }\end{array}$ & $\begin{array}{c}\text { Agree } \\
\text { Strongly } \\
\text { Agree }\end{array}$ \\
\hline $\begin{array}{l}\text { Believes in } \\
\text { serving the greater } \\
\text { good }\end{array}$ & $0.0 \%$ & $1.5 \%$ & $0.0 \%$ & $15.2 \%$ & $36.4 \%$ & $47.0 \%$ \\
$\begin{array}{l}\text { Demonstrates a } \\
\text { strong sense of } \\
\text { community }\end{array}$ & $1.5 \%$ & $1.5 \%$ & $1.5 \%$ & $22.1 \%$ & $47.1 \%$ & $26.5 \%$ \\
$\begin{array}{l}\text { Promotes } \\
\text { healthcare in the } \\
\text { community }\end{array}$ & $1.5 \%$ & $5.9 \%$ & $2.9 \%$ & $30.9 \%$ & $33.8 \%$ & $25.0 \%$ \\
\hline
\end{tabular}

This was in contrast to the remaining ten categories, which weighted heavily on the side of disagreement (Table 9). Specifically, 95.5\% of participants showed some level of disagreement with the idea of writing health columns for the local newspaper. Additionally, greater than $65 \%$ of participants showed some level of disagreement with each of the following: (a) providing health education at local schools (75.5\%), (b) serving on a planning committee or organized a community health event $(72.7 \%)$, (c) volunteers at a community healthcare clinic for the underserved $(80.3 \%)$, (d) participates in global medical missions $(73.1 \%)$, (e) collaborates with community organizations to meet healthcare needs in the community $(67.7 \%)$, and (f) provides lectures or other education to community health groups $(67.7 \%)$. 
Table 9

Prevalence of Agreement of Practicing PAs Who Are Community Activists- Low Levels of Agreement

\begin{tabular}{|c|c|c|c|c|c|c|}
\hline Item & $\begin{array}{l}\text { Strongly } \\
\text { Disagree }\end{array}$ & Disagree & $\begin{array}{l}\text { Somewhat } \\
\text { Disagree }\end{array}$ & $\begin{array}{l}\text { Somewhat } \\
\text { Agree }\end{array}$ & Agree & $\begin{array}{c}\text { Strongly } \\
\text { Agree }\end{array}$ \\
\hline $\begin{array}{l}\text { Participates in global } \\
\text { medical missions }\end{array}$ & $31.3 \%$ & $38.8 \%$ & $3.0 \%$ & $7.5 \%$ & $9.0 \%$ & $10.5 \%$ \\
\hline $\begin{array}{l}\text { Participates in community } \\
\text { health screenings }\end{array}$ & $26.9 \%$ & $26.9 \%$ & $7.5 \%$ & $20.9 \%$ & $7.5 \%$ & $10.5 \%$ \\
\hline $\begin{array}{l}\text { Has served on a planning } \\
\text { committee or organized a } \\
\text { community healthcare } \\
\text { event }\end{array}$ & $28.8 \%$ & $33.3 \%$ & $10.6 \%$ & $12.1 \%$ & $6.1 \%$ & $9.1 \%$ \\
\hline $\begin{array}{l}\text { Volunteers at a } \\
\text { community healthcare } \\
\text { clinic for the underserved }\end{array}$ & $31.8 \%$ & $45.5 \%$ & $3.0 \%$ & $10.6 \%$ & $0.0 \%$ & $9.1 \%$ \\
\hline $\begin{array}{l}\text { Participates in community } \\
\text { health fairs }\end{array}$ & $11.8 \%$ & $29.4 \%$ & $10.3 \%$ & $19.1 \%$ & $20.6 \%$ & $8.8 \%$ \\
\hline $\begin{array}{l}\text { Participates in community } \\
\text { wellness initiatives }\end{array}$ & $25.0 \%$ & $25.0 \%$ & $8.8 \%$ & $22.1 \%$ & $10.3 \%$ & $8.8 \%$ \\
\hline $\begin{array}{l}\text { Collaborates with } \\
\text { community organizations } \\
\text { to meet healthcare needs } \\
\text { in the community }\end{array}$ & $26.5 \%$ & $33.8 \%$ & $7.4 \%$ & $11.8 \%$ & $13.2 \%$ & $7.4 \%$ \\
\hline $\begin{array}{l}\text { Provides health education } \\
\text { at local schools }\end{array}$ & $33.9 \%$ & $33.9 \%$ & $7.7 \%$ & $9.2 \%$ & $9.2 \%$ & $6.2 \%$ \\
\hline $\begin{array}{l}\text { Provides health education } \\
\text { to community groups }\end{array}$ & $25.0 \%$ & $26.5 \%$ & $7.4 \%$ & $22.1 \%$ & $13.2 \%$ & $5.9 \%$ \\
\hline $\begin{array}{l}\text { Provides lectures or other } \\
\text { education to community } \\
\text { health groups }\end{array}$ & $30.9 \%$ & $29.4 \%$ & $7.4 \%$ & $16.2 \%$ & $10.3 \%$ & $5.9 \%$ \\
\hline $\begin{array}{l}\text { Writes health columns for } \\
\text { the local newspaper }\end{array}$ & $40.9 \%$ & $48.5 \%$ & $6.1 \%$ & $1.5 \%$ & $1.5 \%$ & $1.5 \%$ \\
\hline
\end{tabular}

Community activist: qualitative findings. Participants described how their PA training prepared them to be a community activist. Twenty-two participants provided a qualitative response. Of these 22 respondents, 12 reported that they did not feel that their 
PA training prepared them to be a community activist as described in this study. Of those respondents who did feel that their PA training prepared them to be community activists, recognizable themes aligned within the realm of volunteerism and example of professional value and passion modeled by the program faculty and other PAs.

No preparation. Many of the answers from respondents who did not feel that they were prepared were simple responses such as, "Did not prepare me" (PAS, Q33, R20) and "I don't think it did very well" (PAS, Q33, R10). Others reported that if they had only been aware of opportunities they may have pursued them, "I wasn't prepared for this. If I had known about people to contact to help with community, I would have done more of this" (PAS, Q33, R7). Others expressed a lack of interest for seeking volunteer opportunities, "I have a family and I spend my time with them. I do not have time for activism, committees, or boards" (PAS, Q33, R1). Another PA added, "I do not feel my training highlighted this. I have been involved when asked but I have not intentionally sought out areas to volunteer with community health" (PAS, Q33, R13).

Volunteerism. Overall, ten respondents reported that their PA training prepared them in some way to be community activist. Volunteerism, especially with community health clinics seems to be a recognizable way in which PA programs promote community activism. One student replied, "(we had) mandatory volunteer time in local clinic during PA school" (PAS, Q33, R21). Another PA supported this claim and stated:

My PA program continues to be active within the community, creating service clinics and working with the underserved population. This uncompromising initiative plants a seed for all students that community activism is important (PAS, Q33, R19). 
In general, one PA viewed volunteerism as the expectation, "I was simply expected to do whatever was needed to contribute, e.g., volunteerism" (PAS, Q33, R2).

Professional Value. Other PAs felt that they were prepared for the role of a community activist due to program emphasis and passion modeled by the program faculty and other PAs. One PA stated, "Whether my training prepared me, or this is a quality of mine that was inherent before PA school (I suspect the latter), my PA program certainly promoted it as a professional value" (PAS, Q33, R3). Another PA stated he was prepared by watching others getting involved in things they were passionate about, "Informally by being involved in their passions. Some involved in writing for newspapers and articles. Some involved in missionary work. Others ride for MS. Some volunteer at health fairs.” (PAS, Q33, R5).

Team collaborator: quantitative findings. Participants rated their level of agreement with the following statement, "I would consider myself a physician assistant who works effectively within a healthcare team to deliver the best patient care possible (may include direct patient care or as initiatives and policy which affect systems based healthcare delivery)." All respondents agreed with this statement on some level with $63.1 \%$ strongly agreeing, $32.3 \%$ agreeing, and $4.6 \%$ somewhat agreeing. Similarly, PAs reported $100 \%$ agreement when asked to rate their level of agreement with statements regarding how they would consider themselves as a PA who collaborates, openly communicates, and builds trusting relationships with healthcare providers. Additionally, they reported $100 \%$ agreement regarding their beliefs about the importance of aligned goals within the healthcare team (table 10). The greatest level of agreement was found in 
the strongly agree category for each of the four statements regarding PA beliefs about patient care requirements.

Table 10

Prevalence of Agreement of Practicing PAs-Patient Care Requirements

\begin{tabular}{lcccccc}
\hline Item & $\begin{array}{c}\text { Strongly } \\
\text { Disagree }\end{array}$ & Disagree & $\begin{array}{c}\text { Somewhat } \\
\text { Disagree }\end{array}$ & $\begin{array}{c}\text { Somewhat } \\
\text { Agree }\end{array}$ & $\begin{array}{c}\text { Agree } \\
\text { Agree }\end{array}$ & $\begin{array}{c}\text { Strongly } \\
\text { Agree }\end{array}$ \\
$\begin{array}{l}\text { Collaboration } \\
\text { among healthcare } \\
\text { personnel }\end{array}$ & $0.0 \%$ & $0.0 \%$ & $0.0 \%$ & $0.0 \%$ & $14.7 \%$ & $85.3 \%$ \\
$\begin{array}{l}\text { Open } \\
\text { communication } \\
\text { among healthcare }\end{array}$ & $0.0 \%$ & $0.0 \%$ & $0.0 \%$ & $1.5 \%$ & $17.7 \%$ & $80.9 \%$ \\
personnel & & & & & & \\
$\begin{array}{l}\text { Trusting } \\
\text { relationships among } \\
\text { healthcare personnel }\end{array}$ & $0.0 \%$ & $0.0 \%$ & $0.0 \%$ & $0.0 \%$ & $20.6 \%$ & $79.4 \%$ \\
$\begin{array}{l}\text { Alignment of goals } \\
\text { among healthcare } \\
\text { personnel }\end{array}$ & $0.0 \%$ & $0.0 \%$ & $0.0 \%$ & $4.4 \%$ & $25.0 \%$ & $70.6 \%$ \\
\hline
\end{tabular}

Practicing PAs reported how often they communicate with others within healthcare in order to care for patients (Table 11). Greater than $70 \%$ of PAs reported daily communication with a clinical nurse or medical assistant and their supervising physician. This was followed by greater than $70 \%$ of PAs reporting daily or weekly communications with a consulting physician and greater than $60 \%$ of PAs who reported daily or weekly communications with other PAs and hospital nurses. Advanced practice nurses were communicated with on a daily to weekly basis $59.1 \%$ of the time.

Communication with therapists, home health care nurses and nursing staff at skilled care facilities occurred never to monthly. The greatest prevalence occurred in the never 
category with respect to communication with hospice nurses, surgical technologists,

nurse anesthetist, and social workers.

Table 11

Frequency with Which Practicing PAs Communicate With Others to Care for Patients

\begin{tabular}{|c|c|c|c|c|}
\hline Item & Never & Monthly & Weekly & Daily \\
\hline $\begin{array}{l}\text { Clinical nurse or } \\
\text { medical assistant }\end{array}$ & $3.0 \%$ & $9.1 \%$ & $3.0 \%$ & $84.9 \%$ \\
\hline $\begin{array}{l}\text { Supervising } \\
\text { physician }\end{array}$ & $0.0 \%$ & $7.6 \%$ & $18.2 \%$ & $74.2 \%$ \\
\hline Hospital nurse & $24.6 \%$ & $9.2 \%$ & $9.2 \%$ & $56.9 \%$ \\
\hline Physician assistant & $4.6 \%$ & $25.8 \%$ & $27.3 \%$ & $42.4 \%$ \\
\hline $\begin{array}{l}\text { Consulting } \\
\text { physician }\end{array}$ & $1.6 \%$ & $15.6 \%$ & $43.8 \%$ & $39.1 \%$ \\
\hline $\begin{array}{l}\text { Advance practice } \\
\text { nurse }\end{array}$ & $12.1 \%$ & $28.8 \%$ & $31.8 \%$ & $27.3 \%$ \\
\hline $\begin{array}{l}\text { Surgical } \\
\text { technologist }\end{array}$ & $58.5 \%$ & $7.7 \%$ & $13.9 \%$ & $20.0 \%$ \\
\hline Social worker & $27.3 \%$ & $24.2 \%$ & $28.8 \%$ & $19.7 \%$ \\
\hline Nurse anesthetist & $59.1 \%$ & $4.6 \%$ & $18.2 \%$ & $18.2 \%$ \\
\hline Therapist & $22.7 \%$ & $33.3 \%$ & $28.8 \%$ & $15.2 \%$ \\
\hline $\begin{array}{l}\text { Home health care } \\
\text { nurse }\end{array}$ & $44.6 \%$ & $41.5 \%$ & $12.3 \%$ & $1.5 \%$ \\
\hline Hospice nurse & $69.2 \%$ & $41.5 \%$ & $12.3 \%$ & $1.5 \%$ \\
\hline $\begin{array}{l}\text { Nursing staff at } \\
\text { skilled care facility }\end{array}$ & $49.2 \%$ & $40.0 \%$ & $10.8 \%$ & $0.0 \%$ \\
\hline
\end{tabular}


PA participants listed ways communication regarding patients, occurred with medical associates. Sixty-one participants responded to this question, with all but five providing multiple answers as to modes of communication. Fifty reported communication via phone, followed by 43 who reported in-person communication and 33 who reported email. This was followed by 19 who noted team meetings, 11 who reported EMR and instant messaging, and 7 who reported texting. Finally, two reported faxing as a mode of communication and rounds, letter, paging, and chart notes were each noted once (PAS, Q41).

Team collaborator: qualitative findings. PA participants were asked if their training prepared them to work effectively within a healthcare team to deliver the best patient care possible through alignment of goals and trusting relationships based on open and honest communication. Thirty-eight PAs responded to this question. Of the 38 respondents, 18 reported that their clinical training helped to prepare them to work in a healthcare team, 11 said that the didactic year prepared them for this role in healthcare and eight reported that this type of work is inherently part of the profession. Five individuals did not feel that their training prepared them to work in a healthcare team.

Clinical training. PAs reported that training throughout the clinical year proved to be beneficial in teaching a team approach to patient care and medicine. Collaboration among healthcare providers, communication, and patient liaison stood out as recurring themes. With respect to collaboration, one PA said, "Clinical rotations taught me the value of collaboration for all involved and the frustration of non-collaboration" (PAS, Q42, R16). Another PA noted, "I learned the roles of other healthcare providers and the importance of collaboration with them in patient care" (PAS, Q42, R38). Similarly, 
another PA stated, "I guess the clinical year is what prepared me for this aspect of it (working in a healthcare team). Watching how my preceptors interacted with other members of their team" (PAS, Q42, R15). One PA noted that she learned as a student how collaboration could improve patient care, she stated:

Interaction with those in the hospital, clinic and outpatient settings, surgical techs, social workers, nurses, PAs, NPs, and medical assistants, who might not have been a preceptor, but took the time to educate, inform and instruct. That positive interaction formed a touchstone on which I grew to respect the skills, talents and wisdom of people that might not necessarily share my profession, but could positively affect my profession, and could really make my patient care better if I collaborated with them (PAS, Q42, R33).

The art of communication was identified as an important concept to aid collaborative work in a healthcare team. One PA stated, "It (PA training) teaches the importance of working in groups and the importance of communication" (PAS, Q42, R22). The importance of communication with all members of the team was also an important lesson learned in training. One PA noted, "Being a PA student taught me how to be comfortable speaking with all parts of the healthcare team, from the front desk worker all the way up to the doc" (PAS, Q42, R30).

Serving as a liaison between the healthcare team or supervising physician and the patient also seemed to be something PAs took away from their PA training. One PA said, "This (work in a healthcare team) begins during the clinical year. Learning how to be a liaison between the patient and your supervising physician is the first lesson. And it 
continues to build from there" (PAS, Q42, R35). This was supported by another PA who stated:

We are trained to be patient educators, liaisons, and advocates. Our didactic year provides us with the knowledge base, and our clinical year provides us with the opportunity to learn to communicate that knowledge to patients, and our treatment team (PAS, Q42, R9).

Didactic training. Although slightly more PAs recognized the clinical year as the part of their training which best prepared them for working in a healthcare team, some participants identified the didactic year alone or in combination with the clinical year as the right mix of tutelage. For some, preparation in the didactic year of education for working within a healthcare team served as the foundation of teamwork training. One PA stated, "In the didactic year... we would have mock presentations to the supervising physician or consulting physician. At times, these would include interactions with nursing staff or fellow PAs" (PAS, Q42, R24). Another PA said, "During small group learning activities in PA school I learned how to bounce ideas off of each other to formulate a plan for patients" (PAS, Q42, R6).

Specific training in interdisciplinary education was also a key component to working in a healthcare team. One PA reported, "Interdisciplinary education in the form of awareness in the didactic year and more directly in the clinical year (prepared him to be a team collaborator)" (PAS, Q42, R34). Similarly, another PA noted that his "PA program offered classes on interdisciplinary training” (PAS, Q42, R11).

The marriage between didactic and clinical training present in medical education was also identified as preparation for team collaboration. One PA simply stated, "(The) 
team approach was instilled throughout training" (PAS, Q42, R36). Another PA noted that there was, "some discussion in class, but more through observation during clinical rotations" (PAS, Q42, R26). Similarly, another PA said, “The training was all teambased" (PAS, Q42, R19).

Inherent to the profession. Some PAs reported that the team approach to medicine defines the PA profession. From this perspective, working within a team whether that be the physician-PA team or expanding that team to include more healthcare workers, was just about what PAs do; it is inherent to the profession. One PA said, "It was inherent in my training, i.e., the PA-Physician Team concept” (PAS, Q42, R2). Another PA stated, "We were taught that team collaboration was the basis for our profession" (PAS, Q42, R5). Yet another PA who stated, "I think this is the hallmark of being a PA and our training is focused on working in correlation with other providers" (PAS, Q42, R21), supported this.

Summary of research question one. Research question one explored the six conceptual underpinnings of the medical leader both quantitatively and qualitatively with practicing PAs. Quantitative data reported the prevalence of each of the conceptual underpinnings. Qualitative data supported themes for each of the conceptual underpinnings (Table 12).

The quantitative findings of the learning leader showed that nearly all of the PAs surveyed agreed that they would consider themselves a PA who participates in learning for both personal and professional growth. Continuing medical education and medical conference attendance were the two top ways in which PAs learn both personally and professionally. PA participant answers reflected a resounding level of agreement to 
importance of life-long learning. With respect to life-long learning, three main themes emerged from the qualitative findings regarding the learning leader. These themes included: (a) curricular preparations, (b) professional expectations, and (c) self-teaching.

The quantitative findings of the patient advocate showed that of the 21 statements describing the patient advocate 19 of them showed a high level of agreement, supporting the concept of the patient advocate. The qualitative results for the patient advocate revealed themes from 38 PA responses with respect to additional ways in which they advocate for patients or "go above and beyond" over the course of a typical month and included: (a) giving of time (b) giving of financial resources, (c) patient convenience/comfort/safety, and (d) taking care of challenging patients. Second, respondents reported on whether or not their PA training helped prepare them to be a patient advocate. Thirty respondents said that their PA training did provide some instruction on how to be a patient advocate. Recurring themes centered on: (a) PA skill development, (b) modeling, and (c) serving the underserved.

The quantitative findings reflecting the engaged professional revealed that the greatest level of active engagement was with participant's state PA organization followed by the national PA organization. Membership alone within these organizations showed the greatest level of involvement, however, 19 individuals reported serving in an officer role and 34 reported serving on a committee. Additionally, 44 PAs reported being involved on some sort of committee in the past five years within their clinical and hospital settings. A qualitative question regarding leadership roles on clinic and hospital based committees showed that most PAs did not hold leadership roles on these committees. Of the 28 qualitative responses regarding engaged professional training, 14 
reported their training prepared them to be engaged professionals, whereas, 10 respondents did not feel they had been prepared. Of those who reported their training had prepared them, most credited the preparation to exposure to state and national organizations.

Quantitative data for builders of future professionals' conceptual underpinning showed that $63 \%$ of PAs assist students during their didactic year, while $77 \%$ participate in the clinical education of PA students. Precepting students and guest lecturing were the two most common ways in which PAs were involved with PA students. Nearly half of the PA respondents reported spending less than 5 hours a year teaching students. Qualitative findings related to the building of future professionals showed that 26 of the 35 responses reported giving back as a main theme while seven participants reported no preparation to being a builder of future professionals.

The quantitative data for the community activists showed the greatest level of agreement, greater than $85 \%$, with PAs who considered themselves to demonstrate a strong sense of community, promote healthcare in the community, and believe in serving the greater good. This was in contrast to the remaining ten categories, weighted heavily on the side of disagreement. The qualitative data revealed that 12 of 22 respondents did not feel that their PA training prepared them to be a community activist as described in this study. Of the remaining 10 respondents, recognizable themes aligned within the realm of volunteerism and professional value.

Quantitative data for the team collaborator showed 100\% agreement by PAs with how they viewed themselves as working effectively within a team for the best patient care, collaboration among healthcare personnel, having open communication and trusting 
relationships with healthcare personnel, and alignment of goals among healthcare personnel. Communication among healthcare personnel was greatest with clinical nurse or medical assistant and supervising physicians. Communication occurred most frequently via phone, in-person communication and email. PAs provided qualitative data to determine whether their PA training prepared them to as a team collaborator. Three themes emerged from this inquiry and included: (a) clinical training, (b) didactic training, and (c) inherent to profession.

All six conceptual underpinnings were explored with both quantitative and qualitative findings. Quantitative data hinted toward the prevalence of the qualifiers within each conceptual underpinning. Qualitative data focused on PA preparation for the leadership roles they face within their practice. 
Table 12

Supported Quantitative Constructs and Emerging Qualitative Themes for the Medical Leader Conceptual Underpinnings- Practicing PA

\begin{tabular}{|c|c|c|}
\hline $\begin{array}{l}\text { Leadership } \\
\text { Conceptual } \\
\text { Underpinnings }\end{array}$ & Supported Quantitative Constructs & Qualitative Themes \\
\hline $\begin{array}{l}\text { Learning } \\
\text { Leader }\end{array}$ & $\begin{array}{l}\text { Professional growth } 100 \% \\
\text { Personal Growth } 97 \%\end{array}$ & $\begin{array}{l}\text { Curricular preparation } \\
\text { Professional expectations } \\
\text { Self-teaching }\end{array}$ \\
\hline $\begin{array}{l}\text { Patient } \\
\text { Advocate }\end{array}$ & $\begin{array}{c}\text { All constructs supported with }>80 \% \\
\text { agreement, except calling insurance } \\
\text { companies on behalf of patient and making } \\
\text { house calls }\end{array}$ & $\begin{array}{c}\text { Giving of Time } \\
\text { Giving of Resources } \\
\text { Patient Convenience/Comfort/Safety } \\
\text { Curricular Preparation } \\
\text { Modeling } \\
\text { Serving the Underserved }\end{array}$ \\
\hline $\begin{array}{l}\text { Engaged } \\
\text { Professional }\end{array}$ & $\begin{array}{l}\text { State and National organizational } \\
\text { involvement most prevalent at }>60 \%\end{array}$ & $\begin{array}{c}\text { Student Exposure to State and National } \\
\text { Organizations }\end{array}$ \\
\hline $\begin{array}{l}\text { Builders of } \\
\text { Future } \\
\text { Professionals }\end{array}$ & $\begin{array}{c}\text { Actively involved in building future } \\
\text { professionals during } \\
\text { Clinical Training } 77.1 \% \\
\text { Didactic Training } 62.8 \%\end{array}$ & $\begin{array}{l}\text { Giving Back } \\
\text { No Preparation }\end{array}$ \\
\hline $\begin{array}{l}\text { Community } \\
\text { Activist }\end{array}$ & $\begin{array}{l}90 \% \text { agreement or more with serving the } \\
\text { greater good, demonstrating a strong sense } \\
\text { of community, and promoting healthcare in } \\
\text { the community; remaining constructs were } \\
\text { not supported }\end{array}$ & $\begin{array}{l}\text { No Preparation } \\
\text { Volunteerism } \\
\text { Professional Value }\end{array}$ \\
\hline $\begin{array}{l}\text { Team } \\
\text { Collaborator }\end{array}$ & $\begin{array}{l}100 \% \text { agreement with all constructs: } \\
\text { collaboration, open communication, trusting } \\
\text { relationships, and alignment of goals }\end{array}$ & $\begin{array}{l}\text { Clinical Training } \\
\text { Didactic Training } \\
\text { Inherent to Profession }\end{array}$ \\
\hline
\end{tabular}

\section{Research Question Two}

In what ways does current curricula prepare physician assistant (PA) students for future leadership roles?

Learning leader: quantitative findings. Physician assistant faculty were asked if students attending the PA program where they worked were being prepared to become learning leaders, both professionally and personally. Of the 30 respondents, $93.4 \%$ 
showed some level of agreement with PA student preparation for professional growth while $89.9 \%$ showed some level of agreement with preparation for personal growth. The greatest level of agreement was in the strongly agree column for professional growth, while the greatest level of agreement for personal growth was tied between the responses somewhat agree and agree (FS, Q24-25).

Table 13

Prevalence of Agreement of PA Faculty Who Believe Students Are Being Prepared to be Learning Leaders

\begin{tabular}{lcccccc}
\hline Item & $\begin{array}{c}\text { Strongly } \\
\text { Disagree }\end{array}$ & Disagree & $\begin{array}{c}\text { Somewhat } \\
\text { Disagree }\end{array}$ & $\begin{array}{c}\text { Somewhat } \\
\text { Agree }\end{array}$ & Agree & $\begin{array}{c}\text { Strongly } \\
\text { Agree }\end{array}$ \\
\hline $\begin{array}{l}\text { Professional } \\
\text { Growth }\end{array}$ & $0.0 \%$ & $0.0 \%$ & $6.7 \%$ & $16.7 \%$ & $36.7 \%$ & $40.0 \%$ \\
Personal Growth & $0.0 \%$ & $10.0 \%$ & $0.0 \%$ & $33.3 \%$ & $33.3 \%$ & $23.3 \%$ \\
& & & & & & \\
\hline
\end{tabular}

Learning leader: qualitative findings. Faculty participants described ways the PA program where they worked prepared students to be learning leaders, defined as someone who looks for opportunities to improve themselves both personally and professionally. There were seventeen PA faculty responses. Of those responses, answers fell among three common themes, (a) internal preparation (6), (b) external preparation (5), and (c) self-preparation (5).

Internal preparation. Internal preparation can be further defined by PA program coursework, which includes academic preparation through lecture and discussion, as well as, more specific professional development. One faculty member said, "the curriculum is student centered" (FS, Q26, R16). Another faculty member stated, "(there were) many 
opportunities to try lecturing, develop activities during didactic training" (FS, Q26, R10). This was supported by another faculty person who stated that it was a combination of many things that prepared students, "academic requirements, discussions about the everchanging health care field, test questions from texts rather than just from PowerPoints, emphasis on quality patient care and what it takes to prioritize that" (FS, Q26, R8). One PA faculty reported how they have an entire series devoted to this type of training, he said, "Our departmental professional development series where they learn the skills necessary to be successful professionals and leaders in their discipline" (FS, Q26, R4). Another respondent stated that:

The PA program includes a novel student support system with regular involvement of the faculty advisors as well as the PA student support staff member. The program includes activities and discussions on transitioning into the program, surviving the program in a healthy fashion and transitioning out of the program into the profession (FS, Q26, R5).

Another faculty member noted:

I think student participation in a graduate professional program by design selects an individual who is interested in developing themselves personally and professionally. We provide instruction, opportunity, and faculty model these behaviors themselves to reinforce this goal. It is one of our mission goals as well (FS, Q26, R7).

Another respondent noted the importance of maintaining curiosity for students to keep them motivated, "A strong emphasis on information literacy and inter-professional 
education permeates the program. They (students) are motivated by projects in different courses to develop and maintain intellectual curiosity” (FS, Q26, R2).

External preparation. Some faculty reported that their students are prepared to be learning leaders through participation in professional and volunteer activities that take part outside of the program. One respondent noted, "We advocate for attendance at local and national conferences (more professional growth than personal)" (FS, Q26, R3). This was supported by another PA faculty person who stated, "They are encouraged to attend CME and other medical conferences, meetings" (FS, Q26, R13). Another faculty member stated, "We encourage our students to apply for PA student fellowships offered by PAEA" (FS, Q26, R12). Additionally, one faculty member noted the importance of volunteering as a way to grow professionally and personally, she said:

Our student society requires service hours and education hours by requiring a number of hours in each area toward graduation requirements. They can complete these hours through participating with the student society for service projects (i.e. Health fairs, $5 \mathrm{~K}$ run and Fair, etc.). They also can participate in the State Student organization and Challenge Bowl and student education opportunities (FS, Q26, R6).

Self-preparation. Five faculty reported that their programs encourage students to be self-learners and work on self-improvement. One respondent said, "(There is a) constant discussion of life-long learning (and) reinforcement of (the) demonstration of this behavior" (FS, Q26, R15). Similarly, another faculty member stated:

There is a strong focus on the overall self-improvement of the student. In addition, there is regular peer feedback on a number of activities in the program. 
This feedback helps the student learn about themselves and how others perceive them (FS, Q26, R5).

Three faculty members noted how encouraging students to be self-learners in school helps to prepare students for life as a PA. One faculty member noted:

Students are encouraged to look for new venues of learning and are encouraged to attend the offering not only on campus but within the larger health care systems and beyond. They are encouraged to pursue personal and professional growth (FS, Q26, R1).

Similarly, another faculty member stated:

As the students progress in the didactic phase they have an increasing amount of self-learning modules to help them develop the necessary skills to identify deficits and seek out credible sources of information to fill gaps (FS, Q26, R9).

Finally, one faculty member noted a focus on self-improvement is essential to working in healthcare, he said:

The PA profession is never stagnant, so they come into training with the knowledge that they will have to continue to increase their knowledge base over time to stay abreast of medical changes. I think this lends itself to an easier selfstudy mentality (FS, Q26, R14).

Patient advocate: quantitative findings. Faculty participants indicated their level of agreement with 21 statements that addressed how students at the program where they work were being prepared to advocate for patients. Participants graded their level of agreement on a 6 point Likert like scale of agreement. Table 14 shows that greater than 70 percent of PA faculty strongly agreed that the program where they work is preparing 
PAs to respect patient confidentiality (77.4\%), not harm patients (80.7\%), and listen to patients $(74.2 \%)$. When both columns of agree and strongly agree were added together, greater than 70 percent of PA faculty agreed that the program where they work is preparing PAs to demonstrate altruistic behavior (83.9\%), establish ethical relationships with patients (100.0\%), are honest with patients (93.6\%), communicate openly with patients (93.6\%), respect patient autonomy (90.3\%), serve their patient's needs (96.8\%), go beyond the call of duty for their patients (87.1\%), treat patients justly (93.6\%), advocate for marginalized patient populations (77.4\%), educate patients (96.8\%), act in the best interest of patients $(90.3 \%)$ communicate with other healthcare providers on patient's behalf (83.9\%), and develops treatment plans with the patient (87.1\%). PA faculty showed less agreement with preparing their students to put the needs of patients above their own, assist patients with navigating the health system, call insurance companies on behalf of patients, call patients with test results, and make house calls. However, while putting the needs of patients above their own (96.8\%), assisting patients with navigating the health system (90.3\%), calling insurance companies on behalf of patients (74.2\%) and calling patients with test results (90.3\%) resulted in agreement when all three categories of agreement were combined, making house calls showed nearly equal prevalence in the three disagree categories $(48.4 \%)$ when compared to the three agree categories $(51.6 \%)$. 
Table 14

Prevalence of PA Faculty Whose Program Prepares Students to be Patient Advocates

\begin{tabular}{|c|c|c|c|c|c|c|}
\hline Item & $\begin{array}{l}\text { Strongly } \\
\text { Disagree } \\
\end{array}$ & Disagree & $\begin{array}{c}\text { Somewhat } \\
\text { Disagree }\end{array}$ & $\begin{array}{l}\text { Somewhat } \\
\text { Agree }\end{array}$ & Agree & $\begin{array}{c}\text { Strongly } \\
\text { Agree }\end{array}$ \\
\hline Does not harm patients & $0.0 \%$ & $0.0 \%$ & $0.0 \%$ & $6.5 \%$ & $12.9 \%$ & $80.7 \%$ \\
\hline Respects patient confidentiality & $0.0 \%$ & $0.0 \%$ & $0.0 \%$ & $6.5 \%$ & $16.1 \%$ & $77.4 \%$ \\
\hline Listens to patients & $0.0 \%$ & $0.0 \%$ & $0.0 \%$ & $6.5 \%$ & $19.4 \%$ & $74.2 \%$ \\
\hline Acts in the best interest of patients & $0.0 \%$ & $0.0 \%$ & $3.2 \%$ & $6.5 \%$ & $22.6 \%$ & $67.7 \%$ \\
\hline $\begin{array}{l}\text { Establishes ethical patient } \\
\text { relationships }\end{array}$ & $0.0 \%$ & $0.0 \%$ & $0.0 \%$ & $0.0 \%$ & $35.5 \%$ & $64.5 \%$ \\
\hline Serves my patients needs & $0.0 \%$ & $0.0 \%$ & $0.0 \%$ & $3.2 \%$ & $32.3 \%$ & $64.5 \%$ \\
\hline Educates my patients & $0.0 \%$ & $0.0 \%$ & $0.0 \%$ & $3.2 \%$ & $32.3 \%$ & $64.5 \%$ \\
\hline Treats patients justly & $0.0 \%$ & $0.0 \%$ & $0.0 \%$ & $6.5 \%$ & $29.0 \%$ & $64.5 \%$ \\
\hline Are honest with patients & $0.0 \%$ & $0.0 \%$ & $3.2 \%$ & $3.2 \%$ & $29.0 \%$ & $64.5 \%$ \\
\hline Communicates openly with patients & $0.0 \%$ & $0.0 \%$ & $3.2 \%$ & $3.2 \%$ & $32.3 \%$ & $61.3 \%$ \\
\hline Respects patient autonomy & $0.0 \%$ & $0.0 \%$ & $0.0 \%$ & $9.7 \%$ & $32.3 \%$ & $58.1 \%$ \\
\hline $\begin{array}{l}\text { Communicates with other healthcare } \\
\text { providers on patient's behalf }\end{array}$ & $0.0 \%$ & $0.0 \%$ & $3.2 \%$ & $12.9 \%$ & $25.8 \%$ & $58.1 \%$ \\
\hline $\begin{array}{l}\text { Develops treatment plans with the } \\
\text { patient }\end{array}$ & $0.0 \%$ & $0.0 \%$ & $0.0 \%$ & $12.9 \%$ & $35.5 \%$ & $51.6 \%$ \\
\hline Demonstrates altruistic behavior & $0.0 \%$ & $0.0 \%$ & $3.2 \%$ & $12.9 \%$ & $38.7 \%$ & $45.2 \%$ \\
\hline $\begin{array}{l}\text { Advocates for marginalized patient } \\
\text { populations }\end{array}$ & $0.0 \%$ & $0.0 \%$ & $0.0 \%$ & $22.6 \%$ & $35.5 \%$ & $41.9 \%$ \\
\hline Calls patients with test results & $3.2 \%$ & $0.0 \%$ & $6.5 \%$ & $25.8 \%$ & $29.0 \%$ & $35.5 \%$ \\
\hline $\begin{array}{l}\text { Goes above and beyond the call of } \\
\text { duty for my patients }\end{array}$ & $0.0 \%$ & $0.0 \%$ & $3.2 \%$ & $9.7 \%$ & $58.1 \%$ & $29.0 \%$ \\
\hline $\begin{array}{l}\text { Puts the needs of the patient above my } \\
\text { own needs }\end{array}$ & $0.0 \%$ & $0.0 \%$ & $3.2 \%$ & $32.3 \%$ & $35.5 \%$ & $29.0 \%$ \\
\hline $\begin{array}{l}\text { Assists patients with navigating the } \\
\text { health system }\end{array}$ & $0.0 \%$ & $3.2 \%$ & $6.5 \%$ & $29.0 \%$ & $38.7 \%$ & $22.6 \%$ \\
\hline Makes house calls & $6.5 \%$ & $25.8 \%$ & $16.1 \%$ & $29.0 \%$ & $12.9 \%$ & $9.7 \%$ \\
\hline $\begin{array}{l}\text { Calls insurance companies on behalf } \\
\text { of patients }\end{array}$ & $3.2 \%$ & $9.7 \%$ & $12.9 \%$ & $38.7 \%$ & $29.0 \%$ & $6.5 \%$ \\
\hline
\end{tabular}

Patient advocate: qualitative findings. PA faculty described how their programs prepare PA students to become advocates for their patients. Twenty-four 
faculty responded to this question. The main theme that emerged was curriculum preparation (17) followed by volunteering (5) and admission criteria (2). Three respondents stated that preparing students to be patient advocates was challenging.

Curriculum preparation. Within the area of curriculum, subthemes emerged. These subthemes included (a) courses (ethics, professional seminar, history taking) and class discussion, (b) simulation/ objective structured clinical examinations, and (c) interpersonal skill development. Courses in ethics, professional seminar and history taking seemed to be at the heart of where some faculty noted students were being prepared to be patient advocates. One faculty member stated, "This training begins on day one through our ethics course, introduction to the PA profession and history taking. It continues throughout all of the program's courses and is a key focus during the clinical year” (FS, Q14, R2). Another faculty member said, "Our program has 2 quarters of 'Professional Seminar' where these topics are emphasized" (FS, Q14, R5). Similarly, another faculty member stated, "The first course in the curriculum introduces altruism and group projects on ethical decision making, cultural awareness and professional dilemmas. The theme is then carried throughout the curriculum, although in a less formal process" (FS, Q14, R13).

Some faculty reported that students were prepared to be patient advocates through class discussions that take place over the course of their training. One individual stated, "Students are exposed to ethical discussions both in their didactic training and their clinical clerkships. These are moderated by faculty" (FS, Q14, R23). Another faculty person stated, "students discuss scenarios in other courses (related to patient education, 
ethical practice, health care delivery systems) and are required to write reflective essays during the clinical year on these topics (FS, Q14, R11).

Three other faculty members noted that student preparation occurred through a combination of lecture, small group and case study discussions, readings, and service projects. One of these faculty specified that they use, "lectures in the preclinical phase, readings and small group discussions in the clinical year" (FS, Q14, R21) to prepare students to be patient advocates. This was corroborated by another faculty member who stated that they train their students by, "Leading by example, bringing case study discussions into the classroom for dialogue, ethics lectures/activities, community service projects and opportunities" (FS, Q14, R20).

Simulation experiences and OSCEs are another way in which faculty reported training students to be patient advocates. One respondent stated:

We have several simulation experiences dealing with unique patient populations and access to care and how they would help get their patients the best care possible. We also do a poverty simulation, where they have to help low income families navigate through the healthcare system (FS, Q14, R6).

Another PA discussed how their program utilizes OSCEs to train PA students. He said, "We create several scenarios in OSCEs and simulations that require the students to be strong advocates for their patients" (FS, Q14, R11).

Interpersonal skill development over the course of PA training also seemed to be a way in which faculty identified preparing students to advocate for patients. One faculty member stated, "Preparing students to truly listen to patients, to educate and empower patients, to help patients navigate the many nuances of health care and to prioritize 
efficient and high quality care of the patient" (FS, Q14, R10). Similarly, another PA noted, "lectures are dedicated to development of skills of empathy, verbal and nonverbal communication, (and) dealing with difficult personalities” (FS, Q14, R16).

Volunteering. Training PA students to be patient advocates through volunteer activities was another popular activity noted by faculty members. This seemed to be in the form of community service activities and student run healthcare clinics. One faculty member reported:

Throughout the curriculum we discuss how PAs can better provide care and serve patients who are marginalized in our healthcare system. There are regularly scheduled service activities that form a required component of integrative courses" (FS, Q14, R7).

Regarding community health clinics, one faculty respondent said, "Students are encouraged to work for no compensation in a student run free health care clinic. They are also encouraged to think about issues such as health literacy ability to pay and socioeconomic status" (FS, Q14, R14). Another faculty member who corroborated this stated, "Students run a clinic for the uninsured. They do it themselves, and all participate" (FS, Q14, R18). Similarly, another faculty member noted, “Through participation in providing health care to indigent and under-represented populations" (FS, Q14, R24).

Admission criteria. Two faculty members reported that their training for patient advocates begins early on during the admissions phase of PA education. This occurs through a process of screening potential students for qualities that would make them a good fit for their program and the PA profession. One faculty member stated: 
We do this by selecting students who have this ideal as an applicant. We continue to develop their character through professionalism expectations that are modeled by faculty and staff and hold them accountable to that expectation... (FS, Q14, R9).

This was supported by another respondent who noted, "As part of the admissions process (also) a course that covers ethical decision making is required which sets the expectation for program and professional behavior" (FS, Q14, R13).

Engaged professional: quantitative findings. PA faculty were asked how their students are being prepared to be engaged professionals (Table 15). More than $80 \%$ of faculty respondents either agreed or strongly agreed and more than $90 \%$ showed some level of agreement with the statement that students were being prepared to be engaged professionals through being involved at local, state, or national PA organizations. Involvement in specialty PA organizations, political activism for the PA profession, and political involvement in health policy showed greater than $60 \%$ agreement across all three levels of agreement. Preparation for clinic or hospital boards or committees revealed the least amount of agreement with 58.6\% agreement and $48.2 \%$ agreement across all levels respectively. 
Table 15

Prevalence of PA Faculty Whose Program Prepares Students to be Engaged Professionals

\begin{tabular}{|c|c|c|c|c|c|c|}
\hline Item & $\begin{array}{l}\text { Strongly } \\
\text { Disagree }\end{array}$ & Disagree & $\begin{array}{l}\text { Somewhat } \\
\text { Disagree }\end{array}$ & $\begin{array}{l}\text { Somewhat } \\
\text { Agree }\end{array}$ & Agree & $\begin{array}{c}\text { Strongly } \\
\text { Agree }\end{array}$ \\
\hline State PA organization & $0.0 \%$ & $0.0 \%$ & $0.0 \%$ & $10.3 \%$ & $44.8 \%$ & $44.8 \%$ \\
\hline $\begin{array}{l}\text { National PA } \\
\text { organization }\end{array}$ & $0.0 \%$ & $0.0 \%$ & $0.0 \%$ & $13.3 \%$ & $43.3 \%$ & $43.3 \%$ \\
\hline $\begin{array}{l}\text { Local PA } \\
\text { organization }\end{array}$ & $0.0 \%$ & $6.7 \%$ & $0.0 \%$ & $10.0 \%$ & $46.7 \%$ & $36.7 \%$ \\
\hline $\begin{array}{l}\text { Political activism for } \\
\text { the PA profession }\end{array}$ & $3.3 \%$ & $3.3 \%$ & $23.3 \%$ & $30.0 \%$ & $26.7 \%$ & $13.3 \%$ \\
\hline $\begin{array}{l}\text { Political involvement } \\
\text { in health policy }\end{array}$ & $0.0 \%$ & $6.7 \%$ & $26.7 \%$ & $30.0 \%$ & $26.7 \%$ & $10.0 \%$ \\
\hline $\begin{array}{l}\text { Specialty PA } \\
\text { organization }\end{array}$ & $0.0 \%$ & $14.3 \%$ & $21.4 \%$ & $32.1 \%$ & $25.0 \%$ & $7.1 \%$ \\
\hline $\begin{array}{l}\text { Clinic } \\
\text { board/committee }\end{array}$ & $3.5 \%$ & $20.7 \%$ & $17.2 \%$ & $31.0 \%$ & $24.1 \%$ & $3.5 \%$ \\
\hline $\begin{array}{l}\text { Hospital board/ } \\
\text { committee }\end{array}$ & $3.5 \%$ & $24.1 \%$ & $24.1 \%$ & $31.0 \%$ & $17.2 \%$ & $0.0 \%$ \\
\hline
\end{tabular}

Engaged professional: qualitative findings. Faculty respondents shared how their programs prepare PAs to be engaged professionals, described as those who demonstrate organizational stewardship through involvement within local, state, and national organizations in order to form a coalition that is working toward a common goal. Twenty-one faculty respondents shared their views on this item. Two main themes arose from the 21 responses. Sixteen faculty respondents reported involvement in the AAPA or state chapter and six individuals noted areas of the curriculum that prepared students to be future professionals. 
Organizational student involvement. Regarding student involvement with the AAPA and state organizations, three main themes stood out and included: (a) required membership, (b) active student participation, and (c) program support. Of those that responded, seven stated that their PA programs required students to be members of the national and state PA organizations. One faculty member stated, "All students are required to be a member of the State and AAPA organizations upon acceptance into the program and then throughout the program" (FS, Q16, R1). Another faculty respondent who supported this noted, "All students are required to join the national AAPA and the state and local PA organizations" (FS, Q16, R15). Another faculty member said, "Students are required to have and maintain membership in both state and national PA organizations" (FS, Q16, R3). One faculty member noted that her program valued professional membership so much that they provide memberships for their students, she said, "All our students are given memberships to AAPA and our state chapter. Information on opportunities for specialty organizations and advocacy are provided as they come up (more informal notification)" (FS, Q16, R17).

Although membership seemed to be an important piece, some faculty simply felt that membership was not enough, but that the expectation was active participation on the part of the students. One faculty member stated, "Those designated in the Student Society as representatives of these organizations (state and national PA organizations) report to the class quarterly on activities within their respective organizations" (FS, Q16, R3). Another faculty member who corroborated this said, "Our program encourages our students to become active at the state and national levels (through membership and liaison opportunities)" (FS, Q16, R7). Another faculty member stated: 
Our students are encouraged to become participating members, not just members, of our local chapter, state society and the national AAPA. They are also encouraged to participate in any educational/service opportunity possible to promote the PA profession (FS, Q16, R2).

While there was a big focus on professional memberships one faculty member recognized the importance of volunteering locally to start, he stated, "We encourage our students to be involved in their local communities to start and foster development for future leadership positions within the state organization... then ... become further involved in the national organization if possible" (FS, Q16, R7). Another faculty member discussed a more global impact and reported, "global vaccines/health advocacy outside of the curriculum (have) been one focus area" (FS, Q16, R20).

Some faculty reported their programs show support for their students to get involved in the organization by providing financial assistance to attend meetings and or allowing time off from the program to be involved. One faculty member said:

Our students have a seat at the institution student government, State Academy, and AAPA. The program provides funds for student travel to state and national meetings. Specifically, we provide travel to AAPA Summit and the AAPA Annual Meeting (FS, Q16, R8).

Another faculty member who supported this stated, "We provide monetary incentive for students to attend state and national conferences. We have a student elected representative on our state board association" (FS, Q16, R13). Some faculty were specific when it came to allowing time away from classes as a means of program support. One faculty member stated, "(students are given) time off for national/state conferences" 
(FS, Q16, R9). This was supported by another faculty member who said that they prepare students to be engaged professionals by "allowing time away from class during conferences (and) encouraging conference involvement/volunteering” (FS, Q16, R16).

Curriculum. The curriculum also seemed to be an area where faculty felt students were prepared to become engaged professionals. One faculty member stated, "Our department has a professional development series that all students must complete to graduate. This series helps them develop their professional skills to be successful in the workforce" (FS, Q16, R5). Another faculty member who supported this stated, "Curriculum includes investigation of the roles of PA organizations and the roles in those organizations the PA can take. There is discussion on the successes of those organizations in the past in advancing the profession" (FS, Q16, R6). Another faculty respondent who further corroborated this noted:

In the initial course in the curriculum professional organizations, emphasizing the need to participate in professional organizations, in introduced. The concept of teamwork and how various political and organizational issues are all of our concern are covered. While we do a good job from an organizational perspective, I am not sure we do enough for students to consider roles in activism or health policy (FS, Q16, R12).

Builders of future professionals: quantitative findings. Faculty respondents reported their level of agreement with how well their program prepares students to be builders of future professionals described as a PA who demonstrates professional commitment through serving as an educator to new PA professionals during their didactic and clinical training. Of the faculty respondents, $75.8 \%$ and $75.9 \%$ reported some level 
of agreement with preparation of students to be builders of future professionals in their didactic and clinical years respectively (Table 16).

Table 16

Prevalence of PA Faculty Whose Program Prepares Students to be Builders of Future Professionals

\begin{tabular}{|c|c|c|c|c|c|c|}
\hline Item & $\begin{array}{l}\text { Strongly } \\
\text { Disagree }\end{array}$ & Disagree & $\begin{array}{l}\text { Somewhat } \\
\text { Disagree }\end{array}$ & $\begin{array}{c}\text { Somewhat } \\
\text { Agree }\end{array}$ & Agree & $\begin{array}{c}\text { Strongly } \\
\text { Agree }\end{array}$ \\
\hline Clinical Training & $10.3 \%$ & $6.9 \%$ & $6.9 \%$ & $27.6 \%$ & $27.6 \%$ & $20.7 \%$ \\
\hline Didactic Training & $6.9 \%$ & $6.9 \%$ & $10.3 \%$ & $31.0 \%$ & $27.6 \%$ & $17.2 \%$ \\
\hline
\end{tabular}

Builder of future professionals: qualitative findings. Nineteen individuals provided a response to the inquiry regarding ways their program prepares PAs to be builders of future professionals. Of these responses, the overall idea of paying it forward, noted in 17 of the 19 responses, utilized the actual words "paying it forward" or "giving back" six times. Two main ways described how PAs and even PA students could pay it forward. The two themes included recruitment and mentorship.

Recruitment. Active recruitment of graduates was a recurring theme. Recruitment of students prior to graduation through intentional lecture and discussion was noted among programs. One faculty member stated, "During their exit interviews... we stress the importance of giving back to the profession by having pre-PA students shadow them, precepting PA students at their new job, and getting involved at the state level for PA advocacy” (FS, Q19, R5). Another faculty member who supported this said: We encourage them to return to lecture, we discuss with them the importance of taking notes on good and bad preceptors and determine their own path on how to 
be a preceptor when they are practicing. There is much informal encouragement of repaying the profession by teaching to future generations (FS, Q19, R19). Another faculty member stated, "As our students enter their final quarter with us, we encourage them to become preceptors. We also invite them to return as adjunct faculty for skills training sessions, and to teach in small group settings" (FS, Q19, R4). Another faculty member who supported this stated:

Before our students graduate, we hold a meeting that asks them to consider precepting students after 3 years of clinical experience and those we feel have a knack for classroom teaching (as judged by the numerous presentation they have to do throughout the program), we will ask to consider a future in teaching after at least 5 years experience (FS, Q19, R7).

This was corroborated by another faculty member who reported, "Prior to graduation (we) set the expectation that we will reach out to them after they've been in practice a few years to see when they are ready to lecture/precept" (FS, Q19, R17). More support was given by another PA who said, "Throughout the clinical year discussions are held regarding the value of hosting students and how becoming a preceptor is a marvelous way to continue your own education while helping another PA come to be" (FS, Q19, $\mathrm{R} 2)$.

Mentorship. Some faculty members identified mentorship among students as a way to prepare students to help build future professionals. One faculty member stated, "Each day our students are asked to teach others and interact with other learners that may have challenges different than their own" (FS, Q19, R1). Another respondent who supported this said: 
In many instances we foster student helping student behavior. There is a mentor program between $1^{\text {st }}$ and $2^{\text {nd }}$ year students and we regularly invite graduates back in variety of program activities. I think our graduates are good at supporting this program and its students" (FS, Q19, R12).

Another PA faculty member who corroborated this stated, "Students mentor prospective applicants through an in class student mentoring program arranged and managed by students. Second year students organize and conduct a mentor party for incoming first year students" (FS, Q19, R8). Additional support came from another faculty member who said, "We have a mentor/mentee system, but true student to student education is limited" (FS, Q19, R18).

PAs and preceptors also modeled the concept of "giving back" through mentorship. One faculty member stated, "We ask people who cannot take students to serve as clinical mentors for didactic students" (FS, Q19, R12). This was corroborated by another faculty member who stated, "During the clinical year orientation, the importance of paying it forward is stressed and hopefully modeled by PA preceptors" (FS, Q19, R3).

Community activists: quantitative findings. Faculty members rated their level of agreement with the statements found in Table 17. The greatest level of agreement was among the items of demonstrates a strong sense of community, promotes healthcare in the community, and believes in serving the greater good where there was greater than $75 \%$ agreement in the agree and strongly agree categories combined. Participation in community health fairs, volunteering at a community healthcare clinic for the underserved, and participating in community health screenings, followed with $60 \%$ 
agreement or more in the top two categories of agree and strongly agree. Greater than $75 \%$ agreement existed among the categories of participates in community wellness initiatives and provides health education to community groups when all three categories of agreement were combined. Finally, combining all three categories of agreement resulted in greater than $60 \%$ agreement on the items, will serve on a planning committee or organize a community healthcare event, provide health education at local schools, collaborate with community organizations to meet healthcare needs in community, participate in global medical missions, and provide lectures or other education to community health groups. 


\section{Table 17}

Prevalence of Agreement of Faculty Who Believe Their Students are Being Prepared to be Community Activists- High Levels of Agreement

\begin{tabular}{|c|c|c|c|c|c|c|}
\hline Item & $\begin{array}{l}\text { Strongly } \\
\text { Disagree }\end{array}$ & Disagree & $\begin{array}{c}\text { Somewhat } \\
\text { Disagree }\end{array}$ & $\begin{array}{c}\text { Somewhat } \\
\text { Agree }\end{array}$ & Agree & $\begin{array}{c}\text { Strongly } \\
\text { Agree }\end{array}$ \\
\hline $\begin{array}{l}\text { Promotes healthcare in the } \\
\text { community }\end{array}$ & $0.0 \%$ & $0.0 \%$ & $6.7 \%$ & $6.7 \%$ & $40.0 \%$ & $46.7 \%$ \\
\hline $\begin{array}{l}\text { Demonstrates a strong sense } \\
\text { of community }\end{array}$ & $0.0 \%$ & $3.3 \%$ & $3.3 \%$ & $16.7 \%$ & $30.0 \%$ & $46.7 \%$ \\
\hline $\begin{array}{l}\text { Believes in serving the } \\
\text { greater good }\end{array}$ & $0.0 \%$ & $3.3 \%$ & $3.3 \%$ & $16.7 \%$ & $30.0 \%$ & $46.7 \%$ \\
\hline $\begin{array}{l}\text { Volunteers at a community } \\
\text { healthcare clinic for the } \\
\text { underserved }\end{array}$ & $6.7 \%$ & $3.3 \%$ & $6.7 \%$ & $16.7 \%$ & $23.3 \%$ & $43.3 \%$ \\
\hline $\begin{array}{l}\text { Participates in community } \\
\text { health fairs }\end{array}$ & $3.3 \%$ & $3.3 \%$ & $6.7 \%$ & $23.3 \%$ & $30.0 \%$ & $33.3 \%$ \\
\hline $\begin{array}{l}\text { Participates in community } \\
\text { health screenings }\end{array}$ & $3.3 \%$ & $3.3 \%$ & $10.0 \%$ & $23.3 \%$ & $33.3 \%$ & $26.7 \%$ \\
\hline $\begin{array}{l}\text { Participates in community } \\
\text { wellness initiatives }\end{array}$ & $0.0 \%$ & $5.7 \%$ & $3.3 \%$ & $40.0 \%$ & $26.7 \%$ & $23.3 \%$ \\
\hline $\begin{array}{l}\text { Participates in global } \\
\text { medical missions }\end{array}$ & $13.3 \%$ & $6.7 \%$ & $16.7 \%$ & $16.7 \%$ & $26.7 \%$ & $20.0 \%$ \\
\hline $\begin{array}{l}\text { Collaborates with } \\
\text { community organizations to } \\
\text { meet healthcare needs in the } \\
\text { community }\end{array}$ & $3.3 \%$ & $13.3 \%$ & $16.7 \%$ & $20.0 \%$ & $30.0 \%$ & $16.7 \%$ \\
\hline $\begin{array}{l}\text { Provides lectures or other } \\
\text { education to community } \\
\text { health groups }\end{array}$ & $6.7 \%$ & $16.7 \%$ & $13.3 \%$ & $13.3 \%$ & $36.7 \%$ & $13.3 \%$ \\
\hline $\begin{array}{l}\text { Provides health education at } \\
\text { local schools }\end{array}$ & $0.0 \%$ & $10.0 \%$ & $16.7 \%$ & $30.0 \%$ & $30.0 \%$ & $13.3 \%$ \\
\hline $\begin{array}{l}\text { Provides health education to } \\
\text { community groups }\end{array}$ & $0.0 \%$ & $10.0 \%$ & $13.3 \%$ & $40.0 \%$ & $23.3 \%$ & $13.3 \%$ \\
\hline $\begin{array}{l}\text { Will serve on a planning } \\
\text { committee or organized a } \\
\text { community healthcare event }\end{array}$ & $0.0 \%$ & $23.3 \%$ & $3.3 \%$ & $36.7 \%$ & $26.7 \%$ & $10.0 \%$ \\
\hline
\end{tabular}


Only one item fell below $60 \%$ of agreement. As displayed in table 18 the greatest level of disagreement was with the item, writes health columns for the local newspaper. This item showed $50 \%$ of disagreement.

Table 18

Prevalence of Agreement of Faculty Who Believe Their Students are Being Prepared to be Community Activists- Low Levels of Agreement

\begin{tabular}{lcccccc}
\hline Item & $\begin{array}{c}\text { Strongly } \\
\text { Disagree }\end{array}$ & Disagree & $\begin{array}{c}\text { Somewhat } \\
\text { Disagree }\end{array}$ & $\begin{array}{c}\text { Somewhat } \\
\text { Agree }\end{array}$ & $\begin{array}{c}\text { Agree } \\
\text { Agrongly } \\
\text { Agree }\end{array}$ & $\begin{array}{c}\text { Stron } \\
\begin{array}{l}\text { Writes health } \\
\text { columns for the } \\
\text { local newspaper }\end{array}\end{array}$ \\
$10.0 \%$ & $33.3 \%$ & $6.7 \%$ & $40.0 \%$ & $10.0 \%$ & $0.0 \%$ \\
\hline
\end{tabular}

Community activists: qualitative findings. PA faculty addressed two statements related to being a community activist. The first statement asked PA faculty to describe other ways in which their students are involved with promoting health in the community. The second inquiry asked PA faculty to describe in what ways the program in which they work prepares PAs to be community activists described as a PA who demonstrates a strong sense of community and concern for others by promoting healthcare through community health education and formation of community partnerships to serve the greater good.

Sixteen faculty responded to the first question regarding other ways in which their students are involved with promoting health in the community. All 16 responses eluded to some sort of volunteer activity in which students participate. In fact, five faculty responded that their program required volunteering. One faculty member noted, "We require 40 hours of community service as part of one of our courses. The activity needs 
to be approved by the faculty" (FS, Q21, R8). Another faculty member stated, "Our students are required to complete 12 hours of service during their first semester. They also are required to work a minimum of 2 times in our student run clinic which is held 1 time per month" (FS, Q21, R12). A third faculty member said, "Students are required to participate in service activities in the community. The school's public health department has taken a strong role in developing public health instruction for students" (FS, Q21, R6).

Common responses for volunteer activities included participation in health fairs (5) and student run clinics (4). One respondent stated, "We host several community health fairs throughout the year, participate monthly with the Lydia Roper Home and provide many other educational activities" (FS, Q21, R2). Another faculty member who supported this stated, "Our students participate every year in the local Community Health Fair called Levin Health and Wellness Fair. They take blood pressures, perform eye screenings, examine ears, and offer smoking cessation education” (FS, Q21, R7).

With respect to student run clinics, one respondent noted, "Our students run a health clinic once a month in a very run-down neighborhood. They provide immunizations and free care. This is all run by the students. They also give oral health demonstrations at local schools" (FS, Q21, R15). This was corroborated by another faculty member who stated, "We also have a local community clinic for the underserved (Hope House) where during their clinical year they can serve in the clinic as well as give educational classes on diabetes, smoking cessation, and other subjects as needed" (FS, Q21, R7). 
Varieties of other volunteer activities were noted. One respondent stated that their students, "present at the local jail annually, provide a contraception workshop to undergraduate women, volunteer in flu clinics..., (and provide) adolescent cardiac screening program” (FS, Q21, R11). Another faculty member credited the student society as being a vital component of student's volunteer activities and said, “An arm of the student society is philanthropic and continually seeks out needs in the surrounding communities where students can have an impact. Food bank, migrant farm worker clinics, Ronald McDonald House...in conjunction with the School of Pharmacy set up and run health fairs throughout the year" (FS, Q21, R3). Finally, another faculty member stated, "Our students are involved in a school-based health education program, they also are involved in general community activities- tutoring city youth, ... soup kitchen volunteerism, blood drives, large fund-raiser for pediatric childhood cancer research" (FS, Q21, R14).

Next, PA faculty described ways in which the program where they work prepares students to be community activists, described as a PA who demonstrates a strong sense of community and concern for others by promoting healthcare through community health education and formation of community partnerships to serve the greater good. Eighteen faculty responded to this inquiry. The most recognizable theme was student experiences through coursework and volunteerism. Student experiences based on coursework and volunteerism were at the heart of what programs do to prepare students to be community activists.

Coursework. Coursework included specific classes, interprofessional activities, curricular design, and class discussion. One PA faculty stated, "Some of this is promoted 
in our Professional Seminar course" (FS, Q23, R3). Another faculty member who supported this stated, "The program levers existing community relationships to involve students in community healthcare activities. In addition to lectures on public health, there are case discussions, interprofessional activities, service opportunities and overall promotion of community involvement" (FS, Q23, R5).

Although some of these experiences may be inherent to the nature of the profession and training, some were purposely designed to assist students with their own self-discovery of what community activism means for them. One faculty member stated, "The program asks the students to ask why and try to address issues they see during the didactic and clinical portions of their training, often leading to health initiatives and community service" (FS, Q23, R1). Another faculty member who noted, "By placing them in these areas, they can see for themselves the communities needs and how they can impact them" (FS, Q23, R2), supported this. Another faculty member who stated, "We try to give them as much information to stress the importance of giving back to the community and try to provide ample opportunities to give back throughout their tenure with the program" (FS, Q23, R4), further corroborated this. Finally, one faculty member noted how student involvement and experiences during their time as a PA student influence the job choices their students make:

We currently have a HRSA grant to promote primary care as the program is located in the poorest county in the state for health care access, outcomes and statistics. Our students train in this community and $75 \%$ remain in this community for the greater good (FS, Q23, R10). 
Another faculty member stated that although coursework was important, it was only one step in the process of student preparation. He further explained a three step process and stated:

The first part of the process is to select students who already have possess this desire. The next part is to incorporate into the curriculum through instruction and opportunity to practice what they learn. Lastly, students observe faculty participating in those activities as part of their faculty practice (FS, Q23, R7). Volunteerism. Volunteer opportunities, specifically those, which included a free healthcare clinic, continued to be a popular way to promote community activism. One faculty member stated that students learn about community activism, "Through our student run clinic" (FS, Q23, R11) which was supported by another faculty member who noted, "Required volunteering at the free open door clinic" (FS, Q23, R8). However, community volunteering was not limited to student run health clinics. Another faculty member noted that, "During the didactic phase students are involved in health and wellness programs in the local schools and community as well as mission trips both local and abroad" (FS, Q23, R9). Another faculty member stated, "Community engagement and activism is encouraged" (FS, Q23, R15), while another individual noted that students learn about community engagement through, "student organization- community event involvement” (FS, Q23, R14).

Team collaborators: quantitative findings. PA faculty indicated their level of agreement with the following statement, "Students of my PA program are being prepared to be physician assistants who work effectively within a healthcare team to deliver the best patient care possible (may include direct patient care or as initiatives and policy 
which affect systems based healthcare delivery)." Of the respondents, 96.7\% showed some level of agreement with $66.7 \%$ strongly agreeing with the statement. Only $3.3 \%$ somewhat disagreed with the statement. All faculty respondents agreed to some degree that students at their programs were being prepared to be PAs who collaborate with healthcare personnel. The majority, 70.0\% strongly agreed with the statement (Table 19).

Table 19

Prevalence of PA Faculty Who Believe Students Are Being Prepared to Collaborate

\begin{tabular}{lcccccc}
\hline Item & $\begin{array}{c}\text { Strongly } \\
\text { Disagree }\end{array}$ & Disagree & $\begin{array}{c}\text { Somewhat } \\
\text { Disagree }\end{array}$ & $\begin{array}{c}\text { Somewhat } \\
\text { Agree }\end{array}$ & $\begin{array}{c}\text { Agree } \\
\text { Strongly } \\
\text { Agree }\end{array}$ \\
\hline $\begin{array}{l}\text { Healthcare } \\
\text { Personnel }\end{array}$ & $0.0 \%$ & $0.0 \%$ & $0.0 \%$ & $6.7 \%$ & $23.3 \%$ & $70.0 \%$ \\
$\begin{array}{l}\text { Work in a } \\
\text { Healthcare Team }\end{array}$ & $0.0 \%$ & $0.0 \%$ & $3.3 \%$ & $6.7 \%$ & $23.3 \%$ & $66.7 \%$ \\
& & & & & & \\
\hline
\end{tabular}

Team collaborators: qualitative findings. PA faculty described how their programs prepare students to be team collaborators, defined as a PA who works effectively within a healthcare team to deliver the best patient care possible through alignment of goals and trusting relationships based on open and honest communication. Nineteen faculty provided a response to this inquiry. Of the 19 responses, 15 identified interprofessional educational activities as the way in which they prepare students to be team collaborators. Other responses included didactic curriculum (6) and clinical rotations (3).

Interprofessional education. Interprofessional education was a strong and consistent theme noted throughout the responses. One faculty respondent noted, "Our students are required to attend seminars in interprofessional team learning scenarios 
throughout their curriculum" (FS, Q29, R18). Another faculty member who stated, "Interprofessional education experiences within the didactic and clinical curriculum" (FS, Q29, R9), supported this. A few faculty provided examples of how the interprofessional experience allows for collaboration among a variety of healthcare disciplines and a better understanding of what each does. One respondent stated, "We do interprofessional simulations throughout the didactic phase of their education where they interact with several (MD, RN, PT, OT, RT, CLS) professions in clinical scenarios and then discuss each professions roles in the clinical care" (FS, Q29, R5). Another faculty member who supported this stated, "We work on several interprofessional education programs with fields such as OT, clinical mental health counseling, nursing, pharmacy, etc.” (FS, Q29, R12). Finally, another PA faculty said:

A quarterly exercise with the School of Pharmacy, Anesthesia Assisting Program, Physical Therapy Assisting, and Medical Assisting program allows students to explore the team based approach, understand other professional and paraprofessional roles as well as see how the Physician Assistant can take part and even lead a health care team (FS, Q29, R3).

Didactic and clinical education. Although interprofessional education was by far the most popular response, faculty also recognized activities done in both the didactic and clinical years that was important to developing the skills of teamwork and collaboration. One faculty member stated, “Students have several 'group' assignments throughout the curriculum and also have to work as a team in simulation..." (FS, Q29, R10). Another respondent who said, "clinical rotations, team projects and presentations, discussions about various health care professionals and their roles in patient care" (FS, Q29, R9), 
supported this. With respect to the clinical year, one faculty member said, "They learn this during their clinical rotations and during discussions in clinical class when they return to campus at the end of each rotation" (FS, Q29, R14).

Summary of research question two. Research question two explored the six conceptual underpinnings of the medical leader both quantitatively and qualitatively with PA faculty across the United States. Quantitative data noted the prevalence of constructs comprising each of the conceptual underpinnings. Qualitative data revealed themes for each of the conceptual underpinnings (table 20).

The quantitative findings of the learning leader showed that nearly all of the PA faculty surveyed agreed that PA students are being prepared both professionally and personally. This was further explored qualitatively with PA faculty. The findings showed that students are prepared to be learning leaders through three main ways: (a) internal preparations, (b) external preparation, and (c) self-preparation.

The quantitative findings for the patient advocate showed that the vast majority of PA faculty agree that the program where they work is preparing PAs be patient advocates as described by the conceptual underpinning constructs. However, variance was noted among the levels of agreement within these constructs with some constructs showing high levels of agreement and others showing less agreement. Qualitative data allowed PA faculty to comment on how their respective programs prepare students to be patient advocates. The main themes that emerged included: (a) curriculum preparation, (b) volunteering, and (c) admission criteria.

The quantitative findings reflecting the engaged professional revealed that greater than $90 \%$ of PA faculty showed some level of agreement with their program preparing 
students to be engaged professionals through involvement with the local, state, or national PA organizations. Specialty PA organizations, political activism for the PA profession and political involvement in health policy showed positive, but less agreement. Qualitative data described how PA faculty programs prepare students to be engaged professionals. From this inquiry, two main themes emerged and included organizational student involvement and curricular preparation.

Quantitative data showed that just over $75 \%$ of PA faculty felt their programs prepared students to be builders of future professionals in their didactic and clinical years. PA faculty further described how this occurs through their qualitative comments. Recruitment and mentorship emerged as the two main themes from PA faculty responses.

The quantitative data for the community activists showed that the vast majority of PA faculty agree their program is preparing PAs be community activists as described by the conceptual underpinning constructs. Although there was variance among the levels of agreement within these constructs, only one construct, writes health columns for the local newspaper, showed up to $50 \%$ of disagreement. Qualitative findings explored how students were involved in promoting health in the community and what their program does to prepare students to be community activists. All faculty reported that students were involved in promoting health in the community through volunteering; in fact, nearly one-third reported that the PA program required volunteering. Faculty noted that their programs prepare students to be community activists through student experiences in the program, demonstrated through both their volunteerism and coursework.

Quantitative data for the team collaborator showed greater than $95 \%$ of PA faculty agreed their students are being prepared to work effectively within a team for the 
best patient care. All faculty respondents agreed to some degree that students were being prepared to collaborate with healthcare personnel. Qualitative data showed that the vast majority of the faculty respondents noted that student preparation was occurring through interprofessional education. Didactic and clinical education were also noted as ways faculty teach students this skill.

All six conceptual underpinnings were explored quantitatively and qualitatively with PA faculty. Quantitative data hinted toward the prevalence of the constructs within each conceptual underpinning. Qualitative data focused on how PA faculty programs prepared students for future leadership roles. 
Table 20

Supported Quantitative Constructs and Emerging Qualitative Themes for the Medical Leader Conceptual Underpinnings- PA Faculty

\begin{tabular}{|c|c|c|}
\hline $\begin{array}{l}\text { Leadership } \\
\text { Conceptual } \\
\text { Underpinning }\end{array}$ & Supported Quantitative Constructs & Qualitative Themes \\
\hline Learning Leader & $\begin{array}{l}\text { Professional Growth } 93 \% \\
\text { Personal Growth } 90 \%\end{array}$ & $\begin{array}{l}\text { Internal Preparation } \\
\text { External Preparation } \\
\text { Self-Preparation }\end{array}$ \\
\hline Patient Advocate & $\begin{array}{l}\text { All constructs supported with } \\
>90 \% \text { agreement, except for } \\
\text { calling insurance companies on } \\
\text { behalf of patients and making } \\
\text { house calls }\end{array}$ & $\begin{array}{l}\text { Curriculum Preparation } \\
\text { Volunteering } \\
\text { Admission Criteria }\end{array}$ \\
\hline $\begin{array}{l}\text { Engaged } \\
\text { Professional }\end{array}$ & $\begin{array}{c}>90 \% \text { agreement with preparing } \\
\text { students for national, state, and } \\
\text { local PA organizational } \\
\text { involvement }\end{array}$ & $\begin{array}{l}\text { Organizational Student } \\
\text { Involvement } \\
\text { Curriculum }\end{array}$ \\
\hline $\begin{array}{l}\text { Builders of Future } \\
\text { Professionals }\end{array}$ & $\begin{array}{c}>75 \% \text { of faculty reported preparing } \\
\text { students to be builders of future } \\
\text { professionals in their didactic and } \\
\text { clinical years }\end{array}$ & $\begin{array}{l}\text { Pay it Forward } \\
\text { Recruitment } \\
\text { Mentorship }\end{array}$ \\
\hline $\begin{array}{l}\text { Community } \\
\text { Activist }\end{array}$ & $\begin{array}{l}90 \% \text { agreement or more with } \\
\text { promoting healthcare in the } \\
\text { community, demonstrating a strong } \\
\text { sense of community and belief in } \\
\text { serving the greater good; the } \\
\text { remaining constructs showed }>60 \% \\
\text { agreement, with the exception of } \\
\text { writing health columns for local } \\
\text { newspaper, } 50 \% \text { agreement }\end{array}$ & $\begin{array}{c}\text { Volunteering } \\
\text { Student Experiences Through } \\
\text { Volunteerism } \\
\text { Coursework }\end{array}$ \\
\hline $\begin{array}{l}\text { Team } \\
\text { Collaborator }\end{array}$ & $\begin{array}{l}>95 \% \text { of faculty agreed students are } \\
\text { being prepared to collaborate with } \\
\text { healthcare personnel and work in a } \\
\text { healthcare team }\end{array}$ & $\begin{array}{l}\text { Interprofessional Education } \\
\text { Didactic and Clinical Education }\end{array}$ \\
\hline
\end{tabular}




\section{CHAPTER FIVE}

\section{DISCUSSION}

\section{Introduction}

The Association of American Medical Colleges has reported a significant shortage of physicians in the United States with continued projected shortages of between 61,000-95,000 and extending to as far as 2025 (Association of American Medical Colleges, 2016). These shortages are expected to occur throughout medicine affecting not only primary care, but medical and surgical specialties too (Association of American Medical Colleges, 2016). In 2016, the Association of American Medical Colleges reported that it would take more than 95,000 physicians to meet the healthcare needs of all underserved populations (Association of American Medical Colleges, 2016). Providing access to healthcare for all Americans is an ethical challenge. PAs are medical providers identified to help bridge this physician shortage in the United States (Snyderman et al., 2011). However, it is not just the medical skills possessed by these healthcare providers that will be necessary to successfully bridge the healthcare gap, but leadership skills too (Abbas, Quince, Wood, \& Benson, 2011; Nordquist \& Grigsby, 2011).

Leadership qualities are highly recognized in today's society and medicine is no different. Physicians (Collins-Nakai, 2006) and advanced practice providers, such as PAs (Huckabee \& Wheeler, 2008), are often tasked with a variety of leadership roles. Much like physicians, preparedness for the leadership responsibilities physician assistants encounter is an essential component of professional competency (Collins-Nakai, 2006; Huckabee \& Wheeler, 2008). However, recent research showed that although formal leadership training has been identified as helpful (Baird et al., 2012; Deane \& Ringdahl, 
2012; Knowles, et al., 2012), it is not a part of the vast majority of medical training programs (Baird et al., 2012; Knowles et al., 2012; Lee et al, 2011; O'Connell \& Pascoe, 2004) due to the focus being spent on acquisition of medical knowledge, skill, critical thinking, and problem solving ability (Souba, 1998) rather than acquiring leadership skills. Like medical school, traditional PA education does not typically consist of formal leadership training (M. Statler, personal communication, February, 2013).

The medical leader may need to draw upon a variety of leadership styles within their daily life. However, given the ethical nature of the problem and medicine's deep roots within ethical principles it is not surprising that medical leadership would build its foundation with these principles in mind. Ethical leadership in the broadest sense reflects, doing the right thing for the right reason. Ethical leadership is comprised by five guiding principles. These guiding principles have described that an ethical leader: (a) builds community, (b) respects others, (c) serves others, (d) manifests honesty, and (e) shows justice (Northouse, 2010, p. 387).

Ethical undertones support commonalities in transformational, authentic and servant leadership theory. It is through these lenses that the conceptual underpinnings of the medical leader framework were discovered. The medical leader, which was the basis of the conceptual framework for this study included the following underpinnings: (a) learning leader, (b) patient advocate, (c) engaged professional, (d) builder of future professionals, (e) community activist, and (f) team collaborator.

\section{Description of the Study}

The researcher conducted a concurrent mixed methods study of a leadership model for physician assistants. The foundation of the leadership model was designed 
from a compilation of: (a) ethical leadership theory, (b) ethical undertones within transformational leadership, servant leadership and authentic leadership, (c) the researchers and her colleagues' experiences as a PA, and (d) medical literature. Based on the compilation of this data the medical leader was born and consisted of six conceptual underpinnings that included: (a) learning leader, (b) patient advocate, (c) engaged professional, (d) builder of future professionals, (e) community activist, and (f) team collaborator. The following research questions guided this investigation of the conceptual underpinnings of the medical leader framework:

1) What is the prevalence and practice of the leadership roles of physician assistants (PAs) as...
a. learning leaders?
b. patient advocates?
c. engaged professionals?
d. builders of future professionals?
e. community activists?
f. team collaborators?

2) In what ways does current curricula prepare physician assistant (PA) students for future leadership roles?

3) What changes are needed in physician assistant (PA) curriculum to better prepare students for future leadership roles?

The study explored the prevalence of each of the conceptual underpinnings with practicing PAs across the United States. Practicing PAs were selected randomly (Fink, 2009) from AAPA members on an AAPA networking site, called Huddle (AAPA, 2015e) 
as well as a purposive sampling through posting the survey on the Huddle site.

Additionally, a purposive convenience sample (Fraenkel \& Wallen, 2009) was done of PAs practicing in Missouri. Approximately one-sixth of the PAs recruited participated in the survey. PA respondents consisted of a 3:2 split between females and males respectively. The majority of the respondents were between the ages of 31 and 50 and represented nearly two-fifths of all states with just over half of the respondents coming from Missouri. Concurrently, the researcher surveyed PA faculty across the United States to determine if current PA curricula prepares PA students for each of the conceptual underpinnings describing the medical leader. Faculty participants consisted of current PA program faculty from across the United States currently serving on a PAEA Rotation Exam Review Committee (RERC), the Assessment Council, and PA educators within Missouri. Of the faculty participants recruited, over half responded. Nearly threefourths of faculty respondents were female, over a quarter represented males, and one who reported other with respect to gender. The vast majority of respondents were middle-aged adults, with less than $10 \%$ being 35 years old or younger. The faculty respondents represented 17 different states with the most respondents coming from Missouri.

Data collection occurred through the administration of surveys through an on-line commercial survey developer, Qualtrics. Surveys were sent to both practicing PAs and PA faculty and collected both quantitative and qualitative data. A survey, titled Medical Leadership Survey: For Practicing Physician Assistants, completed by practicing PAs was the source of data to answer research question one. A survey, titled Medical Leadership Survey: For Physician Assistant Faculty, administered to PA faculty, was the 
source of data to answer research question two. Triangulation of the data collected in each of the two surveys along with the literature review answered the third research question.

\section{Summary of Findings}

Ethical leadership and its deep roots in transformational leadership, servant leadership and authentic leadership were at the foundation of this study and in describing the medical leader. The medical leader as described throughout this study is based on the conceptual underpinnings of the PA as a: (a) learning leader, (b) patient advocate, (c) engaged professional, (d) builder of future professionals, (e) community activist, and (f) team collaborator. Each of these conceptual underpinnings is summarized below.

\section{Learning Leader}

The learning leader is a physician assistant who participates in learning opportunities to improve himself or herself both personally and professionally. The literature revealed that learning occurs within a variety of venues and in differing ways. Two main perspectives described the medical leader as a learning leader: (a) self-directed learner and (b) self as a learning professional.

\section{Patient Advocate}

The patient advocate is a physician assistant who demonstrates altruistic behavior, by putting the needs of others ahead of themselves (Northouse, 2010; Stone, 2012). This may be demonstrated by developing an ethical relationship with a patient built on trust and respect, open and honest communication, placing service above reward, and justice. The literature revealed that patient advocacy occurs in differing ways. Four main 
perspectives described the medical leader as a patient advocate: (a) trusting and respectful relationships (b) service to others, (c) justice, and (d) above and beyond.

\section{Engaged Professional}

An engaged professional is a PA who demonstrates organizational stewardship through involvement within local, state, and national organizations in order to form a coalition that is working toward a common goal. Engaged professionals are actively involved in politics and health policy, as well as, their local and broader health care system. Three main perspectives described the medical leader as an engaged professional: (a) organizational commitment (b) politics and health policy, and (c) clinical involvement.

\section{Builders of Future Professionals}

A builder of future professionals is a PA who demonstrates professional commitment through serving as an educator to new PA professionals during their didactic and clinical training; modeling both clinical and professional skills. Through their commitment and modeling, they empower future PA professionals to learn. Three main perspectives described the medical leader as a builder of future professionals: (a) modeling (b) empowerment, and (c) professional commitment.

\section{Community Activist}

The community activist is a PA who demonstrates a strong sense of community and concern for others by promoting healthcare through community health education and the formation of community partnerships to serve the greater good. As promoters of healthcare, PAs provide significant contributions in the communities where they practice. Collaborative efforts between healthcare providers and community organizations offers 
an opportunity for a greater number of people to be served. Two main perspectives described the medical leader as a community activist: (a) community health education and (b) community partnerships.

\section{Team Collaborators}

A team collaborator is a PA who works effectively within a healthcare team to deliver the best patient care possible through alignment of goals and trusting relationships based on open and honest communication. This may include direct patient care or initiatives and policy, which affect the systems based healthcare delivery. Four main perspectives described the medical leader as a team collaborator: (a) team sport (b) relationships, (c) open communication, and (d) alignment of goals.

The medical leader served as the overarching theme for the six conceptual underpinnings, which guided the three research questions. The first research question explored each of the conceptual underpinnings of the medical leader framework while the second question focused on PA curricula. The final research question explored whether there was a gap in leadership practiced versus preparation for leadership roles in PA education.

\section{Prevalence in Practice of PA Leadership}

The first research question explored each of the conceptual underpinnings of the medical leader both quantitatively and qualitatively with practicing PAs across the United States. The first research question asked, what is the prevalence and practice of the leadership roles of physician assistants (PAs) as...

a. learning leaders?

b. patient advocates? 

c. engaged professionals?
d. builders of future professionals?
e. community activists?
f. team collaborators?

Findings for each of these conceptual underpinnings are discussed independently within this chapter. Discussion of each conceptual underpinning is represented by prevalence in practice followed by themes that emerged from qualitative findings.

Prevalence of learning leadership. The quantitative findings of the learning leader showed that nearly all of the PAs surveyed agreed that they would consider themselves a PA who participates in learning for both personal and professional growth. Continuing medical education and medical conference attendance were the two top ways in which PAs learn both personally and professionally. Workshops related to medical skill development, practice based performance improvement, and weekly journal reading followed.

Learning leader in practice. PA participant answers reflected a resounding level of agreement to importance of life-long learning. With respect to life-long learning, three main themes emerged from the qualitative findings regarding the learning leader. These themes included: (a) curricular preparations, (b) professional expectations, and (c) selfteaching.

Curricular preparations were evidenced by practicing PAs who noted that the rigor and demands of the PA curriculum, as well as the skills they acquired, as good preparation for a career of life-long learning. Another group of PAs agreed that learning is just part of the professional expectation required to being a medical professional and 
staying current in their field. With respect to self-teaching, respondents noted nothing specific in their training that led them to be a learning leader, but rather their own selfawareness and motivation that came from within as they strived to be successful. Overall, there was more support for programs providing PAs with the tools for professional development over personal development. A vast majority of respondents agreed that their PA training helped them to be learning leaders in some fashion; however, five respondents disagreed with the idea.

Prevalence of patient advocacy. Practicing PAs showed a high level of agreement with nearly all of the statements used to describe the PA as a patient advocate. The vast majority of practicing PAs strongly agree that they (a) establish ethical relationships with patients, (b) are honest with patients, (c) communicate openly with patients, (d) respect patient confidentiality, (e) do not harm patients, (f) treat patients justly, (g) educate patients, and (h) act in the best interest of patients. This was in sharp contrast to the majority of PAs who disagreed with the idea of making house calls.

Patient advocacy in practice. PA participants addressed two statements with regard to being a patient advocate. The first asked them to provide any additional ways in which they advocate for patients or go "above and beyond" over the course of a typical month. While the second asked them to describe ways, in which their PA training prepared them to be a patient advocate.

Themes that emerged from PA responses with respect to additional ways in which they advocate for patients or "go above and beyond" over the course of a typical month included: (a) giving of time (b) giving of financial resources, (c) patient convenience/comfort/safety, and (d) taking care of challenging patients. Nearly one- 
fourth of the responses, included multiple ways of going "above and beyond" which spanned more than one of the above themes.

Giving of time was noted in a variety of ways, which included calling patients and family, writing letters, calling insurance companies, taking extra time with patients, and helping them locate resources were at the top of the list. Giving of resources was evident in PAs conscientiousness of prescribing certain medications that were less expensive, providing supplies to patients, or providing other financial assistance. Patient convenience/comfort/safety was evidenced by PAs who adjusted schedules and daily routines in order to care for patients and included making house calls, working on days off or when the clinic was not open, providing transportation, and allowing patients to call them at home. Caring for challenging patients was described as caring for those with addiction or mental illness who needed more care and referral or were waiting for an appointment, as well as, patients who had been dismissed from other healthcare providers and clinics.

Preparation to be patient advocate. The second statement asked respondents to report on whether or not their PA training helped prepare them to be a patient advocate. Thirty respondents said that their PA training did provide some instruction on how to be a patient advocate. Recurring themes centered on: (a) PA skill development, (b) modeling, and (c) serving the underserved. PA skill development with a patient first mentality was described as listening, building rapport, providing compassionate care, and treating the whole person. Some noted that merely gaining medical knowledge allows them to help patients. PAs reported instruction on how to be a patient advocate through preceptor modeling during the clinical year, modeling from professors during PA school, and a 
team approach to medicine. PAs noted that having patients as a part of their own healthcare team gave them to voice in their treatment. Serving the underserved was noted through exposure to different cultures and those of varying socioeconomic statuses, which allowed them to be more comfortable in caring and advocating for these patients later. PAs noted their training allowed them to learn how to ask difficult and embarrassing questions to patients with alternative lifestyles in order to care and advocate for them more effectively.

Prevalence of professional engagement. The quantitative findings reflecting the engaged professional revealed that the greatest level of active engagement was with participant's state PA organization followed by the national PA organization. Next in line included active engagement in local PA organizations and clinic board/committees. The level of engagement within these organizations was then studied to determine if participants held positions within those organizations traditionally requiring more responsibility. Overall, the membership category was most prevalent, followed by individuals who served on a committee and as an officer respectively. Of those who served on committees, the state APA organization had the most volunteers followed by the AAPA. Of those who served as officers, the largest number served on a state APA chapter.

Further exploration determined the depth of involvement PAs had within their clinical and hospital settings over the last five years. Nearly half of all PA respondents reported being involved on some sort of committee in the past five years. Involvement was most prevalent on the patient improvement, compliance, and safety committees. A variety of other committees were mentioned, but with lower levels of involvement. 
Engaged professional in practice. PA participants addressed two statements with regard to being an engaged professional. The first asked them to describe any leadership roles they held because of their participation on clinic or hospital based committees. While the second asked them to describe ways, in which their PA training prepared them to be an engaged professional.

With respect to leadership roles held because of participation on clinic or hospital based committees, the most consistent response was that PAs did not hold leadership roles on these committees, but rather this was often reserved for physicians. The most frequent response following none was described as the lead APP (advanced practice provider). The remainder of the answers were scattered and showed no particular alignment.

The second question asked PA respondents to describe ways in which their PA training prepared them to be an engaged professional. Over half of the PAs reported that their training prepared them to be engaged professionals, whereas, just under half of the respondents did not feel they had been prepared to be an engaged professional through their PA training. Of those who reported their training had prepared them, nearly half felt this was due to involvement in and exposure to state and national organizations while they were a student.

Prevalence of building future professionals. The quantitative findings for how actively involved PAs are in building future PA professionals revealed that nearly twothirds of PAs assist students during their didactic year, while over three-fourths participate in the clinical education of PA students. Precepting students and guest lecturing were the two most common ways in which PAs were involved with PA 
students. The level of involvement was then further explored to determine the number of hours per year spent building future PA professionals. Nearly half of PAs reported spending less than 5 hours, followed by nearly one-fourth who reported spending 6-15 hours a year. Nearly one-fifth of PAs reported giving more than 45 hours a year.

Builders of future professionals in practice. PA professionals described how their PA training prepared them to be builders of future professionals. Of the qualitative responses, most participants reported that they were taught to give back to the profession while a few stated that they had not been prepared to be a builder of future professionals. PA programs stressing the importance, preceptor modeling, and student's own experiences evidenced the concept of giving back. Some PAs noted that there was nothing done to prepare them to be builders of future professionals and that if anything they were self-taught.

Prevalence of community activist. The quantitative findings for community activist showed that with adding all three columns of agreement together, the vast majority of participants reported that they considered themselves PAs who demonstrate a strong sense of community, promote healthcare in the community, and believe in serving the greater good. This was in contrast to the remaining ten categories, which weighted heavily on the side of disagreement. Specifically, nearly all participants showed some level of disagreement with the idea of writing health columns for the local newspaper.

Community activist in practice. PA professionals described how their PA training prepared them to be a community activist. Of the responses, over half of the PAs did not feel their PA training prepared them to be a community activist as described in this study. Of those respondents who did feel that their PA training prepared them to be 
community activists, volunteerism and professional value and passion modeled by the program faculty and other PAs were the most noted responses.

Prevalence of team collaboration. Quantitative data for the team collaborator revealed all PA participants viewed themselves as working effectively within a team for the best patient care, collaboration among healthcare personnel, having open communication and trusting relationships with healthcare personnel, and alignment of goals among healthcare personnel. Communication among healthcare personnel was found to be greatest with clinical nurse or medical assistant and supervising physicians. Communication with consulting physicians, other PAs and hospital nurses followed. Communication occurred most frequently via phone, in-person communication, and email.

Team collaborator in practice. PAs provided qualitative data to determine whether their PA training prepared them to be a team collaborator. Practicing PAs noted that their clinical training, which required collaboration among healthcare providers, communication, and being a patient liaison were beneficial. Additionally, practicing PAs noted the class discussion and interprofessional educational experiences as vital to their preparation. Finally, some PAs reported how team collaboration is inherent to the PA profession and the physician and PA relationship.

\section{Curriculum for PA Leadership}

The second research question explored each of the conceptual underpinnings of the medical leader both quantitatively and qualitatively with PA faculty from across the United States. The intent of this component of the study was to answer the question, "In what ways does current curricula prepare physician assistant (PA) students for future 
leadership roles?" Results for each of the conceptual underpinnings are discussed independently in the sections ahead. A summary of the quantitative findings followed by a summary of the qualitative findings is below.

Learning leader program preparation. PA faculty were asked if the students attending the program where they worked were being prepared to be learning leaders, both professionally and personally. Almost all faculty respondents agreed that students were being prepared professionally. Personal growth also rated high with levels of agreement.

Faculty participants described ways in which their PA programs prepared students to be learning leaders. The responses noted three common themes. The first was internal preparation, defined by coursework and academic instruction through lecture and discussion. The second theme was external preparation, which focused on professional and volunteer activities taking part outside of the program. The last theme was selfpreparation, defined as program encouragement of students to be self-learners.

Patient advocate program preparation. The vast majority of PA faculty agreed that the program where they work is preparing PAs to be patient advocates as described by the conceptual underpinning constructs. However, there was variance noted among the levels of agreement within the constructs. The highest levels of agreement were with the constructs of patient confidentiality, not harming patients, and listening to patients. The lowest level of agreement was with the construct of making house calls.

Qualitative findings explained how programs teach students to be patient advocates. Three themes emerged from the faculty comments. The first was curriculum preparation, which focused on courses and class discussion, simulation and OSCE 
experiences, and interpersonal skill development. The next theme was volunteering which was described by community service and student run healthcare clinics. The last finding focused on admission criteria and screening students who have qualities that would be a good fit for the program and the profession.

Engaged professional program preparation. Nearly all PA faculty showed some level of agreement with their students being prepared as engaged professionals through involvement with the local, state and national PA organizations. More than half of faculty agreed with student preparation for specialty PA organizations, political activism, and political involvement in health policy. Preparation for clinic or hospital boards or committees revealed the lowest level of agreement.

PA faculty described how their students were taught to be engaged professionals. The responses showed overwhelming support for organizational student involvement through required membership, active student participation and volunteering, and program support. The second theme that arose was through the curriculum where students learn about professional skills and development and the PA organizations and roles.

Builders of future professionals program preparation. Overall, faculty were in support of the builder of future professionals construct. Faculty respondents reported their level of agreement with preparation of students to be builders of future professionals. Just over three-fourths of PA faculty felt their programs did prepare students for this role during the didactic and clinical years.

The finding within the faculty responses of how students are prepared to be builders of future professionals was in the overarching theme of "paying it forward" or "giving back" to the profession. This was further defined through recruitment and 
mentorship. Recruitment was described as discussion and lectures given to students about the importance of giving back to the profession by being a lecturer or preceptor. Mentorship among students, both formal and informal, was another way faculty noted students were trained to give back to the profession and other students.

Community activist program preparation. The vast majority of PA faculty agree their program is preparing PAs to be community activists as described by the conceptual underpinning constructs. The greatest level of agreement was among the items of demonstrates a strong sense of community, promotes healthcare in the community, and believes in serving the greater good. Although there was variance among the levels of agreement within the remaining items there was only one, writes health columns for the local newspaper, where nearly half of the respondents disagreed.

Qualitative findings explored how students were involved in community health promotion and what the program does to prepare students to be community activists. All faculty reported that students were involved in promoting health to the community through volunteering at health fairs, student run clinics, or other community health activity. In fact, nearly one-third of faculty reported that their PA program required students to volunteer. According to faculty, programs prepare students to be community activists through student experiences in the program. Student experiences may include coursework, class discussion, clinical preceptorships in underserved areas, or volunteering.

Team collaborator program preparation. Overall, faculty were in support of the team collaborator constructs. Nearly all of PA faculty agreed their students are being prepared to work effectively within a team. All faculty respondents agreed to some 
degree, and about three-fourths strongly agreed that students were being prepared to collaborate with healthcare personnel.

Qualitative data showed that the vast majority of faculty respondents noted that student preparation to be a team collaborator was occurring through interprofessional education clinical case scenarios, simulation, and others. Although interprofessional education was the most popular response another theme that emerged was that of didactic and clinical education in which faculty reported that group assignments, team simulation experiences and class discussion also teach students to be team collaborator.

\section{Discussion of Findings}

The results from this study explored the conceptual underpinnings of the proposed medical leader with the actual practice of PAs. The results also explored whether PA faculty programs are preparing future PAs for the roles of the medical leader as proposed within this study. The following paragraphs will discuss the alignment of the findings of each medical leader conceptual underpinning individually with the literature. The discussion will end with answering research question number three:

3) What changes are needed in physician assistant (PA) curriculum to better prepare students for future leadership roles?

\section{Learning Leader}

The learning leader, as defined by the medical leader described the learning leader from two main perspectives: (a) self-directed learner and (b) self as a learning professional. More specifically, a learning leader is a PA who participates in learning opportunities to improve themselves both personally and professionally. This was supported by the competencies for the physician assistant profession, noting that it is 
essential for PAs to continue to develop throughout their careers both personally and professionally through continual learning opportunities (Competencies, 2012).

Practicing PAs and PA faculty answered questions based on the constructs created to evaluate the two main perspectives of the learning leader. All practicing PAs reported that they considered themselves a PA who participates in professional growth, with the vast majority falling in the strongly agree and agree categories. Similarly, nearly all of PA faculty reported that their students were being prepared to be learning leaders in professional growth. Additionally, practicing PAs reported nearly unanimous agreement with participating in activities for personal growth. Similarly, PA faculty reported student preparation for personal growth.

These results support the two main perspectives of the learning leader, selfdirected learner and self as the learning professional. The self-directed learning leader recognizes that learning is not purely an external process. Personal growth is an essential component of learning to become a successful leader (Souba, 1998; Wisniewski, 2003). In an address to the PA classes of 2012, Bushardt, PharmD, PA-C wrote, "To be successful, you must be responsible for your own learning. You will never possess all the knowledge you need to serve your patients, so learn to harness knowledge and recognize your limitations" (p. 13). Not only do practicing PAs realize that they must continue to grow professionally and personally, they realize that they must be responsible for this learning. Similarly, PA faculty report they are preparing PA students to be PAs who will further engage in learning past graduation.

Practicing PAs identified continuing medical education and medical conference attendance as the top two ways in which they continue to grow. Workshops related to 
medical skill development, practice based performance improvement and weekly journal reading followed. This data is consistent with the literature, which identified the construct of self as a learning professional. This category was further differentiated into professional development in medical knowledge and experiential learner. Professional development in medical knowledge was described as continuing medical education obtained from a variety of venues such as those described here. Practice based performance improvement is related to the self as an experiential learner. PI-CME is designed to improve the practice of individual PAs and teams (American Academy of Physician Assistants, 2015), thus is relevant to professional development. Formal education and hospital based training programs for administrators were the least common reported ways of continuing learning, with less than one-fourth of PAs participating.

PA respondents reported on whether or not their PA training helped prepare them to be a learning leader. The answers reflected an overall importance of lifelong learning, defined through three themes: (a) curricular preparation, (b) professional expectation, and (c) self-teaching. Similarly, PA faculty were asked if their program prepares students to be learning leaders. Three themes emerged from the faculty comments and included: (a) internal preparation, (b) external preparation, and (c) self-preparation.

First, the overall theme of life-long learning is at the crux of the learning leader and continued professional and personal development. Curricular preparations, noted by practicing PAs evidenced the rigor and demands of the PA curriculum, as well as the skills they acquired, as good preparation for a career of life-long learning. This was supported by the theme, internal preparation, from the faculty survey, which focused on 
the academic preparation and professional development design within professional programs, ultimately setting students up for future success.

Professional expectations aligns perfectly with the self as a learning professional. Within this theme, respondents noted that being a learning leader comes with the territory of being a medical professional; the profession demands that one stays current within the medical literature. These are demands not only from a perspective of competence, but also due to PA certification and licensure. PAs reported that learning was built into the profession and never stopped. No body of evidence noted in the faculty survey supported the theme of professional expectations found in the practicing PA survey.

The self-directed learner as described in the literature was supported by the qualitative theme of self-teaching. Respondents noted that it was their own responsibility, expectation, and self-discipline to learn. Self-awareness of their abilities and personal goals seemed to support the idea of self-directed learning. One group of practicing PA respondents noted that there was nothing specific in their training that led them to be a learning leader, but rather their own self-awareness and motivation that came from within as they strive to be successful. The theme of self-teaching was supported by the faculty survey, which identified self-preparation. This was described by faculty as encouraging students to be self-learners and work on self-improvement by looking for new ways of learning and attending offerings on campus and broader health system.

External preparation emerged as a theme of the faculty survey. Faculty reported that students were being prepared as learning leaders through their involvement in professional activities outside of the program. This included CME and other conferences, 
as well as, student society service projects and activities. This is consistent with the literature and the findings on professional growth. The answers reflected not only a professional growth in the student's medical knowledge, but also a growth in their awareness of the profession and professional organizational involvement.

Although the quantitative responses identified there was strong support for both professional and personal growth, the qualitative responses showed more support for programs providing PAs with the tools for professional development than for personal development. Of the three themes that emerged from the practicing PA survey, two aligned with results from the faculty survey. The practicing PA survey and the faculty survey revealed one theme each that did not align; however, there was alignment with each of the themes with the literature. While a vast majority of respondents agreed their PA training helped them to be learning leaders in some fashion, there were a few respondents who disagreed with the idea.

\section{Patient Advocate}

Patient advocacy, as described by the medical leader was described from four main perspectives: (a) trusting and respectful relationships (George, 2007; Northouse, 2010) (b) service to others (Northouse, 2010, Souba, 2011), (c) justice (Northouse, 2010), and (d) above and beyond. This was based on the concepts of ethical leadership and altruistic behavior, which puts the needs of others ahead of themselves (Northouse, 2010; Stone, 2012).

The constructs created to evaluate the four main perspectives of the medical leader as a patient advocate were asked of practicing PAs and PA faculty through quantitative data collection. Of the 21 statements, which rated the level of participant 
agreement, nearly all constructs showed a high level of agreement with only two statements showing a low level of agreement for practicing PAs. Similarly, the same survey was administered to PA faculty to determine if their students were being prepared to be future patient advocates.

Of the 21 statements rating their level of agreement, nearly all showed a high level of agreement while just one showing a low level of agreement. Greater than twothirds of practicing PAs strongly agree that they (a) establish ethical relationships with patients, (b) are honest with patients, (c) communicate openly with patients, (d) respect patient confidentiality, (e) do not harm patients, (f) treat patients justly, (g) educate patients, and (h) act in the best interest of patients. This was similar to PA faculty, where greater than two-thirds strongly agreed that their students are being prepared to: (a) not harm patients, (b) respect patient confidentiality, and (c) listen to patients. However, when both the agree and strongly agree categories were added together greater than nearly unanimous agreement was noted by PA faculty for the following constructs: (a) act in the best interest of patients, (b) establish ethical relationships with patients (c) serves my patient needs, (d) educate patients, (e) treat patients justly (f) are honest with patients, (g) communicate openly with patients, and (h) respects patient autonomy. This finding was similar among practicing PAs where the addition of the agree category included the constructs of: (a) listens to patients, (b) respects patient autonomy, and (c) serves my patient needs, but also included two additional constructs; the development of treatment plans with the patient and going above and beyond the call of duty for patients. Ultimately, 13 constructs gained nearly unanimous agreement by practicing PAs and 11 constructs gained nearly unanimous agreement by PA faculty. Additionally, 
approximately three-fourths of PA faculty showed agreement in the top two categories for an additional five constructs and when all levels of agreement were combined, an additional four categories revealed these high levels of agreement. This was also true for practicing PAs, where four constructs showed greater than three-fourths of PA agreement in the top two categories and when all levels of agreement were combined the remaining two constructs showed greater than three-fourths of PA agreement.

Both practicing PAs and PA faculty agreed that they did not make house calls nor were students trained to do this. The construct of calling insurance companies on behalf of the patients also showed lower levels of agreement with practicing PAs in comparison with the other constructs. It is important to note that this was consistent with the PA faculty survey as well. Although this construct showed nearly three-fourths agreement among PA faculty, it was the lowest rated construct among those which were favorable.

The compilation of this quantitative data for both practicing PAs and preparation of PAs from the faculty perspective is favorable. Additionally, the quantitative data supports the model of patient advocacy, described from the four main perspectives of: (a) trusting and respectful relationships (George, 2007; Northouse, 2010) (b) service to others (Northouse, 2010, Souba, 2011), (c) justice (Northouse, 2010), and (d) above and beyond. Furthermore, based on the quantitative data there is alignment between what is being practiced and what is being taught.

PA participants addressed two statements with regard to being a patient advocate. The first asked them to provide any additional ways in which they advocate for patients or go "above and beyond" over the course of a typical month. While the second asked them to describe ways, in which their PA training prepared them to be a patient advocate. 
Similarly, PA faculty described how their students were being prepared to be patient advocates.

The idea of going above and beyond was supported by Souba (2011) and his plea of putting service above reward and making ethical decisions that are just and in the best interest of patients. Themes that emerged from PA responses to going above and beyond included the giving of time, financial resources, making decisions based on patient convenience/comfort/safety, and taking care of challenging patients. Several responses fit into multiple categories of ways in which PAs go above and beyond.

The literature often refers to Mother Theresa as the epitome of altruism and doing more than necessary for others. The purpose of this question was to see if practicing PAs went above and beyond their call of duty and what they perceived going above and beyond their duty looked like. Giving of time was noted in a variety of ways, which included calling patients and family, writing letters, calling insurance companies, taking extra time with patients, and helping them locate resources. Giving of resources was evident in PAs conscientiousness of prescribing certain medications that were less expensive, providing supplies to patients, or providing other financial assistance. Patient convenience/comfort/safety was evidenced by PAs who adjusted schedules and daily routines in order to care for patients and included, making house calls, working on days off or when the clinic was not open, providing transportation, and allowing patients to call them at home. Finally, caring for challenging patients was described as caring for those with addiction or mental illness who needed more care and referral or were waiting for an appointment, as well as, patients who had been dismissed from other healthcare providers and clinics. Ultimately, practicing PAs showed ways in which their regular 
duties were expanded upon or they did go above and beyond expectations for their patients. This further supports the construct of the patient advocate as a component of the medical leader in practice.

PA respondents reported whether or not their PA training helped prepare them to be a patient advocate. Nearly all of the respondents said that their PA training did provide some instruction on how to be a patient advocate with recurring themes centered around: (a) PA skill development, (b) modeling, and (c) serving the underserved. Similarly, PA faculty were asked if their program prepares students to be patient advocates. Three themes emerged from the faculty comments and included: (a) curriculum preparation, (b) volunteering, and (c) admission criteria.

PA skill development with a patient first mentality was described as listening, building rapport, providing compassionate care, and treating the whole person. Some noted that merely gaining medical knowledge allows them to help patients. This aligned with the first theme that emerged from the faculty survey, curriculum preparation. PA faculty noted not just the development of medical knowledge through class discussion and simulation, but also the development of interpersonal skills. Findings from both surveys are supported by servant leadership, which is noted for putting a focus on listening and ethical leaders who are respectful and try to not just listen, but also understand Northouse (2010). Additionally the PA competencies recognize the importance of the patient-provider relationship and emphasize communication and ethical interpersonal relationships as vital to practice and as a result an important component of PA student training (Competencies, 2012). 
Preceptor modeling during the clinical year, modeling from professors during PA school, and a team approach to medicine were ways PAs were taught to be patient advocates. This was supported by the faculty survey where a participant commented that they look for qualities that fit the PA profession. Additionally, modeling was a way in which justice, as described in ethical leadership, was highlighted as it gave patients a voice in their treatment as a member of their own healthcare team.

Serving the underserved, noted through exposure to different cultures and those of varying socioeconomic statuses, allowed them to be more comfortable in caring and advocating for these patients later. PAs reported their training allowed them to learn how to ask difficult and embarrassing questions to patients with alternative lifestyles in order to care and advocate for them more effectively. This was very closely related to the theme of volunteering from the faculty survey where faculty described students working in student run free health clinics and serving the underserved. Both service to others and justice, which are rooted in both servant and ethical leadership (Northouse, 2010) supported these last two themes. Justice described fighting for marginalized populations, whereas, service to others discussed treating the whole patient, understanding the patient's concerns and answering their questions. The focus was not solely on treating disease, but leading patients to well-being (Huckabee \& Wheeler, 2008).

The compilation of the qualitative data indicated that there was support for the construct of going above and beyond as a component of the patient advocate and this was documented by extensive support from practicing PA comments. Additionally, there was alignment between the themes that arose from the practicing PA and faculty surveys with 
regard to patient advocate preparation. Furthermore, the themes, which emerged from the survey supported findings in the literature.

\section{Engaged Professional}

The engaged professional, as defined by the medical leader, was described from three main perspectives: (a) organizational commitment (Northouse, 2010), (b) politics and health policy, and (c) clinical involvement. Therefore, an engaged professional is a physician assistant who demonstrates organizational stewardship through involvement within local, state, and national organizations in order to form a coalition that is working toward a common goal (Huckabee \& Wheeler, 2008; Northouse, 2010). The three constructs establishing the engaged professional were explored through eight questions for practicing PAs. Similarly, the same questions were asked of PA faculty to determine if their students were being prepared for these roles.

When considering all levels of agreement, findings showed there was greatest alignment of support for organizational commitment as described above through active involvement of practicing PAs at the state, national and then local PA organization levels. The faculty survey results supported this claim also. A closer look at this data revealed that the vast majority of PAs reporting organizational involvement were only involved at the membership level. This is not surprising given the ratio of organizational leadership positions to the vast number of members. There was a higher level of involvement with officers and committee members at the state level in comparison to others.

Clinic board/committee involvement was next in line for practicing PAs, showing nearly half of PA agreement. Clinical involvement revealed that many PA participants reported being on a committee over the last five years. PA respondents reported 
participation on a variety of different committees. The committees most often noted were patient improvement, compliance, and safety. Although practicing PAs showed evidence of clinic or hospital committee involvement, leadership roles on these committees was often reserved for physicians. This data provides further alignment for the construct of clinical involvement from the literature. The faculty survey results showed a similar level of agreement with preparing students for clinic board/committee involvement with more than half of respondents agreeing.

There was less support for questions supporting political activism and involvement in health policy on the practicing PA survey. This was in sharp contrast to the results from the faculty survey regarding preparing PA students for these roles in which over two-thirds of faculty reported that they are preparing students to be political activists for the PA profession and right at two-thirds of faculty reported students were being prepared to be politically involved in health policy.

Over a quarter of practicing PAs commented on whether or not their training prepared them to be engaged professionals. Of the responses, half felt prepared by their training, while just over a third did not. Of those, who felt prepared, involvement in and exposure to state and national organizations while they were a student was cited as the source of their preparation. This was supported by the faculty survey, which reported that students are prepared to be engaged professionals through organizational student involvement at the state and national levels. This included required membership, active student participation in activities and program support in the way of monetary incentive and time off for national/state conferences. Additionally, faculty reported student preparation in the form of courses, which stressed roles within the PA organizations. 
This evidence further supports organizational commitment within the literature where engaged professionals are stewards of their organization on multiple levels, which promotes collaboration, alignment, and big picture thinking (Northouse, 2010).

The compilation of the data showed both quantitative and qualitative support for the construct of organizational commitment as a component of the engaged professional. This was most evidenced by participation in the state, national and local PA organizations. PA faculty provided evidence for both organizational student involvement and coursework, which supported student preparation. However, although practicing PAs reported student organizational involvement as beneficial, ten students felt they either had not been prepared or did not develop this skill until after graduation. About half of practicing PAs reported being involved on clinic boards/committees, with nearly half being on a clinic board/committee over the last five years. This supported the construct of clinical involvement for the engaged professional. The final construct of politics and health policy showed less support from practicing PAs despite the fact that

the faculty survey reported that in most cases students are being prepared for these roles. Snyderman et al., 2011 noted that without effective practice laws, delays in healthcare treatment are inevitable. Therefore, if practicing PAs fail to become involved in advocating for effective practice laws, which allows them to practice at the top of their license, meeting the healthcare shortage gap is more challenging.

\section{Builder of Future Professionals}

A builder of future professionals, as defined by the medical leader is described from three main perspectives: (a) modeling (b) empowerment, and (c) professional commitment. These PAs demonstrate professional commitment through serving as an 
educator to new PA professionals during their didactic and clinical training, while modeling both clinical and professional skills and empowering future PA professionals to learn. The three main perspectives explored if practicing PAs were involved in educating future PAs and to what level was their commitment.

The practicing PA survey revealed that more were involved in educating students during their clinical year in comparison with their didactic year. The faculty survey showed nearly equivocal levels of agreement with three-fourths of faculty who agree students are being prepared to be builders of future professionals in both the didactic and clinical years. These findings were supported by all three constructs, modeling, empowerment, and professional commitment noted above. Educating future professionals is one way that PAs have the opportunity to empower others and instill among new professionals the expertise and skills related to teamwork and collaborative practice (Northouse, 2010). Pagel (2012) wrote, "One of the most effective ways to advance professionalism and leadership among practicing PAs is through precepting students" (p. 14). Professional commitment is demonstrated in the willingness of PAs to give back to their profession and others by helping to educate future professionals.

The two most frequent ways in which practicing PAs were involved with the education of students was as preceptors and guest lecturers. Additionally, practicing PAs reported how much time they spent educating students over the course of their didactic year. The greatest percentage of PAs reported that they spent less than 5 hours educating. This was followed by PAs who spent 6-15 hours and those who reported spending more than 45 hours a year educating future PA professionals. Similarly, PAs commented on how many weeks they spent precepting students during their clinical year. The most 
popular response was 10 weeks or less, reported by over two-thirds of respondents. This was followed by 11-20 weeks, which was reported by nearly a quarter of PAs. Although the greatest percentage of PAs reported the least amount of time spent for both the didactic and clinical years, any level of commitment shows a willingness to teach others. There is no doubt that lecturing and precepting students can take away time from a busy clinicians day, but as in the Annals of Internal Medicine regarding physician professionalism it states that not only should physicians have a commitment to their own life-long learning, but that we have a responsibility to make sure everyone in our profession is competent.

Practicing PAs were asked how they were prepared to be builders of future professionals. Nearly all the respondents stated that they had been trained to give back to the profession. PA programs stressing the importance of mentoring and precepting students evidenced giving back. PAs also noted that preceptors modeled the behavior. The literature supported the construct of modeling, where leading is done through example (Kouzes \& Posner, 2011). Danielson and Cawley (2007) reported modeling as a great and practical way of passing on professional principles. Some even reported that poor instruction motivated them to give back to future PA professionals, just so they could make it better. This was supported by the construct of professional commitment to the profession as a whole. Giving back was also supported by the faculty survey where the overarching theme was that program faculty teach students to give back to the profession through recruiting future preceptors nearing the end of their time as a PA student and through mentorship of other students while they are in school or once they have graduated. With respect to empowerment of the future generation, Pagel stated, 
"We can build a stronger profession by mentoring our future colleagues" (p. 14). A few practicing PAs did not feel that they had been prepared to be a builder of future professionals. Some noted their own inherent love for teaching prepared them for the role and others simply reported no training.

Through compilation of data and evaluation of prior research, there is strong support for builders of future professionals as a component of the medical leader. Both practicing PA and faculty surveys showed agreement for prevalence of involvement in both the didactic and clinical years of training with slightly more support for the clinical year. Although the number of participants was higher for involvement the level of commitment as it relates to time spent training students was at the lowest level. The overall theme for both the practicing PA and faculty responses to the qualitative question regarding training of future professionals was the idea of giving back to the profession and to future PA professionals through mentoring others to ensure a high level of competency.

\section{Community Activist}

The community activist, as defined by the medical leader was described from two perspectives: (a) community health education and (b) community partnerships. The community activist demonstrated a strong sense of community and concern for others by promoting healthcare through community health education and the formation of community partnerships to serve the greater good. As promoters of healthcare, PAs have an opportunity to provide significant contributions in the communities where they practice. Collaborative efforts between healthcare providers and community organizations offers an opportunity for a greater number of people to be served. 
The practicing PA survey asked participants to rate their level of involvement with fourteen items that represented activities that healthcare providers may participate in as an activist of health within their communities. Some of the items were attitudinal in nature while others were representative of activities one may perform. When adding all three columns of agreement together, greater than three-fourths of participants reported that they considered themselves PAs who demonstrate a strong sense of community, promote healthcare in the community, and believe in serving the greater good. The faculty survey showed even more agreement with these three items, with all three demonstrating near unanimous agreement. Despite the clear alignment between these three items, there was sharp contrast between the faculty survey and the practicing PA survey on the remaining items.

The remaining ten categories on the practicing PA survey weighted heavily on the side of disagreement. Approximately two-thirds of participants showed some level of disagreement with providing health education at local schools, serving on a planning committee or organizing a community health event, volunteering at a community healthcare clinic for the underserved, participation in global medical missions, collaboration with community organizations to meet healthcare needs in the community, and providing lectures or other education to community health groups. Even more significantly, almost all of participants showed some level of disagreement with the idea of writing health columns for the local newspaper. This was in disagreement to both the literature review and the faculty survey. Huckabee and Wheeler (2008) noted how communities benefit from clinician involvement through newspaper healthcare columns, public health, wellness initiative, health fair participation, healthcare education, and 
leadership of organizations. Although the faculty survey showed that nearly half disagreed with preparing students to write health columns for local newspapers, the remaining items showed nearly two-thirds of agreement, with volunteering at a community healthcare clinic for the underserved, participating in community health fairs, participating in community health screening, and participating in wellness initiatives showing at least three-fourths of faculty agreement.

Practicing PAs commented on how their training prepared them to be community activists. More than half of the respondents did not feel that they had received training on being a community activist. Of those that felt they had been trained, respondents noted volunteerism with community health clinics and promotion of involvement as a professional value. Faculty responses were in disagreement with practicing PA responses. Faculty noted that students were prepared to be community activists through both coursework and volunteer activities. Results showed that students receive lectures and other instruction in addition to clinical preceptorships in communities where students can see the need. Additionally, they noted volunteerism at free health clinics, local schools, and mission trips, strengthening the construct of community partnerships noted in the literature. In response to an inquiry about how students promote health in the community, faculty noted that the program requires community service as part of coursework. Other ways to promote health in the community included participation in health fairs, student run health clinics, and education at schools and other community venues.

There seemed to be good alignment with the constructs of community health education and community partnerships from the literature with respect to the 
opportunities that students are getting during their training. However, there is inconsistency with practicing PA reports of having no training and the evidence of training and support noted in the faculty survey. It is possible that the value of volunteerism and the number of student run health clinics has increased in recent years, accounting for this difference. The literature also supported community involvement, but most of the support was derived from student involvement within the community as referenced from both Oregon Health and Science University PA program and the Missouri State University PA program.

The data compiled for the community activist showed some areas of alignment, but also areas of sharp contrast. While there were four items on the survey that were greatly aligned, three in agreement and one in disagreement, there was nearly opposite responses for the remaining ten items between the two surveys. Additionally, while faculty reported training students to be community, the majority of practicing PA respondents did not feel they had been prepared for this role. There was some alignment between the faculty and practicing PA surveys in that both identified volunteerism as a major way in which community activism was taught.

\section{Team Collaborator}

A team collaborator, as defined by the medical leader was described from four main perspectives: (a) team sport (b) relationships, (c) open communication, and (d) alignment of goals. As a team collaborator, PAs work effectively within a healthcare team to deliver the best patient care possible through alignment of goals and trusting relationships based on open and honest communication. This may include direct patient care or initiatives and policy, which affect the systems based healthcare delivery. 
Practicing PAs showed unanimous agreement with the four main perspectives derived from the literature. In fact, more than three-fourths strongly agreed with the importance of collaboration among healthcare personnel and open communication among healthcare personnel, and nearly three-fourths strongly agreed with the two perspectives of trusting relationships among healthcare personnel and alignment of goals among healthcare personnel. The faculty survey supported this, as all faculty agreed that their students were being prepared to work with healthcare personnel and nearly all agreed that they were being prepared to work in a healthcare team. Even more significant was the level of agreement, which revealed over two-thirds of faculty who strongly agreed with student preparation to work with healthcare personnel and right at two-thirds who strongly agree with student preparation to work within a healthcare team.

Kouzes and Posner (2010) and Lencioni (2002) recognized the importance of communication. Specifically, Lencioni (2002) described that functional teams are able to engage in open discussion. With respect to open communication, practicing PAs noted that they communicated most often with a clinical nurse or medical assistant and supervising physicians. This is in alignment with PA practice and the PA-physician relationship. Additionally, communication was most likely to occur via phone, in-person and through email.

In determining whether or not practicing PAs felt prepared to be team collaborators in their training, nearly half of all respondents noted that their clinical training was instrumental in their preparation. Collaboration among healthcare providers, communication and learning to be a patient liaison stood out as themes. Additionally, some noted that the didactic year provided training through small group activities, mock 
training, and interdisciplinary educational experiences, which were key to their preparation. In all these situations, collaboration, teamwork, communication and working toward a common goal are evident. Kouzes and Posner (2010) noted leadership to be a "team sport" (p. 62) and that relationships built on trust are at the heart of good teamwork (Lencioni, 2002). Both Lencioni (2002) and Kouzes and Posner (2010) were proponents of open communication as noted above. Furthermore, being a patient liaison as noted in the survey is consistent with alignment of goals, which Kouzes and Posner (2010) described as having a shared vision and Lencioni (2002) saw as a sign of commitment in successful teams. These constructs as well as findings from the practicing PA survey were supported by the faculty survey too, but with a reverse order of prevalence. The resounding theme from the faculty survey was that students were being prepared to be a team collaborator through interprofessional educational experiences. This was followed by didactic and clinical year training as described above.

A final theme that emerged from the practicing PA survey was that team collaboration is inherent to the profession as evidenced by the physician and PA team concept. Practicing PAs felt that this was the basis for the profession. Additionally, they noted this concept had been ingrained in them from the beginning.

Compilation of data for the team collaborator showed a high level of agreement between the practicing PA and faculty surveys and the four main perspectives derived from the literature. As expected, practicing PAs communicated most often with a clinical nurse or medical assistant and supervising physicians. Additionally, communication was most likely to occur via phone, in-person and through email. Practicing PAs felt prepared for the team collaborator role through their clinical training, didactic training, and a belief 
that collaboration was inherent to the profession. The faculty survey supported this and revealed the themes of interprofessional education and didactic and clinical education. Although there was alignment between the themes, the practicing PAs noted more instruction from their clinical training experience while the faculty focus was on interprofessional educational experiences.

\section{Necessary Changes in PA Curriculum}

The third research question examined the findings from the conceptual underpinnings of the medical leader in research question one with the corresponding findings from research question two. These findings were compared, contrasted, and triangulated using both quantitative and qualitative data (Table 21) to answer the question:

3) What changes are needed in physician assistant (PA) curriculum to better prepare students for future leadership roles? 
Table 21

Supported Constructs for the Medical Leader Conceptual Underpinnings- Comparison of Quantitative and Qualitative Findings

\begin{tabular}{|c|c|c|}
\hline $\begin{array}{l}\text { Medical Leader } \\
\text { Conceptual } \\
\text { Underpinning }\end{array}$ & $\begin{array}{l}\text { Supported Quantitative Constructs } \\
\text { from Study- Practicing PA }\end{array}$ & $\begin{array}{l}\text { Supported Quantitative Constructs } \\
\text { from Study- PA Faculty }\end{array}$ \\
\hline Learning Leader & $\begin{array}{l}\text { Professional Growth } 100 \% \\
\text { Personal Growth } 97 \%\end{array}$ & $\begin{array}{l}\text { Professional Growth 93\% } \\
\text { Personal Growth } 90 \%\end{array}$ \\
\hline Patient Advocate & $\begin{array}{l}\text { All constructs supported with }>80 \% \\
\text { agreement, except for calling insurance } \\
\text { companies on behalf of patients and } \\
\text { making house calls }\end{array}$ & $\begin{array}{l}\text { All constructs supported with }>90 \% \\
\text { agreement, except for calling insurance } \\
\text { companies on behalf of patients and } \\
\text { making house calls }\end{array}$ \\
\hline $\begin{array}{l}\text { Engaged } \\
\text { Professional }\end{array}$ & $\begin{array}{l}\text { State and National organizational } \\
\text { involvement most prevalent at }>60 \%\end{array}$ & $\begin{array}{l}>90 \% \text { agreement with preparing students } \\
\text { for national, state, and local PA } \\
\text { organizational involvement }\end{array}$ \\
\hline $\begin{array}{l}\text { Builders of } \\
\text { Future } \\
\text { Professionals }\end{array}$ & $\begin{array}{c}\text { Actively involved in building future } \\
\text { professionals during } \\
\text { Clinical Training } 77.1 \% \\
\text { Didactic Training } 62.8 \%\end{array}$ & $\begin{array}{c}>75 \% \text { of faculty reported preparing } \\
\text { students to be builders of future } \\
\text { professionals in their didactic and } \\
\text { clinical years }\end{array}$ \\
\hline $\begin{array}{l}\text { Community } \\
\text { Activist }\end{array}$ & $\begin{array}{l}90 \% \text { agreement or more with serving } \\
\text { the greater good, demonstrating a } \\
\text { strong sense of community and } \\
\text { promoting healthcare in the } \\
\text { community; remaining constructs were } \\
\text { not supported }\end{array}$ & $\begin{array}{l}90 \% \text { agreement or more with promoting } \\
\text { healthcare in the community, } \\
\text { demonstrating a strong sense of } \\
\text { community and belief in serving the } \\
\text { greater good; the remaining constructs } \\
\text { showed }>60 \% \text { agreement, with the } \\
\text { exception of writing health columns for } \\
\text { local newspaper, } 50 \% \text { agreement }\end{array}$ \\
\hline $\begin{array}{l}\text { Team } \\
\text { Collaborator }\end{array}$ & $\begin{array}{c}\text { 100\% agreement with all constructs: } \\
\text { collaboration, open communication, } \\
\text { trusting relationships and alignment of } \\
\text { goals }\end{array}$ & $\begin{array}{l}>95 \% \text { of faculty agreed students being } \\
\text { prepared to collaborate with healthcare } \\
\text { personnel and work in a healthcare team }\end{array}$ \\
\hline
\end{tabular}




\begin{tabular}{lccc}
\hline $\begin{array}{l}\text { Medical Leader } \\
\text { Conceptual } \\
\text { Underpinning }\end{array}$ & Themes in Literature & $\begin{array}{c}\text { Emerging Qualitative } \\
\text { Themes from Study- } \\
\text { Practicing PA }\end{array}$ & $\begin{array}{c}\text { Emerging Qualitative } \\
\text { Themes from Study- } \\
\text { PA Faculty }\end{array}$ \\
\hline $\begin{array}{l}\text { Learning } \\
\text { Leader }\end{array}$ & Self-directed Learner & Curricular preparation & Internal Preparation \\
& Self as a Learning & Professional & External Preparation \\
& Professional & Self-Preparation
\end{tabular}

Learning leader. Although the quantitative responses identified that there was strong support for both professional and personal growth, the qualitative responses showed more support for programs providing PAs with the tools for professional development over personal development. As a result, there is an opportunity for programs to provide students with ways to enhance personal growth among students. This was supported in the literature by Wisniewski (2003) who noted that programs 
should help students with their personal growth, which could be enhanced through providing feedback on behavior both effective and ineffective, helping students determine their core beliefs, and determining how they personally feel about leadership. This was supported by Stoller et al. (2013) who noted the importance of self-reflection over the course of one's career, which allows for personal growth and development at different phases in their life. Additionally, program faculty noted that through external preparation students learn to become learning leaders. The practicing PA survey did not corroborate this.

An opportunity exists for program faculty to be intentional when discussing service opportunities where they believe students may grow as a learner. A few practicing PAs did not feel that their programs helped them to become learning leaders. This represents an opportunity for program faculty to take part in a self-reflection process to see if they are being intentional about ensuring their students are being instructed on life-long learning for both personal and professional development.

Patient advocate. The compilation of the quantitative and qualitative data for both practicing PAs and preparation of PAs from the faculty perspective is in alignment with what is being practiced and taught. Although the names of the themes that emerged were different, the ideas showed congruency. This is consistent with the medical literature, as patient advocacy would fall more in line with traditional teaching in medicine, such as acquisition of medical knowledge and skills (Souba, 1998). Therefore, there are no recommendations to improve PA program's teaching students how to be a patient advocate. 
Engaged professional. The compilation of the data showed both quantitative and qualitative support for the construct of organizational commitment as a component of the engaged professional. Involvement in state, national and local organizations provided this evidence. However, some PAs felt that they either had not been prepared or did not develop this skill until after graduation. Therefore, PA program faculty should reflect on their practices and make sure they are offering opportunities for organizational involvement. This is consistent with unintentional leadership practices found in the literature. Through involvement in organizations, students learn leadership skills. However, by making these practices intentional all students may recognize their importance.

Additionally, about half of practicing PAs reported being involved on clinic boards/committees. However, preparation for this did not come through on the practicing PA or faculty surveys. Therefore, seeing that half of the respondents were involved in this activity in their professional life, program faculty should re-evaluate how they are preparing students for these roles. This is consistent with recommendations from the literature that PAs often serve on committees with local health care institutions (Huckabee \& Wheeler, 2008) and recommendations for PA training in quality management and improvement (Fisher \& Briel, 2012; Scott et al., 1997), committee work (Fisher \& Briel, 2012), and meeting facilitation (American Academy of Physician Assistants, 2015d).

The final construct of politics and health policy showed less support from practicing PAs despite the fact that the faculty survey reported that in most cases students are being prepared for these roles. As a result, program faculty may need to re-evaluate 
how they are preparing students for politics and health policy. Program faculty should consider the intention of the training and expected outcomes, as well as, further assess how they may assist students in being involved in politics and health policy. The AAPA who offers political advocacy training as part of its Leadership and Advocacy Summit supported this. Some of the topics covered include promotion of the PA profession, federal laws and regulations affecting PAs, and strategy (American Academy of Physician Assistants, 2015d). Baird et al. (2012) who mentioned teaching residents about health policy evidenced further support.

Builders of future professionals. Both practicing PA and faculty surveys showed a propensity for the idea of giving back and involvement in both the didactic and clinical years of training with slightly more support for the clinical year. Despite a high number of participants, the level of commitment as it relates to time spent training students was at the lowest level. As a result, program faculty should continue their efforts in their preparation of students to give back to the profession. Additionally, reflection on ways to engage their alumni may result in increasing the level of involvement from the lowest end of commitment. Unintentional leadership training from the literature applies to the concept of building future professionals. This was evident through the concept of modeling where students observe PAs giving their time to precept students or guest lecture (R. Canales, personal communication, October 26, 2015).

Community activist. Compilation of data for the community activist showed some areas of alignment, but also areas of sharp contrast. While there were four items on the survey that were greatly aligned, three in agreement and one in disagreement, there was nearly opposite responses for the remaining ten items between the two surveys. 
Additionally, while faculty reported training students to be community activists, the majority of practicing PA respondents did not feel they had been prepared for this role. Although there was some alignment, the sharp contrast in ten of the items suggests disconnect between what faculty believe they are teaching and practicing PA perceptions.

Unintentional leadership training, where students merely learn about leadership through participating in extracurricular activities within the community are examples consistent with this concept from the literature. This may be done through volunteering with student organizations or coursework. In some cases, the differences may simply be in the intentionality of how things are presented and in other cases it may be a clear disconnect. Since, PA faculty generally agreed that students were being prepared for these tasks and practicing PAs showed low levels of agreement with preparation it is likely that further explanation on how the task can develop the student as a leader is warranted. Additionally, it is important to note that education is ever changing and that the educational practices occurring now may be different from when the practicing PAs were in school. Program faculty should evaluate how they promote community activism within their curriculum and identify any areas for improvement.

Team collaborator. Compilation of data for the team collaborator showed a high level of agreement between both the practicing PA and faculty survey. Practicing PAs felt prepared for the team collaborator role through their clinical training, didactic training, and a belief that collaboration was inherent to the profession. This was supported by the faculty survey, which revealed the themes of interprofessional education and didactic and clinical education. Although there was alignment between the themes, the practicing PAs noted more instruction from their clinical training experience while 
the faculty focus was on interprofessional educational experiences. Because of the findings, it is recommended that programs continue their work in preparing PAs to be team collaborators. These findings are consistent with the literature and the efforts of surrounding the development of collaboration and teamwork among students (Awad et al, 2004; Collins-Nakai, 2006; Stoller et al., 2004).

Summary of research question three. Overall, there was very good alignment between the practicing PA survey and the faculty survey (Appendix E). This was especially true for the patient advocate and the team collaborator. Continued efforts to promote patient advocacy and team collaboration is suggested. Alignment was also high for the learning leader and builder of future professionals. The main suggestion for the learning leader was for program faculty to place a little more emphasis on developing personal growth in students. Although participation is high among practicing PAs who build future professionals, the level of commitment demonstrated is lower. Engagement of practicing PAs to increase involvement is recommended. The engaged professional showed high levels of alignment for organizational involvement, but less alignment was seen among practicing PAs and faculty for clinical involvement and engagement in politics and policy; rendering areas in need of curricular improvement. Finally, the patient advocate showed alignment of four items and a sharp contrast between the remaining 10 items, suggesting the need for program faculty to re-evaluate the intentionality of how information regarding community engagement is taught.

\section{Implications for Practice Beyond Changes to Curriculum}

Several implications for practice became apparent with this research for both practicing PAs and PA program faculty. A summary of the recommendations can be 
found in Table 22. Practicing PAs seemed to meet the learning leader, patient advocate and team collaborator components of the medical leader best. It is recommended that practicing PAs continue to advocate for patients by giving of time, resources or concern for patient needs and safety. Additionally, continued collaboration among healthcare disciplines for the best patient care possible is recommended. The main recommendation for the PA as a learning leader would be to continue to find opportunities to grow personally in addition to professionally. The PA as the engaged professional showed a lot of involvement within the state, national and local PA organizations, but there is a need for PAs to become more involved politically in order to be able to practice at the top of their license as well as with health policy. The PA as a builder of future professionals showed a high percentage of PAs that do spend time whether it is through lecturing or instruction in the didactic year or as a preceptor in the clinical year in building future professionals. However, the amount of time spent in these activities could increase which would not only allow students to gain from the knowledge of practicing PAs, but also engage PAs within the education of others. There is a preceptor shortage around the nation and if every PA committed to precepting just one, or one more student, this shortage would diminish significantly. The PA as the community activist showed an opportunity for more PAs to be involved within their communities, such as missions, community health fairs, health education, wellness initiatives, and free health clinics to name a few.

Implications for practice for PA program faculty is directly related to the third research question. PA faculty seemed to be preparing students for the learning leader, patient advocate and team collaborator components of the medical leader best. For 
purposes of the learning leader, the main recommendation would be to continue to find opportunities for students to grow personally in addition to professionally. Therefore, program faculty should be intentional when discussing service opportunities where they believe students may grow as a learner both personally and professionally. A few practicing PAs did not feel that their programs helped them to become learning leaders. This represents an opportunity for program faculty to self-reflect on their processes to see if they are being intentional about ensuring their students are being instructed on life-long learning for both personal and professional development.

With respect to the patient advocate, continuing to promote ways in which to advocate for patients through both curricular experiences and volunteering appeared to resonate with students and perpetuate continued advocacy behaviors. It is recommended these efforts are continued. Likewise, didactic and clinical preparation along with interprofessional education seemed to be strong ways to encourage team collaboration. It is recommended PA program faculty continue these educational efforts.

With respect to the engaged professional, some students felt that they either had not been prepared for organizational leadership or did not develop this skill until after graduation. Therefore, PA program faculty have an opportunity to look for ways to intentionally offer students opportunities for organizational involvement. Additionally, about half of practicing PAs reported being involved on clinic boards/committees. Therefore, program faculty should re-evaluate how they are preparing students for clinic board/committee roles, and determine the best way to train students for these potential opportunities. The final construct of politics and health policy showed less support from practicing PAs despite the fact that the faculty survey reported that in most cases students 
are being prepared for these roles. As a result, program faculty should re-evaluate how students are being trained for these positions and consider the intention of the training and expected outcomes, as well as, further assess how they may assist students in being involved in politics and health policy.

With respect to builders of future professionals, program faculty appear to be successful with their efforts in preparing students to give back to the profession. Continuation of these efforts is encouraged. However, it is recommended that program faculty reflect on ways in which to further engage their alumni with the hopes of increasing each alumnus' level of involvement and commitment.

With respect to the community activist, there was some alignment, but also sharp contrast with practicing PAs and faculty on some of the items. This may suggest disconnect between what faculty believe they are teaching and practicing PA perceptions. PA program faculty evaluation of how they promote community activism within their curriculum and identification of any areas for improvement is likely to increase awareness and decrease the level of disconnect between these findings.

Overall, these findings inform program faculty of topic areas that may be missing from their curriculum. Additionally, if the topics are being covered this allows program faculty to re-evaluate how the topics are being implemented. In some cases, the teaching method may need to be more intentional to deal with instances where PA faculty say they are preparing students, but practicing PAs are not perceiving they have been instructed in these areas. 
Table 22

Summary of Recommendations for Practicing PAs and PA Program Faculty

\begin{tabular}{|c|c|c|}
\hline $\begin{array}{l}\text { Medical Leader } \\
\text { Conceptual } \\
\text { Underpinning }\end{array}$ & $\begin{array}{l}\text { Recommendations } \\
\text { Practicing PA }\end{array}$ & $\begin{array}{l}\text { Recommendations } \\
\text { PA Program Faculty }\end{array}$ \\
\hline Learning Leader & $\begin{array}{l}\text { Continue to find ways to grow } \\
\text { personally in addition to } \\
\text { professionally }\end{array}$ & $\begin{array}{l}\text { Continue to find ways for students to } \\
\text { grow personally and professionally and } \\
\text { be intentional in the purpose and } \\
\text { delivery of the experience both within } \\
\text { the program and through experiences } \\
\text { they may participate in externally }\end{array}$ \\
\hline Patient Advocate & $\begin{array}{l}\text { Continue to advocate for patients } \\
\text { through giving of time, resources and } \\
\text { considering patient needs and safety }\end{array}$ & $\begin{array}{l}\text { Continue to promote ways to advocate } \\
\text { for patients through curricular } \\
\text { experiences and volunteering }\end{array}$ \\
\hline Engaged Professional & $\begin{array}{l}\text { Continue to be involved in within } \\
\text { national, state and local PA } \\
\text { organizations; Seek out opportunity } \\
\text { to be more involved politically }\end{array}$ & $\begin{array}{l}\text { Continue encouraging involvement } \\
\text { with national, state and local PA } \\
\text { organizations; Re-evaluate student } \\
\text { preparation for clinic/hospital } \\
\text { committee work; Re-evaluate student } \\
\text { preparation in political activism for the } \\
\text { profession while considering intention } \\
\text { and expected outcomes }\end{array}$ \\
\hline $\begin{array}{l}\text { Builders of Future } \\
\text { Professionals }\end{array}$ & $\begin{array}{l}\text { Continue to participate in educating } \\
\text { future PAs and work to increase } \\
\text { commitment by precepting one more } \\
\text { student or providing one more lecture }\end{array}$ & $\begin{array}{l}\text { Reflect on ways to engage alumni and } \\
\text { increase each alumnus level of } \\
\text { commitment }\end{array}$ \\
\hline Community Activist & $\begin{array}{l}\text { Seek ways to get involved within } \\
\text { your community via missions, health } \\
\text { fairs, health education, free health } \\
\text { clinics, etc. }\end{array}$ & $\begin{array}{l}\text { Re-evaluate how community activism } \\
\text { is promoted within curriculum and } \\
\text { improve transparency between faculty } \\
\text { intention and student perception }\end{array}$ \\
\hline Team Collaborator & $\begin{array}{l}\text { Continue working with others in the } \\
\text { healthcare team to provide the best } \\
\text { care possible }\end{array}$ & $\begin{array}{c}\text { Continue to promote collaboration } \\
\text { among each other and among other } \\
\text { healthcare disciplines throughout PA } \\
\text { curriculum }\end{array}$ \\
\hline
\end{tabular}

\section{Limitations}

The first limitation of this study was the very limited information on medical leadership, and more specifically, PA leadership at the start of the study. As a result, much of the literature review required evaluation of literature on leadership for physicians and nurses, as well as, obtaining information from personal communications 
from colleagues. Additionally, although the conceptual framework was supported through literature, it was designed by the researcher, therefore, had not yet been validated through previous research. This limitation alone gives relevance for this research.

The second limitation of this study concern the surveys. Although they had been piloted and construction was embedded in literature they had not been used in prior research or subject to reliability and validity studies. Additionally, the construction of the qualitative questions to provide enough information for the participant to answer the question without it leading him or her to an answer was challenging. This also provided some challenge with identifying specific, rather than more global themes.

The third limitation was sample size. Of the 681 practicing PAs recruited from a random sample of 53,500 only $107 \mathrm{PAs}$ responded for a $16 \%$ return rate. Unfortunately, this number is very low and may not be representative of all PAs. However, despite the small sample size, the quantitative results obtained showed consistent alignment and the qualitative results showed clear themes in most cases representing saturation. Therefore, despite the small sample size it is likely that the results may be generalizable to PAs across the United States as the surveyed population is representative of the larger population of PAs and similar results could likely be replicated. However, although the framework for the medical leader may apply to other healthcare professionals, this study focused on PAs specifically. Therefore, generalizability to other healthcare professionals cannot be supported.

A fourth limitation was the return rate on the surveys. Although acceptable and not surprising, a return rate of $16 \%$ for the practicing PA sample is lower than desirable. This contrasts with the better response rate of the PA faculty at $61 \%$. Data collection 
through another mode or through better recruitment of participants through the used mode may have given a better response rate.

The fifth limitation is that the majority of respondents were from MO. This is because not only were participants randomly selected from the AAPA Huddle group, but also from the Missouri state PA organization list. This is a limitation because unfortunately the results may be slightly skewed toward regional practices rather than represent practice across the country.

A sixth limitation is that the qualitative data was survey based rather than done through face-to-face interaction via interview or focus group. This may have lessened the depth of the response that was given by participants. Additionally, it is more challenging to have an appreciation for the emotion involved in the responses when participants cannot be observed.

A seventh limitation was the robustness of the statistics. Although additional analyses could have been completed, the quantitative focus of the study was in determining the prevalence of the six medical leader conceptual underpinnings, which was accomplished. Despite complexity in the statistical analysis, the qualitative component of the study revealed support for quantitative findings adding to their relevance.

The final limitation of the study was that although the purpose was to have randomly selected faculty and practicing PAs participate, the results reflect practicing PAs of a wide age range. This may result in two limitations. The first is the time out of PA school may have been so long ago that they cannot remember if their training 
prepared them for the roles of the medical leader. Second, due to changing teaching practices, PAs may not have had the same educational experience as students do today.

\section{Future Research}

In general, there is very little literature on leadership for PAs. Future research is available within the existing data collected during this research study. A closer look at how PAs define leadership was asked at the beginning of the survey. This was followed by questions regarding formal and informal leadership. This data will further inform the how PAs view leadership and add to the small composite of information that is present on PA leadership.

Additionally, more research is needed to further inform the conceptual underpinnings of the medical leader discussed in this study. Although there was support for the model found within this study, replication of this study with a larger participant group would further strengthen the findings. This model allows all PAs to be leaders within medicine and does not limit leadership to positions within organizations. If as a profession, it is desired that PAs are involved with leadership on a larger scale, they will need to be given the tools necessary to be leaders within their communities and foster involvement and engagement within their profession. This model would allow for leadership among PAs to flourish by giving all PAs the power and tools to succeed, further strengthening the profession by increased engagement of the PA population at large.

Finally, further research needs to be done to evaluate PA leadership training. Further investigation to include if leadership is being taught within PA schools and how programs are implementing the training would add to the composite of literature 
available. Ideally, implementing a program where the underpinnings of the medical leader are intentionally incorporated within a PA program, and then studied would add to the support of this proposed model. 


\section{References}

Abbas, M. R., Quince, T. A., Wood, D. F., \& Benson, J. A (2011). Attitudes of medical students to medical leadership and management: a systematic review to inform curriculum development. BioMedCentral Medical Education, 11, 93. doi:10.1186/1472-6920-11-93

Adams, S. (2015). The 10 most promising jobs of 2015. Retrieved from http://www.forbes.com/sites/susanadams/2015/01/27/the-ten-most-promisingjobs-of-2015/

American Academy of Physician Assistants. (2013). AAPA research agenda. Retrieved from https://www.aapa.org/research/

American Academy of Physician Assistants. (2015a). About AAPA. Retrieved from https://www.aapa.org/about/

American Academy of Physician Assistants. (2015b). Certification maintenance and cme faq. Retrieved from https://www.aapa.org/twocolumnmain.aspx?id=1298

American Academy of Physician Assistants. (2015c). Physician assistants for oral health. Retrieved from https://www.aapa.org/PAsforOralHealth/

American Academy of Physician Assistants. (2015d). Leadership and advocacy summit. Retrieved from https://www.aapa.org/las/

American Academy of Physician Assistants. (2015e). Huddle: Where PAs team up. Retrieved from http://huddle.aapa.org/home?utm_source=aapa.org\&utm_medium=huddle_header \&utm_campaign=huddle

American Academy of Physician Assistants. (2015f). What is a physician assistant? Retrieved from https://www.aapa.org/What-is-a-PA/

Association of American Medical Colleges. (2016). New research confirms looming physician shortage. Retrieved from https://www.aamc.org/newsroom /newsreleases/458074/2016_workforce_projections_04052016.html

Association of Family Practice Physician Assistants. (2015). AFPPA Community Outreach. Retrieved from http://www.afppa.org/index.php?option=com_content\&view=article\&id=11\&Ite mid=13

Avolio, B. J., \& Gardner, W. L. (2005). Authentic leadership development: Getting to the root of positive forms of leadership. The Leadership Quarterly, 16, 315-338. 
Awad, S. S., Hayley, B., Fagan, S. P., Berger, D. H., \& Brunicardi, C. (2004). The impact of a novel resident leadership training curriculum. The American Journal of Surgery, 188, 481-484. doi:10.1016/j.amjsurg.2004.07.024

Baird, D. S., Soldanska, M., Anderson, B., \& Miller, J. (2012). Current leadership training in dermatology residency programs: A survey. Journal of the American Academy of Dermatology, 66, 622-625. doi:10.1016/j.jaad.2009.10.009

Bickley, L. S., \& Szilagyi, P. G. (2013). Bates' guide to physical examination and history taking (11th ed.). Philadelphia, PA: Wolters Kluwer Lippincott Williams \& Wilkins.

Blessing, J. D., \& Forister, J. G. (2013). Introduction to research and medical literature for health professionals ( $3^{\text {rd }}$ ed.). Burlington, MA: Jones \& Bartlett Learning.

Blumenthal, D. M., Bernard, K., Bohnen, J., \& Bohmer, R. (2012). Addressing the leadership gap in medicine: Residents' need for systematic leadership development training. Academic Medicine, 87, 513-522. doi:10.1097/ACM.0b013e31824a0c47

Boulanger, B., Buencamino, A., \& Dovichi, S. (2005). Training young pediatricians as leaders. Pediatrics, 116, 518. doi:10.1542/peds.2005-0831

Bushardt, R. L. (2012). To the PA class of 2012: Choose the path of leadership. Journal of American Academy of Physician Assistants, 25, 12-13.

Cawley, J. F. (2007). Physician assistant education: An abbreviated history. Journal of Physician Assistant Education, 18(3), 6-15.

Central Michigan University College of Health Professions. (2008). Community outreach: CMU pa class of 2009 recognized for community outreach. Retrieved from https://www.cmich.edu/colleges/CHP/hp_academics/physician_assistant/ Pages/Community-Outreach.aspx

Ciampa, E. J., Hunt, A. A., Arneson, K. O., Mordes, D. A., Oldham, W. M., Vin Woo, K., Owens, D. A., Cannon, M. D., \& Darmody, T. S. (2011). A workshop on leadership for md/phd students. Medical Education Online, 16, doi:10.3402/meo.v16i0.7075

Cleary, M., \& Hunt, G. E. (2010). Building community engagement in nursing. Journal of Continuing Education in Nursing, 41, 344-345.

Collins-Nakai, R. (2006). Leadership in medicine. McGill Journal of Medicine, 9, 68-73. 
Competencies for the Physician Assistant Profession. (2012). National Commission on Certification of Physician Assistants. Retrieved from http://www.nccpa.net /Uploads/docs/PACompetencies.pdf

Creswell, J. W. (2009). Research design: Quantitative, qualitative, and mixed methods approaches (3rd ed.). Thousand Oaks, CA: Sage.

Curry, J. R., Smith, H. L., \& Robinson III, E. H. (2009). The development and manifestation of altruistic caring: A qualitative inquiry. Counseling and Values, 54, 2-16.

Danielson, R. D., \& Cawley, J. F. (2007). Compassion and integrity in health professions education. The Internet Journal of Allied Health Sciences and Practice, 5, 1-9.

Davis, S. H. (2004). The leadership journey. Leadership, 34, 8-12.

Deane, K., \& Ringdahl, E. (2012). The family medicine chief resident: A national survey of leadership development. Family Medicine, 44, 117-120.

Doescher, M. P., Fordyce, M. A., Skillman, S. M., Jackson, J. E., \& Rosenblatt, R. A. (2009). Persistent primary care health professional shortage areas (HPSAs) and health care access in rural america. Retrieved from http://depts.washington.edu /uwrhrc/uploads/Persistent_HPSAs_PB.pdf

Eubank, D., Geffken, D., Orzano, J., \& Ricci, R. (2012). Teaching adaptive leadership to family medicine residents: What? why? how? Families, Systems \& Health, 30, 241-252. doi:10.1037/a0029689

Felix, K. G. (1997). Developing trust in teams. (Doctoral thesis). Retrieved from http://search.proquest.com.proxy.mul.missouri.edu/docview/304403722?pqorigsite=summon (9728058)

Fink, A. (2009). How to conduct surveys: A step-by-step guide (4th ed.). Los Angeles, CA: Sage.

Fisher, S. D., \& Briel, R. (2012). A case study to describe and evaluate the experiences of a final year medical student undertaking an eight-week management and leadership placement. The International Journal of Clinical Leadership, 17, 155158.

Fraenkel, J. R., \& Wallen, N. E. (2009). How to design and evaluate research in education (7th ed.). New York, NY: McGraw-Hill.

Gay, L. R., Mills, G. E., \& Airasian, P. (2012). Educational research: Competencies for analysis and applications (10th ed.). Boston, MA: Pearson. 
George, B. with Peter Sims (2007). True north: Discover your authentic leadership. San Francisco, CA: Jossey-Bass.

George, B., Sims, P., McLean, A. N., \& Mayer, D. (2011). Discovering your authentic leadership. In HBR's 10 must reads on leadership (pp. 163-167). Boston, MA: Harvard Business Review Press. (Reprint R0702H, Originally published in February 2007)

Hatch, J. A. (2002). Doing qualitative research in education settings. Albany, NY: State University of New York Press.

Hays, R. (2008). Leadership, medical education and the quality of care. Quality in Primary Care, 16, 139-140.

Health Resources \& Services Administration Health Workforce. (2013). Projecting the supply and demand for primary care practitioners through 2020. U.S. Department of Health and Human Services. Retrieved from http://bhpr.hrsa.gov/healthworkforce/supplydemand/usworkforce/primarycare/

Heifetz, R. \& Laurie, D. L. (2011). The work of leadership. In HBR's 10 must reads on leadership (pp. 57-78). Boston, MA: Harvard Business Review Press. (Reprint R0111K, Originally published in January 1997)

Heppner, P. P., \& Heppner, M. J. (2004). Writing and publishing your thesis, dissertation, \& research: A guide for students in the helping professions. Toronto, Ontario, Canada: Thomson Publishing.

History of Medical Discoveries. (2012). New England Journal of Medicine. Retrieved from http://nejm200.nejm.org/timeline/

Hitti, M. (2006). 7 Key traits of the ideal doctor: A good attitude goes a long way, patients tell researchers. Retrieved from http://www.webmd.com/news /20060309/7-key-traits-of-ideal-doctor?print=true

Huckabee, M. J., \& Wheeler, D. W. (2008). Defining leadership training for physician assistant education. Journal of Physician Assistant Education, 19, 24-28.

Hudson, C. L. (1961). Expansion of medical professional services with nonprofessional personnel. Journal of American Medical Association, 176, 95-97.

Hudson, C. L. (1966). Meeting the challenge. Journal of American Medical Association, 197, 132-134.

Kernis, M. H. (2003). Toward a conceptualization of optimal self-esteem. Psychological Inquiry, 14, 1-26. 
Knowles, L., O’Dowd, C., Hewett, D. G., Schafer, J., \& Wilkinson, D. (2012). The University of Queensland medical leadership program: A case study. The Ochsner Journal, 12, 344-347.

Kochar, M. S., Robertson, R. G., \& Mone, M. A. (2003). A faculty leadership development program at the medical college of Wisconsin. World Medical Journal, 102, 24-28.

Kotter, J. P. (2011). What leaders really do. In HBR's 10 must reads on leadership (pp. 37-55). Boston, MA: Harvard Business Review Press. (Reprint R0111F, Originally published in May 1990)

Kouzes, J. M., \& Posner, B. Z. (2010). The truth about leadership: The no-fads, heartof-the-matter facts you need to know. San Francisco, CA: Jossey-Bass.

Kouzes, J. M., \& Posner, B. Z. (2011). The five practices of exemplary leadership (2nd ed.). San Francisco, CA: Pfeiffer.

LaFasto, F., \& Larson, C. (2002). When teams work best: 6,000 team members and leaders tell what it takes to succeed. Retrieved from https://leadershiphq.files.wordpress.com/2011/02/when-teams-work-best1.pdf

Lee, H., King, D., \& MacDonnell, M. (2011). Training clinicians to lead. British Medical Journal, 343, 996-997. doi:10.1136/bmj.d6932

Lencioni, P. (2002). The five dysfunctions of a team: A leadership fable. San Francisco, CA. Jossey-Bass.

Lucey, C. L., \& Souba, W. (2010). Perspective: The problem with the problem of professionalism. Academic Medicine, 85, 1018-1024.

Marquardt, M. J. (2011). Building the learning organization: Achieving strategic advantage through a commitment to learning (3rd ed.). Boston, MA: Nicholas Brealey Publishing.

McGregor, D. M. (2011). The human side of enterprise. In J. M. Shafritz, J. S. Ott, \& Y. S. Jang (Eds.), Classics of organizational theory (7th ed., pp. 183-188). Boston, MA: Wadsworth. (Reprinted from Management Review, 1957, by the American Management Association, New York. Reprinted by permission.)

Meyers, C., \& Jones, T. B. (1993). Promoting active learning. Strategies for the college classroom. San Francisco, CA: Jossey-Bass.

Middleton, R. (2013). Active learning and leadership in an undergraduate curriculum: How effective is it for student learning and transition to practice? Nurse Education in Practice, 13, 83-88. 
National Center for Healthcare Leadership. (2010). Health leadership competency model summary. Retrieved from

http://www.nchl.org/documents/navlink/competency_model-

summary_uid31020101024281.pdf

National Commission on Certification of Physician Assistants. (2015). About CME requirements. Retrieved from http://www.nccpa.net/ContinuingMedicalEducation

2014 National Healthcare Quality \& Disparities Report. (2015). Agency for Healthcare Research and Quality, Rockville, MD. Retrieved from http://www.ahrq.gov/research/findings/nhqrdr/nhqdr14/index.html

Nordquist, J., \& Grigsby, R. K. (2011). Medical schools viewed from a political perspective: How political skills can improve education leadership. Medical Education, 45, 1174-1180. doi:10.1111/j.1365-2923.2011.04085.x

Northouse, P. G. (2010). Leadership: Theory and practice (5th ed.). Los Angeles, CA: Sage.

O'Connell, M. T., \& Pascoe, J. M. (2004). Undergraduate medical education for the $21 \mathrm{st}$ century: Leadership and teamwork [Supplement]. Family Medicine, 36, S51-S56.

Oregon Health \& Science University School of Medicine Physician Assistant Program (2015). Community outreach project. Retrieved from http://www.ohsu.edu/xd /education/schools/school-of-medicine/academic-programs/physicianassistant/applicants/curriculum/cop.cfm

Pagel, J. K. (2012). Precepting PA students: How you can touch the future. Journal of American Academy of Physician Assistants, 25, 14.

Physician Assistant Education Association. (2015). About PAEA. Retrieved from http://www2.paeaonline.org/index.php?ht=d/sp/i/204/pid/204\%20a

Physician Assistant Foundation. (2015). Caring for communities award. Retrieved from http://www.pa-foundation.org/grants/caring-for-communities/

Schein, E. H. (2011). The concept of organizational culture: Why bother? In J. M. Shafritz, J. S. Ott, \& Y. S. Jang (Eds.), Classics of organizational theory (7th ed., pp. 349-360). Boston, MA: Wadsworth. (Reprinted from Organizational Culture and Leadership, 2004, by San Francisco: Jossey-Bass. Reprinted by permission of John Wiley \& Sons, Inc.)

Schumann, P. L. (2001). A moral principles framework for human resource management ethics. Human Resource Management Review, 11, 93-111. doi:10.1016/S10534822(00)00042-5 
Scott, E. S. (2011). Educational preparation to strengthen nursing leadership. North Carolina Medical Journal, 74, 296-299.

Scott, H. M., Tangalos, E. G., Blomberg, M. A. I. R., \& Bender, C. E. (1997). Survey of physician leadership and management education. Mayo Clinical Procedures, 72, 659-662.

Scruggs Garber, J., Madigan, E. A., Click, E. R., \& Fitzpatrick, J. J. (2009). Attitudes towards collaboration and servant leadership among nurses, physicians and residents. Journal of Interprofessional Care, 23, 331-340.

Seng, S. (2015). I'm a PA because of patient care. Retrieved from http://www.bartonassociates.com/2015/10/06/im-a-pa-because-of-patient-care/

Senge, P. M. (1990). The fifth discipline: The art and practice of the learning organization. New York, NY: Currency.

Shafritz, J. M., Ott, J. S., \& Jang, Y. S. (2011). Classics of organization theory (7th ed.). Boston, MA: Wadsworth.

Shershneva, M. B., Mullikin, E. A., Loose, A. S., \& Olson, C. A. (2008). Learning to collaborate: A case study of performance improvement CME. Journal of Continuing Education in the Health Professions, 28, 140-147.

Snell, A. J., Briscoe, D., \& Dickson, G. (2011). From the inside out: The engagement of physicians as leaders in health care settings. Qualitative Health Research, 2, 952967. doi: $10.1177 / 1049732311399780$

Snyderman, C. H., Eibling, D. E., \& Johnson, J. T. (2011). The physician as team leader: New job skills are required. Academic Medicine, 86, 1348. doi:10.1097/ACM.0b013e3182308d6c

Souba, W. W. (1998). The job of leadership. Journal of Surgical Research, 80, 1-8.

Souba, W.W. (2011). The being of leadership. Philosophy, Ethics, and Humanities in Medicine, 6, 5. doi.org/10.1186/1747-5341-6-5

Sox, H. C. (2002). Medical professionalism in the new millennium: A physician charter a project of the abim foundation, acp-asim foundation, and European federation of internal medicine. Annals of Internal Medicine, 136, 243-246.

Spears, L. C. (2005). The understanding and practice of servant leadership: Servant leadership research roundtable. School of leadership studies Regent University. Retrieved from http://www.regent.edu/acad/sls/publications /conference_proceedings/servant_leadership_roundtable/2005/pdf/spears_practice .pdf 
Stoller, J. K., Rose, M., Lee, R., Dolgan, C., \& Hoogwerf, B. J. (2004). Teambuilding and leadership training in an internal medicine residency training program. Journal of General Internal Medicine, 19, 692-697.

Stoller, J. K., Taylor, C. A., \& Farver, C. F. (2013). Emotional intelligence competencies provide a developmental curriculum for medical training. Medical Teacher, 35, 243-247.

Stone, D. (2012). Policy paradox: The art of political decision making (3rd ed.). New York, NY: W.W. Norton \& Company.

Topper, E. F. (2009). Self-leadership: Road to personal excellence. New Library World, $110,561-563$.

Trochim, W. M. (2006). Qualitative validity. In The research methods knowledge base (2nd ed.). Retrieved from http://www.socialresearchmethods.net/kb/qualval.php

Troncale, J. A. (2010). Turning doctors into leaders. [Special section]. Harvard Business Review, 88, 18-19.

U.S. News and World Report Money. (2015). The 100 best jobs. Retrieved from http://money.usnews.com/careers/best-jobs/rankings/the-100-best-jobs

University of Utah School of Medicine. (2015). Student-run free clinic at Maliheh: Service learning. Retrieved from http://medicine.utah.edu/physician-assistantprogram/program/community-engagement/free-clinic-maliheh.php

Walumbwa, F., Avolio, B., Gardner, W., Wernsing, T., \& Peterson, S. (2008). Authentic leadership: Development and validation of a theory-based measure. Journal of Management, 34, 89-126. doi:10.1177/0149206307308913

Wisniewski, M. A. (2003). Leadership education: A constructivist model for continuing higher education. The Journal of Continuing Higher Education, 51, 31-37.

Yukl, G. (2013). Leadership in organizations (8th ed.). Boston, MA: Pearson. 
Appendix A

\section{Transmittal Letter}

\section{Dear Colleague,}

Hello! My name is Tracy Cleveland. I am a physician assistant and PA educator in the process of completing my doctoral degree. I have a special interest in medical leadership, specifically PA leadership. Leadership can be described in many ways, and can be a part of both formal and informal PA roles and activities. This survey will explore leadership of practicing PAs.

I need your help. Please take 20-25 minutes and go to the Qualtrics survey at the following address... Within the survey are several opportunities for you to voice your level of agreement or disagreement with the statements with respect to your current leadership duties, as well as describe your thoughts on PAs as leaders.

Your time invested in this survey will help our profession move forward by understanding leadership skills within current and future PAs. I would truly appreciate you taking the time to complete this survey. Thank you!

Respectfully,

Tracy Cleveland, MS, PA-C 
Appendix B

\section{Informed Consent}

\section{What is the purpose of this study?}

With the approaching physician shortage, physician assistants (PAs) are being relied upon to fill the healthcare gap being created. This not only requires PAs to provide quality healthcare, but also effective leadership skills. Leadership can be described in various ways. The purpose of this study is to: 1) identify the current leadership roles of practicing PAs and 2) identify specific practices within physician assistant education that cultivate leadership skills.

\section{What is the expectation of participants?}

Participants will partake in a survey that will take approximately 20-25 minutes to complete.

\section{What are the benefits of the study?}

No direct personal benefits from this study are anticipated. The knowledge gained from this study will add to the overall composite of information currently present on leadership in physician assistant education and ultimately assist PA programs to accomplish the dual goals of acquiring medical knowledge and developing leadership abilities in students.

\section{What are the risks of the study?}

Risks of this study are minimal. However, you may experience emotional discomfort with sharing your beliefs about leadership in the physician assistant profession and in physician assistant education.

\section{Can I change my mind?}

Yes, you may choose to skip questions you may not feel comfortable answering or discontinue your participation in the survey at any point.

\section{What will happen to the information I share?}

Your information will remain anonymous as there will be no personal identification attached to the survey information collected through the Qualtrics Survey Software.

\section{Will I receive payment for participating?}

There is no payment for participation in this research study. 


\section{What if I have questions?}

If you have any questions, please contact Tracy Cleveland at tracycleveland@missouristate.edu or 417-836-6152 or Cynthia MacGregor at CMacgregor@missouristate.edu or 417-836-6046. If you have questions about your rights as a human subject or this project (\#2004787), call the University of Missouri's Campus Institutional Review Board at 573-882-9585. 
Appendix C

\section{Medical Leadership Survey: For Practicing Physician Assistants}

A Concurrent Mixed-Methods Study of a Leadership Model for Physician

Assistants: Implications for Practice and Training

\section{Informed Consent}

\section{What is the purpose of this study?}

With the approaching physician shortage, physician assistants (PAs) are being relied upon to fill the healthcare gap being created. This not only requires PAs to provide quality healthcare, but also effective leadership skills. Leadership can be described in various ways. The purpose of this doctoral research study is to: 1) identify the current leadership roles of practicing PAs and 2) identify specific practices within physician assistant education that cultivate leadership skills.

\section{What is the expectation of participants?}

Participants will take a survey that will require approximately 20-25 minutes to complete. Participation in this survey is voluntary and refusal to participate will not involve penalty or loss of benefits.

\section{What are the benefits of the study?}

No direct personal benefits from this study are anticipated. The knowledge gained from this study will add to the overall composite of information currently present on leadership in physician assistant education and ultimately assist PA programs to accomplish the dual goals of acquiring medical knowledge and developing leadership abilities in students.

\section{What are the risks of the study?}

Risks of this study are minimal. However, you may experience emotional discomfort with sharing your beliefs about leadership in the physician assistant profession and in physician assistant education.

\section{Can I change my mind?}

Yes, you may choose to skip questions you may not feel comfortable answering or discontinue your participation in the survey at any point. 


\section{What will happen to the information I share?}

Your information will remain anonymous as there will be no personal identification attached to the survey information collected through the Qualtrics Survey Software.

\section{Will I receive payment for participating?}

There is no payment for participation in this research study.

\section{What if I have questions?}

If you have any questions, please contact Tracy Cleveland at tracycleveland@missouristate.edu or 417-836-6152 or Cynthia MacGregor at CMacgregor@missouristate.edu or (417) 836-6046. If you have questions about your rights as a human subject or this project (\#2004787), call the University of Missouri's Campus Institutional Review Board at 573-882-9585.

\footnotetext{
Agree (1)

Disagree (2)
} 
Q1 I am or have been a practicing physician assistant within the last 5 years.

O Yes (1)

O No (2)

Q2 What does "leadership" mean to you in your role as a PA?

Q3 Describe ways in which your PA training prepared you to be a leader.

Q4 Through which of the following formal leadership training formats did you participate in during your PA education? Please check all that apply.

Required leadership course (1)

As a component of another course; please specify below (2)

Required readings (3)

W Workshop on leadership (4)

Lecture series (5)

Other; please specify below (6)

Not applicable (7)

Q5 I believe formal leadership training should be a part of PA education.

Strongly Disagree (1)

O Disagree (2)

O Somewhat Disagree (3)

O Somewhat Agree (4)

O Agree (5)

O Strongly Agree (6)

Q6 Please describe why you would or would not have liked formal leadership training as a component of your PA education. 
Q7 My PA education included informal leadership training such as observation or modeling of leadership skills by faculty or preceptors.

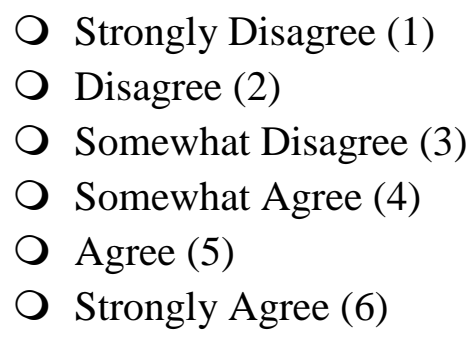

Strongly Disagree (1)

O Disagree (2)

O Somewhat Disagree (3)

O Somewhat Agree (4)

O Agree (5)

Strongly Agree (6)

Q8 Please describe your informal leadership training.

Q9 I believe informal leadership training should be a part of PA education.

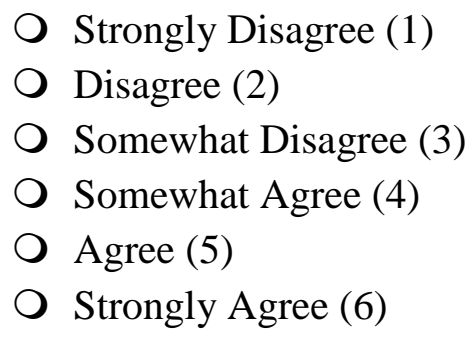

Q10 Please describe why you would or would not have liked informal leadership training as a component of your PA education.

Q11 Please indicate your level of agreement with the following statements. I consider myself to be a physician assistant who: 


\begin{tabular}{|c|c|c|c|c|c|c|}
\hline & $\begin{array}{l}\text { Strongly } \\
\text { Disagree } \\
\text { (1) }\end{array}$ & $\begin{array}{l}\text { Disagree } \\
\text { (2) }\end{array}$ & $\begin{array}{l}\text { Somewhat } \\
\text { Disagree (3) }\end{array}$ & $\begin{array}{l}\text { Somewhat } \\
\text { Agree (4) }\end{array}$ & Agree (5) & $\begin{array}{l}\text { Strongly } \\
\text { Agree (6) }\end{array}$ \\
\hline $\begin{array}{c}\text { Demonstrates } \\
\text { altruistic } \\
\text { behavior (1) }\end{array}$ & $\mathrm{O}$ & $\mathrm{O}$ & 0 & $\mathrm{O}$ & O & $\mathrm{O}$ \\
\hline $\begin{array}{l}\text { Establishes } \\
\text { ethical patient } \\
\text { relationships } \\
\text { (2) }\end{array}$ & 0 & $\mathrm{O}$ & $\mathrm{O}$ & 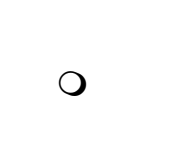 & 0 & $\mathrm{O}$ \\
\hline $\begin{array}{l}\text { Is honest with } \\
\text { patients (3) }\end{array}$ & 0 & 0 & 0 & 0 & 0 & O \\
\hline $\begin{array}{l}\text { Communicates } \\
\text { openly with } \\
\text { patients (4) }\end{array}$ & 0 & 0 & $\mathrm{O}$ & 0 & 0 & 0 \\
\hline $\begin{array}{c}\text { Respects } \\
\text { patient } \\
\text { autonomy (5) }\end{array}$ & $\mathrm{O}$ & 0 & $\mathrm{O}$ & $\mathrm{O}$ & 0 & $\mathrm{O}$ \\
\hline $\begin{array}{c}\text { Respects } \\
\text { patient } \\
\text { confidentiality } \\
\text { (6) }\end{array}$ & $\mathrm{O}$ & 0 & 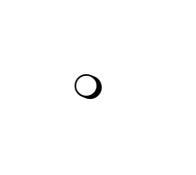 & $\mathrm{O}$ & 0 & 0 \\
\hline $\begin{array}{l}\text { Does not harm } \\
\text { patients }(7)\end{array}$ & $\mathrm{O}$ & O & O & O & 0 & $\mathrm{O}$ \\
\hline $\begin{array}{l}\text { Serves my } \\
\text { patient's needs } \\
\text { (8) }\end{array}$ & $\mathrm{O}$ & $\mathrm{O}$ & $\mathrm{O}$ & $\mathrm{O}$ & 0 & $\mathrm{O}$ \\
\hline $\begin{array}{l}\text { Goes above } \\
\text { and beyond } \\
\text { the call of } \\
\text { duty for my } \\
\text { patients (9) }\end{array}$ & $\mathrm{O}$ & 0 & O & O & O & $\mathrm{O}$ \\
\hline $\begin{array}{l}\text { Puts the needs } \\
\text { of the patient } \\
\text { above my own } \\
\text { needs (10) }\end{array}$ & $\mathrm{O}$ & O & $\mathrm{O}$ & O & $\mathrm{O}$ & $\mathrm{O}$ \\
\hline $\begin{array}{l}\text { Treats patients } \\
\text { justly (11) }\end{array}$ & 0 & O & 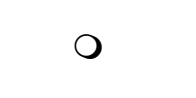 & O & 0 & $\mathrm{O}$ \\
\hline $\begin{array}{l}\text { Advocates for } \\
\text { marginalized } \\
\text { patient } \\
\text { populations } \\
\text { (12) }\end{array}$ & 0 & $\mathrm{O}$ & $\mathrm{O}$ & O & 0 & $\mathrm{O}$ \\
\hline $\begin{array}{c}\text { Listens to } \\
\text { patients (13) }\end{array}$ & 0 & 0 & 0 & 0 & O & $\mathrm{O}$ \\
\hline $\begin{array}{l}\text { Educates my } \\
\text { patients (14) }\end{array}$ & 0 & 0 & 0 & 0 & 0 & O \\
\hline
\end{tabular}




\begin{tabular}{|c|c|c|c|c|c|c|}
\hline $\begin{array}{c}\text { Assists } \\
\text { patients with } \\
\text { navigating the } \\
\text { health system } \\
\text { (15) }\end{array}$ & 0 & 0 & 0 & 0 & 0 & 0 \\
\hline $\begin{array}{l}\text { Acts in the } \\
\text { best interest of } \\
\text { patients (16) }\end{array}$ & 0 & 0 & 0 & 0 & 0 & 0 \\
\hline $\begin{array}{c}\text { Calls } \\
\text { insurance } \\
\text { companies on } \\
\text { behalf of } \\
\text { patients (17) }\end{array}$ & $\mathrm{O}$ & 0 & 0 & 0 & 0 & 0 \\
\hline $\begin{array}{l}\text { Calls patients } \\
\text { with test } \\
\text { results (18) }\end{array}$ & 0 & 0 & 0 & 0 & 0 & 0 \\
\hline $\begin{array}{l}\text { Makes house } \\
\text { calls (19) }\end{array}$ & O & 0 & 0 & 0 & 0 & 0 \\
\hline $\begin{array}{l}\text { Communicates } \\
\text { with other } \\
\text { healthcare } \\
\text { providers on } \\
\text { patient's } \\
\text { behalf (20) }\end{array}$ & 0 & 0 & 0 & 0 & 0 & 0 \\
\hline $\begin{array}{c}\text { Develops } \\
\text { treatment } \\
\text { plans with the } \\
\text { patient }(21)\end{array}$ & $\mathrm{O}$ & 0 & 0 & 0 & 0 & 0 \\
\hline
\end{tabular}

Q12 Describe additional ways in which you advocate for patients or go "above and beyond" over the course of a typical month.

Q13 Describe how your PA training prepared you to be a patient advocate. A patient advocate may be described as a PA who demonstrates an unselfish or altruistic behavior by putting the needs of others ahead of themselves. This may be demonstrated through developing an ethical relationship with patients that is built on trust and respect, open and honest communication, placing service above reward, and justice. 
Q14 Please indicate your level of agreement with the following statement. I am actively involved in...

\begin{tabular}{|c|c|c|c|c|c|c|}
\hline & $\begin{array}{l}\text { Strongly } \\
\text { Disagree } \\
\text { (1) }\end{array}$ & $\begin{array}{l}\text { Disagree } \\
\text { (2) }\end{array}$ & $\begin{array}{l}\text { Somewhat } \\
\text { Disagree (3) }\end{array}$ & $\begin{array}{l}\text { Somewhat } \\
\text { Agree (4) }\end{array}$ & Agree (5) & $\begin{array}{l}\text { Strongly } \\
\text { Agree (6) }\end{array}$ \\
\hline $\begin{array}{c}\text { Local PA } \\
\text { organization(s) } \\
\text { (1) }\end{array}$ & 0 & 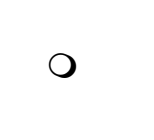 & 0 & 0 & 0 & 0 \\
\hline $\begin{array}{c}\text { State PA } \\
\text { organization(s) } \\
\text { (2) }\end{array}$ & 0 & $\mathrm{O}$ & $\mathrm{O}$ & $\mathrm{O}$ & 0 & $\mathrm{O}$ \\
\hline $\begin{array}{c}\text { National PA } \\
\text { organization(s) } \\
\text { (3) }\end{array}$ & $\mathrm{O}$ & $\mathrm{O}$ & $\mathrm{O}$ & $\mathrm{O}$ & $\mathrm{O}$ & $\mathrm{O}$ \\
\hline $\begin{array}{c}\text { Specialty PA } \\
\text { organization(s) } \\
(4)\end{array}$ & 0 & $\mathrm{O}$ & $\mathrm{O}$ & $\mathrm{O}$ & 0 & 0 \\
\hline $\begin{array}{l}\text { Political } \\
\text { activism for the } \\
\text { PA profession } \\
\text { (5) }\end{array}$ & O & O & 0 & O & $\mathrm{O}$ & O \\
\hline $\begin{array}{c}\text { Political } \\
\text { involvement in } \\
\text { health policy (6) }\end{array}$ & O & 0 & 0 & O & 0 & 0 \\
\hline $\begin{array}{c}\text { Clinic } \\
\text { board/committee } \\
\text { (7) }\end{array}$ & O & 0 & 0 & O & 0 & 0 \\
\hline $\begin{array}{c}\text { Hospital } \\
\text { board/committee } \\
(8)\end{array}$ & 0 & 0 & O & O & 0 & O \\
\hline
\end{tabular}


Q15 Select your level of involvement to the following organizations. Check all roles in which you have participated during the last 5 years.

\begin{tabular}{|c|c|c|c|c|}
\hline & Member (1) & Officer (2) & $\begin{array}{c}\text { Committee } \\
\text { Member (i.e. } \\
\text { CME, political } \\
\text { action, } \\
\text { recruitment, etc.) } \\
\text { (3) }\end{array}$ & Not applicable (4) \\
\hline $\begin{array}{l}\text { Local physician } \\
\text { assistant } \\
\text { organization } \\
\text { (regional location } \\
\text { within a state } \\
\text { organization) (1) }\end{array}$ & $\square$ & $\square$ & $\square$ & $\square$ \\
\hline $\begin{array}{l}\text { State APA chapter } \\
\text { (2) }\end{array}$ & $\square$ & $\square$ & $\square$ & $\square$ \\
\hline $\begin{array}{l}\text { American } \\
\text { Academy of } \\
\text { Physician } \\
\text { Assistants (3) }\end{array}$ & $\square$ & $\square$ & $\square$ & $\square$ \\
\hline $\begin{array}{c}\text { Physician Assistant } \\
\text { Education } \\
\text { Association (4) }\end{array}$ & $\square$ & 口 & 口 & $\square$ \\
\hline $\begin{array}{l}\text { National AAPA } \\
\text { Specialty } \\
\text { Organization (5) }\end{array}$ & $\square$ & $\square$ & $\square$ & $\square$ \\
\hline $\begin{array}{c}\text { State AAPA } \\
\text { Specialty } \\
\text { Organization (6) }\end{array}$ & $\square$ & $\square$ & $\square$ & $\square$ \\
\hline $\begin{array}{c}\text { Other } \\
\text { organizations; } \\
\text { please specify } \\
\text { below (7) }\end{array}$ & $\square$ & $\square$ & $\square$ & 口 \\
\hline
\end{tabular}


Q16 Please select all of the following committees for which you have been a member within your clinic or hospital setting in the past 5 years.

$\square$ Infection control (1)

口 Compliance (2)

$\square$ Safety (3)

$\square$ Patient improvement (4)

$\square$ Conference planning committee (5)

- Clinical executive committee (6)

$\square$ Surgical executive committee (7)

$\square$ Medical executive committee (8)

$\square$ Risk management (9)

$\square$ Ethics committee (10)

$\square$ Others; please specify below (11)

Q17 Please describe any leadership roles you held as a result of your participation on clinic or hospital based committees.

Q18 Describe how your PA training prepared you to be an engaged professional. An engaged professional is a PA who demonstrates organizational stewardship through involvement within local, state, and national organizations in order to form a coalition that is working toward a common goal. 
Q19 I would consider myself a physician assistant who gives back to the profession by serving as an educator to new PA professionals during their didactic training.
Strongly Disagree (1)
O Disagree (2)
Somewhat Disagree (3)
O Somewhat Agree (4)
Agree (5)
Strongly Agree (6)

Q20 I would consider myself a physician assistant who gives back to the profession by serving as an educator to new PA professionals during their clinical training.
Strongly Disagree (1)
Disagree (2)
Somewhat Disagree (3)
Somewhat Agree (4)
O Agree (5)
Strongly Agree (6)

Q21 As a practicing PA, select all of the ways in which you are involved in physician assistant education.

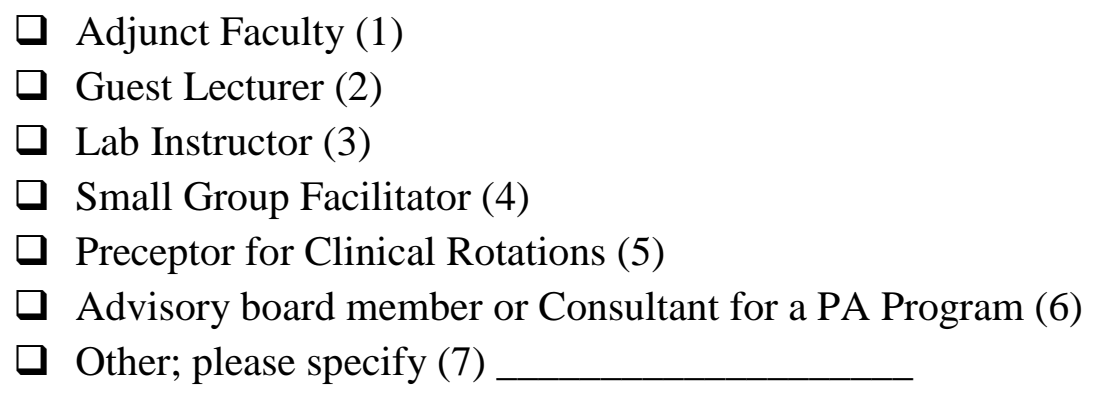


Q22 Over the course of a year how many hours do you spend participating in the didactic education of PA students?
Less than 5 hours (1)
O 6-15 hours (2)
16-25 hours (3)
O 26-35 hours (4)
O 36-45 hours (5)
○ $>45$ hours (6)
Not applicable (7)

Q23 Over the course of a year how many weeks do you precept PA students?
O 10 or less weeks (1)
O 11-20 weeks (2)
O 21-30 weeks (3)
O 31-40 weeks (4)
41-50 weeks (5)
O More than 50 weeks (6)

Q24 Describe how your PA training prepared you to be a builder of future professionals. A builder of future professionals is a physician assistant who demonstrates professional commitment through serving as an educator to new PA professionals during their didactic and clinical training; modeling both clinical and professional skills.

Q25 Please indicate your level of agreement with the following statements. I would consider myself a physician assistant who: 


\begin{tabular}{|c|c|c|c|c|c|c|}
\hline & $\begin{array}{c}\text { Strongly } \\
\text { Disagree } \\
\text { (1) }\end{array}$ & $\begin{array}{l}\text { Disagree } \\
\text { (2) }\end{array}$ & $\begin{array}{l}\text { Somewhat } \\
\text { Disagree (3) }\end{array}$ & $\begin{array}{l}\text { Somewhat } \\
\text { Agree (4) }\end{array}$ & Agree (5) & $\begin{array}{c}\text { Strongly } \\
\text { Agree (6) }\end{array}$ \\
\hline $\begin{array}{l}\text { Demonstrates } \\
\text { a strong sense } \\
\text { of community } \\
\text { (1) }\end{array}$ & 0 & $\mathrm{O}$ & O & O & 0 & 0 \\
\hline $\begin{array}{c}\text { Promotes } \\
\text { healthcare in } \\
\text { the } \\
\text { community (2) }\end{array}$ & $O$ & $\mathrm{O}$ & $\mathrm{O}$ & $\mathrm{O}$ & $\mathrm{O}$ & O \\
\hline $\begin{array}{l}\text { Believes in } \\
\text { serving the } \\
\text { "greater good" } \\
\text { (3) }\end{array}$ & $\mathrm{O}$ & $\mathrm{O}$ & $\mathrm{O}$ & $\mathrm{O}$ & $\mathrm{O}$ & $\mathrm{O}$ \\
\hline $\begin{array}{l}\text { Participates in } \\
\text { community } \\
\text { health fairs (4) }\end{array}$ & O & $\mathrm{O}$ & $\mathrm{O}$ & O & 0 & 0 \\
\hline $\begin{array}{l}\text { Writes health } \\
\text { columns for } \\
\text { the local } \\
\text { newspaper (5) }\end{array}$ & O & 0 & O & O & O & 0 \\
\hline $\begin{array}{l}\text { Provides } \\
\text { health } \\
\text { education to } \\
\text { community } \\
\text { groups (6) }\end{array}$ & 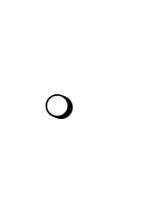 & 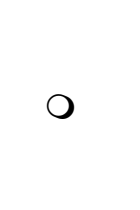 & O & O & O & O \\
\hline $\begin{array}{c}\text { Provides } \\
\text { health } \\
\text { education at } \\
\text { local schools } \\
\text { (7) }\end{array}$ & $\mathrm{O}$ & $\mathrm{O}$ & $\mathrm{O}$ & $\mathrm{O}$ & O & 0 \\
\hline $\begin{array}{l}\text { Participates in } \\
\text { community } \\
\text { wellness } \\
\text { initiatives (8) }\end{array}$ & O & 0 & O & 0 & O & 0 \\
\hline $\begin{array}{l}\text { Has served on } \\
\text { a planning } \\
\text { committee or } \\
\text { organized a } \\
\text { community } \\
\text { healthcare } \\
\text { event (9) }\end{array}$ & 0 & 0 & $\mathrm{O}$ & O & 0 & O \\
\hline $\begin{array}{l}\text { Participates in } \\
\text { community } \\
\text { health } \\
\text { screenings } \\
\text { (10) }\end{array}$ & O & 0 & O & $\mathrm{O}$ & $\mathrm{O}$ & O \\
\hline
\end{tabular}




\begin{tabular}{|c|c|c|c|c|c|c|}
\hline $\begin{array}{l}\text { Volunteers at } \\
\text { a community } \\
\text { healthcare } \\
\text { clinic for the } \\
\text { underserved } \\
\text { (11) }\end{array}$ & 0 & 0 & 0 & 0 & 0 & 0 \\
\hline $\begin{array}{l}\text { Participates in } \\
\text { global medical } \\
\text { missions (12) }\end{array}$ & 0 & 0 & 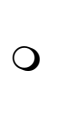 & 0 & 0 & 0 \\
\hline $\begin{array}{c}\text { Collaborates } \\
\text { with } \\
\text { community } \\
\text { organizations } \\
\text { to meet } \\
\text { healthcare } \\
\text { needs in the } \\
\text { community } \\
(13)\end{array}$ & 0 & 0 & 0 & 0 & 0 & 0 \\
\hline $\begin{array}{l}\text { Provides } \\
\text { lectures or } \\
\text { other } \\
\text { education to } \\
\text { community } \\
\text { health groups } \\
\text { (14) }\end{array}$ & 0 & 0 & 0 & 0 & 0 & 0 \\
\hline
\end{tabular}

Q26 Describe any additional ways in which you are involved in promoting health within your community.

Q27 Describe how your PA training prepared you to be a community activist. A community activist is a PA who demonstrates a strong sense of community and concern for others by promoting healthcare through community health education and the formation of community partnerships to serve the greater good. 
Q28 I consider myself to be a physician assistant who participates in learning opportunities for personal growth.
Strongly Disagree (1)
O Disagree (2)
Somewhat Disagree (3)
O Somewhat Agree (4)
Agree (5)
Strongly Agree (6)

Q29 I consider myself a physician assistant who participates in learning opportunities for professional growth.
O Strongly Disagree (1)
$\bigcirc$ Disagree (2)
Somewhat Disagree (3)
Somewhat Agree (4)
O Agree (5)
Strongly Agree (6)

Q30 Please check all that apply...I consider myself a physician assistant who participates in:

Continuing medical education (1)

- Practice based performance improvement (2)

$\square$ Medical conference attendance (3)

Workshops related to medical skill development (4)

$\square$ Weekly journal reading (5)

$\square$ Weekly critical self-reflection (6)

Formal education since graduating from PA school (doctoral or other degree) (7)

$\square$ Hospital based training program for administrators (8)

$\square$ Other; please specify below (9)

Q31 Describe how your PA training prepared you to be a learning leader. A learning leader is a PA who participates in learning opportunities to improve themselves both personally and professionally. 
Q32 I would consider myself a physician assistant who works effectively within a healthcare team to deliver the best patient care possible (may include direct patient care or as initiatives and policy which affect systems based healthcare delivery).

Strongly Disagree (1)

Disagree (2)

O Somewhat Disagree (3)

Somewhat Agree (4)

Agree (5)

Strongly Agree (6)

Q33 I would consider myself to be a physician assistant who believes caring for patients requires:

\begin{tabular}{|c|c|c|c|c|c|c|}
\hline & $\begin{array}{c}\text { Strongly } \\
\text { Disagree } \\
(1)\end{array}$ & $\begin{array}{c}\text { Disagree } \\
(2)\end{array}$ & $\begin{array}{c}\text { Somewhat } \\
\text { Disagree (3) }\end{array}$ & $\begin{array}{c}\text { Somewhat } \\
\text { Agree (4) }\end{array}$ & Agree (5) & $\begin{array}{c}\text { Strongly } \\
\text { Agree (6) }\end{array}$ \\
\hline $\begin{array}{c}\text { Collaboration } \\
\text { among } \\
\text { healthcare } \\
\text { personnel (1) } \\
\text { Open }\end{array}$ & 0 & 0 & 0 & 0 & 0 & 0 \\
$\begin{array}{c}\text { communication } \\
\text { among } \\
\text { healthcare } \\
\text { personnel (2) } \\
\begin{array}{c}\text { Trusting } \\
\text { relationships } \\
\text { among }\end{array}\end{array}$ & 0 & 0 & 0 & 0 & 0 & 0 \\
$\begin{array}{c}\text { healthcare } \\
\text { personnel (3) } \\
\text { Alignment of } \\
\text { goals among } \\
\text { healthcare } \\
\text { personnel (4) }\end{array}$ & 0 & 0 & 0 & 0 & 0 & 0 \\
\hline
\end{tabular}


Q34 Please select the frequency with which you communicate with the following individuals to care for patients.

\begin{tabular}{|c|c|c|c|c|}
\hline & Never (1) & Monthly (2) & Weekly (3) & Daily (4) \\
\hline $\begin{array}{l}\text { Supervising } \\
\text { physician (1) }\end{array}$ & O & $\mathrm{O}$ & $\mathrm{O}$ & $\mathrm{O}$ \\
\hline $\begin{array}{l}\text { Consulting } \\
\text { physician (2) }\end{array}$ & O & O & O & $\mathrm{O}$ \\
\hline $\begin{array}{c}\text { Physician assistant } \\
\text { (3) }\end{array}$ & $\mathrm{O}$ & $\mathrm{O}$ & $\mathrm{O}$ & $\mathrm{O}$ \\
\hline $\begin{array}{l}\text { Advanced practice } \\
\text { nurse (4) }\end{array}$ & $\mathrm{O}$ & $\mathrm{O}$ & $\mathrm{O}$ & $\mathrm{O}$ \\
\hline $\begin{array}{l}\text { Clinical nurse or } \\
\text { medical assistant } \\
\text { (5) }\end{array}$ & $\mathrm{O}$ & $\mathrm{O}$ & $\mathrm{O}$ & $\mathrm{O}$ \\
\hline Hospital nurse (6) & $\mathrm{O}$ & $\mathrm{O}$ & $\mathrm{O}$ & O \\
\hline $\begin{array}{c}\text { Surgical } \\
\text { technologist (7) }\end{array}$ & O & $\mathrm{O}$ & $\mathrm{O}$ & $\mathrm{O}$ \\
\hline $\begin{array}{c}\text { Nurse anesthetist } \\
\text { (8) }\end{array}$ & O & $\mathrm{O}$ & $\mathrm{O}$ & $\mathrm{O}$ \\
\hline Therapist (9) & $\mathrm{O}$ & $\mathrm{O}$ & $\mathrm{O}$ & $\mathrm{O}$ \\
\hline Social worker (10) & $\mathrm{O}$ & $\mathrm{O}$ & $\mathrm{O}$ & $\mathrm{O}$ \\
\hline $\begin{array}{l}\text { Home health care } \\
\text { nurse (11) }\end{array}$ & $\mathrm{O}$ & $\mathrm{O}$ & $\mathrm{O}$ & $\mathrm{O}$ \\
\hline Hospice nurse (12) & $\mathrm{O}$ & $\mathrm{O}$ & $\mathrm{O}$ & $\mathrm{O}$ \\
\hline $\begin{array}{l}\text { Nursing staff at a } \\
\text { skilled care facility } \\
\text { (13) }\end{array}$ & $\mathrm{O}$ & $\mathrm{O}$ & $\mathrm{O}$ & $\mathrm{O}$ \\
\hline $\begin{array}{l}\text { Others; please } \\
\text { specify (14) }\end{array}$ & $\mathrm{O}$ & $\mathrm{O}$ & $\mathrm{O}$ & $\mathrm{O}$ \\
\hline
\end{tabular}

Q35 In which ways do you communicate with medical associates regarding your patients (i.e. phone, email, in person, team meeting, etc.)

Q36 Describe how your PA training prepared you to be a team collaborator. A team collaborator is a PA who works effectively within a healthcare team to deliver the best patient care possible through alignment of goals and trusting relationships based on open and honest communication. 
Q37 Which of the following best represents your gender?

\author{
O Male (1) \\ O Female (2) \\ O Other (3)
}

Q38 Which of the following categories best represents your age?
(1)
O 25-30 years old (2)
O 31-35 years old (3)
O 36-40 years old (4)
O 41-45 years old (5)
O 46-50 years old (6)
O 51-55 years old (7)
O 56-60 years old (8)
O 61-65 years old (9)
O >65 years old (10) 
Q39 In what state do you currently reside?

O Alabama (1)

O Arizona (2)

O Arkansas (3)

O California (4)

O Colorado (5)

O Connecticut (6)

O Delaware (7)

O District of Columbia (8)

O Florida (9)

O Georgia (10)

O Idaho (11)

O Illinois (12)

O Indiana (13)

O Iowa (14)

O Kansas (15)

O Kentucky (16)

O Louisiana (17)

O Maine (18)

O Maryland (19)

O Massachusetts (20)

O Michigan (21)

O Minnesota (22)

O Mississippi (23)

O Missouri (24)

O Montana (25)

O Nebraska (26)

O Nevada (27)

O New Hampshire (28)

O New Jersey (29)

O New Mexico (30)

O New York (31)

O North Carolina (32)

O North Dakota (33)

O Ohio (34)

O Oklahoma (35)

O Oregon (36)

O Pennsylvania (37)

O Rhode Island (38)

O South Carolina (39) 
O South Dakota (40)

O Tennessee (41)

O Texas (42)

O Utah (43)

O Vermont (44)

O Virginia (45)

O Washington (46)

O West Virginia (47)

O Wisconsin (48)

O Wyoming (49)

O Puerto Rico (50)

O Alaska (51)

O Hawaii (52)

I do not reside in the United States (53)

Q40 Which of the following best represents your employment status?

Clinical practice (32+ hours/week) (1)

O Clinical practice ( (2)

O Hospital or Clinic administration (3)

O Academia (4)

O Research (5)

Other; please specify (6)

Q41 Which of the following categories best represents your current employment setting?

Clinic-based (1)

O Hospital-based (2)

O Ambulatory care (3)

O University (4)

Other; please specify (5) 
Q42 Which of the following best represents your primary work setting?

O Family Practice with Urgent Care (1)

O Family Practice without Urgent Care (2)

O Emergency Medicine (3)

O Urgent Care (4)

O Hospitalist (5)

O Internal Medicine; please specify specialty if applicable (6)

Surgery; please specify specialty (7)

O Pediatrics (8)

O OB/GYN (9)

O Dermatology (10)

O Ophthalmology (11)

O Psychiatry (12)

O ENT (13)

Other; please specify (14)

Q43 How many years have you been a practicing PA?
(1)
6-10 years (2)
O $11-15$ years (3)
O $16-20$ years (4)
O 21-25 years (5)
O 26-30 years (6)
O $31-35$ years $(7)$
O $36-40$ years $(8)$
O >40 years (9)

Q44 Which of the following best represents your practice setting?

O Non-metropolitan (1)

O Metropolitan (2)

Other; please specify (3) 
Appendix D

\section{Medical Leadership Survey: For Physician Assistant Faculty \\ A Concurrent Mixed-Methods Study of a Leadership Model for Physician Assistants: Implications for Practice and Training \\ Informed Consent}

\section{What is the purpose of this study?}

With the approaching physician shortage, physician assistants (PAs) are being relied upon to fill the healthcare gap being created. This not only requires PAs to provide quality healthcare, but also effective leadership skills. Leadership can be described in various ways. The purpose of this doctoral research study is to: 1) identify the current leadership roles of practicing PAs and 2) identify specific practices within physician assistant education that cultivate leadership skills.

\section{What is the expectation of participants?}

Participants will take a survey that will require approximately 20-25 minutes to complete. Participation in this survey is voluntary and refusal to participate will not involve penalty or loss of benefits.

\section{What are the benefits of the study?}

No direct personal benefits from this study are anticipated. The knowledge gained from this study will add to the overall composite of information currently present on leadership in physician assistant education and ultimately assist PA programs to accomplish the dual goals of acquiring medical knowledge and developing leadership abilities in students.

\section{What are the risks of the study?}

Risks of this study are minimal. However, you may experience emotional discomfort with sharing your beliefs about leadership in the physician assistant profession and in physician assistant education.

\section{Can I change my mind?}

Yes, you may choose to skip questions you may not feel comfortable answering or discontinue your participation in the survey at any point.

\section{What will happen to the information I share?}

Your information will remain anonymous as there will be no personal identification attached to the survey information collected through the Qualtrics Survey Software. 


\section{Will I receive payment for participating?}

There is no payment for participation in this research study.

\section{What if I have questions?}

If you have any questions, please contact Tracy Cleveland at

tracycleveland@missouristate.edu or 417-836-6152 or Cynthia MacGregor at CMacgregor@missouristate.edu or (417) 836-6046. If you have questions about your rights as a human subject or this project (\#2004787), call the University of Missouri's Campus Institutional Review Board at 573-882-9585.

\footnotetext{
Agree (1)

Disagree (2)
} 
Q1 In the professional role of a PA, what does "leadership" mean?

Q2 The PA training provided to students at the PA program where I work prepares students for leadership roles.

O Strongly Agree (1)

O Agree (2)

O Somewhat Agree (3)

O Somewhat Disagree (4)

O Disagree (5)

O Strongly Disagree (6)

Q3 Describe ways in which the PA training provided in your curriculum prepares PAs for future leadership roles.

Q4 Through which of the following formal leadership formats does leadership training occur within the curriculum at your PA program? Please check all that apply.

Lecture (1)

Workshop on leadership (2)

Coursework (3)

Required leadership course (4)

As a component of another course; please specify below (5)

$\square$ Required reading (6)

Other; please specify (7)

Dot applicable (8)

Q5 I believe formal leadership training should be a part of PA education.

O Strongly disagree (1)

O Disagree (2)

O Somewhat disagree (3)

O Somewhat agree (4)

O Agree (5)

O Strongly agree (6) 
Q6 Please describe why you do or do not think formal leadership training should be a component of PA education at the school where you teach.

Q7 The PA program where I work provides informal leadership training such as observation or modeling of leadership skills by faculty or preceptors.

Strongly disagree (1)

O Disagree (2)

O Somewhat disagree (3)

O Somewhat agree (4)

O Agree (5)

Strongly agree (6)

Q8 Please describe how informal leadership training occurs in your program.

Q9 I believe informal leadership training should be a part of PA education.

O Strongly disagree (1)

O Disagree (2)

O Somewhat disagree (3)

O Somewhat agree (4)

O Agree (5)

Strongly agree (6)

Q10 Please describe why you do or do not believe informal leadership training should be a part of PA education

Q11 Please indicate your level of agreement with the following statements. Students at the PA program where I work are being prepared to be physician assistants who: 


\begin{tabular}{|c|c|c|c|c|c|c|}
\hline & $\begin{array}{c}\text { Strongly } \\
\text { disagree (1) }\end{array}$ & $\begin{array}{l}\text { Disagree } \\
\text { (2) }\end{array}$ & $\begin{array}{c}\text { Somewhat } \\
\text { disagree (3) }\end{array}$ & $\begin{array}{c}\text { Somewhat } \\
\text { agree (4) }\end{array}$ & Agree (5) & $\begin{array}{l}\text { Strongly } \\
\text { agree (6) }\end{array}$ \\
\hline $\begin{array}{l}\text { Demonstrate } \\
\text { altruistic } \\
\text { behavior (1) }\end{array}$ & $\mathrm{O}$ & $\mathrm{O}$ & 0 & $\mathrm{O}$ & 0 & $\mathrm{O}$ \\
\hline $\begin{array}{l}\text { Establish } \\
\text { ethical patient } \\
\text { relationships } \\
\text { (2) }\end{array}$ & $\mathrm{O}$ & $\mathrm{O}$ & 0 & $\mathrm{O}$ & O & 0 \\
\hline $\begin{array}{l}\text { Are honest } \\
\text { with patients } \\
\text { (3) }\end{array}$ & 0 & $\mathrm{O}$ & 0 & $\mathrm{O}$ & $\mathrm{O}$ & $\mathrm{O}$ \\
\hline $\begin{array}{l}\text { Communicate } \\
\text { openly with } \\
\text { patients (4) }\end{array}$ & 0 & O & 0 & O & O & $\mathrm{O}$ \\
\hline $\begin{array}{c}\text { Respect } \\
\text { patient } \\
\text { autonomy (5) }\end{array}$ & $\mathrm{O}$ & $\mathrm{O}$ & $\mathrm{O}$ & $\mathrm{O}$ & 0 & $\mathrm{O}$ \\
\hline $\begin{array}{c}\text { Respect } \\
\text { patient } \\
\text { confidentiality } \\
\text { (6) }\end{array}$ & 0 & $\mathrm{O}$ & 0 & O & $\mathrm{O}$ & 0 \\
\hline $\begin{array}{l}\text { Do not harm } \\
\text { patients (7) }\end{array}$ & O & O & O & $\mathrm{O}$ & $\mathrm{O}$ & $\mathrm{O}$ \\
\hline $\begin{array}{l}\text { Serve patient } \\
\text { needs }(8)\end{array}$ & O & O & O & $\mathrm{O}$ & $\mathrm{O}$ & O \\
\hline $\begin{array}{l}\text { Go above and } \\
\text { beyond the } \\
\text { call of duty } \\
\text { for patients } \\
\text { (9) }\end{array}$ & 0 & $\mathrm{O}$ & $\mathrm{O}$ & O & O & $\mathrm{O}$ \\
\hline $\begin{array}{l}\text { Put the needs } \\
\text { of the patient } \\
\text { above their } \\
\text { own needs } \\
\text { (10) }\end{array}$ & O & O & 0 & O & 0 & O \\
\hline $\begin{array}{l}\text { Treat patients } \\
\text { justly (11) }\end{array}$ & O & O & $\mathrm{O}$ & $O$ & $O$ & 0 \\
\hline $\begin{array}{l}\text { Advocate for } \\
\text { marginalized } \\
\text { patient } \\
\text { populations } \\
\text { (12) }\end{array}$ & 0 & 0 & O & O & $\mathrm{O}$ & $\mathrm{O}$ \\
\hline $\begin{array}{c}\text { Listen to } \\
\text { patients (13) }\end{array}$ & 0 & $\mathrm{O}$ & 0 & O & 0 & $O$ \\
\hline $\begin{array}{c}\text { Educate } \\
\text { patients (14) }\end{array}$ & O & O & $\mathrm{O}$ & $O$ & $O$ & $\mathrm{O}$ \\
\hline
\end{tabular}




\begin{tabular}{|c|c|c|c|c|c|c|}
\hline $\begin{array}{l}\text { Assist patients } \\
\text { with } \\
\text { navigating the } \\
\text { health system } \\
\text { (15) }\end{array}$ & 0 & 0 & 0 & 0 & 0 & 0 \\
\hline $\begin{array}{l}\text { Act in the best } \\
\text { interest of } \\
\text { patients (16) }\end{array}$ & $\mathrm{O}$ & 0 & 0 & $\mathrm{O}$ & $\mathrm{O}$ & $\mathrm{O}$ \\
\hline $\begin{array}{c}\text { Will call } \\
\text { insurance } \\
\text { companies on } \\
\text { behalf of } \\
\text { patients (17) }\end{array}$ & O & 0 & 0 & 0 & $\mathrm{O}$ & 0 \\
\hline $\begin{array}{l}\text { Call patients } \\
\text { with test } \\
\text { results (18) }\end{array}$ & 0 & 0 & 0 & 0 & 0 & O \\
\hline $\begin{array}{l}\text { Make house } \\
\text { calls (19) }\end{array}$ & 0 & 0 & 0 & 0 & 0 & 0 \\
\hline $\begin{array}{l}\text { Communicate } \\
\text { with other } \\
\text { healthcare } \\
\text { providers on } \\
\text { patient's } \\
\text { behalf (20) }\end{array}$ & 0 & 0 & 0 & 0 & 0 & 0 \\
\hline $\begin{array}{c}\text { Develop } \\
\text { treatment } \\
\text { plans with the } \\
\text { patient }(21)\end{array}$ & 0 & 0 & 0 & 0 & $\mathrm{O}$ & 0 \\
\hline
\end{tabular}

Q12 In what ways does your program prepare PAs to be patient advocates. A patient advocate may be described as a PA who demonstrates an unselfish or altruistic behavior by putting the needs of others ahead of themselves. This may be demonstrated through developing an ethical relationship with patients that is built on trust and respect, open and honest communication, placing service above reward, and justice. 
Q13 Please indicate your level of agreement with the following statement. Students at the PA program where I teach are being prepared to demonstrate organizational stewardship through involvement in...

\begin{tabular}{|c|c|c|c|c|c|c|}
\hline & $\begin{array}{c}\text { Strongly } \\
\text { disagree } \\
\text { (1) }\end{array}$ & $\begin{array}{c}\text { Disagree } \\
\text { (2) }\end{array}$ & $\begin{array}{c}\text { Somewhat } \\
\text { disagree (3) }\end{array}$ & $\begin{array}{c}\text { Somewhat } \\
\text { agree (4) }\end{array}$ & Agree (5) & $\begin{array}{l}\text { Strongly } \\
\text { agree (6) }\end{array}$ \\
\hline $\begin{array}{c}\text { Local PA } \\
\text { organizations } \\
\text { (1) }\end{array}$ & O & $\mathrm{O}$ & $\mathrm{O}$ & $\mathrm{O}$ & $\mathrm{O}$ & $O$ \\
\hline $\begin{array}{c}\text { State PA } \\
\text { organizations } \\
(2)\end{array}$ & $\mathrm{O}$ & $\mathrm{O}$ & $\mathrm{O}$ & O & $\mathrm{O}$ & $\mathrm{O}$ \\
\hline $\begin{array}{c}\text { National PA } \\
\text { organizations } \\
\text { (3) }\end{array}$ & $\mathrm{O}$ & O & $\mathrm{O}$ & O & $\mathrm{O}$ & $\mathrm{O}$ \\
\hline $\begin{array}{c}\text { Specialty PA } \\
\text { organizations } \\
\text { (4) }\end{array}$ & O & O & 0 & 0 & $\mathrm{O}$ & 0 \\
\hline $\begin{array}{l}\text { Political } \\
\text { Activism for the } \\
\text { PA profession } \\
\text { (5) }\end{array}$ & O & $\mathrm{O}$ & 0 & O & 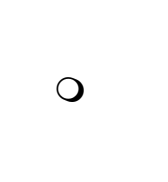 & 0 \\
\hline $\begin{array}{c}\text { Political } \\
\text { involvement in } \\
\text { health policy (6) }\end{array}$ & $\mathrm{O}$ & $\mathrm{O}$ & $\mathrm{O}$ & $\mathrm{O}$ & $\mathrm{O}$ & $\mathrm{O}$ \\
\hline $\begin{array}{c}\text { Clinic } \\
\text { board/committee } \\
\text { (7) }\end{array}$ & 0 & O & 0 & 0 & 0 & O \\
\hline $\begin{array}{c}\text { Hospital } \\
\text { board/committee } \\
\text { (8) }\end{array}$ & O & O & $O$ & O & O & O \\
\hline
\end{tabular}

Q14 In what ways does your program prepare PAs to be engaged professionals? An engaged professional is a PA who demonstrates organizational stewardship through involvement within local, state, and national organizations in order to form a coalition that is working toward a common goal. 
Q15 Students at my PA program are being prepared to be physician assistants who give back to the profession by serving as an educator to new PA professionals during their didactic training.

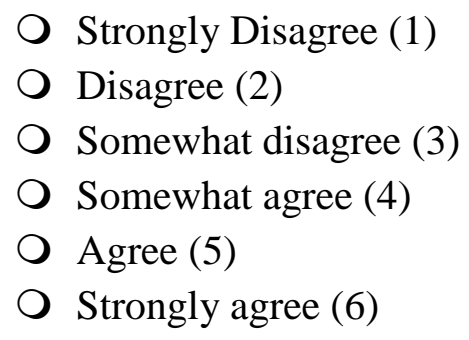

Q16 Students at my PA program are being prepared to be physician assistants who give back to the profession by serving as an educator to new PA professionals during their clinical training.

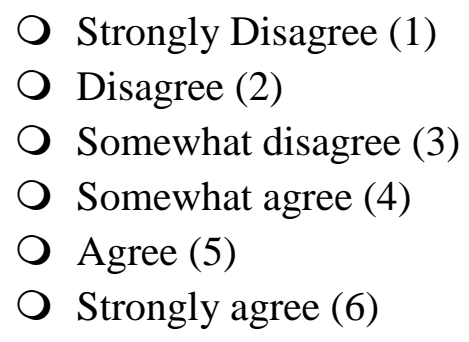

Q17 In what ways does your program prepare PAs to be builders of future professionals? A builder of future professionals is a physician assistant who demonstrates professional commitment through serving as an educator to new PA professionals during their didactic and clinical training; modeling both clinical and professional skills.

Q18 Please indicate your level of agreement with the following statement. Students at my PA program are being prepared to be physician assistants who: 


\begin{tabular}{|c|c|c|c|c|c|c|}
\hline & $\begin{array}{c}\text { Strongly } \\
\text { Disagree } \\
\text { (1) }\end{array}$ & $\begin{array}{l}\text { Disagree } \\
\text { (2) }\end{array}$ & $\begin{array}{l}\text { Somewhat } \\
\text { disagree (3) }\end{array}$ & $\begin{array}{l}\text { Somewhat } \\
\text { Agree (4) }\end{array}$ & Agree (5) & $\begin{array}{c}\text { Strongly } \\
\text { Agree (6) }\end{array}$ \\
\hline $\begin{array}{l}\text { Demonstrate } \\
\text { a strong } \\
\text { sense of } \\
\text { community } \\
\text { (1) }\end{array}$ & $\mathrm{O}$ & O & $\mathrm{O}$ & $\mathrm{O}$ & O & 0 \\
\hline $\begin{array}{l}\text { Promote } \\
\text { healthcare in } \\
\text { the } \\
\text { community } \\
\text { (2) }\end{array}$ & $\mathrm{O}$ & $\mathrm{O}$ & $\mathrm{O}$ & $\mathrm{O}$ & O & $\mathrm{O}$ \\
\hline $\begin{array}{l}\text { Believe in } \\
\text { serving the } \\
\text { "greater } \\
\text { good" (3) }\end{array}$ & $\mathrm{O}$ & 0 & $\mathrm{O}$ & $\mathrm{O}$ & $\mathrm{O}$ & 0 \\
\hline $\begin{array}{l}\text { Participate in } \\
\text { community } \\
\text { health fairs } \\
\text { (4) }\end{array}$ & $\mathrm{O}$ & $\mathrm{O}$ & $\mathrm{O}$ & $\mathrm{O}$ & O & 0 \\
\hline $\begin{array}{l}\text { Write health } \\
\text { columns for } \\
\text { the local } \\
\text { newspaper } \\
\text { (5) }\end{array}$ & $\mathrm{O}$ & 0 & $\mathrm{O}$ & O & O & O \\
\hline $\begin{array}{l}\text { Provide } \\
\text { health } \\
\text { education to } \\
\text { community } \\
\text { groups (6) }\end{array}$ & $\mathrm{O}$ & 0 & $\mathrm{O}$ & $\mathrm{O}$ & 0 & O \\
\hline $\begin{array}{l}\text { Provide } \\
\text { health } \\
\text { education at } \\
\text { local schools } \\
\text { (7) }\end{array}$ & 0 & 0 & $\mathrm{O}$ & O & O & 0 \\
\hline $\begin{array}{l}\text { Participate in } \\
\text { community } \\
\text { wellness } \\
\text { initiatives (8) }\end{array}$ & O & O & $\mathrm{O}$ & $\mathrm{O}$ & 0 & $\mathrm{O}$ \\
\hline $\begin{array}{l}\text { Will serve on } \\
\text { a planning } \\
\text { committee or } \\
\text { organize a } \\
\text { community } \\
\text { healthcare } \\
\text { event (9) }\end{array}$ & $\mathrm{O}$ & O & $\mathrm{O}$ & 0 & O & $\mathrm{O}$ \\
\hline $\begin{array}{l}\text { Participate in } \\
\text { community } \\
\text { health } \\
\text { screenings } \\
\text { (10) }\end{array}$ & O & 0 & $\mathrm{O}$ & 0 & 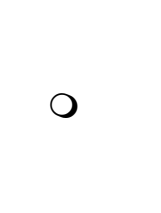 & O \\
\hline
\end{tabular}




\begin{tabular}{|c|c|c|c|c|c|c|}
\hline $\begin{array}{l}\text { Volunteer at } \\
\text { a community } \\
\text { healthcare } \\
\text { clinic for the } \\
\text { underserved } \\
\text { (11) }\end{array}$ & ○ & 0 & O & 0 & 0 & O \\
\hline $\begin{array}{l}\text { Participate in } \\
\text { global } \\
\text { medical } \\
\text { missions (12) }\end{array}$ & 0 & 0 & 0 & 0 & 0 & 0 \\
\hline $\begin{array}{l}\text { Collaborate } \\
\text { with } \\
\text { community } \\
\text { organizations } \\
\text { to meet } \\
\text { healthcare } \\
\text { needs in the } \\
\text { community } \\
\text { (13) }\end{array}$ & O & 0 & $\mathrm{O}$ & 0 & 0 & 0 \\
\hline $\begin{array}{l}\text { Provide } \\
\text { lectures or } \\
\text { other } \\
\text { education to } \\
\text { community } \\
\text { health groups } \\
\quad(14)\end{array}$ & 0 & 0 & $\mathrm{O}$ & 0 & 0 & 0 \\
\hline
\end{tabular}

Q19 Describe other ways in which your students are involved in promoting health within the community.

Q20 In what ways does your program prepare PAs to be a community activist? A community activist is a PA who demonstrates a strong sense of community and concern for others by promoting healthcare through community health education and the formation of community partnerships to serve the greater good. 
Q21 Students at my PA program are being prepared to be physician assistants who participate in learning opportunities for personal growth.

Strongly disagree (1)

Disagree (2)

Somewhat disagree (3)

Somewhat agree (4)

O Agree (5)

Strongly agree (6)

Q22 Students at my PA program are being prepared to be physician assistants who participate in learning opportunities for professional growth.

Strongly disagree (1)

Disagree (2)

Somewhat disagree (3)

Somewhat agree (4)

Agree (5)

Strongly agree (6)

Q23 In what ways does your program prepare PAs to be learning leaders? A learning leader is a PA who participates in learning opportunities to improve themselves both personally and professionally.

Q24 Please indicate your level of agreement with the following question. Students of my PA program are being prepared to be physician assistants who work effectively within a healthcare team to deliver the best patient care possible (may include direct patient care or as initiatives and policy which affect systems based healthcare delivery).

Strongly disagree (1)

Disagree (2)

Somewhat disagree (3)

Somewhat agree (4)

Agree (5)

O Strongly agree (6) 
Q25 Students of my PA program are being prepared to be a physician assistants who collaborate with healthcare personnel.

Strongly disagree (1)

Disagree (2)

Somewhat disagree (3)

Somewhat agree (4)

O Agree (5)

Strongly agree (6)

Q26 In what ways does your program prepare PAs to be team collaborators? A team collaborator is a PA who works effectively within a healthcare team to deliver the best patient care possible through alignment of goals and trusting relationships based on open and honest communication. This may include direct patient care or initiatives and policy which affect the systems based healthcare delivery.

Q27 Which of the following best represents your gender?

Male (1)

Female (2)

Other (3)

Q28 Which of the following categories best represents your age?
O (1)
O 25-30 years old (2)
O 31-35 years old (3)
O 36-40 years old (4)
- 41-45 years old (5)
- 46-50 years old (6)
51-55 years old (7)
O 56-60 years old (8)
O 61-65 years old (9)
○ >65 years old (10) 
Q29 In what state do you currently reside?

O Alabama (1)

O Arizona (2)

O Arkansas (3)

O California (4)

O Colorado (5)

O Connecticut (6)

O Delaware (7)

O District of Columbia (8)

O Florida (9)

O Georgia (10)

O Idaho (11)

O Illinois (12)

O Indiana (13)

O Iowa (14)

O Kansas (15)

O Kentucky (16)

O Louisiana (17)

O Maine (18)

O Maryland (19)

O Massachusetts (20)

O Michigan (21)

O Minnesota (22)

O Mississippi (23)

O Missouri (24)

O Montana (25)

O Nebraska (26)

O Nevada (27)

O New Hampshire (28)

O New Jersey (29)

O New Mexico (30)

O New York (31)

O North Carolina (32)

O North Dakota (33)

O Ohio (34)

O Oklahoma (35)

O Oregon (36)

O Pennsylvania (37)

O Rhode Island (38)

O South Carolina (39) 
O South Dakota (40)

O Tennessee (41)

O Texas (42)

O Utah (43)

O Vermont (44)

O Virginia (45)

O Washington (46)

O West Virginia (47)

O Wisconsin (48)

O Wyoming (49)

O Puerto Rico (50)

O Alaska (51)

O Hawaii (52)

I do not reside in the United States (53)

Q30 Which of the following best represents your employment status?

Clinical practice (32+ hours/week) (1)

O Clinical practice ( (2)

O Hospital or Clinic administration (3)

O Academia (4)

O Research (5)

Other; please describe below (6)

Q31 I have worked in PA education in the last 5 years.

O Yes (1)

O No (2) 
Appendix E

The Medical Leader: Synthesis of Findings

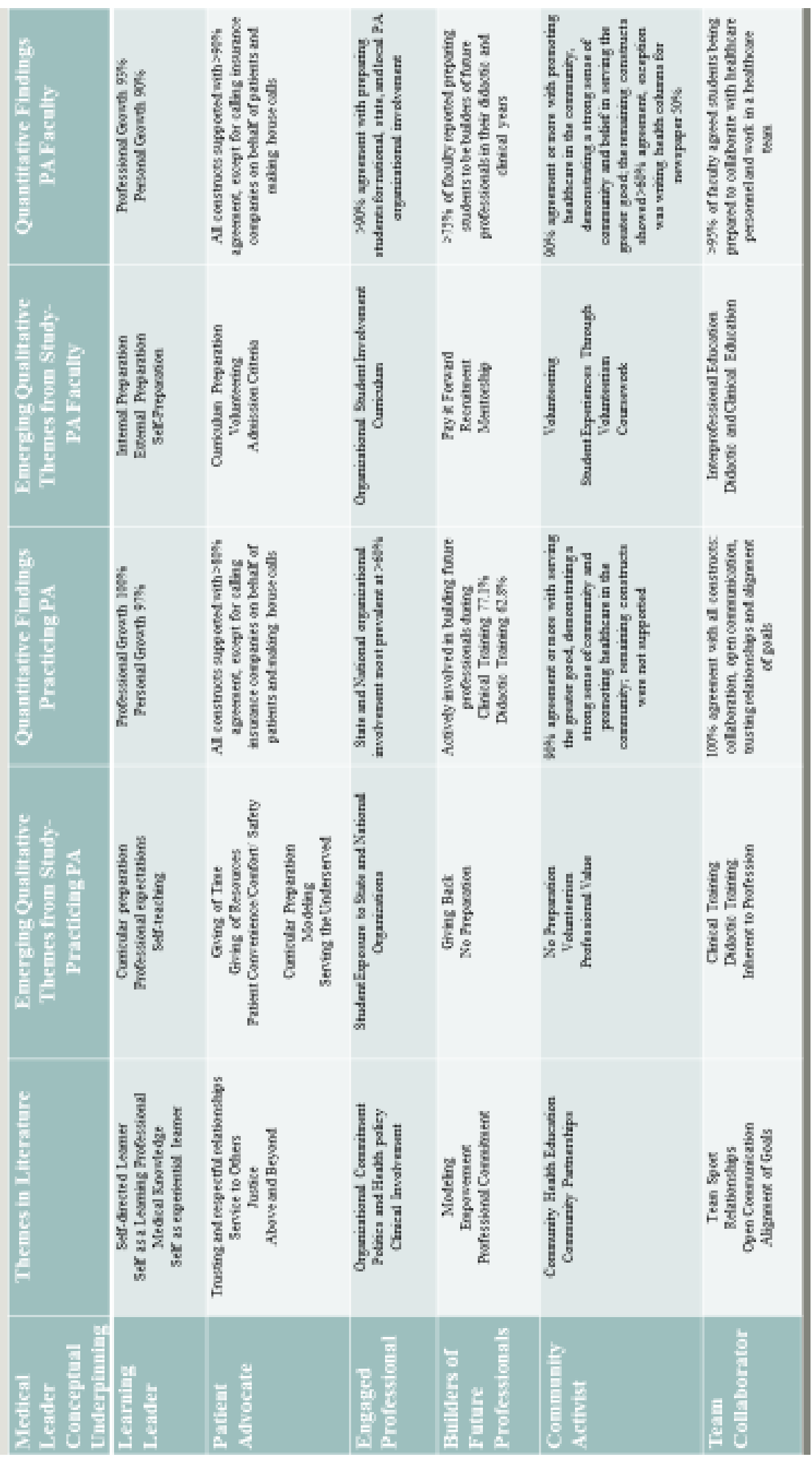




\section{VITA}

Tracy Cleveland was born in Madison, SD to Dave and Ronda Gassman. She grew up on a farm on the outskirts of Canova, SD, a small town of 150 residents. There she lived with her parents, two sisters, and one brother. Farm life and small town living have heavily influenced some of the things Tracy values most, faith, family, hard-work and community. She attended grade school in Canova, SD and high school in Howard, SD. She graduated in 1996 from Howard High School.

Following graduation from Howard High School Tracy attended Northern State University. While there, she played basketball and track and was a four-time academic All-American. She was named South Dakota's NCAA woman of the year in 2000. In December of 2000, she earned bachelor degrees in Biology and Psychology. In 2001, she moved to Springfield, MO and attended Southwest Missouri State University, now Missouri State University where she earned her Master of Science degree in Physician Assistant Studies in December, 2002. Tracy completed her EdD in Educational Leadership and Policy Analysis from the University of Missouri in July, 2017.

Tracy has worked as a physician assistant for over 14 years. After 8 months in rural family practice she moved to Mercy Orthopedics in Springfield, MO and has been there since. In August of 2007, she accepted a full-time position at the Missouri State University Physician Assistant Studies program. Since her time at MSU, she has become the academic coordinator for the program. She achieved tenure and promotion to Associate professor in 2012. In 2010, Tracy received the Springfield Business Journals Healthcare Champion Award for Physician Assistants. She has published a book chapter on Pulmonology and co-authored an article on Emotional Intelligence. She has been 
involved with research on childhood obesity and diabetes prevention, emotional intelligence, and student alcohol training on screening and brief intervention. From this research, she has presented posters at both state and national conferences. Tracy serves as chair for the national Physician Assistant Education Association (PAEA) Emergency Medicine and General Surgery Exam Development Board and has contributed to national published standardized exams through PAEA for 6 years.

Tracy and her husband, Joe, live in Springfield, MO. They have four wonderful children. Jenaya and Chandler are 11 years old, Cale is 6 years old and Tatum is 1 year old. They are raising their children to love God and be an example of love to others. They value their children's individual gifts and strive to teach them the value of hard work and putting forth their best effort always. 